University of Louisville

ThinkIR: The University of Louisville's Institutional Repository

Electronic Theses and Dissertations

$12-2017$

\title{
Evaluating ligand assisted activation of small molecules through proton reduction and alcohol oxidation.
}

Rahul Jain

University of Louisville

Follow this and additional works at: https://ir.library.louisville.edu/etd

Part of the Inorganic Chemistry Commons

\section{Recommended Citation}

Jain, Rahul, "Evaluating ligand assisted activation of small molecules through proton reduction and alcohol oxidation." (2017). Electronic Theses and Dissertations. Paper 2828.

https://doi.org/10.18297/etd/2828

This Doctoral Dissertation is brought to you for free and open access by ThinkIR: The University of Louisville's Institutional Repository. It has been accepted for inclusion in Electronic Theses and Dissertations by an authorized administrator of ThinkIR: The University of Louisville's Institutional Repository. This title appears here courtesy of the author, who has retained all other copyrights. For more information, please contact thinkir@louisville.edu. 


\title{
EVALUATING LIGAND ASSISTED ACTIVATION OF SMALL MOLECULES THROUGH PROTON REDUCTION AND ALCOHOL OXIDATION
}

\author{
By \\ Rahul Jain \\ M.S., Panjab University 2011 \\ M.S., University of Louisville 2016
}

\author{
A Dissertation \\ Submitted to the Faculty of the \\ College of Arts and Sciences of the University of Louisville \\ in Partial Fulfillment of the Requirements \\ for the Degree of \\ Doctor of Philosophy \\ in Chemistry \\ Department of Chemistry \\ University of Louisville \\ Louisville, Kentucky
}

December 2017 
(C) 2017 by Rahul Jain

All rights reserved 



\section{EVALUATING LIGAND ASSISTED ACTIVATION OF SMALL MOLECULES THROUGH PROTON REDUCTION AND ALCOHOL OXIDATION \\ By \\ Rahul Jain \\ M.S., Panjab University, 2011 \\ M.S., University of Louisville, 2016}

A Dissertation Approved on

November 29, 2017

By the following Dissertation Committee

Dr. Craig A. Grapperhaus

(Dissertation Director)

Dr. Robert M. Buchanan

Dr. Francis P. Zamborini

Dr. Gamini U. Sumanasekera 


\section{DEDICATION}

This dissertation is dedicated to the blessings of

my late grandfather

Sh. Shibu Mal Jain

and

my late mother

Smt. Asha Jain 


\section{ACKNOWLEDGEMENTS}

I would like to express my sincere gratitude to my mentor Dr. Craig. A. Grapperhaus for giving me an opportunity to be a part of his research family. I am thankful for his expertise and tutelage during my $\mathrm{PhD}$ studies. His unconditional support and motivation has been instrumental for the completion of this thesis.

Also, my sincere thanks to Dr. Robert M. Buchanan for being a profound source of knowledge and for the great discussions and guidance on the research work. I am grateful to my committee members Dr. Francis P. Zamborini and Dr. Gamini Sumanasekera for serving on my dissertation committee and insightful comments during the presentations.

I am grateful to Dr. Mark S. Mashuta for performing crystallographic studies. I would like to thank Dr. Pawel M. Kozlowski and Mamun for their help with the DFT studies. I am thankful to Dr. Neal Stolowich for the help with the NMR studies. I am grateful to all the staff members: Sherry Nalley, Sabrina Haug, Aaron Howell, Steve Riley and Renu Kakar for their assistance during this term.

I am thankful to all my previous lab members Dr. Rajat Chauhan and Dr. Davinder Kumar for helping me learn the basics of the lab work and my fellow lab members Dr. Andrew, Dr. Wuyu, Nick, Caleb, Nina, Steve, Kritika, Anna, for the stimulating discussions and for their friendship and fun we have had during this tenure.

Finally, I would like to thank my father Sh. Suresh K. Jain, my brother Rohit and my sister Shivani for believing and supporting me with every decision. I am indebted to 
my grandmother Smt. Krishna Devi Jain and uncle Sh. Naresh K. Jain for their blessings and guidance. 


\title{
ABSTRACT \\ EVALUATING LIGAND ASSISTED ACTIVATION OF SMALL MOLECULES THROUGH PROTON REDUCTION AND ALCOHOL OXIDATION
}

\author{
Rahul Jain
}

November 29, 2017

Hydrogen is a potential alternate to the carbon fuels to meet the future demands for energy in an eco-friendly manner. Hydrogen produced by the electrolysis of water is stored in fuel cells which on demand can be converted into electrical energy upon the reaction with oxygen. In the quest for economically viable electrocatalysts for hydrogen evolution, the work in this dissertation describes evaluation of nickel based catalysts coordinated to redox active ligands, dialkyl/diarylphosphine benzenethiol and bis(thiosemicarbazone) for their ability to generate hydrogen with external acids as a proton source. A nickel complex with the benzenethiol ligand framework follows a traditional metal-hydride route and affords a maximum turnover frequency of $51 \mathrm{~s}^{-1}$ with an overpotential of $1.1 \mathrm{~V}$. A Ni(II) complex with the bis(thiosemicarbazone) ligand framework displayed a turnover frequency of $4161 \mathrm{~s}^{-1}$ operating at an overpotential of $0.52 \mathrm{~V}$. Hydrogen evolution proceeds through metal-hydride intermediate distinct from the typical hydride pathway. DFT studies have been performed in gas phase and in solvent phase using polarizable continuum model (PCM) calculations to probe the mechanism of the hydrogen evolution reactions. 
To further evaluate the cooperativity between the redox active ligands and metals in catalysis, complexes that facilitate alcohol oxidation to mimic the activity of galactose oxidase were explored. Copper(II) complexes with an $\mathrm{N}_{4}$-ligand framework have been synthesized and evaluated as catalysts for oxidation of benzylic alcohols to benzylic aldehydes under aerobic conditions. Proton transfer from the protonated NMI to the imidazole arm in the ligand framework helps to open the site for the binding of TEMPO, thus driving the reaction forward. The reaction studied over the period of 4 hours resulted in yields of up to $99 \%$. Optimum conditions are $5 \mathrm{mmol}$ alcohol with $5 \mathrm{~mol} \%$ of catalyst, NMI and TEMPO with respect to substrate in acetonitrile under aerobic conditions. To gain mechanistic insights, the components of the reaction mixture such as benzyl alcohol, catalyst concentration, NMI, oxygen flow rate, TEMPO and solvent have been varied. 


\section{TABLE OF CONTENTS}

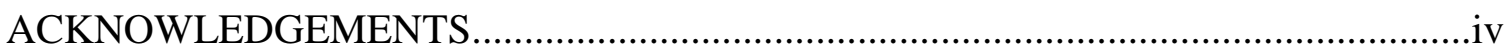

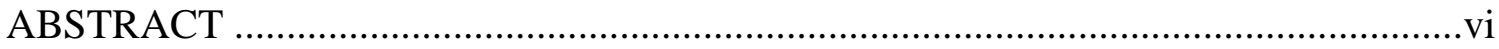

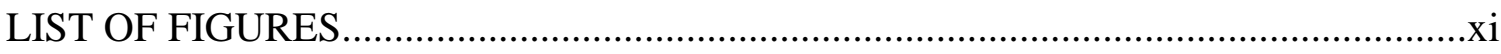

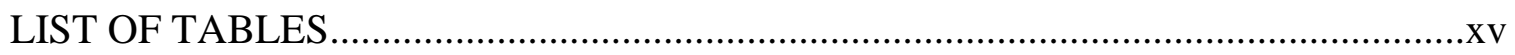

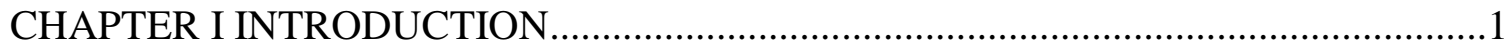

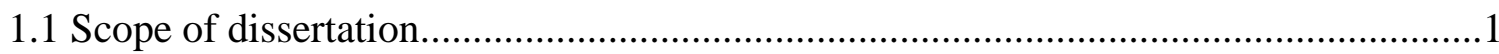

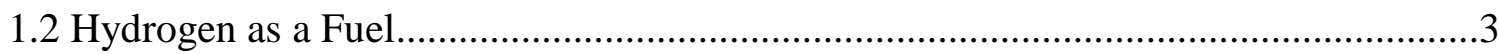

1.3 Hydrogenase: Nature's catalyst for hydrogen production.............................................

1.4 Hydrogenase mimics and molecular catalysts for hydrogen evolution..........................7

1.5 An introduction of redox active ligands in catalysis.................................................10

1.6 An introduction to metal-stabilized thiyl radicals.......................................................11

1.7 Ligand centered hydrogen evolution with $\operatorname{Re}\left(\mathrm{L}^{1}\right)_{3}$ complex.................................12

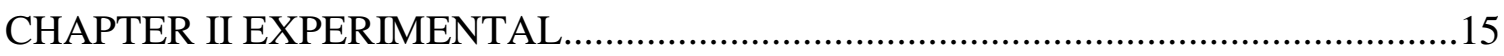

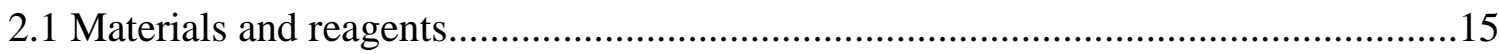

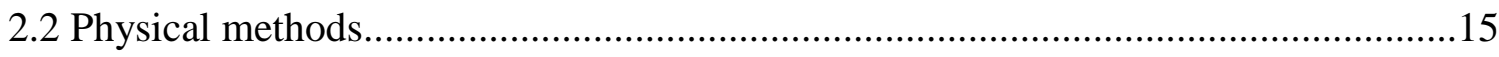

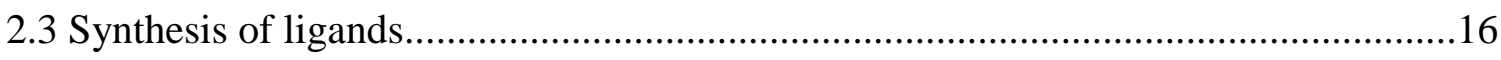

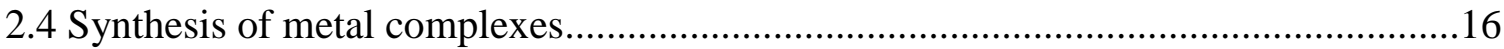

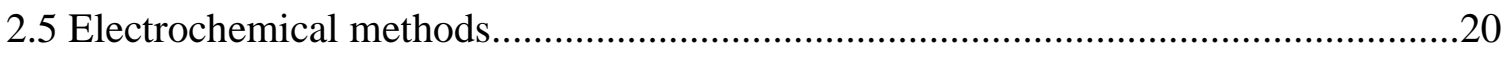

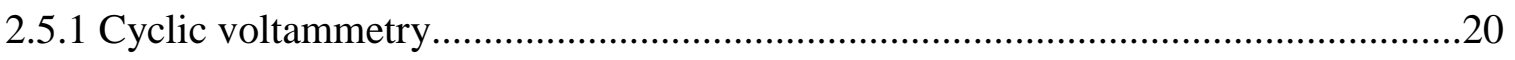

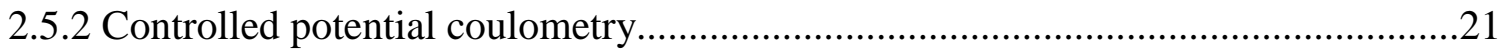

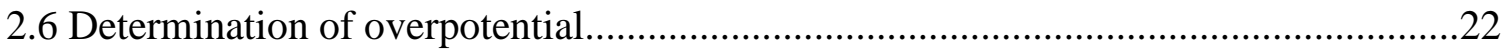

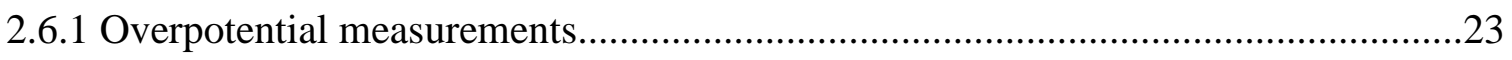

2.7 Procedure for calculation of turnover frequency for HER..........................................25 
2.8 Procedure for calculation of kinetic isotope effect..........................................28

2.9 Procedure for calculation of diffusion coefficient.................................................28

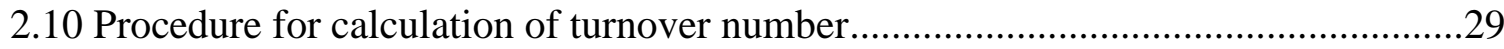

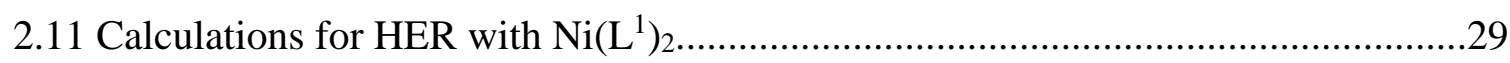

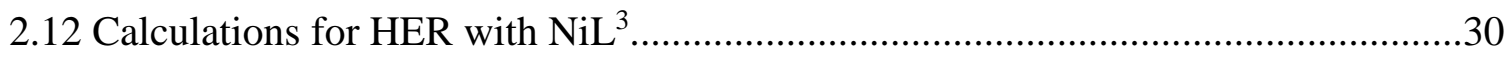

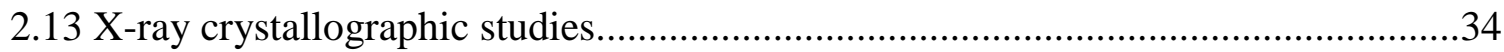

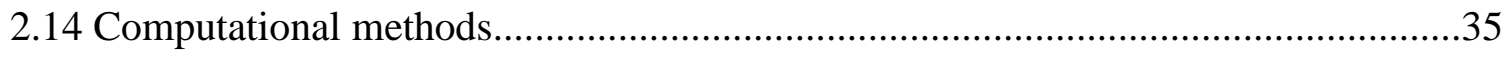

2.15 Procedure used for setting up of benzyl alcohol oxidation reaction and quantification

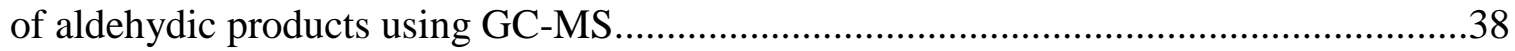

CHAPTER III ELECTROCATALYIC HYDROGEN EVOLUTION AND HYDROGEN OXIDATION WITH A Ni(PS) 2 COMPLEX......................................................41

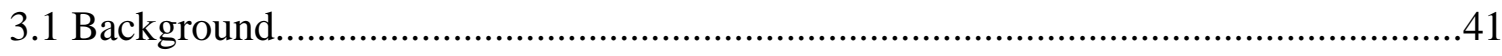

3.2 Synthesis and spectroscopic characterization.....................................................46

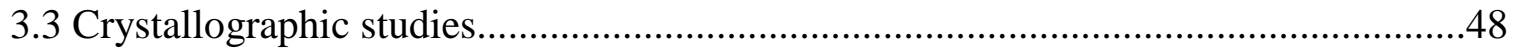

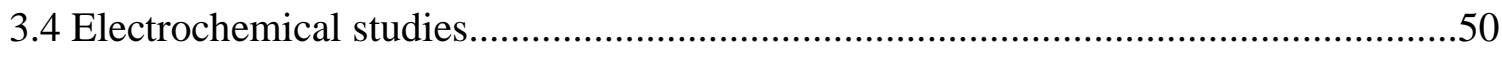

3.5 Electrocatalytic hydrogen evolution reactions.....................................................52

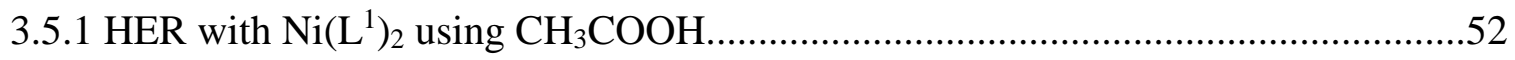

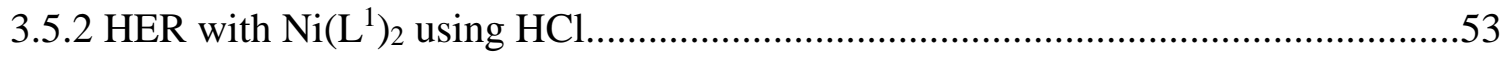

3.6 Mechanistic studies for hydrogen evolution reaction...........................................55

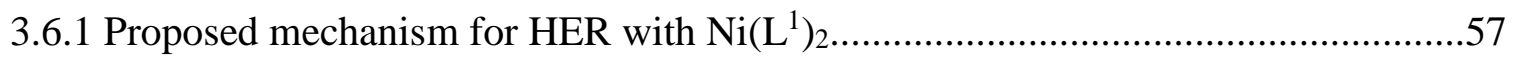

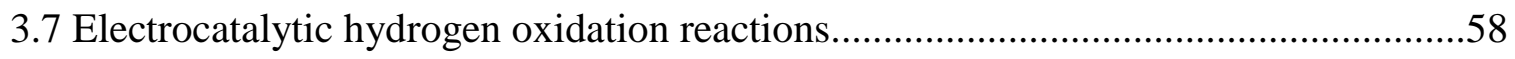

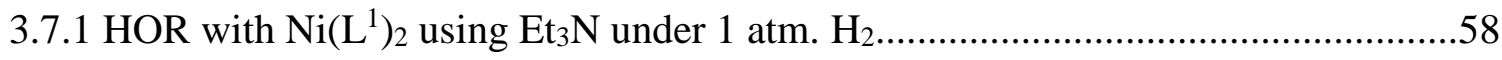

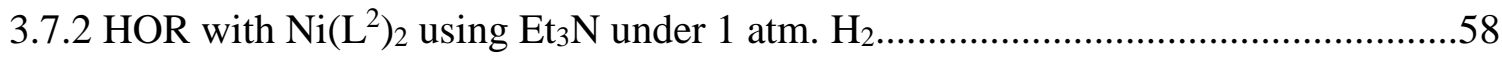

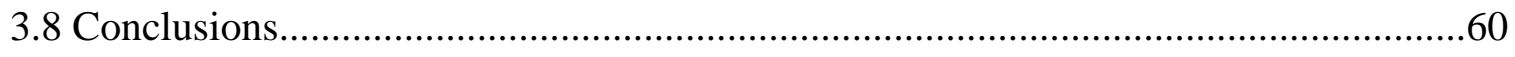

CHAPTER IV ELECTROCATALYTIC HYDROGEN EVOLUTION REACTION WITH BIS(THIOSEMICARBAZONATO)NI (II) COMPLEX..................................61

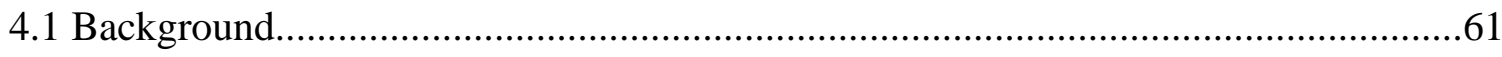

4.1.1 Hydrogen evolution reaction with $\mathrm{ZnL}^{3}$ and $\mathrm{CuL}^{3}$........................................62

4.1.2 Hydrogen evolution reaction with NiL: Straistari's catalyst..............................66 
4.2 Synthesis and characterization of $\mathrm{NiL}^{3}$ 68

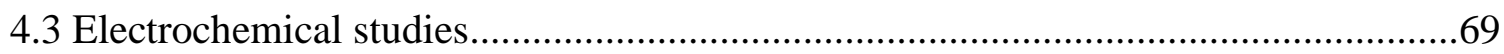

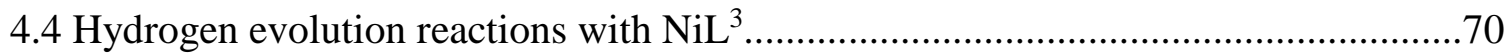

4.4.1 Electrocatalytic HER with $\mathrm{NiL}^{3}$ with acetic acid in acetonitrile............................70

4.4.2 Electrocatalytic HER with $\mathrm{NiL}^{3}$ with acetic acid in dimethylformamide.................71

4.4.3 Electrocatalytic HER with $\mathrm{NiL}^{3}$ with trifuoroacetic acid in acetonitrile..................72

4.4.4 Electrocatalytic HER with $\mathrm{NiL}^{3}$ with trifuoroacetic acid in dimethylformamide....73

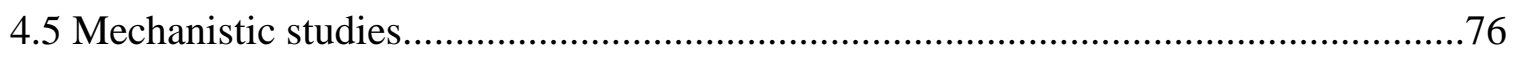

4.5.1 Catalyst dependent studies at a fixed acid concentration in acetonitrile.................76

4.5.2 Acid dependent studies in acetonitrile ...................................................... 77

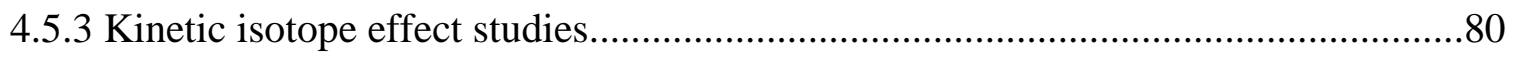

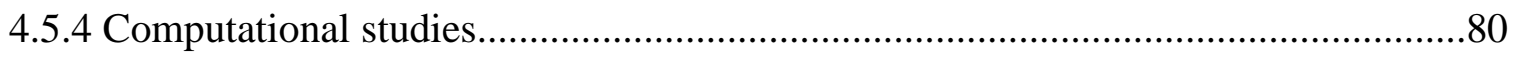

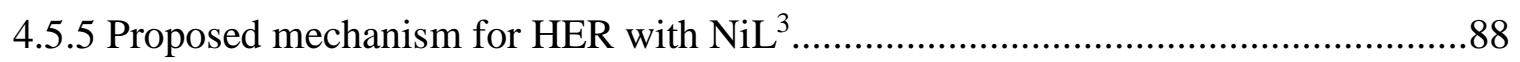

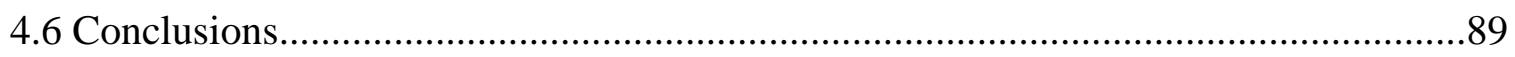

CHAPTER V COPPER CATALYSED AEROBIC OXIDATION OF BENZYLIC ALCOHOLS IN AN IMIDAZOLE CONTAINING N4 LIGAND FRAMEWORK........90

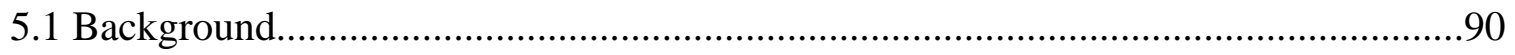

5.1.1 Mechanism of alcohol oxidation by galactose oxidase ......................................91

5.1.2 Copper complexes for oxidation of alcohols to aldehydes..................................92

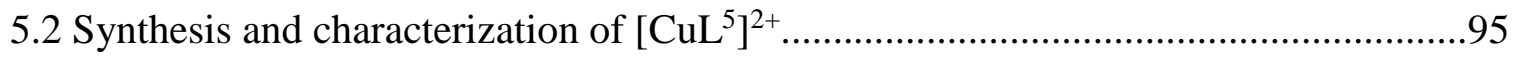

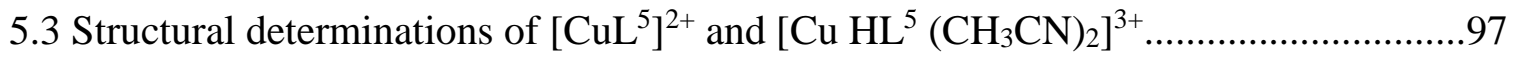

5.4 Catalytic oxidations: Identification of system components....................................99

5.5 Catalytic oxidations: Mechanistic studies...........................................................103

5.6 Proposed mechanism for aerobic oxidation of benzylic alcohols with $\left[\mathrm{CuL}^{5}\right]^{2+} \ldots \ldots .108$

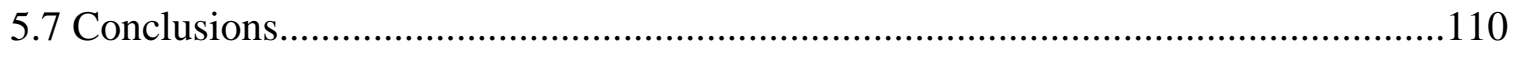

CHAPTER VI CONCLUSIONS AND FUTURE DIRECTIONS...............................111

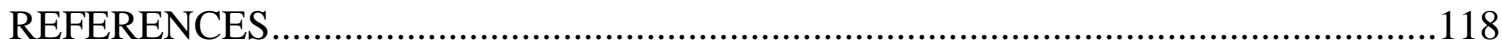

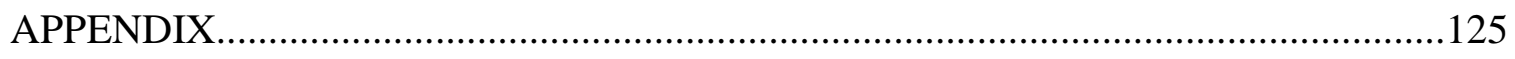

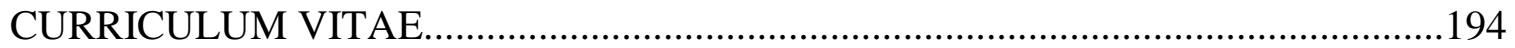




\section{LIST OF FIGURES}

Figure 1.1 Percentage distribution of energy consumption in U.S. in 2016......................3

Figure 1.2 Active sites for $[\mathrm{NiFe}],[\mathrm{FeFe}]$ and $[\mathrm{Fe}]-$ only hydrogenases...........................

Figure 1.3 Proposed hydrogen evolution mechanism for [FeFe]-hydrogenase..................6

Figure 1.4 Representation of PEM fuel cell...........................................................

Figure 1.5 Nickel complexes reported in literature for catalyzing hydrogen evolution.......8

Figure 1.6 Postulated mechanism for hydrogen evolution reaction by $\mathrm{Ni}\left(\mathrm{P}_{2}{ }^{\mathrm{R}} \mathrm{N}_{2}{ }^{\mathrm{R}}\right)_{2} \ldots \ldots \ldots . .9$

Figure 1.7 Possible pathways for hydrogen evolution reaction in catalysis......................10

Figure 1.8 Postulated homogeneous hydrogen evolution reaction mechanism with

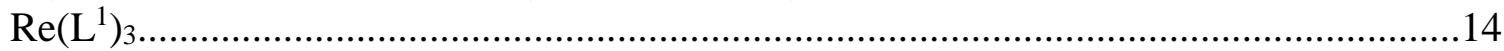

Figure 3.1 Schematic representation of thermodynamic squares for ethylene addition to

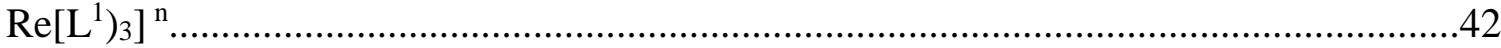

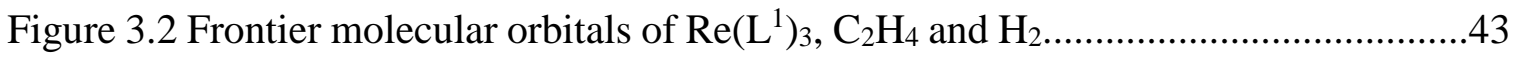

Figure 3.3 Catalytic dehalogenation of dihaloalkanes...................................................44

Figure 3.4 Synthesis of metal complexes $\mathrm{Ni}\left(\mathrm{L}^{1}\right)_{2}, \mathrm{Ni}\left(\mathrm{L}^{2}\right)_{2}, \mathrm{Zn}\left(\mathrm{L}^{1}\right)_{2}$ and $\mathrm{Zn}\left(\mathrm{L}^{2}\right)_{2} \ldots \ldots \ldots \ldots \ldots . .47$

Figure 3.5 Overlay of the electronic spectra of the metal complexes recorded in

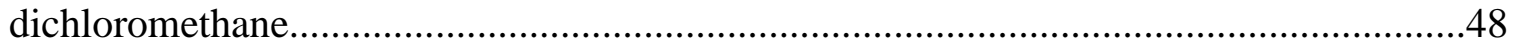

Figure 3.6 ORTEP representation of $\mathrm{Ni}\left(\mathrm{L}^{2}\right)_{2}$ and $\mathrm{Zn}\left(\mathrm{L}^{2}\right)_{2}$ with thermal ellipsoids at $50 \%$ probability level.

Figure 3.7 Cyclic voltammograms recorded in dichloromethane on $0.50 \mathrm{mM}$ solutions of each complex with $0.1 \mathrm{M} \mathrm{Bu}_{4} \mathrm{NPF}_{6}$ as supporting electrolyte at a scan rate of $200 \mathrm{mV} / \mathrm{s} . .51$

Figure 3.8 Cyclic voltammograms $(\mathrm{CVs})$ of $0.50 \mathrm{mM} \mathrm{Ni}\left(\mathrm{L}^{1}\right)_{2}$ in the presence of $0.1 \mathrm{M}$ $\left[\mathrm{Bu}_{4} \mathrm{NPF}_{6}\right]$ in dichloromethane solution with subsequent addition of acetic acidat scan rate of $200 \mathrm{mV} / \mathrm{s}$. CVs showing no acid (red), $1.4 \mathrm{mM}$ (green), $2.8 \mathrm{mM}$ (blue), $3.5 \mathrm{mM}$ (black). (Inset) Plot of $i_{\text {cat }} / i_{p}$ vs $\left[\mathrm{CH}_{3} \mathrm{COOH}\right]^{1 / 2}$

Figure 3.9 Cyclic voltammograms $(\mathrm{CVs})$ of $0.50 \mathrm{mM} \mathrm{Ni}\left(\mathrm{L}^{1}\right)_{2}$ in the presence of $0.1 \mathrm{M}$ $\left[\mathrm{Bu}_{4} \mathrm{NPF}_{6}\right]$ in dichloromethane solution with subsequent addition of hydrochloric acid at scan rate of $200 \mathrm{mV} / \mathrm{s}$. CVs showing no acid (red), $2.6 \mathrm{mM}$ (blue), $3.9 \mathrm{mM}$ (green), 5.2 $\mathrm{mM}$ (violet), $6.5 \mathrm{mM}$ (yellow). 
Figure 3.10 Plot of $i_{c a} / i_{p}$ vs $[\mathrm{HCl}]^{1 / 2}$

Figure 3.11 UV-Vis spectra showing titrations of $\mathrm{Ni}\left(\mathrm{L}^{1}\right)_{2}$ with hydrochloric acid in dichloromethane .55

Figure 3.12 Catalyst dependence studies. A plot showing variation catalytic current vs catalyst concentration at constant acetic acid concentration of $3.5 \mathrm{mM}$ in dichloromethane solution. .56

Figure 3.13 Proposed HER mechanism with $\mathrm{Ni}\left(\mathrm{L}^{1}\right)_{2}$. Path (a) shows ECEC type of mechanism while Path (b) shows CEEC type of mechanism. .57

Figure 3.14 Cyclic voltammograms $(\mathrm{CVs})$ of $0.50 \mathrm{mM} \mathrm{Ni}\left(\mathrm{L}^{1}\right)_{2}$ in the presence of $0.1 \mathrm{M}$ $\left[\mathrm{Bu}_{4} \mathrm{NPF}_{6}\right]$ in dichloromethane solution with subsequent addition of redox active base triethylamine under $1 \mathrm{~atm} . \mathrm{H}_{2}$ at scan rate of $200 \mathrm{mV} / \mathrm{s}$ .58

Figure 3.15 Cyclic voltammograms $(\mathrm{CVs})$ of $0.50 \mathrm{mM} \mathrm{Ni}\left(\mathrm{L}^{2}\right)_{2}$ in the presence of $0.1 \mathrm{M}$ $\left[\mathrm{Bu}_{4} \mathrm{NPF}_{6}\right]$ in dichloromethane solution with subsequent addition of redox active base triethylamine under $1 \mathrm{~atm} . \mathrm{H}_{2}$ at scan rate of $200 \mathrm{mV} / \mathrm{s}$ .59

Figure 4.1 Schematic representation of synthesis of ligand diacetyl-bis(N-4-methyl-3thiosemicarbazonate), $\mathrm{H}_{2} \mathrm{~L}^{3}$......

Figure 4.2 Structural representation of diacetyl-bis(N-4-methyl-3-thiosemicarbazonato) zinc(II), $\mathrm{ZnL}^{3}$ and diacetyl-bis(N-4-methyl-3-thiosemicarbazonato) copper(II), $\mathrm{CuL}^{3}$ complexes. .63

Figure 4.3 Postulated ligand centered mechanism for hydrogen evolution reaction with $\mathrm{ZnL}^{3}$ .64

Figure 4.4 Proposed metal assisted ligand centered mechanism for hydrogen evolution reaction with $\mathrm{CuL}^{3}$ .66

Figure 4.5. Structural representation of NiL, [4-\{bis(4-(p-methoxyphenyl)thiosemicarbazonato) \}-2,3-butane] $\mathrm{Ni}$ (II) complex)

Figure 4.6 Proposed hydrogen evolution reaction mechanism with NiL .68

Figure 4.7 Structural representation of $\mathrm{NiL}^{3}$, diacetyl-bis(N-4-methyl-3thiosemicarbazonato) $\mathrm{Ni}(\mathrm{II})$ 68

Figure 4.8 Cyclic voltammograms of $0.30 \mathrm{mM} \mathrm{NiL}^{3}$ in $25 \mathrm{ml}$ dimethylformamide solution collected at scan rates from 100-500 mV/s (top)Plot of the peak current vs square root of scan rate collected from scan rates from $100-500 \mathrm{mV} / \mathrm{s}$ (bottom) .70

Figure 4.9 Cyclic voltammograms of $0.30 \mathrm{mM} \mathrm{NiL}^{3}$ in $25 \mathrm{ml}$ acetonitrile solution collected at scan rate of $500 \mathrm{mV} / \mathrm{s}$ with the increasing acetic acid concentrations of $0,1.4,2.8,4.2$, 5.6, 7.0, 8.4, 9.8, 11.2, $12.6 \mathrm{mM}$ (top). .71 
Figure 4.10 Cyclic voltammograms of $0.30 \mathrm{mM} \mathrm{NiL}^{3}$ in $25 \mathrm{ml}$ dimethylformamide solution collected at scan rate of $200 \mathrm{mV} / \mathrm{s}$ with the increasing acetic acid concentrations of $0,4.2$, 5.6, 7, 8.4, $9.8 \mathrm{mM}$ (top)

Figure 4.11 Cyclic voltammograms of $0.30 \mathrm{mM} \mathrm{NiL}^{3}$ in $25 \mathrm{ml}$ acetonitrile solution collected at scan rate of $200 \mathrm{mV} / \mathrm{s}$ with the increasing trifluoroacetic acid concentrations of $0,6,8,10,12,14,16,18 \mathrm{mM}$ (top) .73

Figure 4.12 Cyclic voltammograms of $0.30 \mathrm{mM} \mathrm{NiL}^{3}$ in $25 \mathrm{ml}$ dimethylformamide solution collected at scan rate of $200 \mathrm{mV} / \mathrm{s}$ with the increasing trifluoroacetic acid concentrations of $0,4,8,12,16,20,24,32 \mathrm{mM}$ (top) .74

Figure 4.13 Controlled potential coulometry of $0.30 \mathrm{mM} \mathrm{NiL}^{3}$ in $0.1 \mathrm{M} \mathrm{Bu}_{4} \mathrm{NPF}_{6}$ with 12.6 $\mathrm{mM}$ acetic acid added in acetonitrile solutions .75

Figure 4.14 Catalyst dependence studies. Plot of catalytic current catalyst concentration at a constant acid concentration of $12.6 \mathrm{mM}$ in acetonitrile solutions .77

Figure 4.15 Acid dependence studies. Plot of icat/ip vs $\left[\mathrm{CH}_{3} \mathrm{COOH}\right]$ in acetonitrile solutions .78

Figure 4.16 Acid dependence studies. Plot of icat/ip vs $\left[\mathrm{CH}_{3} \mathrm{COOH}\right]$ in dimethylformamide solutions .78

Figure 4.17 Acid dependence studies. Plot of icat/ip vs $\left[\mathrm{CF}_{3} \mathrm{COOH}\right]$ in acetonitrile solutions .79

Figure 4.18 Acid dependence studies. Plot of icat/ip vs $\left[\mathrm{CF}_{3} \mathrm{COOH}\right]$ in dimethylformamide solutions .79

Figure 4.19 Optimized structure of $\mathrm{NiL}^{3}$ with B3LYP/6311g (d, p), $(M s=1, q=0)$ .81

Figure 4.20 Spin density plot of $\left[\mathrm{NiL}^{3}\right]^{-}(M s=2, q=-1)$. Spin density on the H-atoms has not been included in the figure.

Figure 4.21 Energetic stability of the reduced/ protonated species [NiL $\left.{ }^{3} \mathrm{H}\right]$ using B3LYP/6311g $(\mathrm{d}, \mathrm{p})(M s=2, q=0)$, using PCM calculations in acetonitrile solvent.........84

Figure 4.22 Energetic stability of the reduced/ protonated species/ reduced $\left[\mathrm{NiL}^{3} \mathrm{H}\right]{ }^{-}$ B3LYP/6311g (d, p) $(M s=3, q=-1)$, using PCM calculations in acetonitrile solvent .......86

Figure 4.23 Energetic stability of the reduced/ protonated species/ reduced $\left[\mathrm{NiL}^{3} \mathrm{H}\right]{ }^{-}$ B3LYP/6311g (d,p) $(M s=1, q=-1)$, using PCM calculations in acetonitrile solvent........87

Figure 4.24 Proposed mechanism for hydrogen evolution reaction with $\mathrm{NiL}^{3}$..................88

Figure 5.1 Active site of galactose oxidase and iron-only hydrogenase ..........................91

Figure 5.2 Mechanism of alcohol oxidation by galactose oxidase .................................92

Figure 5.3 Proposed mechanism of alcohol oxidation by CuIOTf/TEMPO/bpy system....94 
Figure 5.4 Comparison of alcohol reactivity of $\left[\mathrm{CuL}^{4}\right]^{2+}$ and $\left[\mathrm{CuL}^{5}\right]^{2+}$

Figure 5.5 UV-Vis spectra collected with the titrations of $\left[\mathrm{CuL}^{5}\right]^{2+}$ with perchloric acid in acetonitrile

Figure 5.6 ORTEP representation of $\left[\mathrm{CuL}^{5}\right]\left[\mathrm{ClO}_{4}\right]_{2}$ and $\left[\mathrm{Cu}\left(\mathrm{HL}^{5}\right)\left(\mathrm{CH}_{3} \mathrm{CN}\right)_{2}\right]\left[\mathrm{ClO}_{4}\right]_{3} \ldots . .98$

Figure 5.7 Plot of TON (red squares, left axis) and \% yield (green diamonds, right axis) versus substrate quantity. $\left[\mathrm{CuL}^{5}\right]^{2+}=\mathrm{NMI}=\mathrm{TEMPO}=250 \mu \mathrm{mol}, 10 \mathrm{~mL} \mathrm{CH}_{3} \mathrm{CN}$, aerobic conditions 104

Figure 5.8 Plot of TON (red squares, left axis) and \% yield (green diamonds, right axis) versus catalyst quantity. $\mathrm{C}_{6} \mathrm{H}_{5} \mathrm{CH}_{2} \mathrm{OH}=5 \mathrm{mmol}, \mathrm{NMI}=\mathrm{TEMPO}=250 \mu \mathrm{mol}, 10 \mathrm{~mL}$ $\mathrm{CH}_{3} \mathrm{CN}$, aerobic conditions. .105

Figure 5.9 Plot of TON versus TEMPO equivalents relative to $\left[\mathrm{L}_{5}-\mathrm{Cu}\right]^{2+} . \mathrm{C}_{6} \mathrm{H}_{5} \mathrm{CH}_{2} \mathrm{OH}=5$ mmol, $\left[\mathrm{CuL}^{5}\right]^{2+}=\mathrm{NMI}=250 \mu \mathrm{mol}, 10 \mathrm{~mL} \mathrm{CH}_{3} \mathrm{CN}$, aerobic conditions ........................106

Figure 5.10 Plot of TON versus NMI equivalents relative to $\left[\mathrm{L}_{5}-\mathrm{Cu}\right]^{2+} \cdot \mathrm{C}_{6} \mathrm{H}_{5} \mathrm{CH}_{2} \mathrm{OH}=5$ mmol, $\left[\mathrm{CuL}^{5}\right]^{2+}=\mathrm{TEMPO}=250 \mu \mathrm{mol}, 10 \mathrm{~mL} \mathrm{CH}_{3} \mathrm{CN}$, aerobic conditions ..................107

Figure 5.11 Plot of TON versus $\mathrm{O}_{2}$ flowrate. $\mathrm{C}_{6} \mathrm{H}_{5} \mathrm{CH}_{2} \mathrm{OH}=5 \mathrm{mmol},\left[\mathrm{CuL}^{5}\right]^{2+}=\mathrm{NMI}=$ $\mathrm{TEMPO}=250 \mu \mathrm{mol}, 10 \mathrm{~mL} \mathrm{CH}_{3} \mathrm{CN}$ .108

Figure 5.12 A proposed mechanism for alcohol oxidation with $\left[\mathrm{CuL}^{5}\right]^{2+}$ .109 


\section{LIST OF TABLES}

Table 3.1 Comparison of bond distances $(\AA)$ and bond angles $\left(^{\circ}\right)$ for $\mathrm{Ni}\left(\mathrm{L}^{1}\right)_{2}, \mathrm{Ni}\left(\mathrm{L}^{2}\right)_{2}$ and

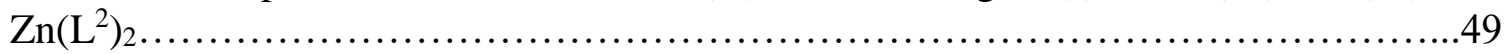

Table 3.2 Electrochemical data for complexes.............................................................51

Table 4.1 Comparison of optimized and experimental bond distances $(\AA)$ and bond angles $\left({ }^{\circ}\right)$ for $\mathrm{NiL}^{3}$ 81

Table 4.2 Comparison of optimized bond distances $(\AA)$ and bond angles $\left(^{\circ}\right)$ for $\mathrm{NiL}^{3}$ and $\left[\mathrm{NiL}^{3}\right]^{-}$..... .83

Table 5.1 Comparison of bond distances $(\AA)$ and bond angles $\left(^{\circ}\right)$ for $\left[\mathrm{CuL}^{5}\right]\left[\mathrm{ClO}_{4}\right]_{2}$

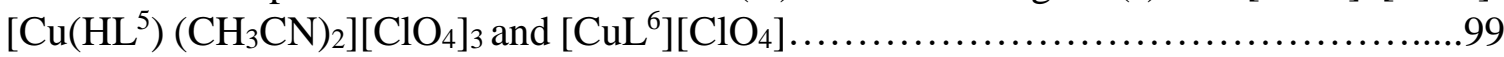

Table 5.2 Oxidation of selected benzylic alcohols to corresponding carbonyl compounds at $298 \mathrm{~K}$ 101 


\section{CHAPTER I}

\section{INTRODUCTION}

\subsection{Scope of dissertation}

This dissertation describes the importance of ligand architecture in the activation of small molecules through $(a)$ proton reduction with nickel (II) complexes having redoxactive PS and $\mathrm{N}_{2} \mathrm{~S}_{2}$ ligand frameworks, and $(b)$ aerobic alcohol oxidation with copper (II) complexes containing $\mathrm{N}_{4}$-ligand backbone. For studies involving hydrogen evolution reaction (HER) and hydrogen oxidation reactions (HOR), a series of techniques were employed including: anaerobic synthesis and techniques like nuclear magnetic resonance (NMR), Fourier-transform infrared (FT-IR), mass spectrometry (ESI-MS), single crystal X-ray crystallography, and elemental analysis. Additional techniques include electrochemical studies like cyclic voltammetry and controlled potential coulometry, product analysis using gas chromatography (GC), kinetics including kinetic isotope effect (KIE) determination, and density functional theory (DFT) studies. DFT studies were found to be crucial for gaining a mechanistic insight of hydrogen evolution reactions with $\mathrm{N}_{2} \mathrm{~S}_{2}$ complex. For studies, involving oxidation of benzylic alcohols to benzylic aldehydes, similar synthesis and spectroscopic techniques were employed as described above and the product formation was analyzed using gas chromatography-mass spectrometry (GC-MS), which is a useful technique for quantitative and qualitative analysis. 
Chapter 1 of this dissertation highlights the importance and need for hydrogen. It includes an introduction to hydrogenase and a review of previously reported electrocatalysts for the hydrogen evolution reaction. In Chapter 2, experimental details including the synthesis and spectroscopic characterization of the metal complexes and calculations of turnover frequencies, turnover number, and overpotential for hydrogen evolution and hydrogen oxidation reactions are presented. Computational studies employed for DFT optimizations have also been described. The chapter describes a procedure to calculate percentage yield and turnover number for analyzing the product for aerobic benzylic alcohol oxidation.

In Chapter 3, results of electrocatalytic screening of $\mathrm{Ni}(\mathrm{PS})_{2}$ and $\mathrm{Zn}(\mathrm{PS})_{2}$ complexes for hydrogen evolution and hydrogen oxidation reactions in dichloromethane solutions are discussed. The chapter highlights the importance of the orientation of the redox non-innocence PS chelates on the metal center. Chapter 4 of the dissertation discusses the hydrogen evolution ability of a $\mathrm{Ni}\left(\mathrm{N}_{2} \mathrm{~S}_{2}\right)$ complex in acetonitrile and dimethylformamide solutions. DFT studies were conducted to optimize possible intermediates involved in the reaction mechanism. Chapter 5 describes $\mathrm{N}_{4}-\mathrm{Cu}$ catalytic systems employed for aerobic oxidation of benzylic alcohols to benzylic aldehydes at room temperature. It provides a description of various substrates tested, the optimum conditions required to achieve higher yields and the mechanistic details for the catalytic reaction. Chapter 6 of the dissertation summarizes all three projects described in Chapter $3-5$, and discusses future directions in terms of exploitation of the redox non-innocence of the ligands for catalytic reactions involving hydrogen evolution and alcohol oxidation. 


\subsection{Hydrogen as a fuel}

From the past century, demand for energy has been gratified by the exploitation of fossil fuels like coal, petroleum, and natural gas. The energy generated by burning fossils fuels is used for transportation, electricity, and other industries. These are the nonrenewable sources of energy and cannot be replenish once exhausted from the planet. For the year 2016, total consumption of energy in USA was reported to be 97.4 quadrillion BTUs. About $81 \%$ of this energy was generated using fossil fuels, while energy generated by employing renewable sources such as biomass, wind, and hydroelectric sources constituted only $10 \%$. Figure 1.1 gives the percent distribution of the energy consumption in the U.S. in 2016. ${ }^{1}$ The extensive use of fossil fuels is leading to increased levels of $\mathrm{CO}_{2}$ and $\mathrm{N}_{2} \mathrm{O}_{\mathrm{x}}$ gases in the atmosphere, which is responsible for global warming and acid rain and affects life forms in all spheres whether it is on land, air, or water. ${ }^{2}$ Also, the mining of fossil fuels is very expensive and the hazardous waste generated after their use is usually dumped in landfills leading to long lasting negative effects on the environment.

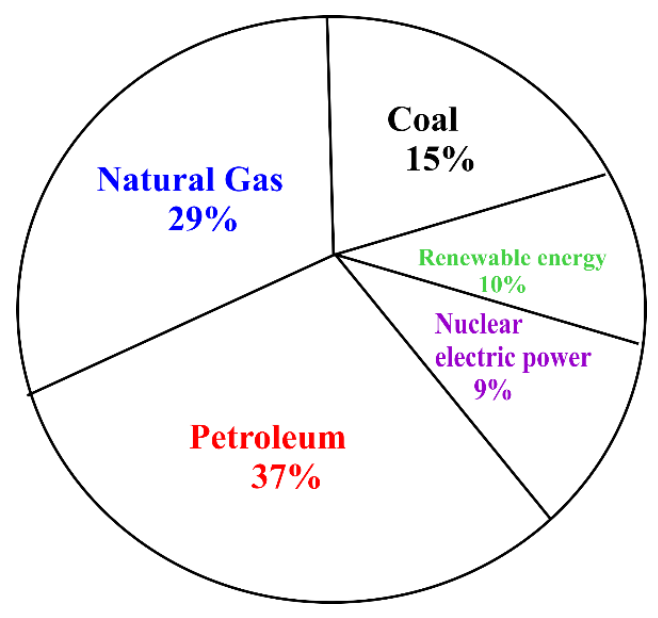

Figure 1.1 Percentage distribution of energy consumption in U.S. in 2016. 
The adverse and irreversible effects of the use of fossil fuels on the environment has increased the search for clean alternate sources of energy. Hydrogen, a simple molecule, that can serve as a carbon-free fuel as the combustion of hydrogen in the presence of oxygen generates water as the only by-product. ${ }^{3}$ Hydrogen production from renewable sources of energy such as light, water, or biomass would be an excellent pathway to generate energy as it is environment friendly with negligible impact on the natural environment. ${ }^{4}$ Microorganisms like algae and cyanobacteria, in nature, generate hydrogen by splitting water through the process called biophotolysis. ${ }^{5}$ Also, hydrogen generation from dark fermentation and photo-fermentation of organic substrates by fermentative and photosynthetic bacteria is renewable and an environmental friendly, as it recycles the byproducts from food and agricultural industries. ${ }^{6-7}$

\subsection{Hydrogenase: Nature's catalyst for hydrogen production}

Hydrogenase is a metalloenzyme that is responsible for hydrogen production and hydrogen oxidation in microorganisms by catalyzing the reactions involving protons and electrons. Hydrogenase with iron and/or nickel in the active site was discovered in 1931 in the bacterium Escherichia Coli and found to catalyze the reversible reduction of dye with hydrogen. ${ }^{8}$ Based upon the metal ion in the active center, hydrogenases, are known to occur in three different classes known as $[\mathrm{NiFe}],[\mathrm{FeFe}]$ and $[\mathrm{Fe}]-$ hydrogenases, Figure 1.2.9-11 The hydrogen molecule is heterolytically cleaved at the metal center, due to the presence of base in the proximity of the active center. The activity of hydrogenase was found to be reversibly inhibited by carbon monoxide. Generation of hydrogen occurs due to the coupling of a hydride and an exogenous proton during the enzymatic catalytic cycle. 


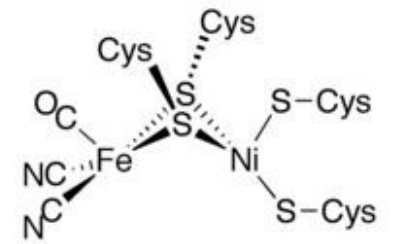

A

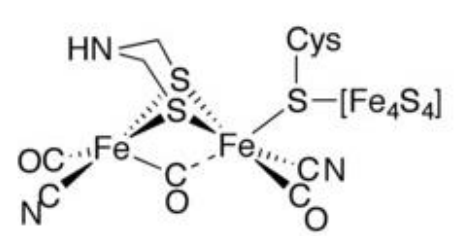

B

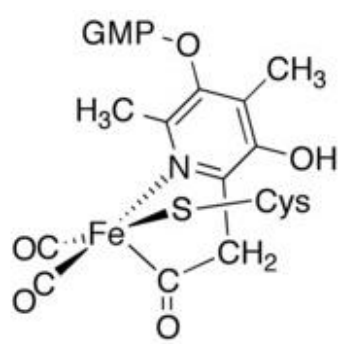

C

Figure 1.2 Active sites for $[\mathrm{NiFe}](\mathrm{A}),[\mathrm{FeFe}](\mathrm{B})$ and $[\mathrm{Fe}]-$ only $(\mathrm{C})$ hydrogenases.

The first structural characterization of [ $\mathrm{NiFe}]$ hydrogenase was reported in 1995 by Volbeda. ${ }^{12-13}$ The $[\mathrm{NiFe}]$ hydrogenase is composed of heterodimer having a Ni ion in the larger subunit and a smaller subunit consisting of an $[\mathrm{FeS}]$ cluster that plays a key role as a transfer relay system for electrons. The smaller [FeS] subunit allows electron hopping across the protein matrix. Hydrogen travels between the active site and the exterior of the protein through gas channels and proton transfer occurs because of accessible deprotonated/protonated residues. [NiFe] hydrogenase has number of spectroscopically discrete states that under electron deficiency reacts with oxygen, to generate less reactivating state, best described as the unready state. Under reductive conditions, a peroxide ligand coordinates between the $\mathrm{Ni}$ and Fe ions. A more accessible state known as the ready state of hydrogenase enzymes is achieved under oxidizing potentials consisted of hydroxide ligand bridged between the metal centers. Carbon monoxide and sulphide inhibit the activity of the enzyme. [Fe-Fe] hydrogenases are analogous to [NiFe] hydrogenase in the manner of having one or more $[\mathrm{FeS}]$ clusters. Two active sites of the enzyme known as $\mathrm{H}_{\mathrm{ox}}$ and $\mathrm{H}_{\mathrm{red}}$ are generated. An inactive state, $\mathrm{H}_{\mathrm{ox}}{ }^{\text {inact }}$ is incapable of reacting with carbon dioxide or oxygen is obtained upon the oxidation of $\mathrm{H}_{\mathrm{ox}}$, while the active form of the enzyme is known to be naïve towards the small molecules like $\mathrm{CO}_{2}$ and/ 
or $\mathrm{O}_{2}$. The active site of $[\mathrm{FeFe}]$ hydrogenase is comprised of cubane [4Fe-4S] cluster connected to a diiron [2Fe] sub cluster through a thiolate of cysteine. Both proximal and distal Fe ions are coordinated by one $\mathrm{CO}$ and one $\mathrm{CN}^{-}$ligands. The two metal centers are bridged by a $\mathrm{CO}$ ligand. The postulated mechanism for hydrogen evolution with [FeFe] hydrogenase has been shown in Figure 1.3. ${ }^{14-15}$

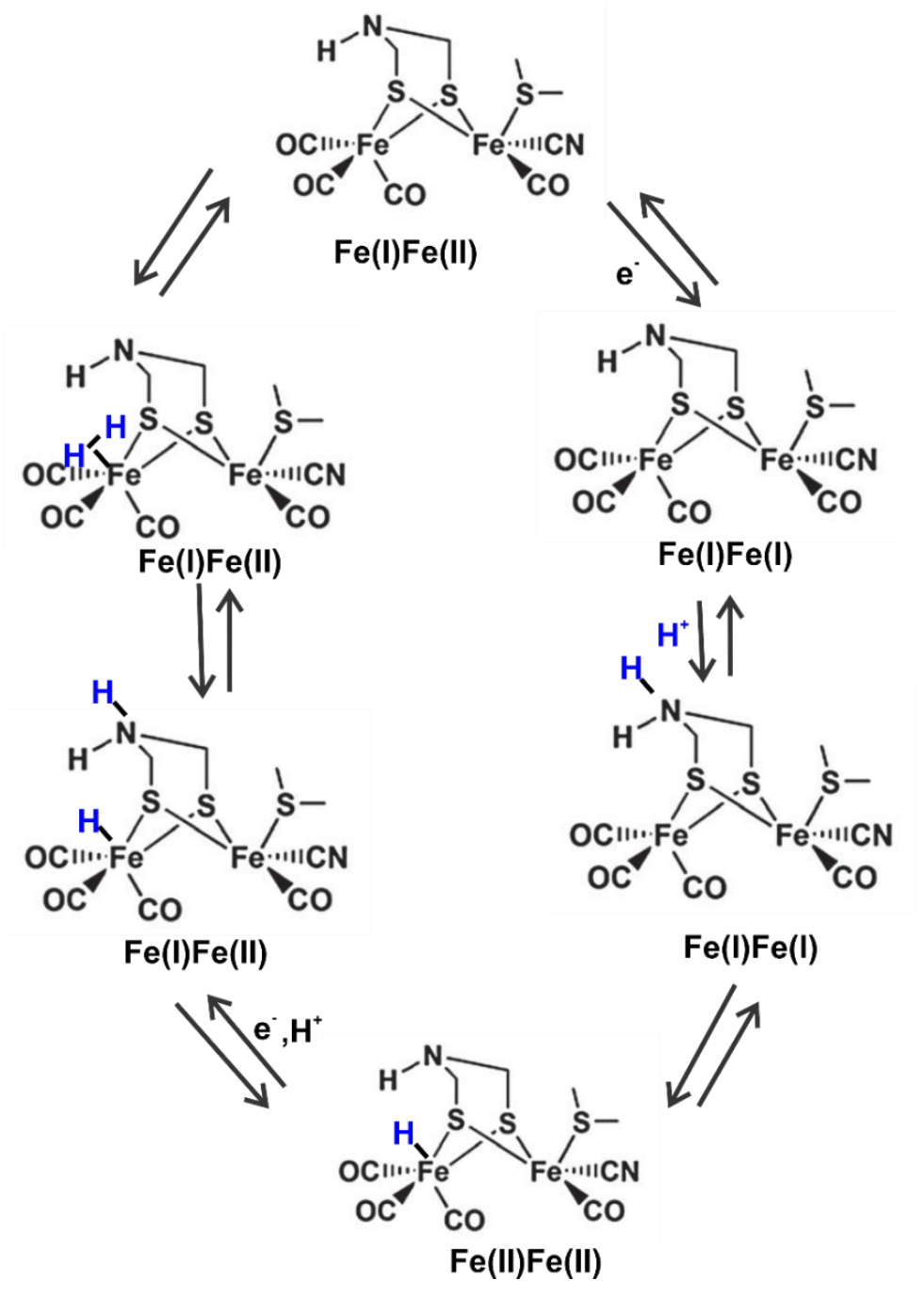

Figure 1.3 Proposed hydrogen evolution mechanism for [FeFe]-hydrogenase.

The bidirectional nature of Hydrogenases to efficiently catalyze hydrogen evolution and hydrogen oxidation reactions, make them ideal candidates for energy storage 
devices. The energy obtained from renewable sources like wind, solar and/ or hydrothermal can be stored in hydrogen molecule which can be used on demand. ${ }^{16}$ For instance, in fuel cells the chemical energy stored in the hydrogen can be converted into electrical energy upon the electrochemical reaction between hydrogen and oxygen, Figure $1.4 .{ }^{17}$

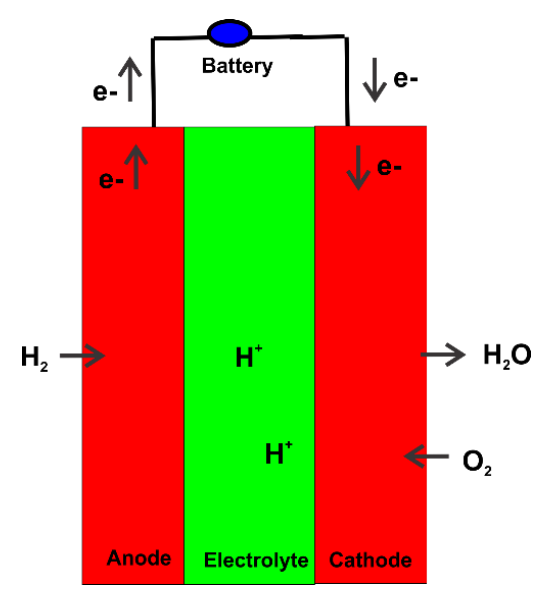

Figure 1.4 Representation of PEM fuel cell. ${ }^{17}$

Platinum metal, works efficiently to carry out hydrogen evolution and hydrogen oxidation electrocatalytically. But its utilization on the global scale is limited by its cost and availability. ${ }^{18} \mathrm{Pt}$ can be easily poisoned by $\mathrm{H}_{2} \mathrm{~S}$ and $\mathrm{CO}$. Hydrogenases with low cost first-row transition metals $\mathrm{Ni}$ and $\mathrm{Fe}$ in their active site, can serve as an excellent alternate to $\mathrm{Pt}$ due to comparable activity and reversible inhibition to $\mathrm{H}_{2} \mathrm{~S}$ and $\mathrm{CO} .{ }^{19-22}$

\subsection{Hydrogenase mimics and molecular catalysts for hydrogen evolution}

In the pursuit to develop efficient and economically affordable catalysts for hydrogen evolution and/or hydrogen oxidation reactions, several chemists have attempted to mimic the active sites of hydrogenases in laboratory. Few examples have been shown in Figure 1.5. Darensbourg reported first non-catalytic mimic of the enzyme with bridging thiolate and Fe-CO ligands (Figure 1.5 D, E) ${ }^{23}$ In 2009, Rauchfuss proposed the first active 
[NiFe] hydrogenase model having hydride bridge and shown to evolve hydrogen with strong acids at acceptable overpotentials (Figure $1.5 \mathrm{~F}) .{ }^{24}$ Weber showed hydrogen evolution by reversible protonation of the terminal thiolate ligand attached to nickel. ${ }^{25}$ Bidirectional behavior of the native enzyme, catalyzing both hydrogen production and oxidation was mimicked by Ogo. ${ }^{26}$ Several mononuclear complexes have also been reported as an active functional hydrogenase mimics with the emphasis on the role of first and second coordination spheres. DuBois's nickel catalyst (Figure, $1.5 \mathrm{G}$ ) is one of the best reported electrocatalyst for hydrogen evolution so far. ${ }^{4}$

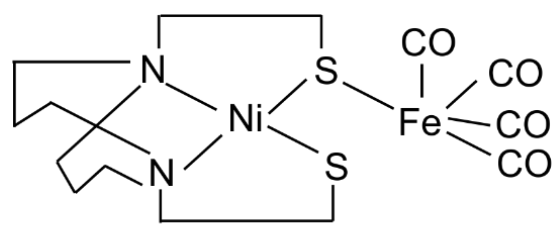

D

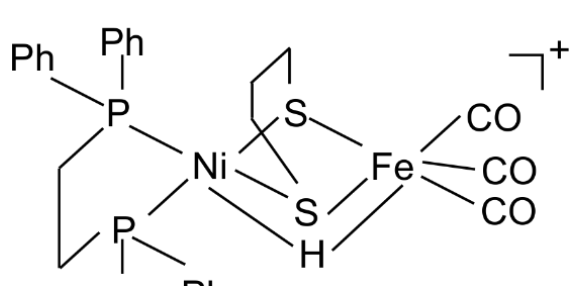

$\mathrm{Ph} \mathrm{Ph}$<smiles>CCN1S[N+]23SC1SC(C(C)(C)C=O)(S2)S3</smiles>

E

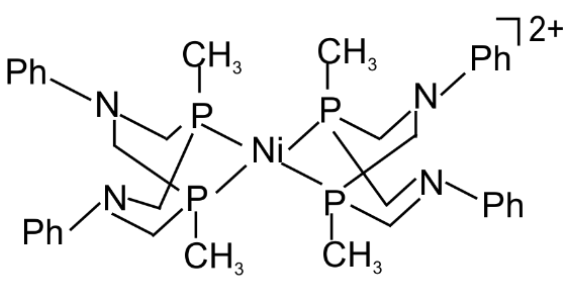

G

Figure 1.5 Nickel complexes reported in literature for catalyzing hydrogen evolution.

DuBois's mononuclear nickel complexes with bis(1,5- $R^{\prime}$-diphospha-3,7- $R^{\prime \prime}-$ diazacyclooctane) ligands has been reported to show the TON of $105 \mathrm{~s}^{-1}$ at an overpotential of $0.5-0.6 \mathrm{~V}$ for hydrogen production and TON of $50 \mathrm{~s}^{-1}$ for hydrogen oxidation at $1.0 \mathrm{~atm}$. of hydrogen atmosphere at an overpotential of $0.4 \mathrm{~V}$ using triethylamine as an external base. ${ }^{4}$ The $\left[\mathrm{Ni}\left(\mathrm{P}_{2}{ }^{\mathrm{R}} \mathrm{N}_{2}{ }^{\mathrm{R}^{\prime}}\right)_{2}\right]^{2+}$ complexes were inspired from the active site of hydrogenase 
enzyme in terms of (a) having an open coordination site for the binding of proton at the metal center, (b) close coordination of basic nitrogen site to the metal and (c) energetic similarity between the metal hydride and capability of basic ligand to accept protons, which avoids the high energy route of intermediate formation and provides reversibility in the catalytic cycle. $^{27}$

The HER with $\left[\mathrm{Ni}\left(\mathrm{P}_{2}{ }^{\mathrm{R}} \mathrm{N}_{2}{ }^{\mathrm{R}^{\prime}}\right)_{2}\right]^{2+}$ complex was proposed to occur through ECEC type of mechanism, Figure $1.6{ }^{28}$ In the first step, the $\mathrm{Ni}$ (II) species was reduced to $\mathrm{Ni}$ (I) species followed by protonation at the pendant amine nitrogen in the second step to yield $\left[\mathrm{Ni}\left(\mathrm{P}_{2}{ }^{\mathrm{R}} \mathrm{N}_{2}{ }^{\mathrm{R}^{\prime}} \mathrm{H}\right)\left(\mathrm{P}_{2}{ }^{\mathrm{R}} \mathrm{N}_{2}{ }^{\mathrm{R}^{\prime}}\right)\right]^{2+}$. In the next step, second electron addition reduced the $\mathrm{Ni}(\mathrm{I})$ species to $\mathrm{Ni}(0)$ species $\left[\mathrm{Ni}\left(\mathrm{P}_{2}{ }^{\mathrm{R}} \mathrm{N}_{2}{ }^{\mathrm{R}^{\prime}} \mathrm{H}\right)\left(\mathrm{P}_{2}{ }^{\mathrm{R}} \mathrm{N}_{2}{ }^{\mathrm{R}^{\prime}}\right)\right]^{+}$. After the second electron addition, an intramolecular proton transfer occurs that generates $\mathrm{Ni}(\mathrm{II})$ hydride, $\left[\mathrm{HNi}\left(\mathrm{P}_{2}{ }^{\mathrm{R}} \mathrm{N}_{2}{ }^{\mathrm{R}^{\prime}}\right)_{2}\right]^{+}$. With the formation of $\mathrm{Ni}(\mathrm{II})$ hydride, the second proton addition takes place on the pendant amine base. In the final step of the mechanism, hydrogen is eliminated, and the original catalyst was regenerated for the next cycle. The mechanism for HER with $\left[\mathrm{Ni}\left(\mathrm{P}_{2}{ }^{\mathrm{R}} \mathrm{N}_{2}{ }^{\mathrm{R}^{\prime}}\right)_{2}\right]^{2+}$ is ligand assisted metal-centered reaction as initially the substrate addition occurs on the pendant amine which directs it on the reactive metal center, which in the later steps interacts with the added proton on the ligand to form hydrogen.

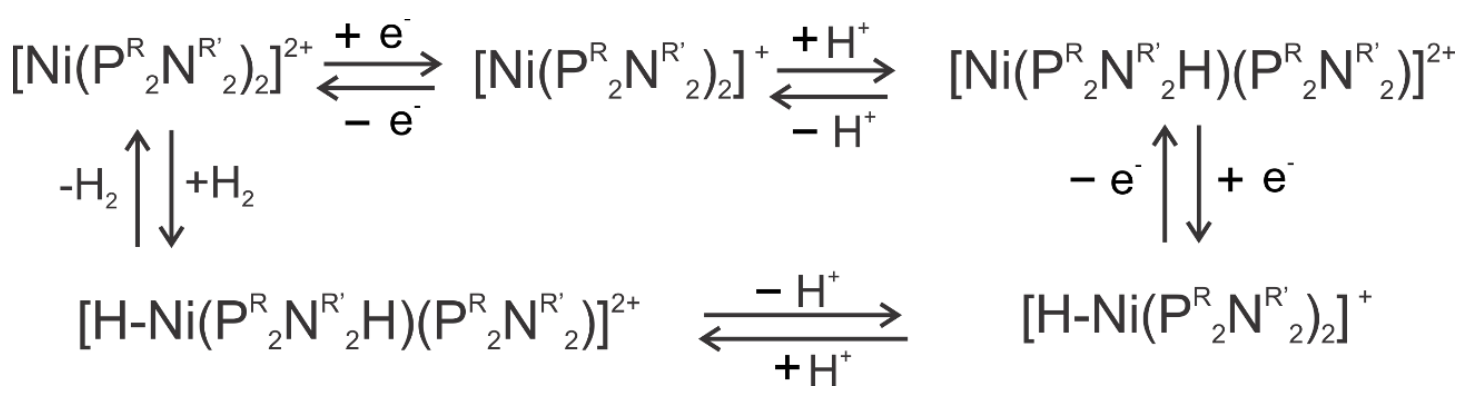

Figure 1.6 Postulated mechanism for hydrogen evolution reaction by $\mathrm{Ni}\left(\mathrm{P}_{2}{ }^{\mathrm{R}} \mathrm{N}_{2}{ }^{\mathrm{R}^{\prime}}\right)_{2} \cdot{ }^{28}$ 
In the hydrogen evolution reactions, the generation of metal hydride as an intermediate species has been identified to be crucial and higher activities can be achieved by the clever tuning and optimization of its reactivity. The catalysis for HER, can occur through reduction steps followed by protonation or it can be initiated by the initial protonation steps leading to the reduction in the later steps, described in Figure 1.7. Features like catalyst's structure, electrochemical potential of protons, determines the sequence of electron addition and the chemical steps.

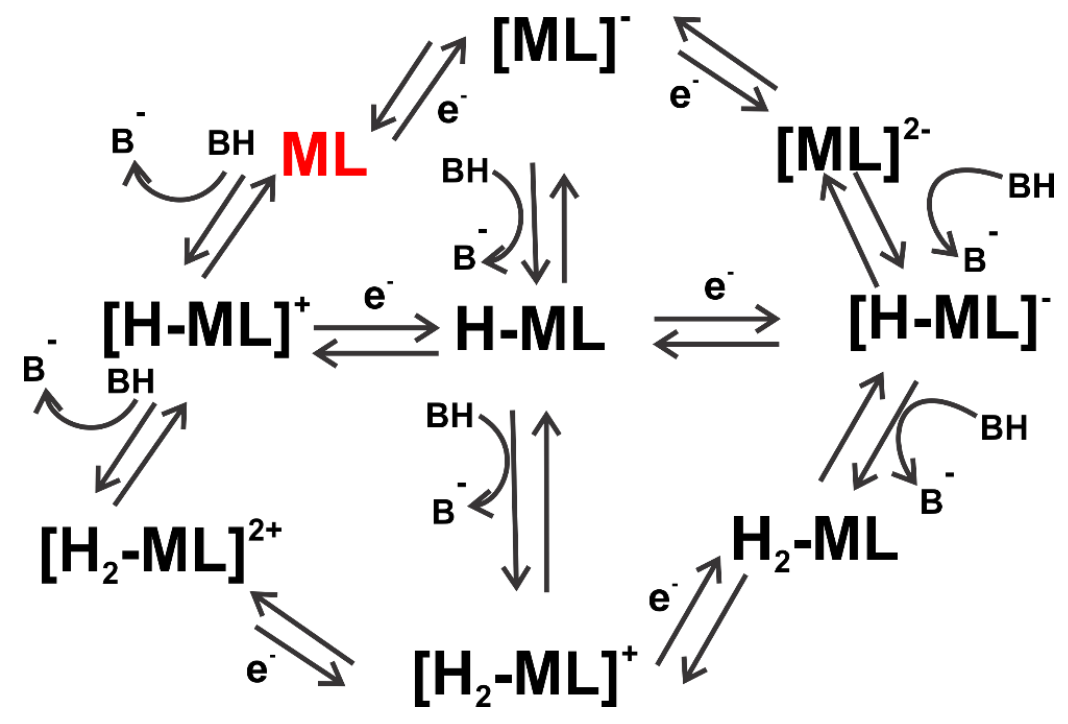

Figure 1.7 Possible pathways for hydrogen evolution reaction in catalysis. ${ }^{29}$

\subsection{An introduction of redox active ligands in catalysis}

The term redox-active ligand implies to the non-innocent ligand framework which has an ability to undergo oxidation and reduction reactions in the transition metal complexes. The redox assignments in the complexes possessing redox active ligands like dithiolenes, dioxalenes, carbenes, porphyrins, semithiocarbazones are different from the typical metal centered redox events. ${ }^{30-34}$

Gray reported the dithiolene Ni(II) complexes as a model of square planar transition metal complexes with redox-active ligands. ${ }^{35}$ Chirik reported the square pyramidal $\mathrm{Fe}(0)$ 
complex with redox active ligand bis(imino) pyridine as active catalysts for hydrogenation and hydrosilylation of unsaturated hydrocarbons. ${ }^{36-37}$ Mononuclear square planar Co(III) complexes with aminodiphenolate ligands reported by Soper showed their affinity for organozinc systems to yield C-C coupling of alkyl halides. ${ }^{38}$ The redox-active ligand framework participates in the two-electron reductive elimination while cobalt ion behaves as a spectator without undergoing any change in oxidation state. Heyduk demonstrated the $\mathrm{Zr}(\mathrm{IV})$ and $\mathrm{Ta}(\mathrm{V})$ complexes with tridentate $[\mathrm{NON}]$ and $[\mathrm{NNN}]$ pincer ligands for their ability to perform reactions like imide reduction and nitrene coupling. ${ }^{39-40}$ In Grapperhaus lab, current research attempts focus on the complexation of the redox active ligands to cheap earth abundant first-row transition metals and analysis of the systems for their electrocatalytic ability in the field of catalysis of sustainable fuel production.

\subsection{An introduction to metal-stabilized thiyl radicals}

Metal-stabilized thiyl radicals are generated by the ligand-centered oxidations of the metal thiolate complexes. ${ }^{41}$ Repulsions between metal- sulfur $\mathrm{d} \pi$-p $\pi$ orbitals results in the increase in the nucleophilic character of the metal thiolates, resulting in the excess of electron distribution on the $3 p$ orbital of sulfur. Highest occupied molecular orbital (HOMO) is generated with metal-sulfur $\pi^{*}$ anti-bonding character. Metal-centered oxidation is observed when the HOMO is localized on the metal, while the thiyl radical species is obtained with the heavy localization of HOMO towards the sulfur. The metal stabilized thiyl radical is generated by the equal distribution of HOMO between the metal center and the sulfur atom and thus, it is difficult to exclusively assign the oxidation to be metal-centered or sulfur-centered. The significantly strong $\mathrm{d} \pi$-p $\pi$ interactions between

metal and sulfur imparts distribution of spin density on metal and sulfur center. ${ }^{42-44}$ The 
highly reactive thiyl radical is stabilized by the metal center in a controlled fashion leading to their exploitation as selective catalysts for the functionalization of unsaturated hydrocarbons.

The Grapperhaus group has studied metal stabilized thiyl radicals for their ability bind simple alkene molecules like ethylene, 1-hexene, 2-ethyl-1-butene, cyclohexene etc. $^{45-46}$ Ruthenium and rhenium complexes with the ligand $\mathrm{L}^{1} \quad\left(\mathrm{~L}^{1}=\right.$ bis(diphenylphoshinebenzenethiolate) has been synthesized using procedure reported by Dilworth. ${ }^{47-48} \mathrm{Ru}\left[\left(\mathrm{L}^{1}\right)_{3}\right]^{-}$generated metal stabilized thiyl radical species $\mathrm{Ru}\left[\left(\mathrm{L}^{1}\right)_{3}\right]^{+}$, upon the consecutive two electron oxidation. The cationic species thus generated $\operatorname{Ru}\left[\left(\mathrm{L}^{1}\right)_{3}\right]^{+}$, binds the alkene across the cis-sulfur giving metal-dithioether complexes, $\operatorname{Ru}\left[\left(\mathrm{L}^{1}\right)_{3^{-}}\right.$ alkene $]^{+}{ }^{49} \operatorname{Re}\left(\mathrm{L}^{1}\right)_{3}$ complex upon single oxidation yields $\left[\operatorname{Re}\left(\mathrm{L}^{1}\right)_{3}\right]^{+}$, which was found to bind ethylene in the reversible fashion. ${ }^{50}$ Upon increasing the charge of the complex, an increase in the equilibrium binding constant was observed.

\subsection{Ligand centered hydrogen evolution with $\operatorname{Re}\left(L^{1}\right)_{3}$ complex}

Due to the similarity in the HOMO/LUMO molecular frontier orbital arrangements in hydrogen and ethylene, recently, our group has reported the exploitation of ligand centered reactivity of $\operatorname{Re}\left(\mathrm{L}^{1}\right)_{3}$ complex, $\left(\mathrm{L}^{1}=\right.$ diphenylphoshinebenzenethiolate) for hydrogen evolution and hydrogen oxidation. ${ }^{51-52}$ The metal center was acting as an electron pool and helped in the proper orientation the ligands to facilitate the coordination of the substrate to the sulfur atoms on the ligands. $\operatorname{Re}\left(\mathrm{L}^{1}\right)_{3}$ was found to electrocatalytic active for hydrogen evolution in dichloromethane solution with the turnover frequency (TOF) of 32 $\pm 3 \mathrm{~s}^{-1}$ with an overpotential of $708 \mathrm{mV}$. For hydrogen oxidation in the presence of external 
base triethylamine under $1 \mathrm{~atm} . \mathrm{H}_{2}$ the TOF of $4 \pm 1 \mathrm{~s}^{-1}$ with an overpotential of $670 \mathrm{mV}$ has been recorded.

Mechanistic studies on the HER activity of $\operatorname{Re}\left(\mathrm{L}^{1}\right)_{3}$ reveal a second order dependence on the acid concentration while first order dependence on the catalyst concentration. Thus, overall the reaction was third order with the overall rate constant $k=$ $184 \mathrm{M}^{-2} \mathrm{~s}^{-1}$. The kinetic isotope effect studies reveal the $\mathrm{KIE}\left(k_{\mathrm{H}} / k_{\mathrm{D}}\right)$ to be $9 \pm 1$ with $\mathrm{CH}_{3} \mathrm{COOH} / \mathrm{CD}_{3} \mathrm{COOD}$ and $\mathrm{CF}_{3} \mathrm{SO}_{3} \mathrm{H} / \mathrm{CF}_{3} \mathrm{SO}_{3} \mathrm{D}$. The higher values of KIE supports the reaction to proceeds through ligand centered route as has been reported by Gray and Fukuzumi. ${ }^{53-54}$ With $\operatorname{Re}\left(\mathrm{L}^{1}\right)_{3}$, a maximum turnover number (TON) of 54 has been recorded by performing controlled potential coulometry at a fixed potential of $-1.8 \mathrm{~V}$ vs ferrocenium/ferrocene for 6 hours. A minimum faradaic efficiency for hydrogen evolution with $\operatorname{Re}\left(\mathrm{L}^{1}\right)_{3}$ has been found to be $73 \%$. The ligand centered hydrogen evolution reaction with $\operatorname{Re}\left(\mathrm{L}^{1}\right)_{3}$ was credited to the meridional arrangement of the $\mathrm{L}^{1}$ ligands around the metal center. This leads to the coplanar orientation of lone pairs on the two sulfur atoms in the PS chelated framework.

The hydrogen evolution with $\operatorname{Re}\left(\mathrm{L}^{1}\right)_{3}$ was proposed to follow the ligand centered mechanism, Figure 1.8. In the initial steps, transfer of a proton and an electron to $\operatorname{Re}\left(\mathrm{L}^{1}\right)_{3}$ generates a neutral intermediate species, $\left[\operatorname{Re}\left(\mathrm{L}^{1} \mathrm{H}\right)\left(\mathrm{L}^{1}\right)_{2}\right]$ with a $\mathrm{H}$-atom on one of the cissulphur. The next step is the chemical step where with the second proton addition takes place generating protonated species $\left[\mathrm{Re}\left(\mathrm{L}^{1}\right)_{3} \cdot \mathrm{H}_{2}\right]^{+}$. In the following step electrochemical reduction of $\left[\operatorname{Re}\left(\mathrm{L}^{1}\right)_{3} \cdot \mathrm{H}_{2}\right]^{+}$, generates the neutral hydrogen evolving complex $\left[\operatorname{Re}\left(\mathrm{L}^{1}\right)_{3} \cdot \mathrm{H}_{2}\right]$. The neutral complex thus generated has $\mathrm{H}$-atoms coordinated to the two cis sulfurs which 
through homolytic cleavage in the final step, leads to the evolution of dihydrogen as a product and regeneration of the original catalyst, $\operatorname{Re}\left(\mathrm{L}^{1}\right)_{3} \cdot{ }^{51-52}$

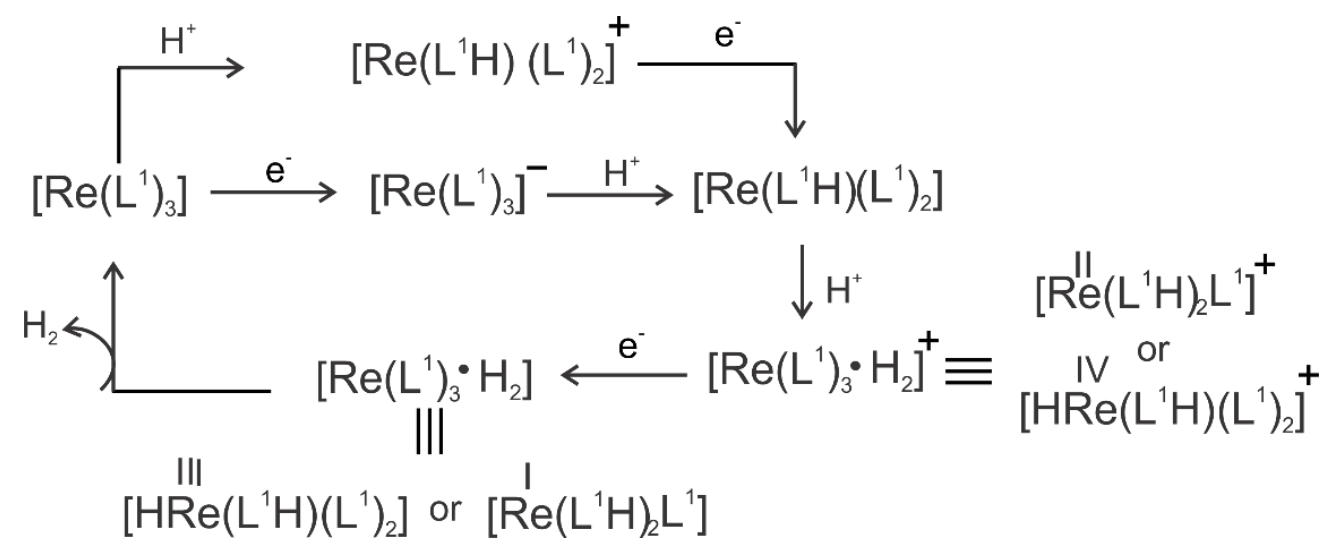

Figure 1.8 Postulated homogeneous hydrogen evolution reaction mechanism with $\operatorname{Re}\left(\mathrm{L}^{1}\right)_{3} .{ }^{51-52}$

For hydrogen oxidation with $\operatorname{Re}\left(\mathrm{L}^{1}\right)_{3}$, the mechanism was proposed to occur through two-electron oxidation of $\operatorname{Re}\left(\mathrm{L}^{1}\right)_{3}$ in the initial stage giving dicationic $\left[\operatorname{Re}\left(\mathrm{L}^{1}\right)_{3}\right]^{2+}$ species. This was followed by the addition of the dihydrogen molecule giving rise to hydrogen addition complex, $\left[\operatorname{Re}\left(\mathrm{L}^{1}\right)_{3} \cdot \mathrm{H}_{2}\right]^{2+}$. In the final steps, cleavage of $\mathrm{S}-\mathrm{H}$ bonds in the presence of external base, leads to the formation of protonated base and regeneration of the catalyst, $\operatorname{Re}\left(\mathrm{L}^{1}\right)_{3}$.

This dissertation describes the synthesis of tetracoordinated $\mathrm{Ni}$ (II) and $\mathrm{Zn}$ (II) analogues of diaryl/dialkylphoshinebenzenethiolate and their electrocatalytic behavior for hydrogen evolution and hydrogen oxidation in Chapter 3. In another study, Ni(II) complex with redox active ligand bis(thiosemicarbazonato) has also been evaluated for hydrogen evolution reaction and the results has been discussed in Chapter 4. 


\section{CHAPTER II}

\section{EXPERIMENTAL}

\subsection{Materials and reagents}

All chemicals were purchased from commercial sources and used without purification unless reported otherwise. Solvents like ethanol, diethylether, dichloromethane, dimethylformamide, acetonitrile were dried and purified using an MBraun solvent purification system unless otherwise noted. Solvents like tetrahydrofuran and methanol were freshly distilled using standard distillation procedures. ${ }^{55}$ Reactions were conducted using standard Schlenk line techniques under an inert (nitrogen or argon) atmosphere or in an argon-filled glove-box unless otherwise noted.

\subsection{Physical methods}

${ }^{1} \mathrm{H}$ NMR (400 MHz) and ${ }^{31} \mathrm{P}$ NMR (161 MHz) spectra were recorded on solutions in deuterated solvents using a Varian $400 \mathrm{MHz}$ spectrometer at room temperature. Elemental analyses were obtained from Midwest Microlab (Indianapolis, IN). Infrared spectra were recorded on a Thermo Nicolet Avatar 360 spectrometer with ATR attachment $\left(4 \mathrm{~cm}^{-1}\right.$ resolution) on solid powders. Mass spectrometry (+ESI-MS) was performed by the Laboratory for Biological Mass Spectrometry at Texas A\&M University. X-band electronic paramagnetic resonance (EPR) spectra were collected as powder samples at 77 $\mathrm{K}$ temperature using a Bruker EMX spectrometer and simulated using EasySpin. ${ }^{56}$ 
Electronic absorption spectra were recorded with an Agilent 8453 diode array spectrometer with a $1 \mathrm{~cm}$ path length quartz cell. The sample solutions were degassed before the collecting the spectrum. The GC-MS instrument was obtained from Agilent Technologies augmented with 7820A GC system and 5975 series MSD using Helium as a carrier gas at a flow rate of $1 \mathrm{~mL} / \mathrm{min}$. The oven temperature was set to $100^{\circ} \mathrm{C}$. The column used was poly (5\% diphenyl, 95\% dimethylsiloxane) with length $30 \mathrm{~m}, 250 \mu \mathrm{m}$ inner diameter and $0.25 \mu \mathrm{m}$ thickness. X-ray crystallographic studies were performed by Dr. M.S. Mashuta at the Department of Chemistry, University of Louisville on an Agilent Technologies/Oxford Diffraction Gemini CCD diffractometer.

\subsection{Synthesis of ligands}

The ligands 2-(diphenylphosphanyl)benzenethiol $\quad\left(\mathrm{HL}^{1}\right) \quad$ and 2 (diisopropylphosphanyl)benzenethiol $\left(\mathrm{HL}^{2}\right)$ were prepared by slight modifications of previously reported methods. ${ }^{57-59}$ The ligand diacetyl-bis(N4-methyl-3thiosemicarbazone) $\left(\mathrm{H}_{2} \mathrm{~L}^{3}\right)$ was prepared by previously reported methods. ${ }^{60}$ The ligands 1,2-bis[(1-methyl-2-imidazolyl)methyleneamino]ethane $\left(\mathrm{L}^{4}\right)$ and [(1-methyl-4,5-dihydro1H-imidazol-2-yl)methyl](2-ethyl)amine] $\left(\mathrm{L}^{5}\right)$ was prepared by slight modifications of previously reported methods. ${ }^{61}$

\subsection{Synthesis of metal complexes}

bis[2-(diphenylphosphanyl)benzenethiolato]nickel(II), Ni(L $\left.\mathbf{L}^{1}\right)_{2}$. A sodium ethoxide solution $(0.11 \mathrm{~g}, 1.60 \mathrm{mmol})$ was prepared in degassed ethanol $(10 \mathrm{~mL})$ under a nitrogen atmosphere to which solid $\mathrm{HL}^{1}(0.40 \mathrm{~g}, 1.50 \mathrm{mmol})$ was added under a nitrogen and the mixture was stirred until all ligand dissolved. $\mathrm{NiCl}_{2} \cdot 6 \mathrm{H}_{2} \mathrm{O}(0.15 \mathrm{~g}, 0.75 \mathrm{mmol})$ dissolved 
in degassed ethanol $(10 \mathrm{~mL})$ was added to the ligand solution via cannula under nitrogen atmosphere. After stirring the mixture for $10 \mathrm{~min}$, color change from light green to dark green was observed. A dark green solid product $\mathrm{Ni}\left(\mathrm{L}^{1}\right)_{2}$ was filtered from the reaction mixture which was then washed with ethanol $(20 \mathrm{~mL})$ and diethyl ether $(20 \mathrm{~mL})$ and dried under vacuum. Yield: $0.31 \mathrm{~g}, 81 \%$. + ESI-MS: $\mathrm{m} / \mathrm{z}$ calcd. for $\mathrm{C}_{36} \mathrm{H}_{28} \mathrm{P}_{2} \mathrm{~S}_{2} \mathrm{Ni} 645.39$, found 645.04. $\mathrm{C}_{36} \mathrm{H}_{28} \mathrm{NiP}_{2} \mathrm{~S}_{2}$ (645.39): calcd. C 66.99, H 4.37; found C 64.33, H 4.16. 1 H NMR (400 MHz, $\left.\mathrm{CD}_{2} \mathrm{Cl}_{2}\right): \delta=7.66(\mathrm{dd}, \mathrm{J}=12.7,5.9 \mathrm{~Hz}, 8 \mathrm{H}), 7.49(\mathrm{t}, \mathrm{J}=7.4 \mathrm{~Hz}, 4 \mathrm{H}), 7.40(\mathrm{~m}$, $10 \mathrm{H}), 7.18(\mathrm{t}, \mathrm{J}=7.8 \mathrm{~Hz}, 3 \mathrm{H}), 7.07(\mathrm{~m}, 2 \mathrm{H}), 6.92(\mathrm{t}, \mathrm{J}=7.5 \mathrm{~Hz}, 2 \mathrm{H}) \mathrm{ppm} .{ }^{31} \mathrm{P}\left\{{ }^{1} \mathrm{H}\right\}(161$ $\left.\mathrm{MHz}, \mathrm{CD}_{2} \mathrm{Cl}_{2}\right): \delta=55.69 \mathrm{ppm}$.

bis[2-(diphenylphosphanyl)benzenethiolato]zinc(II), $\mathbf{Z n}\left(\mathbf{L}^{1}\right)_{2}$. To prepare $\mathrm{Zn}\left(\mathrm{L}^{1}\right)_{2}$, the same procedure was followed as described above for $\mathrm{Ni}\left(\mathrm{L}^{1}\right)_{2}$ but now the metal precursor used was zinc acetate dihydrate. The zinc acetate dihydrate solution $(0.16 \mathrm{~g}, 0.75 \mathrm{mmol})$ in degassed ethanol $(10 \mathrm{~mL})$ was added to the ethanol solution of $\mathrm{HL}^{1}$ containing sodium ethoxide. A white solid product $\mathrm{Zn}\left(\mathrm{L}^{1}\right)_{2}$ was filtered from the solution which was then washed with ethanol $(20 \mathrm{~mL})$ and diethyl ether $(20 \mathrm{~mL})$ and dried under vacuum. Yield $0.42 \mathrm{~g}, 86 \%$. +ESI-MS: m/z calcd. for $\mathrm{C}_{36} \mathrm{H}_{28} \mathrm{P}_{2} \mathrm{~S}_{2} \mathrm{Zn}$ 652.09, found 652.06. $\mathrm{C}_{36} \mathrm{H}_{28} \mathrm{P}_{2} \mathrm{~S}_{2} \mathrm{Zn}$ (652.06): calcd. C 66.30, H 4.32; found C 64.32, H 5.44. ${ }^{1} \mathrm{H} \mathrm{NMR}\left(400 \mathrm{MHz}, \mathrm{CD}_{2} \mathrm{Cl}_{2}\right.$ ): $\delta$ = $7.65(\mathrm{~m}, 4 \mathrm{H}), 7.44(\mathrm{~m}, 6 \mathrm{H}), 7.33(\mathrm{~m}, 10 \mathrm{H}), 7.20(\mathrm{~m}, 4 \mathrm{H}), 7.02(\mathrm{~m}, 2 \mathrm{H}), 6.93(\mathrm{t}, \mathrm{J}=$ $7.5 \mathrm{~Hz}, 2 \mathrm{H}) \mathrm{ppm} .{ }^{31} \mathrm{P}\left\{{ }^{1} \mathrm{H}\right\}\left(161 \mathrm{MHz}, \mathrm{CD}_{2} \mathrm{Cl}_{2}\right): \delta=-9.77 \mathrm{ppm}$.

bis[2-(diisopropylphosphanyl)benzenethiolato]nickel(II), $\mathbf{N i}\left(\mathbf{L}^{2}\right)_{2}$. To prepare $\mathrm{Ni}\left(\mathrm{L}^{2}\right)_{2}$, the same procedure was followed as described above for $\mathrm{Ni}\left(\mathrm{L}^{1}\right)_{2}$ but now the ligand $\mathrm{HL}^{2}$ was used as a ligand source. $\mathrm{HL}^{2}(0.30 \mathrm{~g}, 1.50 \mathrm{mmol})$ was dissolved in degassed ethanol $(10 \mathrm{~mL})$ and the mixture yields brown-red product $\mathrm{Ni}\left(\mathrm{L}^{2}\right)_{2}$ which then was washed with 
ethanol $(20 \mathrm{~mL})$ and diethyl ether $(20 \mathrm{~mL})$ and dried under vacuum. Yield: $0.28 \mathrm{~g}, 88 \%$. Liquid diffusion of a dichloromethane/diethyl ether mixture yields orange crystals for Xray studies (CCDC 1549464). +ESI-MS: m/z calcd. for $\mathrm{C}_{24} \mathrm{H}_{36} \mathrm{P}_{2} \mathrm{~S}_{2} \mathrm{Ni}$ 509.30, found 509.09. $\mathrm{C}_{24} \mathrm{H}_{36} \mathrm{NiP}_{2} \mathrm{~S}_{2}$ (509.33): calcd. C 56.59, H 7.12; found C 53.51, H 7.67. ${ }^{1} \mathrm{H}$ NMR (400 MHz, $\left.\mathrm{CD}_{2} \mathrm{Cl}_{2}\right): \delta=7.45(\mathrm{~m}, 2 \mathrm{H}), 7.30(\mathrm{~m}, 2 \mathrm{H}), 7.20(\mathrm{~m}, 2 \mathrm{H}), 6.96(\mathrm{~m}, 2 \mathrm{H}), 2.50$ $(\mathrm{m}, 4 \mathrm{H}), 1.24(\mathrm{~d}, \mathrm{~J}=7.2 \mathrm{~Hz}, 24 \mathrm{H}) \mathrm{ppm} .{ }^{31} \mathrm{P}\left\{{ }^{1} \mathrm{H}\right\}\left(161 \mathrm{MHz}, \mathrm{CD}_{2} \mathrm{Cl}_{2}\right): \delta=75.62 \mathrm{ppm}$.

bis[2-(diisopropylphosphanyl)benzenethiolato]zinc(II), $\mathbf{Z n}\left(\mathbf{L}^{2}\right)_{2}$. To prepare $\mathrm{Zn}\left(\mathrm{L}^{2}\right)_{2}$, the same procedure was followed as described above for $\mathrm{Ni}\left(\mathrm{L}^{2}\right)_{2}$ but now the metal precursor used was zinc acetate dihydrate. The zinc acetate dihydrate solution $(0.16 \mathrm{~g}, 0.75$ mmol) in degassed ethanol $(10 \mathrm{~mL})$ was added to the ethanol solution of $\mathrm{HL}^{2}$ containing sodium ethoxide. A white solid product $\mathrm{Zn}\left(\mathrm{L}^{1}\right)_{2}$ was filtered from the solution which was then washed with ethanol $(20 \mathrm{~mL})$ and diethyl ether $(20 \mathrm{~mL})$ and dried under vacuum. Yield: 0.34 g, $88 \%$. +ESI-MS: $\mathrm{m} / \mathrm{z}$ calcd. for $\mathrm{C}_{24} \mathrm{H}_{36} \mathrm{P}_{2} \mathrm{~S}_{2} \mathrm{Zn}$ 515.96, found 515.11. $\mathrm{C}_{24} \mathrm{H}_{36} \mathrm{P}_{2} \mathrm{~S} 2 \mathrm{Zn}$ (516.00): calcd. C 55.86, H 7.03; found C 55.96, H 7.33. ${ }^{1} \mathrm{H}$ NMR (400 MHz, $\left.\mathrm{CD}_{2} \mathrm{Cl}_{2}\right): \delta=7.89(\mathrm{~m}, 2 \mathrm{H}), 7.47(\mathrm{~m}, 2 \mathrm{H}), 7.31(\mathrm{~m}, 2 \mathrm{H}), 7.24(\mathrm{~m}, 2 \mathrm{H}), 2.26(\mathrm{~m}, 4$ $\mathrm{H}), 1.26(\mathrm{~d}, \mathrm{~J}=83.1 \mathrm{~Hz}, 24 \mathrm{H}) \mathrm{ppm} .{ }^{31} \mathrm{P}\left\{{ }^{1} \mathrm{H}\right\}\left(161 \mathrm{MHz}, \mathrm{CD}_{2} \mathrm{Cl}_{2}\right): \delta=11.5 \mathrm{ppm}$.

diacetyl-bis(N4-methyl-3-thiosemicarbazonato) $\mathbf{N i ( I I ) , ~} \mathbf{N i L}^{3}$. To synthesize $\mathrm{NiL}^{3}$ complex, the ligand $\mathrm{ATSMH}_{2}(1.50 \mathrm{~g}, 5.8 \mathrm{mmol})$ was dissolved in methanol and $\mathrm{Ni}(\mathrm{OAc})_{2} \cdot 4 \mathrm{H}_{2} \mathrm{O}$ was added $(1.57 \mathrm{~g}, 6.3 \mathrm{mmol})$. The reaction mixture was refluxed for 4 hours. The dark green precipitates were filtered and washed with methanol and diethyl ether and dried under vacuum. Yield: $1.56 \mathrm{~g}, 85.3 \% .{ }^{1} \mathrm{H}$ NMR (400 MHz, DMSO- $\left.d_{6}\right): 7.66$ (2H, br. s), $2.75(6 \mathrm{H}), 1.91(6 \mathrm{H}, \mathrm{s})$. 
Caution! Although we have experienced no problems in handling the $\mathrm{Cu}$ complexes of $L^{4}$ and $L^{5}$, metal-organic perchlorates are potentially explosive and should be handled with due care in small quantities.

\section{[(1-methyl-4,5-dihydro-1H-imidazol-2-yl)methyl](2-ethyl)amine]copper(II),}

$\left[\mathrm{CuL}^{5}\right]\left[\mathrm{ClO}_{4}\right]_{2}$. The reduced Schiff base ligand $\mathrm{L}^{5}(0.50 \mathrm{~g}, 2.0 \mathrm{mmol})$ was dissolved in 50 $\mathrm{ml}$ of methanol and a slow dropwise addition of a slight excess of $\mathrm{Cu}\left(\mathrm{ClO}_{4}\right)_{2} \cdot 6 \mathrm{H}_{2} \mathrm{O}(1.0 \mathrm{~g}$, $2.6 \mathrm{mmol}$ ) solution in $25 \mathrm{ml}$ of methanol resulted in blue colored solution. The reaction mixture was stirred for 4 hours. A blue solid precipitate formation was observed after the addition of $50 \mathrm{ml}$ of diethyl ether to the solution. The precipitated solid was filtered and washed with diethyl ether and then dried under vacuum. Yield $0.76 \mathrm{~g}(1.5 \mathrm{mmol}, 75 \%)$. A royal blue prisms crystals of $\left[\mathrm{CuL}^{5}\right]\left[\mathrm{ClO}_{4}\right]_{2}(\mathrm{CCDC} 1501547)$ were obtained by the liquid diffusion of methanol/ether mixture. Electronic absorption $\left(\mathrm{CH}_{3} \mathrm{CN}\left(22^{\circ} \mathrm{C}\right)\right)$ : $\lambda \max (\varepsilon) 212$ $\mathrm{nm}\left(10350 \mathrm{M}^{-1} \mathrm{~cm}^{-1}\right), 302 \mathrm{~nm}\left(9150 \mathrm{M}^{-1} \mathrm{~cm}^{-1}\right), 630 \mathrm{~nm}\left(940 \mathrm{M}^{-1} \mathrm{~cm}^{-1}\right)$. FT-IR (ATR), $\mathrm{cm}^{-}$ ': 3509 (s, sh), 3248 (w), 2962 (w), 2839 (w), 2357 (w, b), 2242 (w), 1262 (w, sh), 1102 (s, sh), 808 (w, b), 759 (w,b). (+)ESI-MS, $m / z$ calcd for $[\mathrm{M}]^{2+},\left[\mathrm{C}_{12} \mathrm{~N}_{6} \mathrm{H}_{20} \mathrm{Cu}\right]^{2+} ; 155.94$, Found, 155.55. Anal. Calcd. for $\mathrm{C}_{12} \mathrm{~N}_{6} \mathrm{H}_{20} \mathrm{CuCl}_{2} \mathrm{O}_{8}$ : C, 28.22; H, 3.95; N, 16.45. Found: $\mathrm{C}$, 28.44; H, 3.91; N, 16.13.

$\left[\mathrm{Cu}\left(\mathrm{HL}^{5}\right)\left(\mathrm{CH}_{3} \mathrm{CN}\right)_{2}\right]\left[\mathrm{ClO}_{4}\right]_{3}$. X-ray quality crystals for $\left[\mathrm{Cu}\left(\mathrm{HL}^{5}\right)\left(\mathrm{CH}_{3} \mathrm{CN}\right)_{2}\right]\left[\mathrm{ClO}_{4}\right]_{3}$ (CCDC 1501548) were obtained by the liquid diffusion of acetonitrile/ether solution. The crystals obtained were sapphire blue in colour with the monoclinic space group $P 2{ }_{1} / c$. 


\subsection{Electrochemical methods}

\subsubsection{Cyclic voltammetry}

Cyclic Voltammetry is a technique that ramps the electrode potential with respect to time in cyclic phases. The rate of change of potential over time is known as scan rate measured in volts per unit time. In a three-electrode electrochemical cell, the potential is applied between the working electrode (glassy carbon) and reference electrode $(\mathrm{Ag} / \mathrm{AgCl})$ and the current is measured between the working electrode and counter electrode (platinum). For analysis, the graph is plotted between the current and the applied potential. ${ }^{62-63}$

A Gamry Interface potentiostat was used to perform the cyclic voltammetry (CV) and controlled potential coulometry (CPC) measurements, using glassy carbon working electrode $\left(\right.$ diameter $=6.5 \mathrm{~mm}$, surface area $\left.=0.07 \mathrm{~cm}^{2}\right)$, a platinum wire counter electrode, and $\mathrm{Ag} / \mathrm{AgCl}$ reference electrode. Before the data collection, glassy carbon electrode was polished using aqueous alumina slurry. Also, both working and counter electrodes were washed thoroughly with solvents like water, ethanol, acetone, acetonitrile, methanol, dichloromethane and then sonicated in working solvent. To conduct CV measurements, a three-neck electrochemical cell was used which was washed and dried in oven over night before recording the data. All electrochemical experiments were conducted under a $\mathrm{N}_{2}$ atmosphere.

To conduct the $\mathrm{CV}$ measurements $25 \mathrm{ml}$ of the working solvent was taken initially in three-neck electrochemical cell to which the working electrode, reference electrode and the counter electrode were attached. To this cell, $0.1 \mathrm{M}$ electrolyte $\mathrm{Bu}_{4} \mathrm{NPF}_{6}$ was added. 
Then the solvent was purged with $\mathrm{N}_{2}$ for 15 minutes to remove any oxygen from it. A blank $\mathrm{CV}$ of the solvent was recorded. Then the required quantity of the compound was added to the cell and then the solvent was again purged with $\mathrm{N}_{2}$ for 15 minutes. A CV of the compound was recorded. For evaluation of catalytic HER, external acid was added to the solution in regular intervals and data collected after each addition. An increase in the cathodic current during the potential sweep indicates the catalytic current attributed to HER. Identification of the evolved gas and quantification was done by CPC and GC analysis.

\subsubsection{Controlled potential coulometry}

A two-chambered electrolysis cell with a volume of $20 \mathrm{~mL}$ was used to perform the CPC measurements. The working compartment was fitted with a platinum working electrode (surface area $=0.07 \mathrm{~cm}^{2}$ ) and an $\mathrm{Ag} / \mathrm{AgCl}$ reference electrode. The auxiliary compartment was fitted with a Pt wire counter electrode. The working compartment contained the acid, added to a $0.1 \mathrm{M} \mathrm{Bu}_{4} \mathrm{NPF}_{6}$ in the desired solvent solution, while the auxiliary compartment was filled with $0.1 \mathrm{M} \mathrm{Bu}_{4} \mathrm{NPF}_{6}$ in the desired solvent. Before performing experiments both the compartments were purged for $15 \mathrm{~min}$ with nitrogen gas and during the measurements kept under a constant nitrogen flow. A blank CPC measurement was taken and then subtracted from experimental results as a control study. Electrolysis was then measured with the addition of the catalyst.

For $\mathrm{Ni}\left(\mathrm{L}^{1}\right)_{2}$, the working compartment was filled with $0.1 \mathrm{M} \mathrm{Bu} \mathrm{NPF}_{6}$ dichloromethane solution. To this solution $0.50 \mathrm{mM} \mathrm{Ni}\left(\mathrm{L}^{1}\right)_{2}$ and $3.5 \mathrm{mM}$ acetic acid and the auxiliary compartment contained $0.1 \mathrm{M} \mathrm{Bu}_{4} \mathrm{NPF}_{6}$ dichloromethane solution. Both working and auxiliary compartment was purged with nitrogen gas for 15 minutes. 
Electrolysis measurements were performed for 24 hours. For $\mathrm{NiL}^{3}$, the electrolysis was done with both $\mathrm{CH}_{3} \mathrm{COOH}$ and $\mathrm{CF}_{3} \mathrm{COOH}$ in acetonitrile and dimethylformamide solutions. With acetic acid in acetonitrile solutions electrolysis was performed for 18 hours with $0.30 \mathrm{mM} \mathrm{NiL}{ }^{3}$ and $12.6 \mathrm{mM}$ acetic acid in the working compartment with $0.1 \mathrm{M}$ $\mathrm{Bu}_{4} \mathrm{NPF}_{6}$ and the auxiliary compartment contained $0.1 \mathrm{M} \mathrm{Bu}_{4} \mathrm{NPF}_{6}$ acetonitrile solution. In another set of experiment, with the similar concentration of supporting electrolyte in working and auxiliary compartment, electrolysis with $18 \mathrm{mM}$ trifloroacetic acid and 0.30 $\mathrm{mM} \mathrm{NiL}^{3}$ was performed for 18 hours. Controlled potential coulometry measurements in dimethylformamide solutions employing the similar concentrations of catalyst with 9.8 $\mathrm{mM}$ acetic acid and $32 \mathrm{mM}$ trifloroacetic acid in separate experiments were performed for 18 hours.

\subsection{Determination of overpotential}

The overpotential is the difference between the thermodynamic reduction potential for a given reaction and the potential at which the reaction occurs under a set of specific conditions. $^{64}$

$$
2 \mathrm{H}^{+}+2 \mathrm{e}^{-} \longrightarrow \mathrm{H}_{2} \longrightarrow \quad \text { overpotential }=\left|\mathrm{E}_{\mathrm{H}+}-\mathrm{E}_{\mathrm{cat} / 2}\right|
$$

$\mathrm{E}_{\mathrm{cat} / 2}$ is defined as the potential at one-half of the $i_{c a t}$, the maximum of catalytic current, recorded for hydrogen evolution and hydrogen oxidation reactions. The equilibrium potential $\mathrm{E}_{\mathrm{H}+}$ is calculated from the standard acid potential $\mathrm{E}^{0} \mathrm{H}_{+}$and the $\mathrm{pKa}$ of the acid. If the standard acid potential and the $\mathrm{pKa}$ of the acid are unavailable, then it can be calculated directly using open circuit potential measurements as described by Bullock et al. ${ }^{65}$ 


\subsubsection{Overpotential measurements}

The overpotential $(\eta)$ for proton reduction by $\mathrm{Ni}\left(\mathrm{L}^{1}\right)_{2}$ and $\mathrm{NiL}^{3}$ under specific experimental conditions can be estimated as:

$$
\eta=\left|\left(E_{\mathrm{OCP}}-\mathrm{E}_{\mathrm{cat} / 2}\right)\right|
$$

$E_{O C P}=$ measured OCP under catalytic conditions specific for each reaction,

$\mathrm{E}_{\mathrm{cat} / 2}=$ the potential at one-half of the maximum catalytic current measured for proton reduction or hydrogen oxidation by the catalyst.

To determine the overpotential for electrocatalysts $\mathrm{Ni}\left(\mathrm{L}^{1}\right)_{2}$ and $\mathrm{Ni}\left(\mathrm{L}^{2}\right)_{2}$ described in Chapter 3, Bullock's open circuit potential measurements were employed for which four electrodes set up was used. Glassy carbon electrode was used as a working electrode, annealed Pt wire as a working sense, annealed Pt wire as a counter electrode and $\mathrm{Ag} / \mathrm{Ag}^{+}$ as a reference electrode. A dichloromethane solution containing $0.1 \mathrm{M} \mathrm{Bu}_{4} \mathrm{NP}_{6}$ was used to which the desired acid or base was added. The acid or base concentration used to calculate the OCP measurements is the concentration at which acid or base independence is observed while performing the cyclic voltammetry experiments in the dichloromethane.

To determine the overpotential for electrocatalyst $\mathrm{NiL}^{3}$ described in Chapter 4, Artero's method was employed. ${ }^{66}$ The acids with higher $\mathrm{pKa}$, incapable of protonating the solvents acetonitrile and dimethylformamide were reported at three different concentrations of $1 \mathrm{mM}, 10 \mathrm{mM}$ and $100 \mathrm{mM}$. For our purposes, reported $\mathrm{E}_{\mathrm{ref}} \mathrm{vs} \mathrm{Fc}^{+} / \mathrm{Fc}$ values were used to calculate the overpotential for electrocatalyst $\mathrm{NiL}^{3}$. 
Overpotential determination with $\mathrm{Ni}\left(\mathrm{L}^{1}\right)_{2}$ using $\mathrm{CH}_{3} \mathrm{COOH}$ in dichloromethane (HER)

$$
\begin{gathered}
\eta=\left|\left(\mathrm{E}_{\mathrm{BH}+(\mathrm{OCP})}\right)-\left(\mathrm{E}_{\mathrm{cat} / 2)}\right)\right| \\
\eta=\mid(-0.789-(-1.934) \mid \\
\boldsymbol{\eta}=\mathbf{1 . 1 4} \mathbf{V} \mathbf{v s} \mathbf{F c}^{+} / \mathbf{F c}^{\mathbf{0}}
\end{gathered}
$$

Overpotential determination with $\mathrm{Ni}\left(\mathrm{L}^{1}\right)_{2}$ using $\mathrm{HCl}$ in dichloromethane (HER)

$$
\begin{gathered}
\eta=\left|\left(\mathrm{E}_{\mathrm{BH}+(\mathrm{OCP})}\right)-\left(\mathrm{E}_{\mathrm{cat} / 2}\right)\right| \\
\eta=\mid(-0.847-(-1.934) \mid \\
\boldsymbol{\eta}=\mathbf{1 . 0 9} \mathbf{V} \mathbf{~ v s ~} \mathbf{F c}^{+} / \mathbf{F c}^{\mathbf{0}}
\end{gathered}
$$

Overpotential determination with $\mathrm{Ni}\left(\mathrm{L}^{1}\right)_{2}$ using $\mathrm{Et}_{3} \mathrm{~N}$ in dichloromethane (HOR)

$$
\begin{aligned}
& \eta=\left|\left(\mathrm{E}_{\mathrm{BH}+(\mathrm{OCP})}\right)-\left(\mathrm{E}_{\mathrm{cat} / 2)}\right)\right| \\
& \eta=\mid(0.178-(0.510) \mid \\
& \boldsymbol{\eta}=\mathbf{0 . 3 3} \mathbf{V} \mathbf{v s ~} \mathbf{F c}^{+} / \mathbf{F c}^{\mathbf{0}}
\end{aligned}
$$

Overpotential determination with $\mathrm{Ni}\left(\mathrm{L}^{2}\right)_{2}$ using $\mathrm{Et} 3 \mathrm{~N}$ in dichloromethane (HOR)

$$
\begin{aligned}
& \eta=\left|\left(\mathrm{E}_{\mathrm{BH}+(\mathrm{OCP})}\right)-\left(\mathrm{E}_{\mathrm{cat} / 2}\right)\right| \\
& \eta=\mid(0.164-(0.657) \mid \\
& \boldsymbol{\eta}=\mathbf{0 . 4 9} \mathbf{V} \mathbf{v s ~} \mathbf{F c}^{+} / \mathbf{F c}^{\mathbf{0}}
\end{aligned}
$$

Overpotential determination with $\mathrm{NiL}^{3}$ using $\mathrm{CH}_{3} \mathrm{COOH}$ in acetonitrile (HER)

$$
\eta=\left|\left(E_{\text {ref })}\right)-\left(E_{\text {cat } / 2}\right)\right|
$$




$$
\begin{gathered}
\eta=|(-1.23)-(-1.75)| \\
\boldsymbol{\eta}=\mathbf{0 . 5 2} \mathbf{V} \mathbf{v s ~ F c}^{+} / \mathbf{F c}^{\mathbf{0}}
\end{gathered}
$$

Overpotential determination with $\mathrm{NiL}^{3}$ using $\mathrm{CF}_{3} \mathrm{COOH}$ in acetonitrile (HER)

$$
\begin{aligned}
& \eta=\mid\left(E_{\text {ref }}\right)-\left(E_{\text {cat } / 2)}\right) \\
& \eta=|(-0.65)-(-1.32)| \\
& \boldsymbol{\eta}=\mathbf{0 . 6 7} \mathbf{V ~ v s ~} \mathbf{F c}^{+} / \mathbf{F c}^{\mathbf{0}}
\end{aligned}
$$

Overpotential determination with $\mathrm{NiL}^{3}$ using $\mathrm{CH}_{3} \mathrm{COOH}$ in dimethylformamide (HER)

$$
\begin{aligned}
& \eta=\left|\left(E_{\text {ref }}\right)-\left(E_{\text {cat } / 2}\right)\right| \\
& \eta=|(-1.40)-(-1.95)| \\
& \boldsymbol{\eta}=\mathbf{0 . 5 5} \mathbf{~} \mathbf{~ v s ~} \mathbf{F c}^{+} / \mathbf{F c}^{\mathbf{0}}
\end{aligned}
$$

\subsection{Procedure for calculation of turnover frequency (TOF) for HER}

The procedure to calculate the TOF has been mentioned below according to the reported literature. ${ }^{67-68}$ The current obtained with the catalyst by itself prior to the addition of acid is known as peak current, ip and is given by

$i_{p}=0.4463[\mathrm{cat}] \sqrt{\frac{F v D}{R T}}$

Equation 2-1 known as Randles-Sevcik equation that describes the relation between peak current and the catalyst concentration [cat], Faraday's constant (F), diffusion constant (D), scan rate $(v)$, universal gas constant $(\mathrm{R})$ and Temperature $(\mathrm{T}){ }^{62}$ 
For catalytic HER reactions that are first-order in acid and first-order catalyst, the catalytic current in the presence of $\mathrm{Ni}\left(\mathrm{L}^{1}\right)_{2}$ with acetic acid and hydrochloric acid in dichloromethane solutions is calculated using

$i_{\text {cat }}=n F A[c a t]\left[D k H^{+}\right]^{1 / 2}$

Equation 2-2 that explains the dependency of catalytic current, $\mathrm{i}_{c a t}$, on the first order acid concentration $\left[\mathrm{H}^{+}\right]$, catalyst concentration [cat], diffusion constant (D), and the electrochemical parameters like number of electrons (n), Faraday's constant (F) and the electrode area (A).

Dividing equation 2-2 by equation 2-1 yields equation 2-3

$\frac{i c a t}{i p}=\frac{n}{0.4463}\left(\frac{R T k\left[H^{+}\right]}{F v}\right)^{\frac{1}{2}}$

Under pseudo first order acid concentrations, $k_{o b s}=k\left[H^{+}\right]$, giving equation 2-4

$\frac{i c a t}{i p}=\frac{n}{0.4463}\left(\frac{R T k o b s}{F v}\right)^{\frac{1}{2}}$

To obtain TOF $\left(k_{o b s}\right)$, under scan rate independent conditions at $298 \mathrm{~K}$, the equation 2-4 gets deduced to equation 2-5

$$
k_{o b s}=v\left(\frac{\frac{i c a t}{i p}}{0.35}\right)^{2}
$$

Equation 2-5 is used under ideal conditions, when a perfect S- shaped curved is observed. But in most of the cases due to substrate depletion, catalyst degradation the perfect Sshaped cyclic voltammograms are hard to obtain. ${ }^{69-70}$ These phenomenon leads to under reported values for TOF. These drawbacks can be overcome by using Foot-of-the-wave 
analysis (FOWA) where the calculation of TOF is done at the foot or initiation point of the non-ideal catalytic wave which resembles the ideal theoretical value. ${ }^{71-72}$ Foot-of-the-wave analysis (FOWA) to calculate the TOF developed by Saveant et.al. ${ }^{73-75}$ The prerequisite condition for the FOWA is the first step in the mechanism has to be electron reduction. Thus FOWA, is limited to ECEC, ECCE, EECC type of mechanism. ${ }^{76}$ For $\mathrm{Ni}\left(\mathrm{L}^{1}\right)_{2}$, even though perfect S-shaped waves were not obtained in the catalysis, FOWA was not applied for TOF calculation because of the possibility of protonation in the first step with $\mathrm{HCl}$ as a proton source. To calculate TOF for $\mathrm{NiL}^{3}$, FOWA was employed as the catalytic mechanism for HER with $\mathrm{NiL}^{3}$ was proposed to initiate by the electron reduction in the first step. It is proposed that foot of the non-ideal wave is similar to the theoretical ideal. Under non-ideal conditions the catalytic current $i_{c a t}$ can be given as

$$
i_{\text {cat }}=\left(\frac{2 F A[c a t] \sqrt{D k o b s}}{1+\exp \left[\left(\frac{F}{R T}\right)\left(E-\frac{E c a t}{2}\right)\right]}\right)
$$

Dividing 2-6 by 2-1 gives

$$
\begin{aligned}
& i_{\text {cat }} i_{p}=\frac{2 \sqrt{(R T / F v)} \sqrt{k o b s}}{0.4463} \times\left(\frac{1}{1+\exp \left[(\mathrm{F} / \mathrm{RT})\left(E-\frac{E c a t}{2}\right)\right]}\right) \\
& \text { On plotting } i_{\text {cat }} / i_{p} \text { vs }\left(\frac{1}{1+\exp \left[(\mathrm{F} / \mathrm{RT})\left(E-\frac{E c a t}{2}\right)\right]}\right) \\
& \text { slope, } \mathrm{m}=\frac{2 \sqrt{(R T / F v)} \sqrt{k o b s}}{0.4463} \\
& i_{\text {cat }} i_{p}=\frac{n}{0.4463} \sqrt{\frac{R T k c a t\left[H^{+}\right]}{F v}} \\
& \text { TOF }=\frac{T O F m a x}{1+\exp \left[\frac{F}{R T}\right]\left[E-\frac{E c a t}{2}\right]}
\end{aligned}
$$


$\eta=E^{0}\left(H^{+} / H_{2}\right)-E$

$\mathrm{TOF}=\frac{\text { TOFmax }}{1+\exp \left[\frac{F}{R T}\right]\left[E^{0}\left(H^{+} / H_{2}\right)-\eta-\frac{E c a t}{2}\right]}$

For HER/ HOR catalysts, TOF and $\eta$ are the crucial parameters related to the efficacy of the catalyst. Tafel plot is generally used that relates these two parameters together. Tafel plot establishes the relation between $\log (\mathrm{TOF})$ and $\eta$. Thus, a direct comparison between

the different catalyst can be made using these plots. In general, $\operatorname{TOF}_{\max }\left(\mathrm{s}^{-1}\right)$ can be defined as the theoretical ideal turnover frequency from FOWA, at $1 \mathrm{M}$ acid concentrations. ${ }^{77}$

\subsection{Procedure for calculation of kinetic isotope effect (KIE)}

The kinetic isotope effect results from the change in the reaction rate of a chemical reaction when some of the atoms in the reactant are replaced by their heavy isotope. ${ }^{78}$ Mathematically, it is the ratio of the rate constant of the reaction with the light isotope and the rate constant of the reaction with the heavy isotope.

$$
\mathrm{KIE}=k_{\mathrm{L}} / k_{\mathrm{H}}
$$

To calculate KIE, the TOF with the normal acid is calculated using the methods above. This value is assigned as $k_{\mathrm{L}}$. Then, in a separate experiment the TOF is calculated using $D$ acid to obtain $k_{\mathrm{H}}$. Then, their ratio is taken to calculate KIE.

\subsection{Procedure for calculation of diffusion coefficient (D)}

Using the Randles-Sevcik equation,

$i_{p}=0.4463 \mathrm{FA}[\mathrm{cat}] \sqrt{\frac{F v D}{R T}}$ 
and plotting peak current vs the square root of the scan rate allows for accurate calculation of the diffusion coefficient, D.

\subsection{Procedure for calculation of turnover number (TON)}

$\mathrm{TON}=$ Moles of $\mathrm{H}_{2}$ produced $/$ Moles of catalyst used

\subsection{Calculations for $\mathrm{HER}$ with $\mathrm{Ni}\left(\mathrm{L}^{1}\right)_{2}$}

TOF calculations:

Using equation $2-5$

$k_{o b s}=v\left(\frac{\frac{i c a t}{i p}}{0.35}\right)^{2}$

Calculations of $\mathrm{TOF} / k_{o b s}$

For HER using $\mathrm{Ni}\left(\mathrm{L}^{1}\right)_{2}$ with acetic acid:

At $5 \mathrm{~V} / \mathrm{s}, i_{p}=59.87 \mu \mathrm{A} ; i_{c a t}=66.90 \mu \mathrm{A}, \mathbf{T O F} / \boldsymbol{k}_{\text {obs }}=\mathbf{5 1} \mathbf{s}^{-1}$

For HER using $\mathrm{Ni}\left(\mathrm{L}^{1}\right)_{2}$ with hydrochloric acid:

At $5 \mathrm{~V} / \mathrm{s}, i_{p}=59.87 \mu \mathrm{A} ; i_{c a t}=111.40 \mu \mathrm{A}, \mathbf{T O F} / k_{o b s}=140 \mathbf{s}^{-1}$

KIE calculations using $\mathrm{Ni}\left(\mathrm{L}^{1}\right)_{2}$ :

$\mathrm{KIE}=k_{\mathrm{CH} 3 \mathrm{COOH}} / k_{\mathrm{CD} 3 \mathrm{COOH}}=0.82$

Diffusion Coefficient (D) calculations:

For $\mathrm{Ni}\left(\mathrm{L}^{1}\right)_{2}$ : Using the Randles-Sevcik equation, 
$i_{p}=0.4463 \mathrm{FA}[\mathrm{cat}] \sqrt{\frac{F v D}{R T}}$

and plotting peak current vs the square root of the scan rate allows for accurate calculation of the diffusion coefficient, D.

Slope $\equiv 2 \mathrm{E}-5=0.4463 \mathrm{FA}[\mathrm{cat}][(\mathrm{FD} / \mathrm{RT})]^{0.5}$

$\mathrm{A}=0.071 \mathrm{~cm}^{2}$

$[\mathrm{cat}]=5 \mathrm{E}-7$ moles $/ \mathrm{cm}^{3}$

$\mathrm{F}=96485 \mathrm{C} / \mathrm{mole} \mathrm{e}^{-}$

$\mathrm{R}=$ ideal gas constant

$\mathrm{T}=298 \mathrm{~K}$

$D=4.3 E-6 \mathrm{~cm}^{2} / \mathrm{s}$ in $\mathrm{CH}_{2} \mathrm{Cl}_{2}$

TON Calculations:

$\mathrm{TON}=$ Moles of $\mathrm{H}_{2}$ produced $/$ Moles of $\mathrm{Ni}\left(\mathrm{L}^{1}\right)_{2}$ used

TON $=\left(0.000043\right.$ moles $\mathrm{H}_{2}$ produced $) /\left(0.0000125\right.$ moles $\mathrm{Ni}\left(\mathrm{L}^{1}\right)_{2}$ used $)$

$T O N=3.4$

\subsection{Calculations for HER with $\mathrm{NiL}^{3}$}

TOF calculations for $\mathrm{NiL}^{3}$ using FOWA:

To calculate TOF for HER with $\mathrm{NiL}^{3}$, FOWA was used as described above

On plotting, $i_{\text {cat }} / i_{p}$ vs $\left(\frac{1}{1+\exp \left[(\mathrm{F} / \mathrm{RT})\left(E-\frac{E c a t}{2}\right)\right]}\right)$ using $\mathrm{NiL}^{3}$ with acetic acid in acetonitrile, 


$$
\begin{aligned}
& \text { Slope }=\mathrm{m}=1.9651=\frac{2 \sqrt{(R T / F v)} \sqrt{k o b s}}{0.4463} \\
& k_{o b s}=(0.4463)^{2} \mathrm{~m}^{2} \mathrm{Fv} / 4 \mathrm{RT} \\
& k_{o b s}=52.43 \mathrm{~s}^{-1} \\
& k_{c a t}=k_{o b s} /\left[H^{+}\right]=52.43 / 0.0126=4161 \mathrm{~s}^{-1}
\end{aligned}
$$

On plotting $i_{\text {cat }} / i_{p}$ vs $\left(\frac{1}{1+\exp \left[(\mathrm{F} / \mathrm{RT})\left(E-\frac{E c a t}{2}\right)\right]}\right)$ using $\mathrm{NiL}^{3}$ with trifloroacetic acid in acetonitrile,

$$
\begin{aligned}
& \text { Slope }=\mathrm{m}=1.3249=\frac{2 \sqrt{(R T / F v)} \sqrt{k o b s}}{0.4463} \\
& k_{o b s}=(0.4463)^{2} \mathrm{~m}^{2} \mathrm{Fv} / 4 \mathrm{RT} \\
& k_{o b s}=23.83 \mathrm{~s}^{-1} \\
& k_{c a t}=k_{o b s} /\left[H^{+}\right]=23.83 / 0.018=1324 \mathrm{~s}^{-1}
\end{aligned}
$$

On plotting $i_{\text {cat }} / i_{p} \quad$ vs $\left(\frac{1}{1+\exp \left[(\mathrm{F} / \mathrm{RT})\left(E-\frac{E c a t}{2}\right)\right]}\right)$ using $\mathrm{NiL}^{3}$ with acetic acid in dimethylformamide,

$$
\begin{aligned}
& \text { Slope }=\mathrm{m}=1.0993=\frac{2 \sqrt{(R T / F v)} \sqrt{k o b s}}{0.4463} \\
& k_{o b s}=(0.4463)^{2} \mathrm{~m}^{2} \mathrm{Fv} / 4 \mathrm{RT} \\
& k_{o b s}=11.72 \mathrm{~s}^{-1} \\
& k_{\text {cat }}=k_{\text {obs }} /\left[H^{+}\right]=11.72 / 0.098=1196 \mathrm{~s}^{-1}
\end{aligned}
$$


On plotting $i_{\text {cat }} / i_{p}$ vs $\left(\frac{1}{1+\exp \left[(\mathrm{F} / \mathrm{RT})\left(E-\frac{E c a t}{2}\right)\right]}\right)$ using $\mathrm{NiL}^{3}$ with trifluoroacetic acid in dimethylformamide,

Slope $=\mathrm{m}=0.6165=\frac{2 \sqrt{(R T / F v)} \sqrt{k o b s}}{0.4463}$

$k_{o b s}=(0.4463)^{2} \mathrm{~m}^{2} \mathrm{Fv} / 4 \mathrm{RT}$

$k_{o b s}=3.685 \mathrm{~s}^{-1}$

$k_{\text {cat }}=k_{\text {obs }} /\left[H^{+}\right]=3.685 / 0.032=115 \mathrm{~s}^{-1}$

Diffusion coefficient $(D)$ with $N i L^{3}$

For $0.30 \mathrm{mM} \mathrm{NiL}{ }^{3}$ in DMF: Using the Randles-Sevcik equation,

$i_{p}=0.4463 \mathrm{FA}[\mathrm{cat}] \sqrt{\frac{F v D}{R T}}$

and plotting peak current vs the square root of the scan rate allows for accurate calculation of the diffusion coefficient, D.

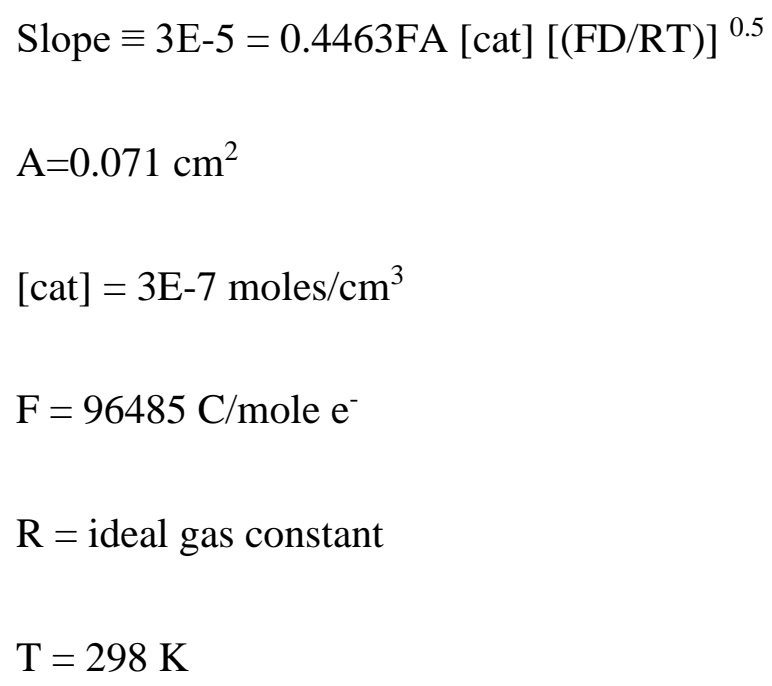




\section{$D=2.74 E-5 \mathrm{~cm}^{2} / \mathrm{s}$ in $\mathrm{DMF}$}

TON calculations:

a) $\mathrm{NiL}^{3}$ with acetic acid in acetonitrile, Theoretical Moles of $\mathrm{H}_{2}$ via Total Charge:

$92 \mathrm{C} \mathrm{x}(1 \mathrm{~mol} \mathrm{e}-/ 96485 \mathrm{C}) \times\left(1 \mathrm{~mol} \mathrm{H}_{2} / 2 \mathrm{~mol} \mathrm{e}^{-}\right)=$moles $\mathrm{H}_{2}$ theoretical

Moles $\mathrm{H}_{2}$ theoretical $=0.000476$ moles $\mathrm{H}_{2}$ based on charge from electrolysis

TON $=$ Moles $\mathrm{H}_{2}$ theoretical/ Moles of catalyst used

$\mathrm{TON}=0.000476 / 0.0000075=63$

b) $\mathrm{NiL}^{3}$ with acetic acid in dimethylformamide, Theoretical Moles of $\mathrm{H}_{2}$ via Total Charge:

$37 \mathrm{C} \mathrm{x}(1 \mathrm{~mol} \mathrm{e}-/ 96485 \mathrm{C}) \times\left(1 \mathrm{~mol} \mathrm{H}_{2} / 2 \mathrm{~mol} \mathrm{e}^{-}\right)=$moles $\mathrm{H}_{2}$ theoretical

Moles $\mathrm{H}_{2}$ theoretical $=0.000192$ moles $\mathrm{H}_{2}$ based on charge from electrolysis

TON $=$ Moles $\mathrm{H}_{2}$ theoretical/ Moles of catalyst used

$\mathrm{TON}=0.000192 / 0.0000075=26$

c) $\mathrm{NiL}^{3}$ with trifluoroacetic acid in acetonitrile, Theoretical Moles of $\mathrm{H}_{2}$ via Total Charge:

$36 \mathrm{C} \mathrm{x}(1 \mathrm{~mol} \mathrm{e}-/ 96485 \mathrm{C}) \times\left(1 \mathrm{~mol} \mathrm{H}_{2} / 2 \mathrm{~mol} \mathrm{e}^{-}\right)=$moles $\mathrm{H}_{2}$ theoretical

Moles $\mathrm{H}_{2}$ theoretical $=0.000187$ moles $\mathrm{H}_{2}$ based on charge from electrolysis

TON $=$ Moles $\mathrm{H}_{2}$ theoretical/ Moles of catalyst used

$\mathrm{TON}=0.000187 / 0.0000075=25$

d) $\mathrm{NiL}^{3}$ with trifluoroacetic acid in dimethylformamide, Theoretical Moles of $\mathrm{H}_{2}$ via Total Charge: 
$23 \mathrm{C} \times\left(1 \mathrm{~mol} \mathrm{e}^{-} / 96485 \mathrm{C}\right) \times\left(1 \mathrm{~mol} \mathrm{H}_{2} / 2 \mathrm{~mol} \mathrm{e}-\right)=$ moles $\mathrm{H}_{2}$ theoretical

Moles $\mathrm{H}_{2}$ theoretical $=0.000119$ moles $\mathrm{H}_{2}$ based on charge from electrolysis

TON $=$ Moles $\mathrm{H}_{2}$ theoretical/ Moles of catalyst used

$\mathrm{TON}=0.000119 / 0.0000075=16$

\subsection{X-ray crystallographic studies}

A royal blue colored crystal of $\left[\mathrm{CuL}^{5}\right]\left[\mathrm{ClO}_{4}\right]_{2}$ measured $0.40 \times 0.21 \times 0.16 \mathrm{~mm}^{3}$ was obtained from the liquid diffusion of methanol/ether solution and was mounted on an Agilent Technologies/Oxford Diffraction Gemini CCD diffractometer for X-ray data collection. In order to acquire a total of 397 twenty second frame $\omega$-scan exposures of data at $100 \mathrm{~K}$ to a $2 \theta \max =56.4^{\circ}$, The CrysAlisPro ${ }^{79} \mathrm{CCD}$ software package (v 1.171.36.32) was employed. For determining final unit cell parameters, CrysAlisPro ${ }^{79}$ RED was used for processing the frame data giving the values of $a=17.244(2) \AA, b=8.1023(10) \AA, c=$ 13.7251(15) $\AA, \alpha=90^{\circ}, \beta=96.258(12)^{\circ}, \gamma=90^{\circ}, \mathrm{V}=1906.2(4) \AA^{3}, \mathrm{Z}=4$ and Dcalc $=$ $1.780 \mathrm{Mg} \mathrm{m}^{-3}$ to produce raw hkl data. The values were then corrected for absorption (transmission min. $/ \max .=0.830 / 1.000 ; \mu=1.482 \mathrm{~mm}^{-1}$ ) using SCALE3 ABSPACK ${ }^{80}$ The structure of was then solved by Direct methods using SHELX. ${ }^{81}$

Sapphire blue crystals of $\left[\mathrm{Cu}\left(\mathrm{HL}^{5}\right)\left(\mathrm{CH}_{3} \mathrm{CN}\right)_{2}\right]\left[\mathrm{ClO}_{4}\right]_{3}$ measuring $0.26 \times 0.12 \times 0.09$ $\mathrm{mm}^{3}$ were obtained from the liquid diffusion of acetonitrile/ether solution and for X-ray data collection were mounted on CryoLoop on an Agilent Technologies/Oxford Diffraction Gemini CCD diffractometer. The analysis was performed using a 439, sixty-second frame $\omega$-scan data collection strategy at $103 \mathrm{~K}$ to a $2 \theta \max =53.20^{\circ}$. The crystals obtained in

monoclinic space group P21/c with unit cell parameters: $a=23.0000(5) \AA, b=8.71951(15)$ 
$\AA, c=30.2613(6) \AA, \alpha=90^{\circ}, \beta=92.295(2)^{\circ}, \gamma=90^{\circ}, \mathrm{V}=6064.0(2) \AA^{3}, \mathrm{D}_{\text {calc }}=1.609 \mathrm{Mg}$ $\mathrm{m}^{-3}, \mathrm{Z}=8.12678$ independent data were corrected for absorption (transmission min./max. $=0958 / 1.000 ; \mu=1.056 \mathrm{~mm}^{-1}$ ) using SCALE3 ABSPACK ${ }^{80}$ The structure was solved by Direct methods using SHELXS. ${ }^{81}$

An orange colored crystal of $\mathrm{Ni}\left(\mathrm{L}^{2}\right)_{2}$ with a size $0.38 \times 0.30 \times 0.10 \mathrm{~mm}^{3}$ was obtained by the liquid diffusion of dichloromethane/ether solution and mounted on a glass fiber on an Agilent Technologies/Oxford Diffraction Gemini CCD diffractometer for data collection. A total of 401 ten second frame $\omega$-scan exposures of data at $100 \mathrm{~K}$ to a $2 \theta$ max $=56.30^{\circ}$ using monochromated Mo- $K \alpha$ radiation $(0.71073 \AA)$ from a sealed tube was acquired by employing the CrysAlisPro ${ }^{79} \mathrm{CCD}$ software package (v 1.171.36.32). Using CrysAlisPro ${ }^{79}$ RED frame data were processed to obtain the final unit cell parameters: $a=$ 8.23199(17) $\AA, b=20.1632(3) \AA, c=15.2322(4) \AA, \beta=99.355(3)^{\circ}, V=2494.67(9) \AA^{3}$, $D_{\text {calc }}=1.356 \mathrm{Mg} \mathrm{m}^{-3}, Z=4$ to produce raw hkl data that were then corrected for absorption (transmission min. $/$ max. $=0.916 / 1.000 ; \mu=1.083 \mathrm{~mm}^{-1}$ ) using SCALE3 ABSPACK. ${ }^{80} \mathrm{The}^{\circ}$ structure was solved by Direct methods in the space group $P 2_{1} / n$ using SHELXS ${ }^{81}$ and refined by least-squares methods on $F^{2}$ using SHELXL. ${ }^{81}$

\subsection{Computational methods}

The use of computational methods tends to be helpful in the search for the solutions for chemical problems. These allows us to calculate various properties associated with the molecule such as absolute and relative energies, geometry optimization, electronic charge distribution, dipole and higher multipole moments, vibrational frequencies, electronic transitions and various other spectroscopic data. Also, to have a better insight of the structure stability and reaction mechanisms, the computational modelling done using 
various available functional and basis sets gives us better understanding of the reaction pathway of the system. The theoretical methods used to perform the computational modelling can be divided into following categories. $\left.{ }^{82} 1\right) a b$-initio method: This method as the name suggests, is indicative of the beginning. To obtain the solution of the Schrodinger equation, only the physical constants are used to develop and solve the Hamiltonian for the system with no fitting of any experimental data. ${ }^{83}$ Hartree-Fock (HF) method used for solving time-independent Schrödinger equation, is the simplest ab-initio method. HF method involves approximations such as: a) Born-Oppenheimer approximation (b) Exclusion of any relativistic effects $(c)$ Consideration of the mean field of the electrons but excluding the specific interaction of the electrons with each other. 2) Semi-empirical methods: In these calculations, experimental data or the ab-initio calculations are fitted using simple Hamiltonian solutions. Larger systems can be studied using these methods as these are much faster than the ab-initio method. 3) Molecular mechanics (MM): In this method instead of using Hamiltonian, wave function or electron density, the molecule is considered as the set of atoms joined together by chemical bonds and the parameters like force constants, bond stretching, bending, and torsion are used to describe the molecular energy. Compared to ab-initio and semi-empirical methods, this method can be employed to very large systems involving several atoms. 4) Density functional methods (DFT): Density functional method is a methodology used for calculation of the electron density ( $\rho$ ) of ground-state of the molecules. The benefit of using DFT is that it reduces the complexity of the calculations as only the energy in terms of electron density is considered and the calculation of wave-function $(\Phi)$ is not considered. So, in case of system with $\mathrm{N}$ electrons, it is feasible to account three variables rather than $3 \mathrm{~N}$ degrees of freedom. DFT 
is helpful in providing the ample understanding of the chemical properties of the molecules. The key theorems for understanding DFT are: a) First Hohenberg-Kohn (H-K) Theorem: The ground state properties of the system are determined by its electron density, $\mathrm{E}=\mathrm{E}[\rho]$, where $\rho$ is the ground state electron density of the system. $b$ ) Second Hohenberg-Kohn ( $H$ K) Theorem: The energy density functional, $\mathrm{E}\left[\rho^{\prime}\right]$, where $\rho^{\prime}$ is different from the exact electron density of the system, determines the variability in the energy density functional, $E[\rho]$, giving $E\left[\rho^{\prime}\right]>E[\rho]$.

According to the Kohn-Sham ${ }^{84}$, the energy functional of the system can be equated as, $E[\rho]=T[\rho]+\operatorname{Eext}[\rho]+\operatorname{Ecoul}[\rho]+\operatorname{Exc}[\rho]$

In equation 2-8, the term $\operatorname{Exc}[\rho]$ is calculated using various approximations by various methods like a) Local Density Approximation (LDA), which assumes that the electron density is not much affected in non-homogeneous environment and it can be calculated using a homogeneous electron gas functional. b) Generalized Gradient Approach considered the actual non-homogeneous nature of electron density thus accounting for the electron density gradient. ${ }^{85} c$ ) Hybrid Methods employs both exchange and correlation fuctionals. B3LYP is the most common hybrid functional employed by inorganic and organometallic chemists to perform computational investigations. ${ }^{86-89}$

Methodology: The structural optimizations were performed using B3LYP functional and using 6-31G(d) basis set for $\mathrm{NiL}^{3}$ complex. The results were also investigated using BP86 functional in combination with TZV/P basis set. The initial coordinates for $\mathrm{NiL}^{3}$ complex were obtained from the reported crystal structure. ${ }^{90}$ The calculations were carried out in gas phase and in the solution phase, using acetonitrile solvent. Using the conductor-like polarized continuum model (CPCM), the effect of polarity of the bulk solvent was taken 
into consideration. In the studies described in Chapter 4, for structures with even number of electrons with spin state $(s=0,1)$, the spin multiplicity $(M s=1,3)$ was considered. The calculations were performed as restricted singlet, restricted triplet and unrestricted singlet. To optimize the structures with odd number of electrons $(s=1 / 2)$, the spin multiplicity (Ms = 2) was considered and the calculations were performed as restricted doublet. The transition states were taken as the one with single negative frequency. Gaussian09 program was used to conduct the quantum- chemical calculations and for visualization Chemcraft software was used.

\subsection{Procedure used for setting up the benzyl alcohol oxidation reaction and quantification of aldehydic products using GC-MS}

The experimental procedure to obtain the data from the GC-MS has been described. To a vial containing a small stir bar, $0.5 \mathrm{ml}(5 \mathrm{mmol})$ benzyl alcohol was dissolved in $10 \mathrm{ml}$ of acetonitrile. To this solution was added; $127 \mathrm{mg}$ ( $5 \mathrm{~mol} \%$ of alcohol) of $\left[\mathrm{CuL}^{5}\right]^{2+}, 0.039 \mathrm{~g}$ TEMPO (5 mol \% of alcohol) and $20 \mu \mathrm{L}$ NMI (5mol\% of alcohol). An internal standard of $0.08 \mathrm{M}$ toluene solution was added. The blue colored solution was stirred for 4 hours open to air. The color of the reaction mixture was changed to dark green solution indicating the formation of the aldehyde product. $10 \mu \mathrm{L}$ of analyte was abstracted from the solution which was diluted with acetonitrile to $1.5 \mathrm{ml}$ and was analyzed by GCMS to determine the yield and TON.

Calculation of Molarity of an internal standard (toluene)

Density of toluene $=0.87 \mathrm{~g} / \mathrm{mL}$

$0.1 \mathrm{ml}$ weighs $0.087 \mathrm{~g}$ 
No. of moles $=0.087 / 92.14=0.0009$

$\mathrm{M}=(0.0009 / 10.63) * 1000=0.08 \mathrm{M}$

Total volume $=10.63\left(10 \mathrm{~mL} \mathrm{CH}_{3} \mathrm{CN}+0.51 \mathrm{~mL} \mathrm{C}_{6} \mathrm{H}_{5} \mathrm{CH}_{2} \mathrm{OH}+0.02 \mathrm{~mL} \mathrm{NMI}+0.1 \mathrm{~mL}\right.$ toluene)

$\mathrm{M}_{1} \mathrm{~V}_{1}=\mathrm{M}_{2} \mathrm{~V}_{2}$

$0.08 \times 10 \times 10^{-3} \mathrm{ml}=\mathrm{M}_{\mathrm{t}} \times 1.5 \mathrm{ml}$ $\mathrm{V}_{1}=10 \mathrm{uL}$ (volume of analyte for GC-MS)

$M_{t}=0.08 \times 10 \times 10^{-3} / 1.5=5.3 \times 10^{-4}$

Calculation of Molarity of Benzaldehyde (product)

$\mathrm{R}_{\mathrm{F}}=\left(\mathrm{A}_{\mathrm{b}} / \mathrm{M}_{\mathrm{b}}\right) \times\left(\mathrm{M}_{\mathrm{t}} / \mathrm{A}_{\mathrm{t}}\right)$

$M_{b}=\left(A_{b} / R_{F}\right) \times\left(M_{t} / A_{t}\right)$

$\mathrm{M}_{\mathrm{b}} \times 1.5 \mathrm{ml}=\mathrm{M}_{\mathrm{b} 1} \times 10 \times 10^{-3} \mathrm{ml}$

$M_{b 1}=(M b x 1.5) / 10 \times 10^{-3}$ put the value of $M_{b}$ from 2-9

$M_{b 1}=\left\{\left(A_{b} / A_{t}\right) \times\left(M_{t} / 0.998\right)\right\} \times\left(1.5 / 10 \times 10^{-3}\right) \quad$ put the value of $M_{t}$ from above $\left(R_{F}=0.998\right)$

$\mathrm{M}_{\mathrm{b} 1}=\left\{\left(\mathrm{A}_{\mathrm{b}} / \mathrm{A}_{\mathrm{t}}\right) \times\left(0.56 \times 10^{-3} / 0.998\right\} \times\left(1.5 / 10 \times 10^{-3}\right)\right.$

$M_{b 1}=\left(A_{b} / A_{t}\right) \times 0.084$

Calculations of number of moles of product (benzaldehyde)

$\mathrm{N}_{1}=\left(\mathrm{M}_{\mathrm{b} 1} \times 10.63\right) / 1000$

$\%$ Yield $=\left(\mathrm{N}_{1} /\right.$ number of moles of alcohol $) \times 100$

Standard deviation in $\%$ yield $=($ dev in average $M \times 10.63) / 5 \times 100$ 
Turnover number $=$ Moles of product $/$ moles of catalyst used $=($ Average $M \times 10.63) / 0.25$

Standard deviation in turnover number $=$ standard deviation in $(\mathrm{Av} M \times 10.63) / 0.25$

or $($ standard deviation in $\%$ yield $/ \%$ yield $)=($ standard deviation in TON $/$ TON $)$

standard deviation in TON $=($ standard deviation in $\%$ yield $/ \%$ yield $) \times$ TON 


\section{CHAPTER III}

\section{ELECTROCATALYIC HYDROGEN EVOLUTION AND HYDROGEN OXIDATION WITH A Ni(PS $)_{2}$ COMPLEX}

\subsection{Background}

As described in Chapter 1, there is a need for small molecular electrocatalysts for the hydrogen evolution reaction (HER) and hydrogen oxidation reaction (HOR). While numerous HER electrocatalysts have been reported, the number of reported catalysts that perform both HER and HOR is much more limited. These include Ogo's and Rauchfuss's [Ni-Fe] complexes, DuBois's $\mathrm{Ni}\left(\mathrm{P}^{\mathrm{R}}{ }_{2} \mathrm{~N}^{\mathrm{R}}{ }_{2}\right)$ complex and $\mathrm{Re}\left(\mathrm{L}^{1}\right)_{3 .}{ }^{26,51-52,91}$ The latter complex has been extensively studied in the Grapperhaus group and was proposed to follow a ligand centered mechanism (Figure 1.8). Density functional theory calculations including functional M06 exchange correlation functional and the LANL2DZ basis set are consistent with the proposed mechanism. ${ }^{52}$

Previous work done in Grapperhaus group described ability of $\left[\operatorname{Re}\left(\mathrm{L}^{1}\right)_{3}\right]^{\mathrm{n}+}(\mathrm{n}=0$, $1,2)$ to bind ethylene in the reversible fashion. ${ }^{45}$ The ethylene binding was found to be in dynamic equilibrium as the cleavage of $\mathrm{C}-\mathrm{S}$ bond was observed under inert conditions while ethylene purging in the dichloromethane solutions of the charged complex induces C-S bond formation. The redox controlled ethylene binding was found to show an increase in the equilibrium binding constant with the increase in the charge on $\operatorname{Re}\left(\mathrm{L}^{1}\right)_{3}$. The proposed mechanism for ethylene binding was found to follow ECE pathway. In the first 
step, one electron oxidation of $\operatorname{Re}\left(\mathrm{L}^{1}\right)_{3}$ makes it susceptible to the ethylene binding, and the addition of ethylene molecule in the second step takes palce with an equilibrium binding constant of $\mathrm{K}_{1}=4.0 \mathrm{M}^{-1}$. The second electron oxidation of the di-thioether complex imparts stability to the C-S bonds and thus huge increment in the equilibrium binding constant from $4.0 \mathrm{M}^{-1}$ in the single oxidized species to $\mathrm{K}_{2}=2.5 \times 10^{9}$ was observed. Upon reduction of $\left[\operatorname{Re}\left(\mathrm{L}^{1}\right)_{3}\right]^{+}$to $\operatorname{Re}\left(\mathrm{L}^{1}\right)_{3}$ decreases the ethylene binding and significantly lower binding constant $\mathrm{K}_{3}=1.9 \times 10^{-11} \mathrm{M}^{-1}$ was recorded. The thermodynamic squares based on the ethylene affinity of $\left.\left[\operatorname{ReL}^{1}\right)_{3}\right]^{\mathrm{n+}}(\mathrm{n}=0,1,2)$ has been shown in Figure 3.1.

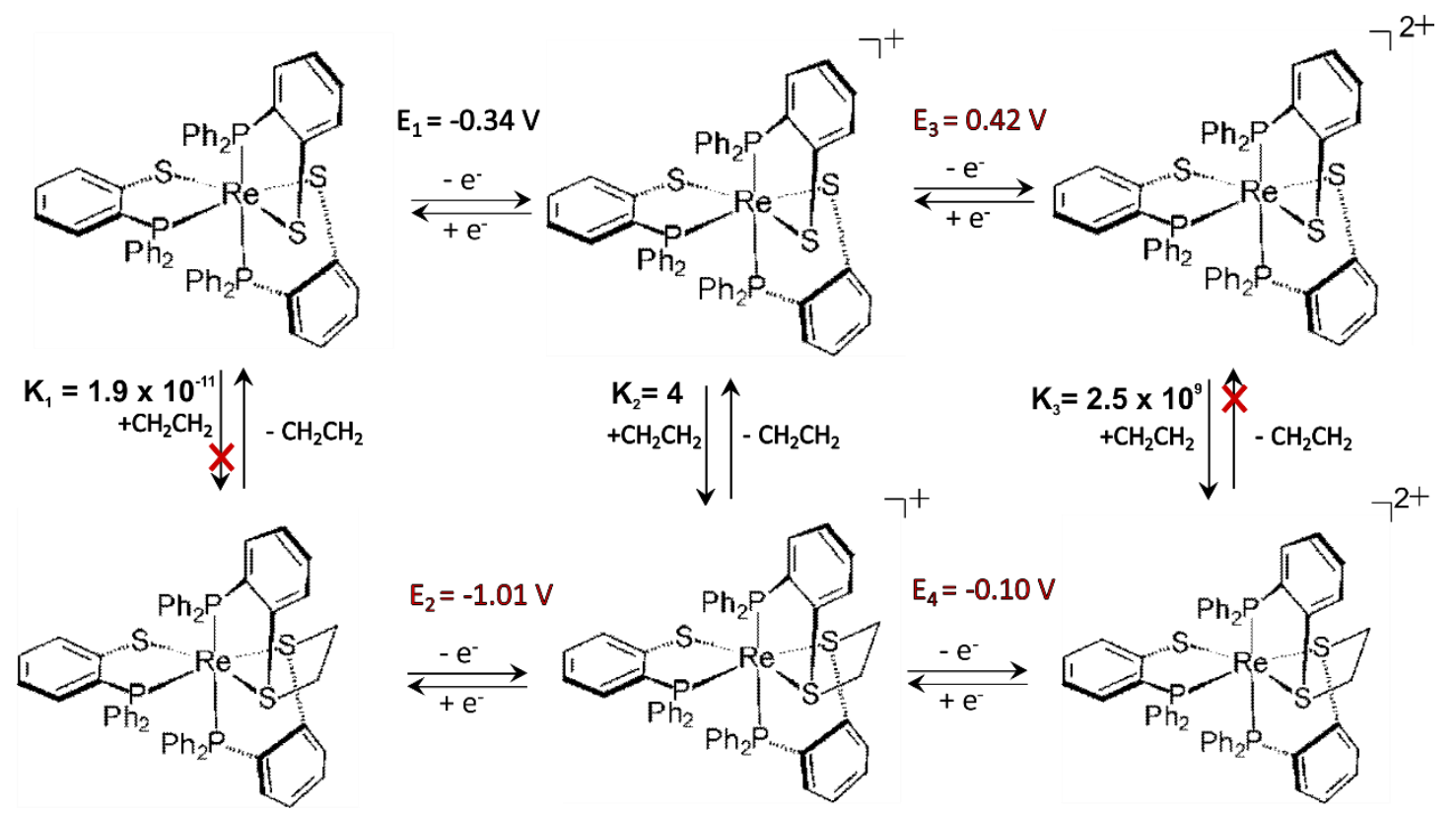

Figure 3.1 Schematic representation of thermodynamic squares for ethylene addition to $\left.\operatorname{Re}\left[\mathrm{L}^{1}\right)_{3}\right]^{\mathrm{n+}}$ $(\mathrm{n}=0,1,2) .45,50$

$\operatorname{Re}\left[\left(\mathrm{L}^{1}\right)_{3}\right]$ possess a meridional arrangement of the three PS chelates, each with a ptype sulfur lone-pair that is potentially reactive. An enhancement of nucleophilic character of the metal thiolate is observed when the metal character in the highest occupied molecular orbital (HOMO) was equal to the sulfur p-type character. In these cases, oxidation of the 
complex leads to a metal stabilized thiyl radical which has a radical shared between the metal and the sulfur. The thiyl radical character of cis sulfur donors supports reversible binding of simple alkenes such as ethylene to yield dithioether-metal complexes. ${ }^{45,50}$ The coplanarity of the p-type lone pairs on sulfur atoms allows an out-of-phase combination of molecular orbitals that interacts with the $\pi^{*}$-orbital of ethylene. Also, the $\pi$-orbital of ethylene interacts with the vacant in-phase combination of sulfur p-orbitals, which are antibonding to the metal d-orbital, Figure 3.2. Hydrogen and ethylene share the same arrangement of HOMO/LUMO molecular frontier orbital arrangement, thus when analyzed for its ability to generate hydrogen or oxidize hydrogen, $\operatorname{Re}\left[\left(\mathrm{L}^{1}\right)_{3}\right]$ was found to be electrocatalytically active.

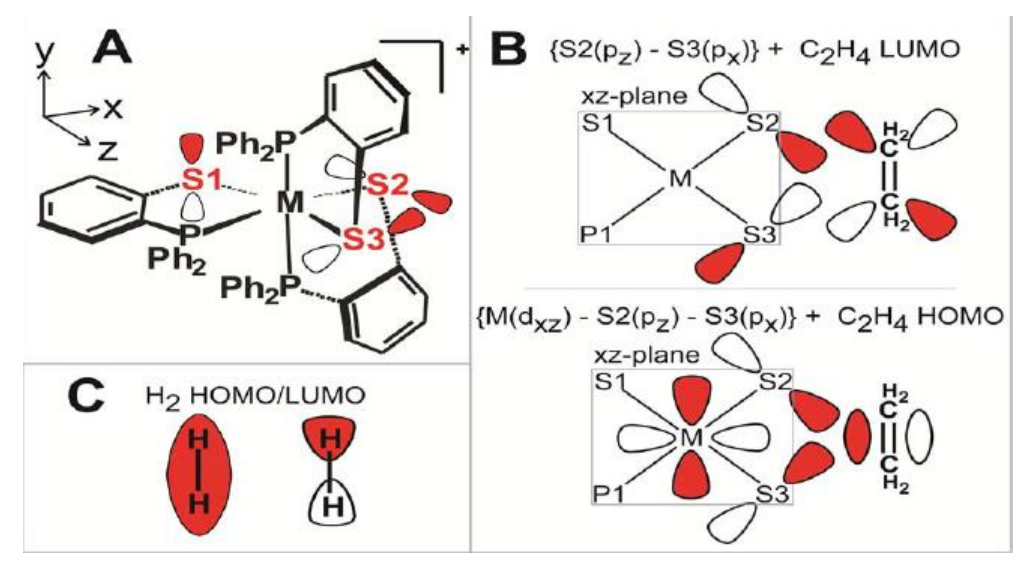

Figure 3.2 Frontier molecular orbitals of $\operatorname{Re}\left(\mathrm{L}^{1}\right)_{3}, \mathrm{C}_{2} \mathrm{H}_{4}$ and $\mathrm{H}_{2}$. (A) Meridional PS-chelates in $\operatorname{Re}\left(\mathrm{L}^{1}\right)_{3}$ displaying "p-type" lone-pair orientation. (B) (top) Interactions of $\operatorname{Re}\left(\mathrm{L}^{1}\right)_{3}$ frontier orbitals with LUMO of ethylene (B) (bottom) Interactions of $\operatorname{Re}\left(\mathrm{L}^{1}\right)_{3}$ frontier orbitals with HOMO of ethylene (C) HOMO/LUMO orbital symmetry of hydrogen. ${ }^{51}$

The addition of ethylene to the $\operatorname{Re}\left(\mathrm{L}^{1}\right)_{3}$ through the metal stabilized thiyl radical route has been shown in Figure 3.3 [path (a)]. Path (b) shows a traditional route of addition of ethylene through the dehalogenation of 1,2-dihaloalkanes. Following path (b) ethylene 
can be generated back after one electron reduction of dicationic dithioether. Due to similarity in the frontier orbitals of ethylene and hydrogen, addition of hydrogen halides instead of dihaloalkanes can lead to the generation of hydrogen as a product.

(a) S-thiyl radical addition

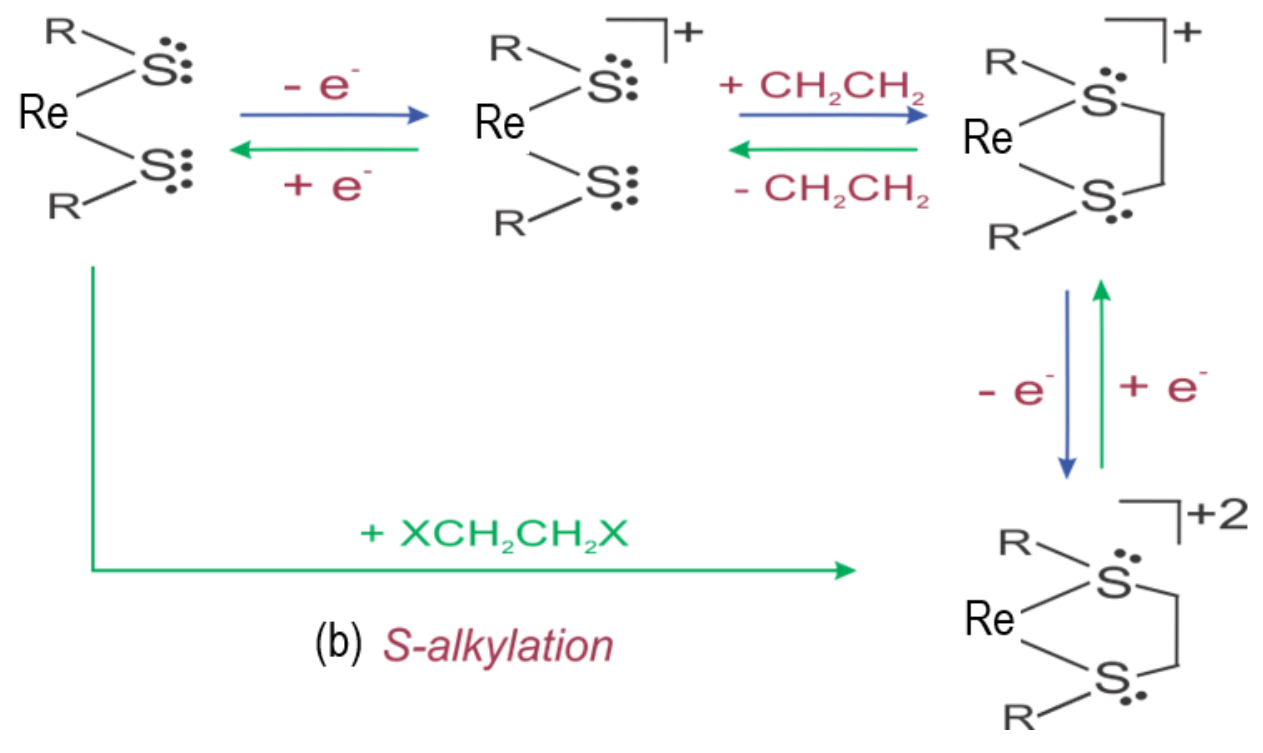

Figure 3.3 Catalytic dehalogenation of dihaloalkanes.

$\operatorname{Re}\left[\left(\mathrm{L}^{1}\right)_{3}\right]$ was found to evolve hydrogen through the ligand centered mechanism with the maximum TOF of $32 \pm 3 \mathrm{~s}^{-1}$. The overpotential recorded for HER with $\operatorname{Re}\left[\left(\mathrm{L}^{1}\right)_{3}\right]$ was $0.708 \mathrm{~V}$. The Re-complex was also found to cleave dihydrogen in basic solutions with maximum TOF of $4 \pm 1 \mathrm{~s}^{-1}$ at an overpotential of $0.970 \mathrm{~V}$. This was the first ligand centered HER/HOR catalyst reported but has its limitations due to the high cost of Re-complex. ${ }^{51}$

The benzenethiol ligands serve as excellent donor atoms in the phosphanyl complexes due to the rapid deprotonation at the S-H functionality. ${ }^{92}$ Numerous complexes employing metals like Mo, Tc, Rh, Ir, Pd and Ni etc. has been reported in literature. ${ }^{93} \mathrm{~A}$ mixture of $\mathrm{Mo}_{2} \mathrm{Cl}_{3}\left(\mathrm{~L}^{1}\right)_{3}$ and $\mathrm{MoCl}_{2}\left(\mathrm{~L}^{1}\right)_{2}$ is generated upon the reaction of $\mathrm{HL}^{1}$ ligand with $\mathrm{MoCl}_{5} .{ }^{94}$ Thiolate ligand acting as a ligand and reducing agent as the +5 oxidation state of 
Mo in $\mathrm{MoCl}_{5}$ was reduced to +3 in $\mathrm{Mo}_{2} \mathrm{Cl}_{3}\left(\mathrm{~L}^{1}\right)_{3}$ and to +4 in $\mathrm{MoCl}_{2}\left(\mathrm{~L}^{1}\right)_{2}$. Technetium (III) complex, $\mathrm{Tc}\left(\mathrm{L}^{1}\right)_{3}$ with $\mathrm{HL}^{1}$ has been synthesized using $\mathrm{TcCl}_{4}\left(\mathrm{PPh}_{3}\right)_{2}$ and $\mathrm{TcO}_{4}{ }^{-} \cdot{ }^{47}, 95$ Rhenium (III) complex, $\left[\mathrm{Re}\left(\mathrm{L}^{1}\right)_{2}\left(\mathrm{~S}_{2} \mathrm{CNEt}_{2}\right)\right] \cdot\left(\mathrm{CH}_{3}\right)_{2} \mathrm{CO}$ in a distorted octahedral geometry has been reported by the reaction of $\left[\mathrm{ReCl}_{3}\left(\mathrm{~N}_{2} \mathrm{C}_{5} \mathrm{H}_{4} \mathrm{NH}\right)\left(\mathrm{HN}_{2} \mathrm{C}_{5} \mathrm{H}_{4} \mathrm{~N}\right)\right], \mathrm{HL}^{1}$ and $\mathrm{Et}_{3} \mathrm{~N}$ in methanolic solutions. ${ }^{96}$ A sulfur-bridged dimeric rhodium complex, $\left[\mathrm{Rh}\left(\mathrm{L}^{1}\right)(\mathrm{CO})\right]_{2}$, which is found to catalyze the carbonylation of methanol to acetic acid is generated using $\left[\mathrm{RhCl}(\mathrm{CO})_{2}\right]_{2}$ as a metal precursor. ${ }^{97}$ In another report, $\mathrm{Rh}(\mathrm{I})$ complex with $\mathrm{HL}^{1}$, $\mathrm{Rh}\left(\mathrm{L}^{1}\right)(\mathrm{CO})\left(\mathrm{PPh}_{3}\right)$ was found to reversibly bind sulfur dioxide while $\mathrm{Ir}(\mathrm{I})$ complex $\operatorname{Ir}\left(\mathrm{L}^{1}\right)(\mathrm{CO})\left(\mathrm{PPh}_{3}\right)$ showed an affinity for hydrogen. ${ }^{98} \mathrm{Pd}\left(\mathrm{L}^{1}\right)_{2}$ is reported to obtain by the Menschutkin-type reaction by the S-dealkylation of the corresponding thioether complex. ${ }^{99}$ The reaction of $\left[\mathrm{Ni}\left(\mathrm{PMe}_{3}\right)_{4}\right]$ with $\mathrm{HL}^{1}$ in the pentane solutions generated unstable complex, $\mathrm{NiH}\left(\mathrm{L}^{1}\right)\left(\mathrm{PMe}_{3}\right)_{2}$, which dissociates into $\mathrm{Ni}\left(\mathrm{L}^{1}\right)\left(\mathrm{PMe}_{3}\right)_{2}$ and $\mathrm{Ni}\left(\mathrm{L}^{1}\right)_{2}$ with the evolution of hydrogen. ${ }^{100-103}$

The synthesis of $\mathrm{HL}^{2}$ employed the reaction of chlorodiispropylphoshine with lithium 2-lithiobenzenethiolate in the THF solutions instead of chlorodiphenylphoshine which was used to prepare $\mathrm{HL}^{1}{ }^{59}$ The Iridium complex with $\mathrm{HL}^{2}$ has been reported by Morales-Morales in 2002, by the reaction of $\mathrm{IrCl}_{3}$ with $\mathrm{HL}^{2}$ in the presence of triethylamine in the methanolic solutions. ${ }^{59}$ Yellow prism crystals were obtained from dichloromethane/methanol mixture and structural determination demonstrated a distorted octahedral arrangement around the Ir. The $\mathrm{Zn}(\mathrm{II})$ complex with $\mathrm{HL}^{2}$ was synthesized by Barry in an endeavor to isolate the $\mathrm{CO}_{2}$ adducts upon the reaction with gaseous carbon dioxide. ${ }^{104}$ 
In the pursuit to develop the economically viable catalysts for energy production, we employed first-row transition elements nickel and zinc metal precursors with redox non-innocent dialkyl/diarylbenzenethiol ligands. In this chapter, the syntheses, characterization and electrocatalytic behavior of nickel and zinc complexes with

diphenylphosphine benzenethiol $\left(\mathrm{HL}^{1}\right)$ and diisopropylphosphine benzenethiol $\left(\mathrm{HL}^{2}\right)$ ligands have been reported. ${ }^{105}$

\subsection{Synthesis and spectroscopic characterization}

The ligands $\mathrm{HL}^{1}$ and $\mathrm{HL}^{2}$ were synthesized by previously reported methods. ${ }^{57-59}$ Metal complexation was done by employing simple salts like $\mathrm{NiCl}_{2} \cdot 6 \mathrm{H}_{2} \mathrm{O}$ and $\mathrm{Zn}\left(\mathrm{O}_{2} \mathrm{CCH}_{3}\right)_{2} \cdot 2 \mathrm{H}_{2} \mathrm{O}$ to the deprotonated ethanolic solutions of the ligands to afford high yields up to $88 \%$, Figure $3.4 . \mathrm{Ni}\left(\mathrm{L}^{1}\right)_{2}$ has been previously reported by Darensbourg by photolytic demethylation of the the bis(phosphinothioether) derivative. ${ }^{101} \mathrm{Zn}\left(\mathrm{L}^{2}\right)_{2}$ has been synthesized by Kemp in the alcoholic solutions using triethylamine as an external base. ${ }^{104}$ All the four complexes were characterized by employing various spectroscopic techniques including NMR, FT-IR, UV-Vis, and ESI-MS. ${ }^{1} \mathrm{H}-\mathrm{NMR}$ and ${ }^{1} \mathrm{P}-\mathrm{NMR}$ have been collected at room temperature in deuterated dichloromethane solutions. The results for complexes $\mathrm{Ni}\left(\mathrm{L}^{1}\right)_{2}$ and $\mathrm{Zn}\left(\mathrm{L}^{2}\right)_{2}$ were found to be consistent with prior reports. (See appendix for NMR and FT-IR data.) The electronic spectra of all the complexes have been compared below. 


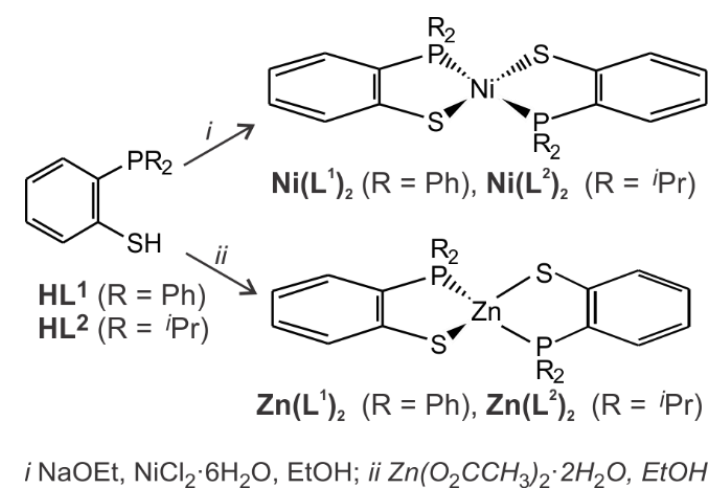

Figure 3.4 Synthesis of metal complexes $\mathrm{Ni}\left(\mathrm{L}^{1}\right)_{2}, \mathrm{Ni}\left(\mathrm{L}^{2}\right)_{2}, \mathrm{Zn}\left(\mathrm{L}^{1}\right)_{2}$ and $\mathrm{Zn}\left(\mathrm{L}^{2}\right)_{2} \cdot{ }^{105}$

The electronic spectra of all the four complexes were recorded in dichloromethane solutions, Figure 3.5. The UV-Vis spectrum of $\mathrm{Ni}\left(\mathrm{L}^{1}\right)_{2}$ in dichloromethane shows an intense charge transfer band at $301 \mathrm{~nm}\left(18,500 \mathrm{M}^{-1} \mathrm{~cm}^{-1}\right)$ with a shoulder at $412 \mathrm{~nm}(1860$ $\left.\mathrm{M}^{-1} \mathrm{~cm}^{-1}\right)$. Also seen at $615 \mathrm{~nm}\left(150 \mathrm{M}^{-1} \mathrm{~cm}^{-1}\right)$ was a weak $d$-d transition band. The comparable data for $\mathrm{Ni}\left(\mathrm{L}^{1}\right)_{2}$ with charge transfer bands at $298 \mathrm{~nm}\left(25,560 \mathrm{M}^{-1} \mathrm{~cm}^{-1}\right)$ and $424 \mathrm{~nm}\left(2850 \mathrm{M}^{-1} \mathrm{~cm}^{-1}\right)$ in chloroform has been reported by Darensbourg. ${ }^{101}$ The electronic spectra of $\mathrm{Ni}\left(\mathrm{L}^{2}\right)_{2}$ shows two high intensity bands at $303\left(14,580 \mathrm{M}^{-1} \mathrm{~cm}^{-1}\right)$ and $284 \mathrm{~nm}\left(15,190 \mathrm{M}^{-1} \mathrm{~cm}^{-1}\right)$. As compared to $\mathrm{Ni}\left(\mathrm{L}^{1}\right)_{2}$, the charge transfer band at $412 \mathrm{~nm}$ was found to show a blue shift to lower wavelength at $408 \mathrm{~nm}\left(2,605 \mathrm{M}^{-1} \mathrm{~cm}^{-1}\right)$. A similar blueshift for the weak $d$ - $d$ transition from $615 \mathrm{~nm}$ in $\mathrm{Ni}\left(\mathrm{L}^{1}\right)_{2}$ to $610 \mathrm{~nm}$ in $\mathrm{Ni}\left(\mathrm{L}^{2}\right)_{2}\left(1,185 \mathrm{M}^{-1}\right.$ $\mathrm{cm}^{-1}$ ) was observed. For $\mathrm{Zn}\left(\mathrm{L}^{1}\right)_{2}$, the charge transfer bands were recorded at higher energies of $272\left(23,600 \mathrm{M}^{-1} \mathrm{~cm}^{-1}\right)$ and $347 \mathrm{~nm}\left(3,900 \mathrm{M}^{-1} \mathrm{~cm}^{-1}\right)$ as compared to the intense charge transfer bands of $\mathrm{Ni}\left(\mathrm{L}^{1}\right)_{2}$ at 301 and $412 \mathrm{~nm}$. On substituting isopropyl groups in $\mathrm{Zn}\left(\mathrm{L}^{2}\right)_{2}$, a more intense band was observed at $279 \mathrm{~nm}\left(21,352 \mathrm{M}^{-1} \mathrm{~cm}^{-1}\right)$ and a less intense band at $326 \mathrm{~nm}\left(7,170 \mathrm{M}^{-1} \mathrm{~cm}^{-1}\right)$ as compared to the electronic bands of $\mathrm{Ni}\left(\mathrm{L}^{2}\right)_{2}$ at 303 and $284 \mathrm{~nm}$. 


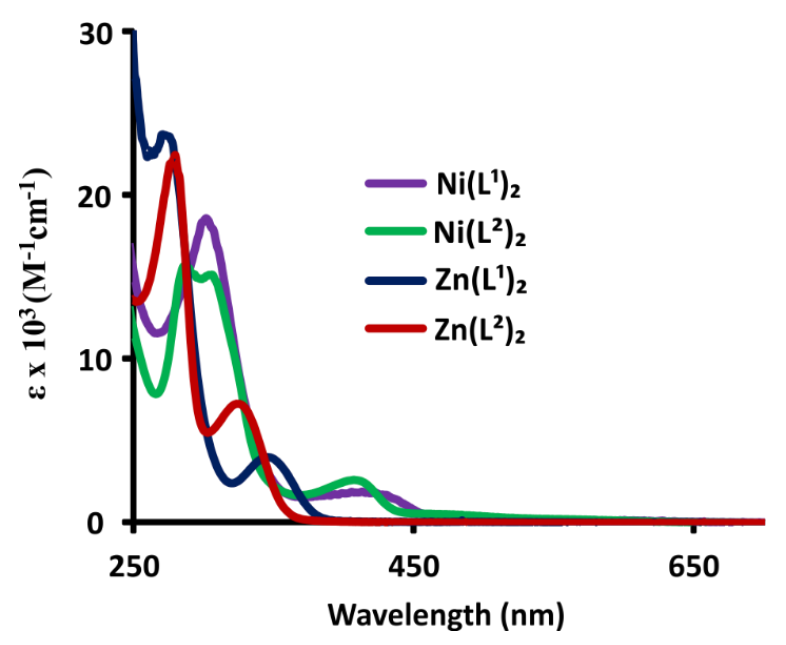

Figure 3.5 Overlay of the electronic spectra of the metal complexes recorded in dichloromethane

\subsection{Crystallographic studies}

Single crystal $\mathrm{x}$-ray diffraction was used to determine the solid state structure of $\mathrm{Ni}\left(\mathrm{L}^{2}\right)_{2}$ (CCDC 1549464). The crystal structures of $\mathrm{Ni}\left(\mathrm{L}^{1}\right)_{2}$ and $\mathrm{Zn}\left(\mathrm{L}^{2}\right)_{2}$ have been previously reported by Darensbourg and Kemp, respectively. ${ }^{101,104}$ An ORTEP representation of $\mathrm{Ni}\left(\mathrm{L}^{2}\right)_{2}$ and $\mathrm{Zn}\left(\mathrm{L}^{2}\right)_{2}$ has been shown in Figure 3.6. Orange colored crystals of $\mathrm{Ni}\left(\mathrm{L}^{2}\right)_{2}$ in the monoclinic space group $P 2_{1} / n$ were obtained upon liquid diffusion of a dichloromethane/ether mixture. The asymmetric unit contains a $\mathrm{Ni}(\mathrm{II})$ ion in a pseudosquare planar geometry coordinated to two phosphorus and two sulfur donors. Simiar to $\mathrm{Ni}\left(\mathrm{L}^{1}\right)_{2}$, the bidentate chelates in $\mathrm{Ni}\left(\mathrm{L}^{2}\right)_{2}$ were found to be in trans arrangement. When compared to $\mathrm{Ni}\left(\mathrm{L}^{1}\right)_{2}, \mathrm{Ni}\left(\mathrm{L}^{2}\right)_{2}$ has statistically equivalent Ni-S bond distances, Table 3.1. The Ni-S distance reported for $\mathrm{Ni}\left(\mathrm{L}^{1}\right)_{2}$ was $2.166(3) \AA$ whereas for $\mathrm{Ni}\left(\mathrm{L}^{2}\right)_{2}$, the $\mathrm{Ni}-\mathrm{S}$ distances found to be 2.1591(3) and 2.1641(3) $\AA$. The Ni-P distances for $\mathrm{Ni}\left(\mathrm{L}^{2}\right)_{2}$ and $\mathrm{Ni}\left(\mathrm{L}^{1}\right)_{2}$ were also found to be similar. The Ni-P distance of 2.173(3) $\AA$ was found in $\mathrm{Ni}\left(\mathrm{L}^{1}\right)_{2}$, while $\mathrm{Ni}\left(\mathrm{L}^{2}\right)_{2}$ has Ni-P distances of 2.1897(3) and 2.1798(3) $\AA$. The Zn-S bonds in $\mathrm{Zn}\left(\mathrm{L}^{2}\right)_{2}$ were found to be longer than the $\mathrm{Ni}\left(\mathrm{L}^{1}\right)_{2}$ and $\mathrm{Ni}\left(\mathrm{L}^{2}\right)_{2}$. $\mathrm{Zn}-\mathrm{S} 1$ was found to be 
2.3034(4) while Zn-S2 was 2.3130(4) A. Also, the Zn-P distances were found to be little longer. For $\mathrm{Zn}\left(\mathrm{L}^{2}\right)_{2}, \mathrm{Zn}-\mathrm{P} 1$ and $\mathrm{Zn}-\mathrm{P} 2$ distances were found to be 2.3966(4) and 2.3760(4) $\AA$. The P-M-S bond angles in $\mathrm{Ni}\left(\mathrm{L}^{1}\right)_{2}$ and $\mathrm{Ni}\left(\mathrm{L}^{2}\right)_{2}$ are have values between $88.7(1)$ and $91.791(13)^{\circ}$. For $\mathrm{Zn}\left(\mathrm{L}^{2}\right)_{2}$, the geometry was distorted tetrahedral with S2-Zn-P2 bond angle of $89.178(12)^{\circ}$ which was statistically equivalent to $\mathrm{S} 1-\mathrm{Zn}-\mathrm{P} 1$ bond angle of $88.782(11)^{\circ}$. The values of S1-Zn-P2 and S2-Zn-P1 for $\mathrm{Zn}\left(\mathrm{L}^{2}\right)_{2}$ were $116.169(12)$ and $118.303(12)^{\circ}$, which were larger than the corresponding S-Ni-P angles in $\mathrm{Ni}\left(\mathrm{L}^{1}\right)_{2}$.

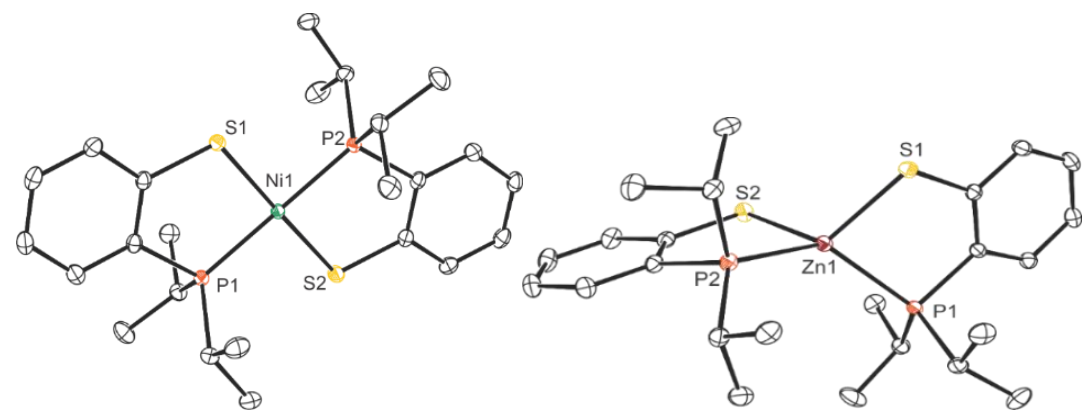

Figure 3.6 ORTEP ${ }^{106}$ representation of $\mathrm{Ni}\left(\mathrm{L}^{2}\right)_{2}$ and $\mathrm{Zn}\left(\mathrm{L}^{2}\right)_{2}$ with thermal ellipsoids at $50 \%$ probability level.

Table 3.1 Comparison of Bond Distances $(\AA)$ and Bond Angles $\left({ }^{\circ}\right)$ for $\mathrm{Ni}\left(\mathrm{L}^{1}\right)_{2}, \mathrm{Ni}\left(\mathrm{L}^{2}\right)_{2}$ and $\mathrm{Zn}\left(\mathrm{L}^{2}\right)_{2}$.

\begin{tabular}{llll}
\hline & $\mathrm{Ni}\left(\mathrm{L}^{1}\right)_{2}$ & $\mathrm{Ni}\left(\mathrm{L}^{2}\right)_{2}$ & $\mathrm{Zn}\left(\mathrm{L}^{2}\right)_{2}$ \\
\hline M1-S1 & $2.166(3)$ & $2.1591(3)$ & $2.3066(3)$ \\
M1-S2 & $2.166(3)$ & $2.1641(3)$ & $2.3170(3)$ \\
M1-P1 & $2.173(3)$ & $2.1897(3)$ & $2.3864(3)$ \\
M1-P2 & $2.173(3)$ & $2.1798(3)$ & $2.3711(3)$ \\
S1-M1-S2 & $180.0(1)$ & $177.689(15)$ & $115.866(13)$ \\
S1-M1-P1 & $88.7(1)$ & $89.503(13)$ & $88.782(11)$ \\
S1-M1-P2 & $91.3(1)$ & $89.211(13)$ & $116.169(12)$ \\
S2-M1-P1 & $91.3(1)$ & $91.791(13)$ & $118.303(12)$ \\
S2-M1-P2 & $88.7(1)$ & $89.573(13)$ & $89.178(12)$ \\
P1-M1-P2 & $180.0(1)$ & $177.325(15)$ & $131.031(12)$ \\
\hline
\end{tabular}




\subsection{Electrochemical studies}

Cyclic voltammograms were obtained using $0.10 \mathrm{M}$ tetrabutylammonium hexafluorophosphate as a supporting electrolyte in $25 \mathrm{~mL}$ dichloromethane solutions using $0.50 \mathrm{mM}$ concentrations of the complex at room temperature, Figure 3.7. The cyclic voltammogram of $\mathrm{Ni}\left(\mathrm{L}^{1}\right)_{2}$ when recorded at $200 \mathrm{mV} / \mathrm{s}$ in dichloromethane showed metal centered quasi-reversible oxidation $\mathrm{Ni}^{\mathrm{III} / \mathrm{II}}$ at $+0.25 \mathrm{~V}$ versus ferrocenium/ferrocene $\left(\mathrm{Fc}^{+} / \mathrm{Fc}^{0}\right)$. A ligand centered irreversible oxidation at $+1.22 \mathrm{~V}$ was attributed to the sulphur oxidation present in the ligand framework. $\mathrm{Ni}\left(\mathrm{L}^{2}\right)_{2}$ showed at metal centered quasireversible oxidation $\mathrm{Ni}{ }^{\mathrm{III} / \mathrm{II}}$ at $+0.13 \mathrm{~V}$ versus ferrocenium/ferrocene $\left(\mathrm{Fc}^{+} / \mathrm{Fc}^{0}\right)$. The shift in the oxidation event can be explained by the increased electron density by isopropyl groups at phosphorus in $\mathrm{L}^{2}$ ligand framework. An anodic shift in the ligand-centered oxidation was observed from $+1.22 \mathrm{~V}$ to $+1.28 \mathrm{~V}$. In Zinc (II) analogues, the irreversible oxidations consistent with the ligand- centered oxidations was observed at +0.71 and $+0.76 \mathrm{~V}$, respectively. When analyzed in the cathodic region, a quasi-reversible reduction assigned to $\mathrm{Ni}^{\mathrm{II} / \mathrm{I}}$ was observed at $-2.15 \mathrm{~V}$ vs $\mathrm{Fc}^{+} / \mathrm{Fc}^{0}$ and $\mathrm{Ni}^{\mathrm{I} / 0}$ reduction was observed at $-2.71 \mathrm{~V}$. Though prior reports by Darensbourg did not mention any reduction events after $-2.5 \mathrm{~V}$ vs $\mathrm{Fc}^{+} / \mathrm{Fc}^{0}$. However, on the sweeping the potential to the negative potential up to $-3.0 \mathrm{~V}$ vs $\mathrm{Fc}^{+} / \mathrm{Fc}^{0}$ and then subtraction of the background current associated with the reduction of the solvent, dichloromethane reveals $\mathrm{Ni}^{\mathrm{I} / 0}$ event which was hidden in the solvent reduction before. The reduction events recorded for $\mathrm{Ni}\left(\mathrm{L}^{1}\right)_{2}$ were found to be shifted by 1.61 and $1.48 \mathrm{~V}$ when compared with $\left[\mathrm{Ni}\left(\mathrm{PS}-\mathrm{CH}_{3}\right)_{2}\right]^{2+}$ previously reported. This shift in reduction potentials was in accordance with the dissociation of the two $\mathrm{CH}_{3}{ }^{+}$groups. Cyclic voltammogram of $\mathrm{Ni}\left(\mathrm{L}^{2}\right)_{2}$ shows reduction of $\mathrm{Ni}^{\mathrm{II} / \mathrm{I}}$ at $-2.48 \mathrm{~V}$ vs. $\mathrm{Fc}^{+} / \mathrm{Fc}^{0}$. Substitution of 
electron releasing isopropyl groups in $\mathrm{Ni}\left(\mathrm{L}^{2}\right)_{2}$ shits the reduction potential of $\mathrm{Ni}^{\mathrm{i} / 0}$ out of solvent window as expected, Table 3.2.

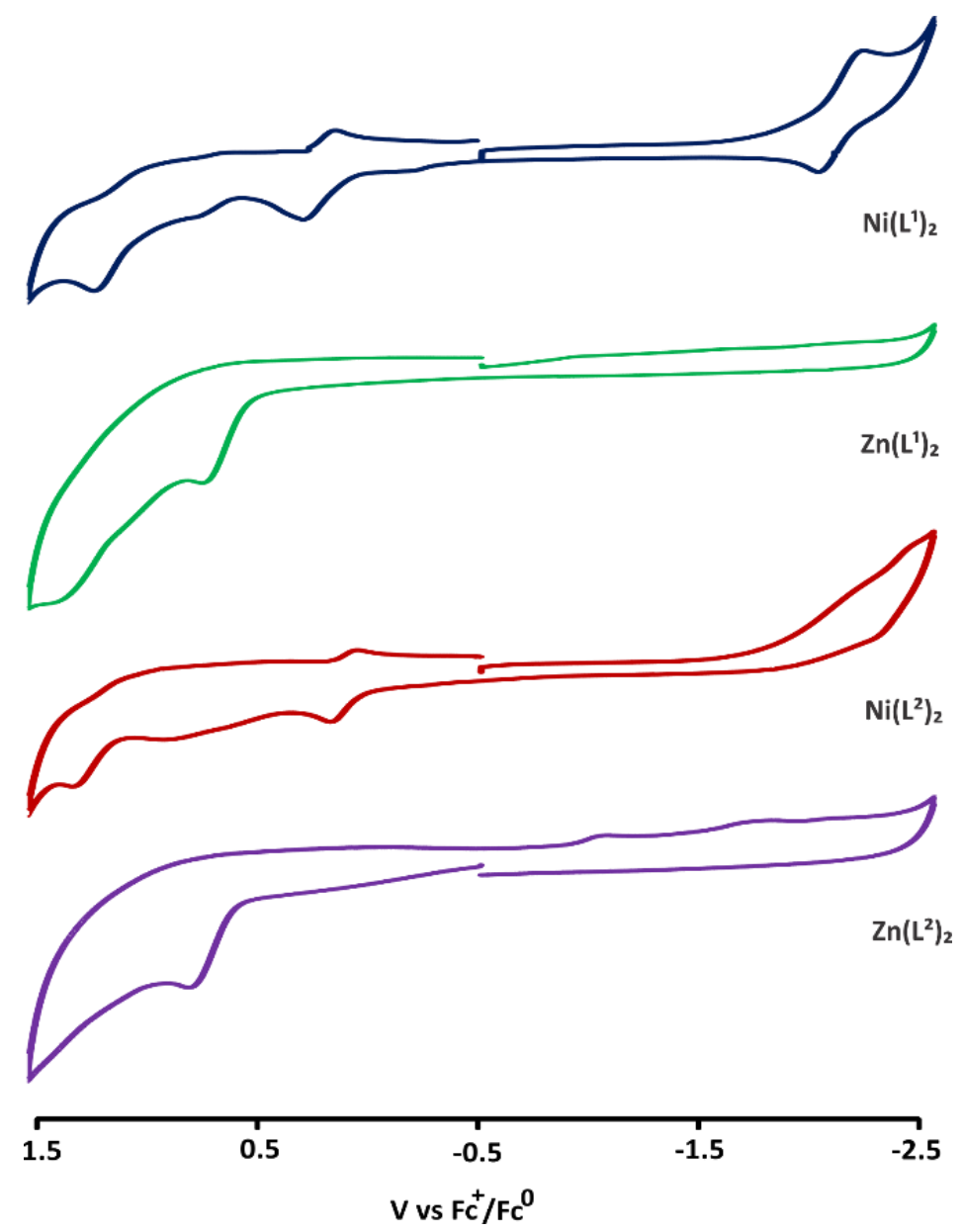

Figure 3.7 Cyclic voltammograms recorded in dichloromethane on $0.50 \mathrm{mM}$ solutions of each complex with $0.1 \mathrm{M} \mathrm{Bu}_{4} \mathrm{NPF}_{6}$ as supporting electrolyte at a scan rate of $200 \mathrm{mV} / \mathrm{s}$.

Table 3.2 Electrochemical data for complexes.

\begin{tabular}{|c|c|c|c|c|}
\hline Compound & $\begin{array}{c}\mathrm{ML} / \mathrm{ML} \\
(\mathrm{V})\end{array}$ & $\begin{array}{c}\mathrm{Ni}(\mathrm{III} / \mathrm{II}) \\
(\mathrm{V})\end{array}$ & $\begin{array}{c}\mathrm{Ni}(\mathrm{II} / \mathrm{I}) \\
(\mathrm{V})\end{array}$ & $\begin{array}{c}\mathrm{Ni}(\mathrm{I} / 0) \\
(\mathrm{V})\end{array}$ \\
\hline $\mathrm{Ni}\left(\mathrm{L}^{1}\right)_{2}$ & $+1.22(\mathrm{i})$ & $+0.25(\mathrm{q})$ & $-2.15(\mathrm{q})$ & $-2.71(\mathrm{i})$ \\
\hline $\mathrm{Zn}\left(\mathrm{L}^{1}\right)_{2}$ & $+0.71(\mathrm{i})$ & - & - & - \\
\hline $\mathrm{Ni}\left(\mathrm{L}^{2}\right)_{2}$ & $+1.28(\mathrm{i})$ & $+0.12(\mathrm{q})$ & $-2.48(\mathrm{q})$ & - \\
\hline $\mathrm{Zn}\left(\mathrm{L}^{2}\right)_{2}$ & $+0.76(\mathrm{i})$ & - & - & - \\
\hline$\left[\mathrm{Ni}\left(\mathrm{PS}-\mathrm{CH}_{3}\right)_{2}\right]^{2+}$ & & - & $-0.54(\mathrm{q})$ & $-1.23(\mathrm{i})$ \\
\hline
\end{tabular}

Data collected with $0.1 \mathrm{M} \mathrm{Bu}_{4} \mathrm{NPF}_{6}$ in dichloromethane solution with potentials versus $\mathrm{Fc}^{+} / \mathrm{Fc}^{0}$. (i) denotes irreversible process and (q) denotes quasi-reversible process. For quasi-reversible events, the $E_{1 / 2}$ value is reported. Data for $\left[\mathrm{Ni}\left(\mathrm{PS}-\mathrm{CH}_{3}\right)_{2}\right]^{2+}$ is taken from report by Darensbourg. ${ }^{101}$ 


\subsection{Electrocatalytic hydrogen evolution reactions}

All the four complexes $\mathrm{M}\left(\mathrm{L}^{\mathrm{a}}\right)_{2}(\mathrm{M}=\mathrm{Ni}, \mathrm{Zn})(\mathrm{a}=1$ or 2$)$ have been screened for their ability to evolve hydrogen in dichloromethane solutions upon the addition of external acids $\mathrm{CH}_{3} \mathrm{COOH}$ and $\mathrm{HCl}$. Also, the complexes were studied for their ability to cleave dihydrogen molecule in the presence of external base $\mathrm{Et}_{3} \mathrm{~N}$ under $1 \mathrm{~atm} . \mathrm{H}_{2}$. Only $\mathrm{Ni}\left(\mathrm{L}^{1}\right)_{2}$ was found to be active for both hydrogen evolution as well for the cleaving dihydrogen molecule. $\mathrm{Ni}\left(\mathrm{L}^{2}\right)_{2}$ was found be active for hydrogen oxidation but was ineffective towards hydrogen evolution reactions. $\mathrm{Zn}\left(\mathrm{L}^{1}\right)_{2}$ and $\mathrm{Zn}\left(\mathrm{L}^{2}\right)_{2}$ was insufficient towards performing both HER and HOR.

3.5.1 HER with $\mathrm{Ni}\left(\mathrm{L}^{1}\right)_{2}$ using $\mathrm{CH}_{3} \mathrm{COOH}$. An increase in the cathodic currents at -2.15 $\mathrm{V}$ vs. $\mathrm{Fc}^{+} / \mathrm{Fc}^{0}$ was observed upon the successive additions of $\mathrm{CH}_{3} \mathrm{COOH}$ to the solutions of $\mathrm{Ni}\left(\mathrm{L}^{1}\right)_{2}$, indicating electrocatalytic reduction. The cyclic voltammograms of $0.50 \mathrm{mM}$ $\mathrm{Ni}\left(\mathrm{L}^{1}\right)_{2}$ in the presence of $0.1 \mathrm{MBu}_{4} \mathrm{NPF}_{6}$ in dichloromethane solutions were collected with the gradual increase in the acid concentrations and shown to displays an increment in the peak intensity at $-2.15 \mathrm{~V}$. The data were collected at three different scan rates $0.2 \mathrm{~V} / \mathrm{s}, 0.5$ $\mathrm{V} / \mathrm{s}$ and $1 \mathrm{~V} / \mathrm{s}$. At lower acid concentrations, the linear increase in the catalytic current was observed with the increase in $\mathrm{CH}_{3} \mathrm{COOH}$ concentration, suggesting first order rate dependence with respect to acid concentration. The catalytic current becomes acid independent above $3.5 \mathrm{mM}$ acid concentrations indicating that current was not diffusion controlled now and an acid saturated condition has been achieved, Figure 3.8. To evaluate turnover frequency, the data were collected at higher scan rates until the scan rate independence was achieved. For $\mathrm{Ni}\left(\mathrm{L}^{1}\right)_{2}$, at $5 \mathrm{~V} / \mathrm{s}$, the maximum TOF was found to be 51 
$\mathrm{s}^{-1}$. The overpotential of $1.1 \mathrm{~V}$ vs. $\mathrm{Fc}^{+} / \mathrm{Fc}^{0}$ was recorded using open circuit potential experiment.

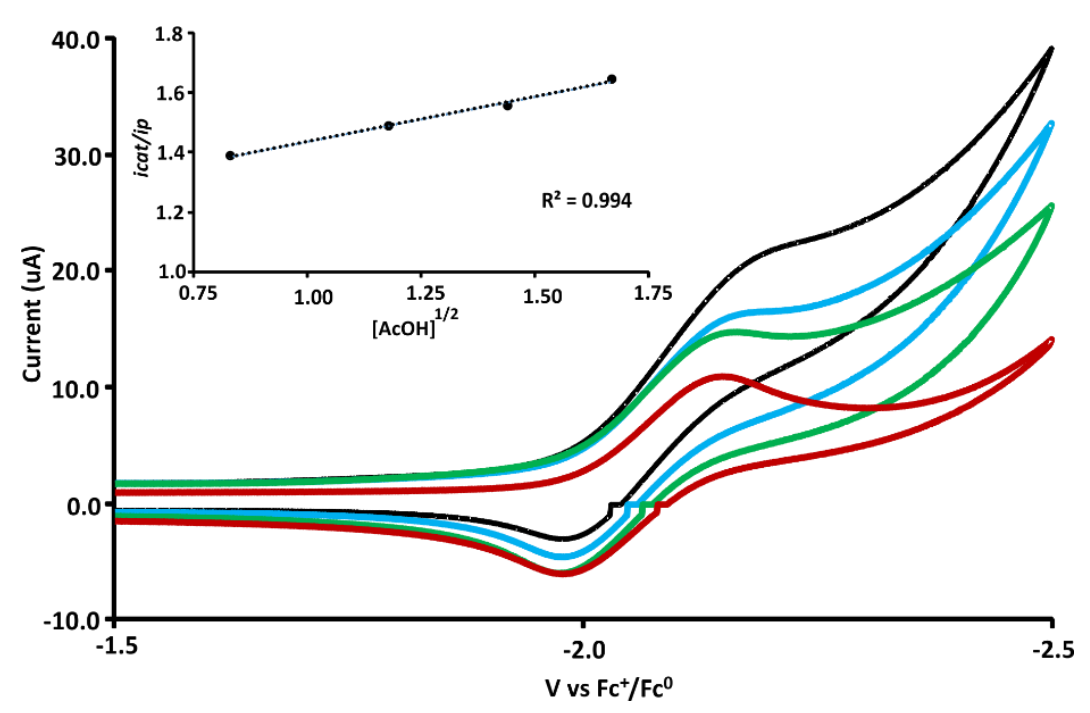

Figure 3.8 Cyclic voltammograms $(\mathrm{CVs})$ of $0.50 \mathrm{mM} \mathrm{Ni}\left(\mathrm{L}^{1}\right)_{2}$ in the presence of $0.1 \mathrm{M}\left[\mathrm{Bu}_{4} \mathrm{NPF}_{6}\right]$ in dichloromethane solution with subsequent addition of acetic acid at scan rate of $200 \mathrm{mV} / \mathrm{s}$. CVs showing no acid (red), $1.4 \mathrm{mM}$ (green), $2.8 \mathrm{mM}$ (blue), $3.5 \mathrm{mM}$ (black). (Inset) Plot of $i_{c a} / i_{p}$ vs $\left[\mathrm{CH}_{3} \mathrm{COOH}\right]^{1 / 2}$

3.5.2 HER with $\mathrm{Ni}\left(\mathrm{L}^{1}\right)_{2}$ using $\mathbf{H C l}$. When titrated with strong acid $\mathrm{HCl}$, an additional cathodic event was observed at $-1.9 \mathrm{vs} . \mathrm{Fc}^{+} / \mathrm{Fc}^{0}$ was observed which was attributed to the reduction of protonated species $\mathrm{NiL}^{1}\left(\mathrm{~L}^{1} \mathrm{H}\right)$. Also, the cathodic increase at $-2.15 \mathrm{vs} . \mathrm{Fc}^{+} / \mathrm{Fc}^{0}$ was observed indicating electrolytic reduction. With $\mathrm{HCl}$, catalytic current becomes acid independent above $6.5 \mathrm{mM}$ acid concentrations Figure 3.9. At lower acid concentrations, the linear increase in the catalytic current was observed with the increase in $\mathrm{HCl}$ concentration, suggesting first order rate dependence with respect to acid concentration, Figure 3.10. At higher scan rates, the maximum TOF with $\mathrm{HCl}$ using $\mathrm{Ni}\left(\mathrm{L}^{1}\right)_{2}$ was found to be $140 \mathrm{~s}^{-1}$ at an overpotential of $1.1 \mathrm{~V}$. 


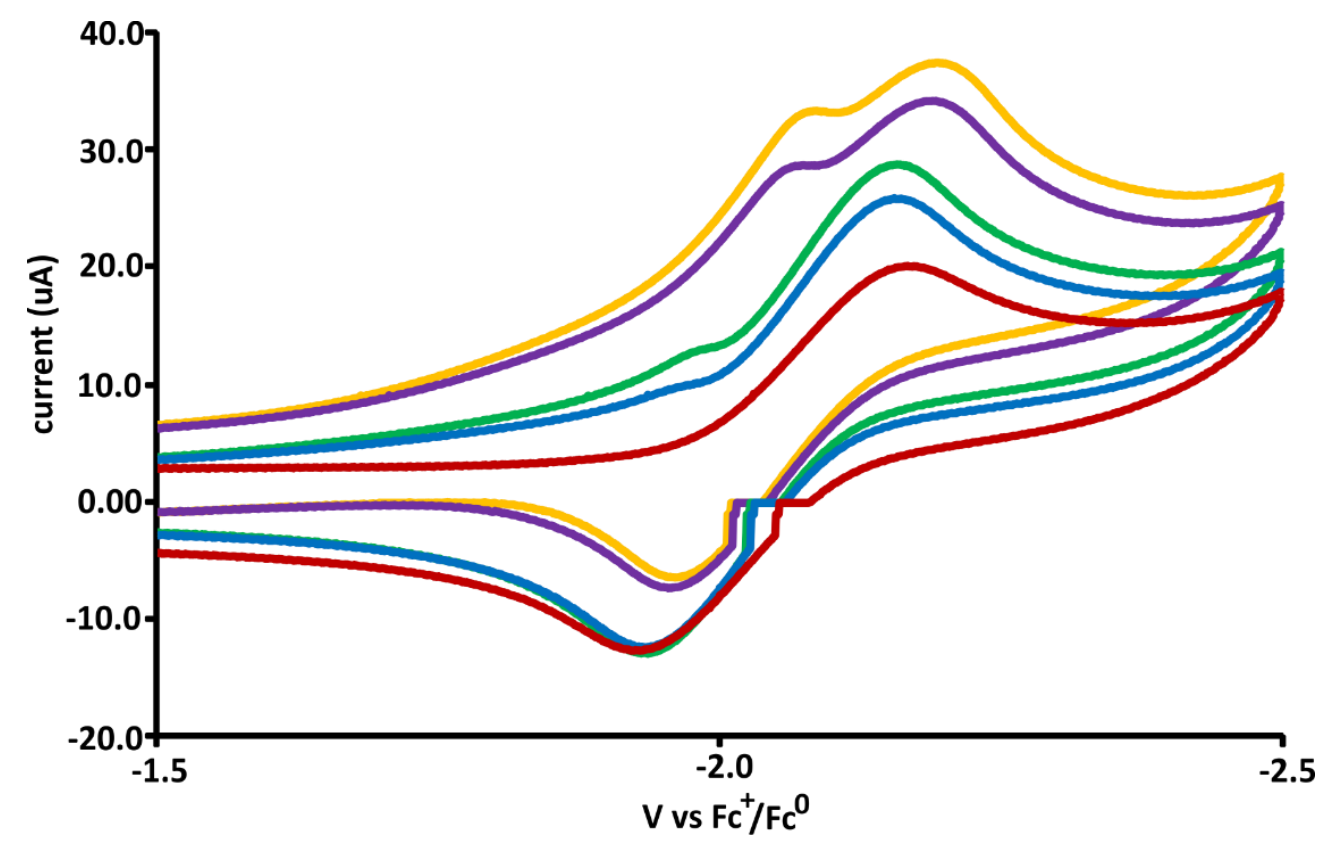

Figure 3.9 Electrocatalytic hydrogen evolution reaction. Cyclic voltammograms (CVs) of $0.50 \mathrm{mM}$ $\mathrm{Ni}\left(\mathrm{L}^{1}\right)_{2}$ in the presence of $0.1 \mathrm{M}\left[\mathrm{Bu}_{4} \mathrm{NPF}_{6}\right]$ in dichloromethane solution with subsequent addition of hydrochloric acid at scan rate of $200 \mathrm{mV} / \mathrm{s}$. CVs showing no acid (red), $2.6 \mathrm{mM}$ (blue), $3.9 \mathrm{mM}$ (green), $5.2 \mathrm{mM}$ (violet), $6.5 \mathrm{mM}$ (yellow).

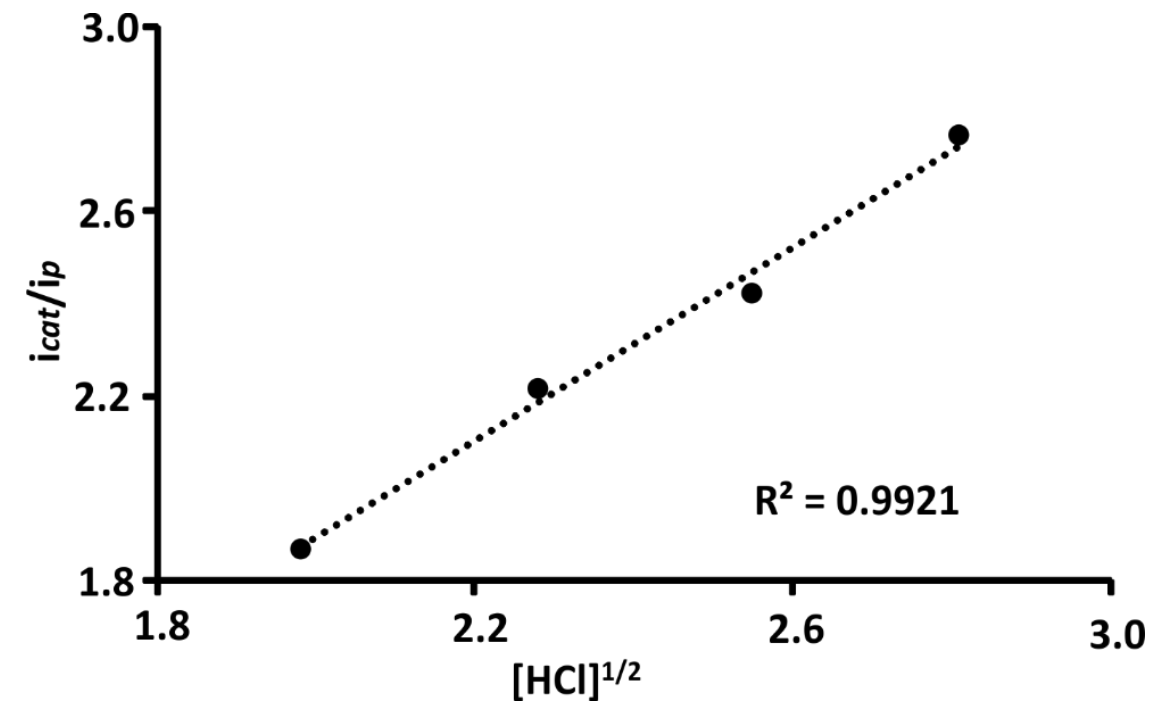

Figure 3.10 Plot of $i_{c a t} / i_{p}$ vs $[\mathrm{HCl}]^{1 / 2}$. 
Titrations of $\mathrm{Ni}\left(\mathrm{L}^{1}\right)_{2}$ in dichloromethane solutions with $\mathrm{HCl}$ showed a shift in charge transfer band from 412 to $420 \mathrm{~nm}$. This indicates towards the protonation of the $\mathrm{Ni}\left(\mathrm{L}^{1}\right)_{2}$ with $\mathrm{HCl}$, Figure 3.11. Such charge transfer bands were found to be absent on titrations of $\mathrm{Ni}\left(\mathrm{L}^{1}\right)_{2}$ in dichloromethane solutions with $\mathrm{CH}_{3} \mathrm{COOH}$.

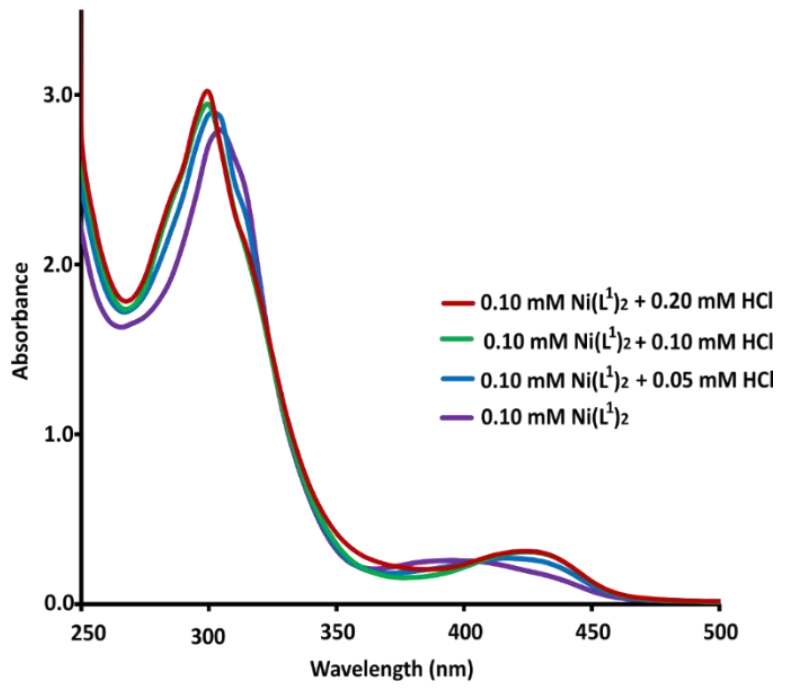

Figure 3.11 UV-Vis spectra showing titrations of $\mathrm{Ni}\left(\mathrm{L}^{1}\right)_{2}$ with hydrochloric acid in dichloromethane.

\subsection{Mechanistic studies for hydrogen evolution reaction}

When evaluated for the catalyst dependence at a fixed acetic acid concentration of $3.5 \mathrm{mM}$, the catalytic current was found to be first order dependence on the catalyst, Figure 3.12. To get more insights into the mechanism, the solutions of $\mathrm{Ni}\left(\mathrm{L}^{1}\right)_{2}$ was titrated with deuterated acid $\left(\mathrm{CD}_{3} \mathrm{COOD}\right)$ and analyzed for HER. The $\mathrm{KIE}\left(\mathrm{CH}_{3} \mathrm{COOH} / \mathrm{CD}_{3} \mathrm{COOD}\right)$ observed for HER in dichloromethane solutions was 0.82 indicating inverse isotope effect which is consistent with the formation of metal hydride as suggested by reports from Gray and Fukuzumi. ${ }^{53-54}$ 
The robustness of the $\mathrm{Ni}\left(\mathrm{L}^{1}\right)_{2}$ was evaluated using controlled potential coulometry (CPC) experiments for 24 hours. During CPC experiments, the potential was hold to -1.9 $\mathrm{V}$ vs $\mathrm{Fc}^{+} / \mathrm{Fc}^{0}$ and the hydrogen was collected in dicholormethane solutions with the turnover number (TON) of 3.4 based on the total charge of $15 \mathrm{C}$.

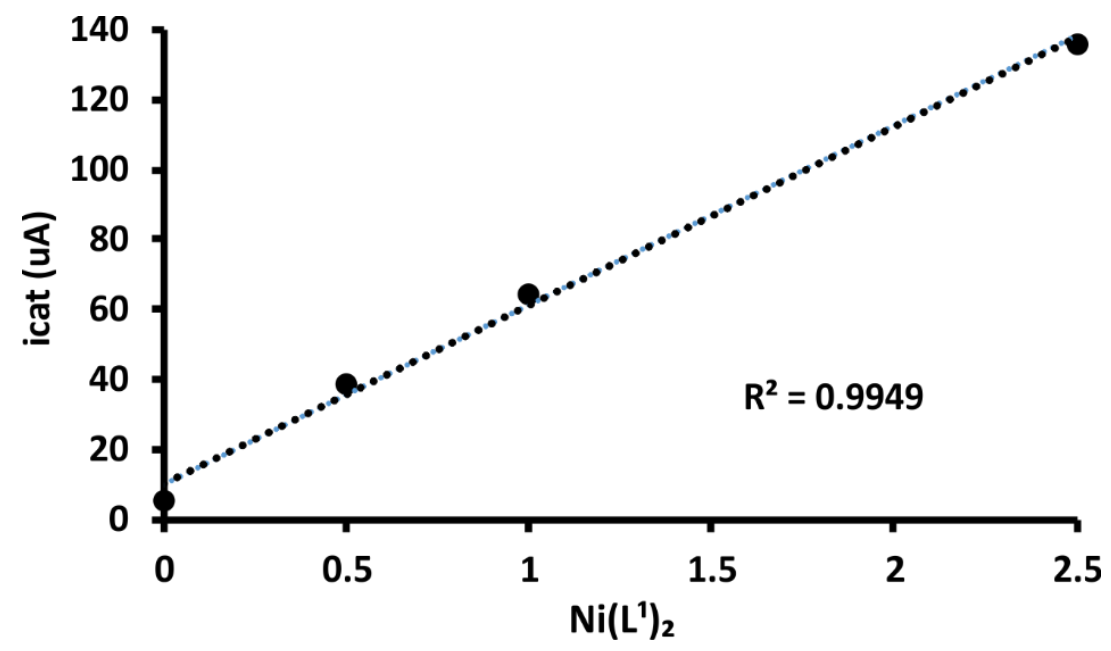

Figure 3.12 Catalyst dependence studies. A plot showing variation catalytic current vs catalyst concentration at constant acetic acid concentration of $3.5 \mathrm{mM}$ in dichloromethane solution.

Control experiments performed in the absence of $\mathrm{Ni}\left(\mathrm{L}^{1}\right)_{2}$ with $\mathrm{CH}_{3} \mathrm{COOH}$ and $\mathrm{HCl}$ shows no catalytic current. This excludes the possibility of increase in current by the reduction of acid by itself. To analyze for any adsorbed species on the electrode surface, the working electrode (glassy carbon electrode) was taken out of the solution after performing the $\mathrm{CV}$ experiments and then washed with the working solvent dichloromethane and put back in the fresh dichloromethane solution containing acid and electrolyte and then $\mathrm{CV}$ experiments were performed. The absence of any catalytic current indicates that there was no adsorbed species or any degraded product on the electrode surface was deposited that might be responsible for catalytic current. ${ }^{51-52,107}$ This indicates that the catalytic increment observed was entirely obtained from homogenous solutions. 
3.6.1 Proposed mechanism for HER with $\mathrm{Ni}\left(\mathbf{L}^{\mathbf{1}}\right)_{2}$. The hydrogen evolution with $\mathrm{Ni}\left(\mathrm{L}^{1}\right)_{2}$ was proposed to follow ECEC or CEEC mechanism, Figure 3.13. ECEC type of mechanism, with weak acid $\left(\mathrm{CH}_{3} \mathrm{COOH}\right)$, involves the reduction $(\mathrm{E})$ of $\mathrm{Ni}\left(\mathrm{L}^{1}\right)_{2}$ in the first step, followed by metal centered protonation (C) in the second step. This leads to the formation of $\mathrm{Ni}(\mathrm{III})-\mathrm{H}$. The formed $\mathrm{Ni}(\mathrm{III})-\mathrm{H}$ species was reduced (E) to $\mathrm{Ni}(\mathrm{II})-\mathrm{H}$ after the addition of second electron and in the final step, the proton (C) from the solution reacts with anionic $\mathrm{Ni}(\mathrm{II})-\mathrm{H}$ to release $\mathrm{H}_{2}$. This is in accordance with previous postulated mechanisms for HER with $\mathrm{Ni}(\mathrm{II})$ systems. ${ }^{108-109}$ With strong acid $(\mathrm{HCl})$, the protonation event (C) occurs before the reduction leads to the formation of $\left[\mathrm{NiL}^{1}\left(\mathrm{HL}^{1}\right)\right]^{+}$. This species then gets reduced (E) to form $\mathrm{Ni}(\mathrm{III})-\mathrm{H}$ after the second step. In the following step, $\mathrm{Ni}(\mathrm{III})$ $\mathrm{H}$ species gets reduced (E) to $\mathrm{Ni}(\mathrm{II})-\mathrm{H}$ which reacts with external proton $(\mathrm{C})$ from the solution to evolve hydrogen,

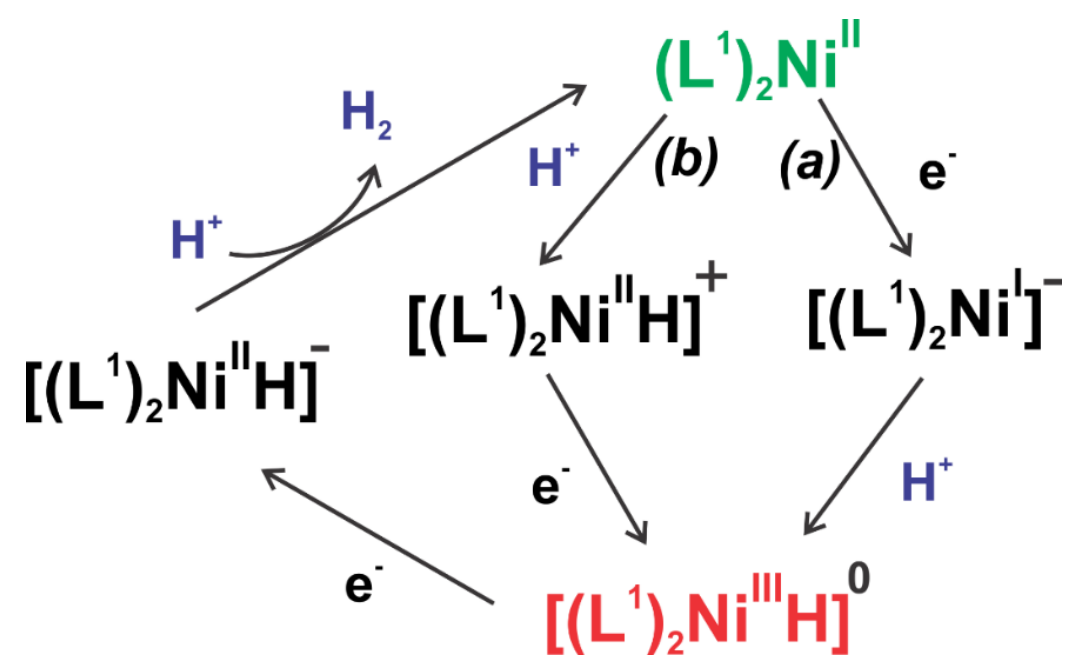

Figure 3.13 Proposed HER mechanism with $\mathrm{Ni}\left(\mathrm{L}^{1}\right)_{2}$. Path (a) shows ECEC type of mechanism while Path (b) shows CEEC type of mechanism. 


\subsection{Electrocatalytic hydrogen oxidation reactions}

3.7.1 HOR with $\mathrm{Ni}\left(\mathrm{L}^{1}\right)_{2}$ using $\mathrm{Et}_{3} \mathrm{~N}$ under $1 \mathrm{~atm} . \mathrm{H}_{2}$. When screened for cleaving dihydrogen molecule, $\mathrm{Ni}\left(\mathrm{L}^{1}\right)_{2}$ was found to be active electrocatalysts in the presence of external redox active base triethylamine $\left(\mathrm{Et}_{3} \mathrm{~N}\right)$ under 1 atmosphere of hydrogen. The cyclic voltammograms of $0.50 \mathrm{mM} \mathrm{Ni}\left(\mathrm{L}^{1}\right)_{2}$ in the presence of $0.1 \mathrm{M} \mathrm{Bu}_{4} \mathrm{NPF}_{6}$ in dichloromethane solutions were collected with the gradual increase in the base concentrations and shown to displays an increment in the peak intensity at $+0.9 \mathrm{~V}$. The catalytic current becomes base independent above $1.68 \mathrm{mM} \mathrm{Et}_{3} \mathrm{~N}$ concentrations indicating base saturated conditions, Figure 3.14. The maximum TOF recorded for hydrogen oxidation with $\mathrm{Ni}\left(\mathrm{L}^{1}\right)_{2}$ using $\mathrm{Et}_{3} \mathrm{~N}$ was $23 \mathrm{~s}^{-1}$ with an overpotential of $0.33 \mathrm{~V}$.

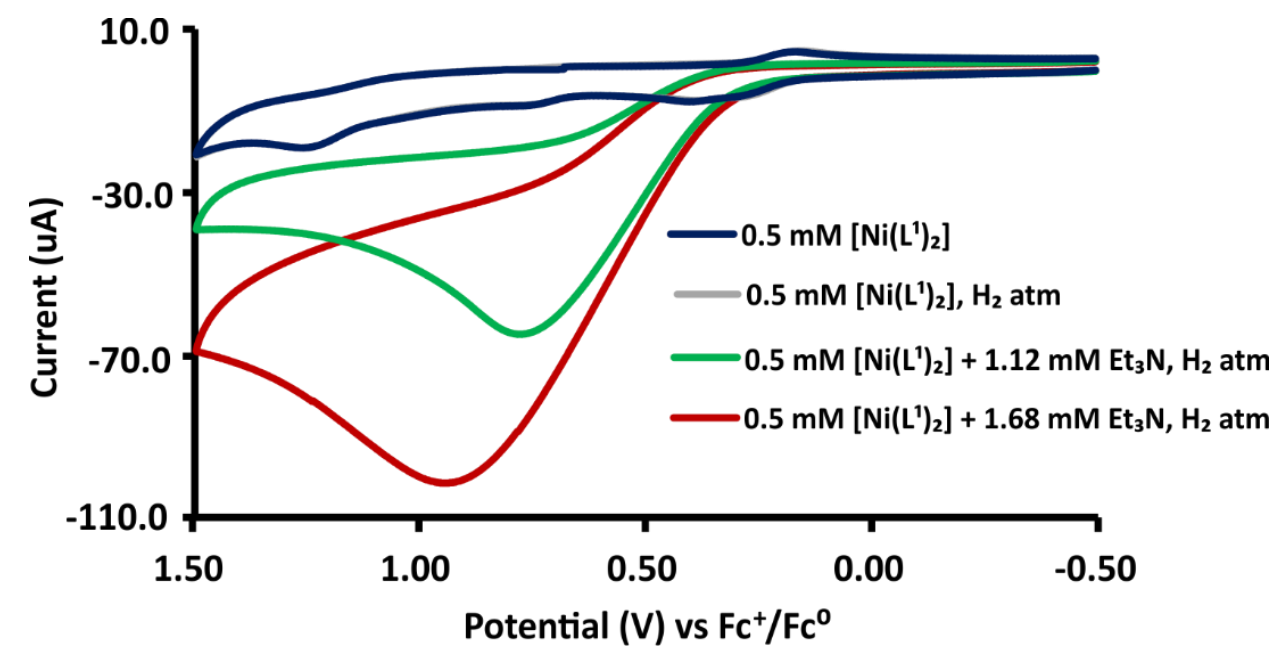

Figure 3.14 Electrocatalytic hydrogen oxidation reaction. Cyclic voltammograms (CVs) of 0.50 $\mathrm{mM} \mathrm{Ni}\left(\mathrm{L}^{1}\right)_{2}$ in the presence of $0.1 \mathrm{M}\left[\mathrm{Bu}_{4} \mathrm{NPF}_{6}\right]$ in dichloromethane solution with subsequent addition of redox active base triethylamine under $1 \mathrm{~atm} . \mathrm{H}_{2}$ at scan rate of $200 \mathrm{mV} / \mathrm{s}$.

3.7.2 HOR with $\mathrm{Ni}\left(\mathrm{L}^{2}\right)_{2}$ using $\mathrm{Et}_{3} \mathrm{~N}$ under $1 \mathrm{~atm} . \mathrm{H}_{2} . \mathrm{Ni}\left(\mathrm{L}^{2}\right)_{2}$ was also found to catalyze hydrogen oxidation with the maximum TOF of $19 \mathrm{~s}^{-1}$ at an overpotential of $0.49 \mathrm{~V}$. The catalytic current becomes base independent above $0.84 \mathrm{mM} \mathrm{Et}_{3} \mathrm{~N}$ concentrations indicating 
that current was not diffusion controlled now and a base saturated condition has been achieved, Figure 3.15.

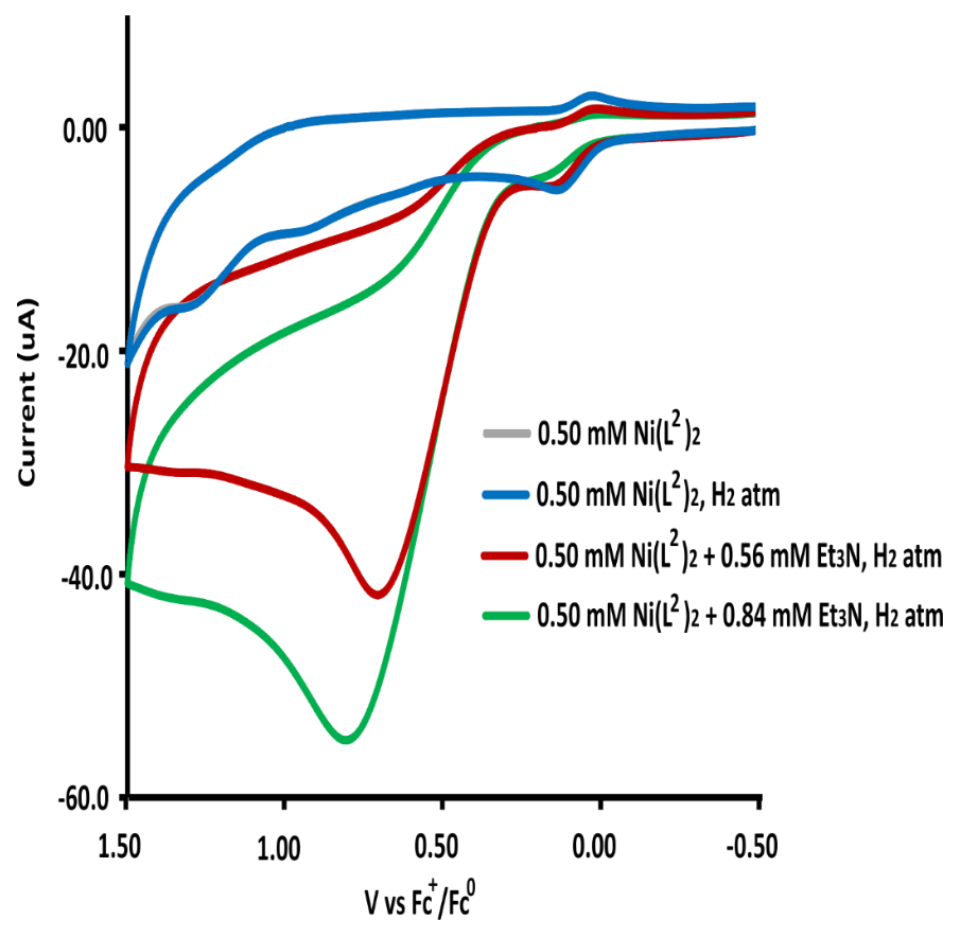

Figure 3.15 Electrocatalytic hydrogen oxidation reaction. Cyclic voltammograms (CVs) of 0.50 $\mathrm{mM} \mathrm{Ni}\left(\mathrm{L}^{2}\right)_{2}$ in the presence of $0.1 \mathrm{M}\left[\mathrm{Bu}_{4} \mathrm{NPF}_{6}\right]$ in dichloromethane solution with subsequent addition of redox active base triethylamine under $1 \mathrm{~atm} . \mathrm{H}_{2}$ at scan rate of $200 \mathrm{mV} / \mathrm{s}$.

Control experiments were performed in the presence of $\mathrm{Ni}\left(\mathrm{L}^{1}\right)_{2}$ or $\mathrm{Ni}\left(\mathrm{L}^{2}\right)_{2}$ with $\mathrm{Et}_{3} \mathrm{~N}$ under $\mathrm{N}_{2}$ atmosphere shows no catalytic current. This excludes the possibility of increase in the current due to oxidation of the redox active base $\mathrm{Et}_{3} \mathrm{~N}$. Also, to be noted that, $\mathrm{Ni}\left(\mathrm{L}^{1}\right)_{2}$ and $\mathrm{Ni}\left(\mathrm{L}^{2}\right)_{2}$ were found to be inadequate for hydrogen oxidation using redox non-active bases like 2,6 lutidine $\left.\left[\left(\mathrm{CH}_{3}\right)_{2} \mathrm{C}_{5} \mathrm{H}_{3} \mathrm{~N}\right)\right] .{ }^{110}$ This indicates that $\mathrm{Et}_{3} \mathrm{~N}$ serves the dual role as base and redox mediator in initiating the hydrogen cleavage. Initial oxidation of $\mathrm{Et}_{3} \mathrm{~N}$ yields $\left[\mathrm{NEt}_{3}{ }^{\cdot}\right]^{+}$, which on reaction with second molecule of $\mathrm{Et}_{3} \mathrm{~N}$ leads to $\mathrm{H}$ - atom abstraction forming protonated species $\left[\mathrm{HNEt}_{3}\right]^{+}$and radical species $\left[\mathrm{Et}_{2} \mathrm{~N} \cdot=\mathrm{CHMe}\right] .^{24,}{ }^{111-113} \mathrm{This}$ 
radical species was the probable active radical species for $\mathrm{H}_{2}$ oxidation, but still the exact nature of the species and exact mechanism for dihydrogen oxidation remains unresolved at this point.

\subsection{Conclusions}

The Ni (II) and Zn (II) complexes with dialkyl/diaryl-phosphine benzenethiolate ligands have been synthesized and characterized by spectroscopic techniques and screened for their ability to electrocatalytically evolve hydrogen and oxidize hydrogen. $\mathrm{Ni}\left(\mathrm{L}^{1}\right)_{2}$ has been found to be active electrocatalyst to evolve hydrogen with the maximum turnover frequency of $140 \mathrm{~s}^{-1}$ at an overpotential of $1.1 \mathrm{~V}$ and oxidize dihydrogen with maximum turnover frequency of $23 \mathrm{~s}^{-1}$ at an overpotential of $0.49 \mathrm{~V}$. The maximum TON of 3.4 was recorded for hydrogen evolution. $\mathrm{Ni}\left(\mathrm{L}^{2}\right)_{2}$ was found to be an active electrocatalyst for dihydrogen oxidation with maximum turnover frequency of $19 \mathrm{~s}^{-1}$ at an overpotential of $0.33 \mathrm{~V}$. The mechanism for HER with $\mathrm{Ni}\left(\mathrm{L}^{1}\right)_{2}$ was proposed to be ECEC or CEEC type. The mechanism for HOR still remains unresolved but believed to proceed through a radical species formed after the oxidation of $\mathrm{Et}_{3} \mathrm{~N}$. 


\section{CHAPTER IV \\ ELECTROCATALYTIC HYDROGEN EVOLUTION REACTION WITH BIS(THIOSEMICARBAZONATO)NI (II) COMPLEX}

\subsection{Background}

Recently, our lab reported electrocatalytic hydrogen evolution with $\mathrm{Zn}(\mathrm{II})$ and $\mathrm{Cu}(\mathrm{II})$ by employing redox active bis(thiosemicarbazone) ligands. This chapter details the study of the evolution of hydrogen with a bis(thiosemicarbazonato) Ni(II) complex. The synthesis of these systems is comparatively convenient as compared to one described in Chapter 3 as the ligand synthesis can be done under aerobic conditions using cheap and easily available starting materials.

Bis(thiosemicarbazone) complexes, which have been known for more than 50 years, are a class of Schiff base systems generated from the elimination reaction between thiosemicarbazides and diones in the presence of catalytic amounts of acid at room temperature, Figure 4.1. ${ }^{60}$ Bis(thiosemicarbazones) and their metal complexes have been extensively studied for their biological activities including ant-viral, anti-cancer, and antimalarial. ${ }^{14-115}$ The radiolabeled $\mathrm{Cu}(\mathrm{II})$ complex, $\mathrm{CuL}^{3}$, has been explored as an imaging agent to locate the hypoxic tissues for PET studies. ${ }^{116}$ This has been attributed to the easy transport of $\mathrm{Cu}(\mathrm{II})$ complex through the cells while the reduced $\mathrm{Cu}(\mathrm{I})$ species gets trapped inside the cell under low oxygen amounts. $\mathrm{CuL}^{3}$ has also been evaluated for its therapeutic use for Parkinson's disease in various animal studies. ${ }^{117} \mathrm{Cu}$ (II) complexes with modified 
ligand glyoxalbis[N4-methylthiosemicarbazonato] has been found to increase cellular metabolism is observed in the mice cells. ${ }^{117}$ Additionally, the $\mathrm{Zn}(\mathrm{II})$ complex, $\mathrm{ZnL}{ }^{3},\left(\mathrm{~L}^{3}=\right.$ diacetyl-bis(N-4-methyl-3-thiosemicarbazonato) has been found to have fluorescent properties. $^{118}$
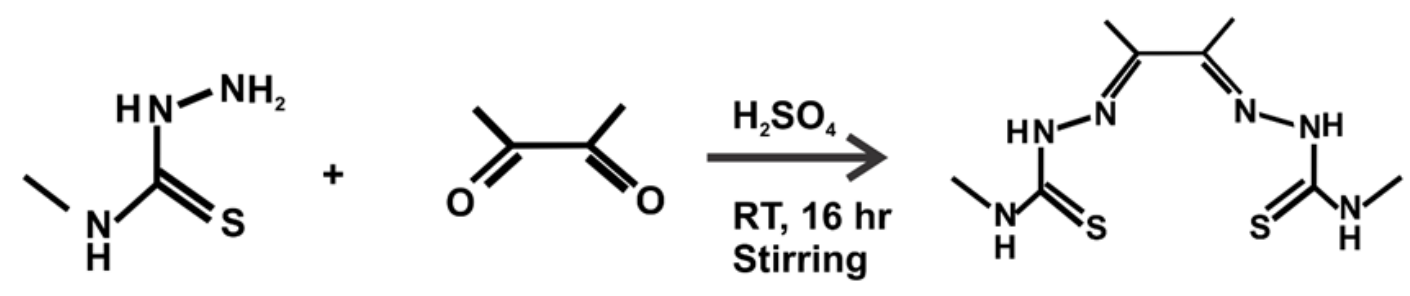

$\mathbf{H}_{2} \mathbf{L}^{3}$

Figure 4.1 Schematic representation of synthesis of ligand diacetyl-bis(N-4-methyl-3thiosemicarbazonate), $\mathrm{H}_{2} \mathrm{~L}^{3}$.

Bis(thiosemicarbazone) are redox active ligands that provide a tetradentate, square planar $\mathrm{N}_{2} \mathrm{~S}_{2}$ coordination sphere. The soft donors impart stability to the lower oxidation states of the metals like zinc, copper and nickel. ${ }^{119-123}$ The redox non-innocence of the ligand is attributed to the reduction of the terminal $\alpha$-diimine unit into a $\pi$-radical anion. ${ }^{123-}$ 124

\subsubsection{Hydrogen evolution reaction with $\mathrm{ZnL}^{3}$ and $\mathrm{CuL}^{3}$}

Present work in our group focuses on the exploitation of the redox non-innocence of the bis(thiosemicarbazone) ligands for their electrocatalytic ability to generate hydrogen using external acid source in organic solvents. $\mathrm{ZnL}^{3}$ and $\mathrm{CuL}^{3}$ has been found to be active electrocatalysts for hydrogen evolution reactions, Figure $4.2 .{ }^{125-126} \mathrm{ZnL}^{3}$ represents the example of the transition metal free active catalyst for hydrogen evolution reaction under homogenous conditions. 

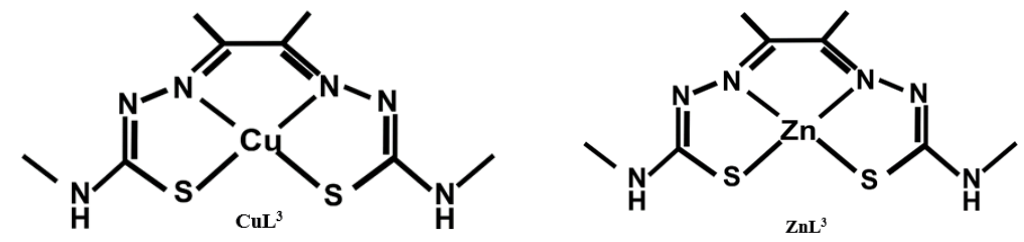

Figure 4.2 Structural representation of diacetyl-bis(N-4-methyl-3-thiosemicarbazonato) zinc(II), $\mathrm{ZnL}^{3}$ and diacetyl-bis(N-4-methyl-3-thiosemicarbazonato) copper(II), $\mathrm{CuL}^{3}$ complexes.

The HER activity of $\mathrm{ZnL}^{3}$ is attributed to a ligand centered mechanism. ${ }^{125}$ With acetic acid as a proton source in methanol solutions, $\mathrm{ZnL}$ is found to evolve hydrogen with the maximum TOF of $1170 \mathrm{~s}^{-1}$ at an overpotential of $756 \mathrm{mV}$. In acetonitrile solutions, $\mathrm{ZnL}^{3}$ operates to evolve hydrogen with the TOF of $1170 \mathrm{~s}^{-1}$ at a higher overpotential of 1.07 $\mathrm{V}$ with an acid independent regime is observed above $23 \mathrm{mM}$ of acetic acid concentrations. The lower value of overpotential recorded in methanol solutions is attributed to easier ligand protonation before the reduction step which due to the proton shuttling on the outer coordination sphere in $\mathrm{ZnL}^{3} .{ }^{127}$ The HER catalysis is second-order in catalyst and second order with respect to acetic acid concentration. Kinetic isotope effect studies performed using deuterated acetic acid $\mathrm{CD}_{3} \mathrm{COOD}$ gave a value of 1.2 which is inconsistent with values reported for metal hydrides. The catalyst displayed 37 turnovers over 2.5 hours at a constant potential of $-1.7 \mathrm{~V}$ with a minimum faradaic efficiency of 85 $\%$.

The HER mechanism for $\mathrm{ZnL}^{3}$ is evaluated using density functional theory calculations by employing the B97D functional with the $6311 \mathrm{~g}(\mathrm{~d})$ basis set. The proposed mechanism involves protonation and reduction at the ligand center giving rise to radical species $\left(\mathrm{ZnHL}^{3} \cdot\right)$, Figure 4.3. Homocoupling of two molecules of $\left(\mathrm{ZnHL}^{3} \cdot\right)$ in the later step, generates hydrogen evolving complex $\left[\mathrm{Zn}_{2}\left(\mathrm{HL}^{3} \cdot\right)_{2}\right]$. Homolytic cleavage of the $\mathrm{N}-\mathrm{H}$ bonds 
leads to the evolution of hydrogen, giving back two molecules of $\mathrm{ZnL}^{3}$ catalyst. A parallel route of the mechanism is proposed to be heterocoupling of $\left(\mathrm{ZnHL}^{3} \cdot\right)$ and $\left[\mathrm{Zn}\left(\mathrm{H}_{2} \mathrm{~L}^{3}\right)\right]^{+}$ yielding $\left[\mathrm{Zn}_{2}\left(\mathrm{H}_{3} \mathrm{~L}^{3} \cdot\right)_{2}\right]^{+}$which than evolves hydrogen in the next step and gives back $\mathrm{ZnL}^{3}$.

$\mathrm{ZnL}^{3}$ is also screened for its ability to cleave dihydrogen molecule in the presence of external base triethylamine in methanolic solutions and is found to catalyze hydrogen oxidation reaction with a TOF of $72 \mathrm{~s}^{-1}$ under $1 \mathrm{~atm}$. of $\mathrm{H}_{2}$ on the addition of triethylamine. The overpotential recorded for $\mathrm{HOR}$ with $\mathrm{ZnL}^{3}$ is $310 \mathrm{mV}$.

The metal free bis(thiosemicarbone) ligand $\mathrm{H}_{2} \mathrm{~L}^{3}$ is also investigated for HER and HOR. When analyzed under acidic conditions in methanolic solutions, $\mathrm{H}_{2} \mathrm{~L}^{3}$ is found to evolve hydrogen with TOF of $1320 \mathrm{~s}^{-1}$ at an overpotential of $1430 \mathrm{mV}$. For HOR, $\mathrm{H}_{2} \mathrm{~L}^{3}$ displays a TOF of $32 \mathrm{~s}^{-1}$ with an overpotential of $330 \mathrm{mV}$ under $1 \mathrm{~atm}$. of hydrogen. ${ }^{128}$

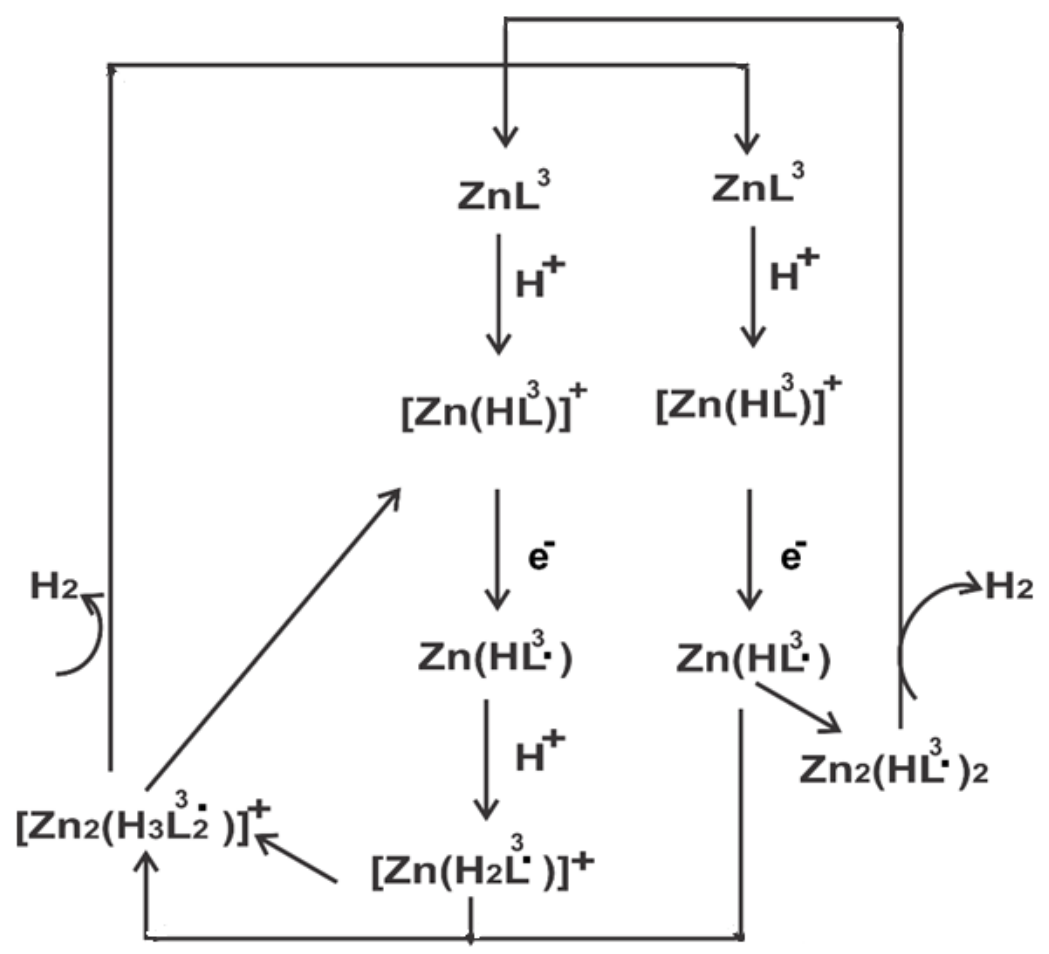

Figure 4.3 Postulated ligand centered mechanism for hydrogen evolution reaction with $\mathrm{ZnL}^{3} .{ }^{125}$ 
In addition to $\mathrm{ZnL}^{3}$, the neutral, monomeric $\mathrm{Cu}$ (II) complex, $\mathrm{CuL}^{3}$, is also screened for HER activity in acetonitrile and dimethylformamide solutions. ${ }^{126}$ In acetonitrile solutions, a maximum TOF of $9,900 \mathrm{~s}^{-1}$ is reported at an overpotential of $0.80 \mathrm{~V}$. In dimethylformamide solutions, $\mathrm{CuL}^{3}$ is found to evolve hydrogen electrocatalytically with TOF of $5140 \mathrm{~s}^{-1}$ with an overpotential of $0.76 \mathrm{~V}$. The maximum TON of 73 is recorded by performing by the controlled potential electrolysis at a potential of $-1.65 \mathrm{~V}$ vs ferrocenium/ferrocene in acetonitrile solutions for 3.6 hours. While the same TON of 73 is determined in dimethylformamide solutions when the electrolysis is performed for 23.4 hours. To gain further insights into the HER mechanism, the H/D kinetic isotope effect (KIE) is evaluated and KIE of 7.54 is recorded which is consistent with ligand centered activity. ${ }^{51}$ The catalyst displays first-order dependence on the catalyst concentration and second-order dependence on the acid concentration.

To elucidate the HER mechanism for $\mathrm{CuL}^{3}$, density functional theory calculations using B3LYP functional and the 6-311 $\mathrm{g}(\mathrm{d}, \mathrm{p})$ basis set were performed. The mechanism for HER with $\mathrm{CuL}^{3}$ is proposed to be CECE type, Figure 4.4. The first step involves the ligand centered protonation at hydrazine nitrogen generating cationic species $\left[\mathrm{CuL}^{3} \mathrm{H}\right]^{+}$. In the second step, metal centered reduction takes place that yields the neutral $\mathrm{Cu}(\mathrm{I})$ species $\left[\mathrm{CuL}^{3} \mathrm{H}\right]$. This is followed by the protonation on the second hydrazino nitrogen generating $\left[\mathrm{CuL}^{3} \mathrm{H}_{2}\right]^{+}$. In the next step, electron reduction at the ligand center gives neutral species, $\left[\mathrm{CuL}^{3} \mathrm{H}_{2}\right]$. The radical on the nitrogen induces the tautomeric arrangement of the proton leading to the coordination of the protons on the adjacent nitrogens in the hydrogen evolving complex. In the final step of the mechanism, the evolution of hydrogen takes place and generation of $\mathrm{CuL}^{3}$ complex takes place. $\mathrm{CuL}^{3}$ system demonstrates the metal-assisted 
ligand-centered reactivity for hydrogen evolution where metal center is acting as an electron reservoir to facilitate the catalysis at the redox active ligand framework. ${ }^{128}$

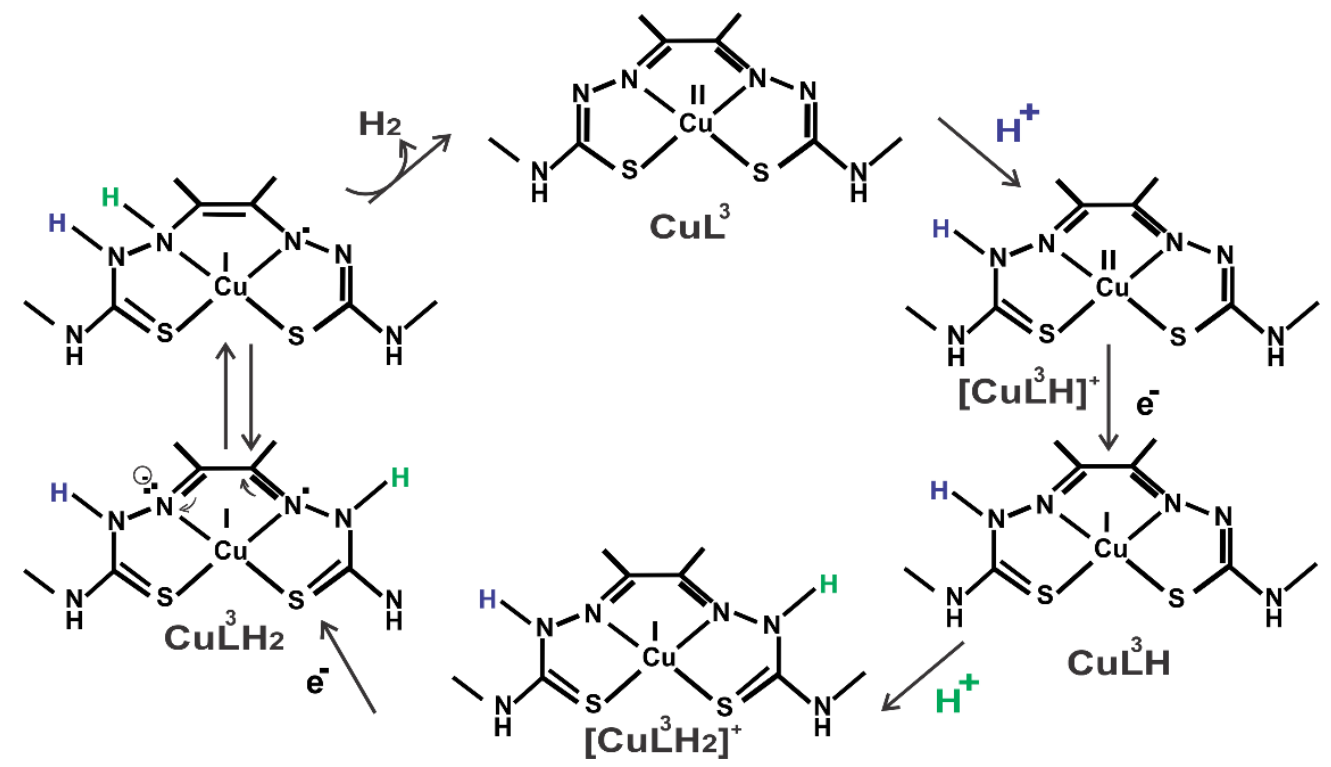

Figure 4.4 Proposed metal assisted ligand centered mechanism for hydrogen evolution reaction with $\mathrm{CuL}^{3}{ }^{126}$

\subsubsection{Hydrogen evolution reaction with NiL: Straistari's catalyst}

In addition to the $\mathrm{Zn}(\mathrm{II})$ and $\mathrm{Cu}(\mathrm{II})$ complexes of diacetyl-bis(N-4-methyl-3thiosemicarbazonato) studied by our group, Straistari reported HER activity on the neutral, monomeric $\mathrm{Ni}(\mathrm{II})$ bis(thiosemicarbazonato) complex, $\mathrm{NiL} \quad[\mathrm{L}=4-\{$ bis $(4-(\mathrm{p}-$ methoxyphenyl)-thiosemicarbazonato)\}-2,3-butane], Figure $4.5^{129}$ The reported ligand, $\mathrm{H}_{2} \mathrm{~L}$ has been synthesized differently than diacetyl-bis(N-4-methyl-3thiosemicarbazonate), $\mathrm{H}_{2} \mathrm{~L}^{3}$ described above. $\mathrm{H}_{2} \mathrm{~L}$ has been obtained by the refluxing 2,3dihydrazide-butane with two equivalents of 1-isothiocyanato-4-methoxy-benzene in ethanolic solutions. 


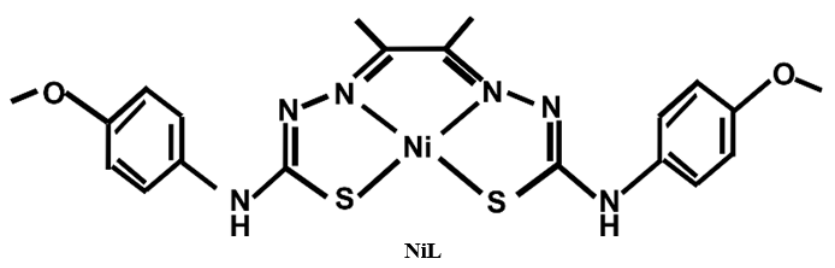

Figure 4.5 Structural representation of [4-\{bis(4-(p-methoxyphenyl)-thiosemicarbazonato) $\}-2,3-$ butane] $\mathrm{Ni}(\mathrm{II})$ complex NiL. ${ }^{129}$

$\mathrm{NiL}$ is found to evolve hydrogen in the dimethylformamide solution with trifluoroacetic acid as an external acid. The turnover frequency of $3080 \mathrm{~s}^{-1}$ is recorded at an overpotential of $0.4 \mathrm{~V}$. At a constant potential of $-1.2 \mathrm{~V}$ controlled potential coulometry is performed for 16 hours and a faradaic efficiency of $80 \%$ is determined with a TON of 21. Mechanistic details were elucidated using density functional theory calculations using BP86 functional and TZV/P basis set. The mechanism for HER is proposed to be ECEC type in which the first step is the ligand-centered reduction followed by the protonation at the coordinated nitrogen. In the next step, reduction at the metal center takes place thus, generating $\mathrm{d}^{9} \mathrm{Ni}(\mathrm{I})$. In the later step after reduction, the protonation occurs at the $\mathrm{Ni}(\mathrm{I})$ center thus yielding Ni(III)-H species. This species is considered as the catalytically active moiety to evolve hydrogen. NiL is believed to follow the ligand assisted metal centered catalysis in which the redox active ligand is facilitating the chemistry to takes place at the active metal center, Figure 4.6. 


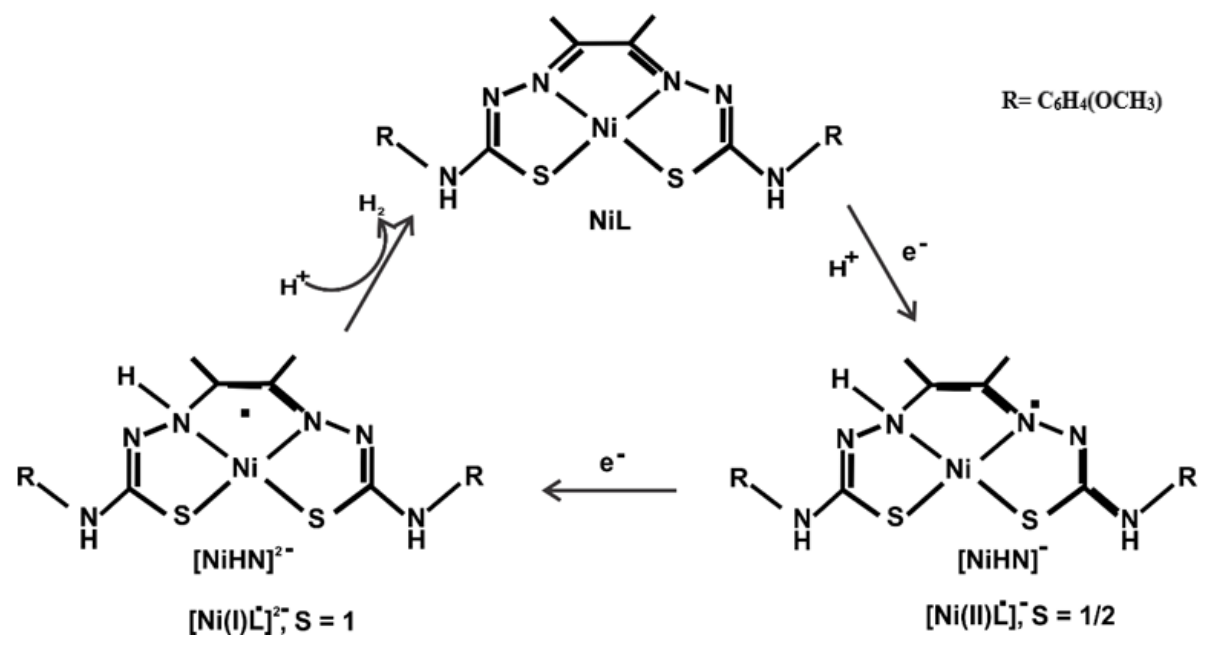

Figure 4.6 Proposed hydrogen evolution reaction mechanism with NiL. ${ }^{129}$

\subsection{Synthesis and characterization of $\mathrm{NiL}^{3}$}

Analogous to the $\mathrm{ZnL}^{3}$ and $\mathrm{CuL}^{3}$ complexes described above, the neutral, monomeric Ni(II) complex, $\mathrm{NiL}^{3}$, Figure 4.7 is evaluated for its ability to evolve hydrogen. The dark green $\mathrm{NiL}^{3}$ complex is synthesized in the methanolic solutions of nickel acetate and $\mathrm{H}_{2} \mathrm{~L}^{3}$ as described in Chapter 2 of this dissertation. The identity is confirmed by ${ }^{1} \mathrm{H}$ NMR in $\mathrm{d}_{6}$-DMSO and FT-IR spectrum collected on the solid powdered sample using ATR attachment. The single crystal $\mathrm{x}$-ray structure of $\mathrm{NiL}^{3}$ is previously reported by Dilworth. ${ }^{90}$

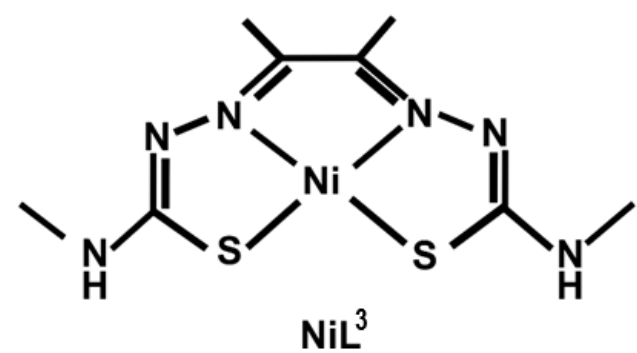

Figure 4.7 Structural representation of diacetyl-bis(N-4-methyl-3-thiosemicarbazonato) $\mathrm{Ni}(\mathrm{II})$, $\mathrm{NiL}^{3}$. 


\subsection{Electrochemical studies}

Cyclic voltammograms (CVs) of $0.30 \mathrm{mM} \mathrm{NiL}^{3}$ in dimethylformamide solutions, Figure 4.8 containing $0.1 \mathrm{M}$ tetrabutylammonium hexafluorophosphate as a supporting electrolyte were collected. On sweeping the potential in the cathodic region two quasireversible peaks and one irreversible peak were observed in the region from 0 to $-2.5 \mathrm{vs}$ $\mathrm{Fc}^{+} / \mathrm{Fc}$. The first reduction event observed at $-1.55 \mathrm{~V} \mathrm{vs} \mathrm{Fc}^{+} / \mathrm{Fc}^{0}$ is assigned to the ligand centered reduction, the second reduction event is assigned to the $\mathrm{Ni}^{\mathrm{I} / \mathrm{I}}$ reduction at $-2.18 \mathrm{~V}$ vs $\mathrm{Fc}^{+} / \mathrm{Fc}^{0}$. CVs were collected at scan rates from 100 to $500 \mathrm{mV} / \mathrm{s}$ and an increase in the current is reported. The diffusion limited regime of the ligand-centered and $\mathrm{Ni}^{\mathrm{I} / \mathrm{I}}$ reduction is established and increase in the peak current respect with respect to the potential is plotted. The resulting Cottrell plots gave the diffusion coefficient of $2.74 \times 10^{-5} \mathrm{~cm}^{2} / \mathrm{s}$ in dimethylformamide solutions using Randles- Sevcik equation. ${ }^{62}$

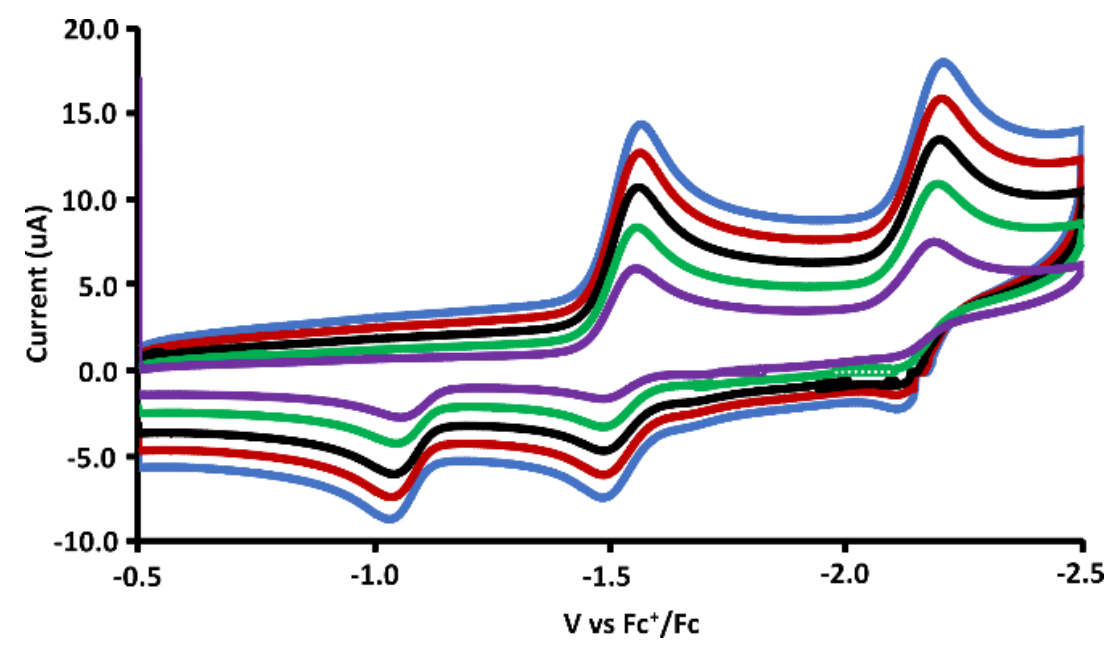




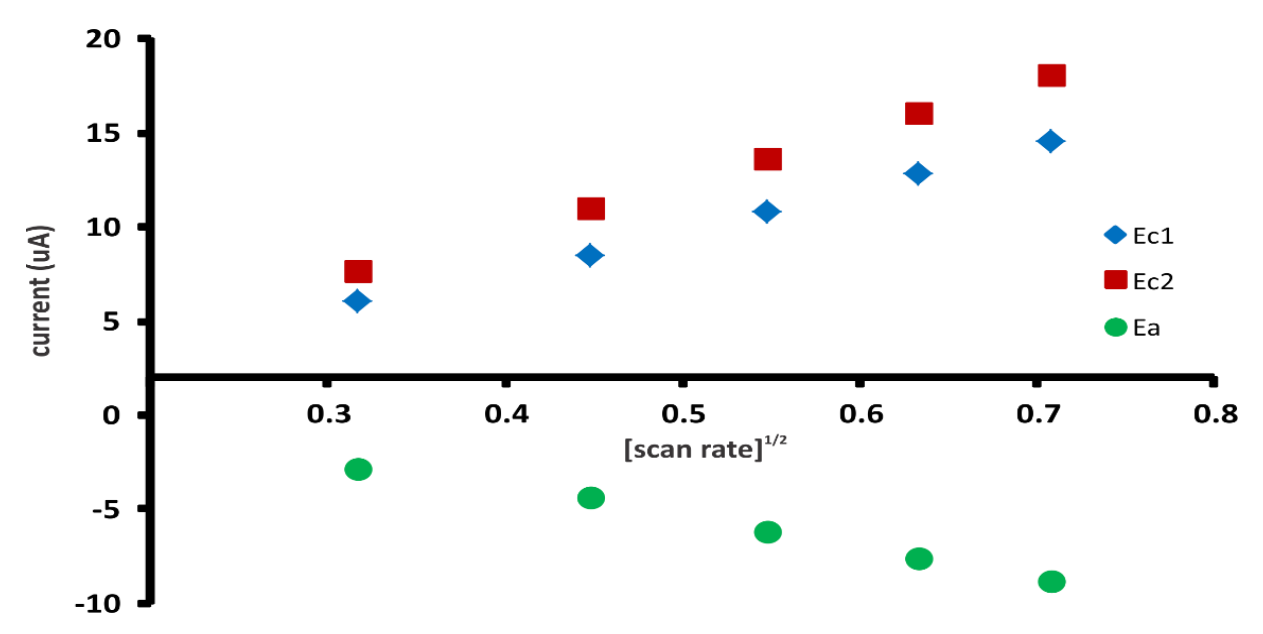

Figure 4.8 Cyclic voltammograms of $0.30 \mathrm{mM} \mathrm{NiL}^{3}$ in $25 \mathrm{ml}$ dimethylformamide solution collected at scan rates from 100-500 mV/s (top). Plot of the peak current vs square root of scan rate collected from scan rates from 100-500 mV/s (bottom).

\subsection{Hydrogen evolution reactions with $\mathrm{NiL}^{3}$}

Hydrogen evolution reactions with $\mathrm{NiL}^{3}$ has been studied using acetic acid and trifluoracetic acid as an external proton source in acetonitrile and dimethylformamide solutions. In acetonitrile, $\mathrm{NiL}^{3}$ is found to have higher catalytic activity as compared to dimethylformamide solutions. The recorded results are explained below.

\subsubsection{Electrocatalytic hydrogen evolution reaction with $\mathrm{NiL}^{3}$ with acetic acid in acetonitrile solutions}

To evaluate the HER, acetic acid is added as a proton source to $0.30 \mathrm{mM}$ acetonitrile solutions of $\mathrm{NiL}^{3}$ and CVs were at three different scan rates of 200,500 and $1000 \mathrm{mv} / \mathrm{s}$ for acid dependent studies. An increase in the cathodic current is observed at a potential of $2.20 \mathrm{~V} \mathrm{vs} \mathrm{Fc}^{+} / \mathrm{Fc}^{0}$ at a scan rate of $500 \mathrm{mV} / \mathrm{s}$. The catalytic current is found to be acidindependent at an acetic acid concentration above $12.60 \mathrm{mM}$, Figure 4.9. Upon establishing the acid independent region at these scan rates, CVs were recorded at higher scan rates in 
order to establish the scan rate independent region. At a scan rate of $7000 \mathrm{mV} / \mathrm{s}$, the cathodic current is found to be independent of the scan rate where catalytic current $\left(i_{c}\right)$ of $2.32 \mathrm{~mA}$ is recorded. The TOF of $4161 \mathrm{~s}^{-1}$ is recorded at a scan rate of $7000 \mathrm{mV} / \mathrm{s}$ using foot-of-the-wave analysis described in Chapter 2. The overpotential of $0.52 \mathrm{~V}$ is determined. ${ }^{66}$

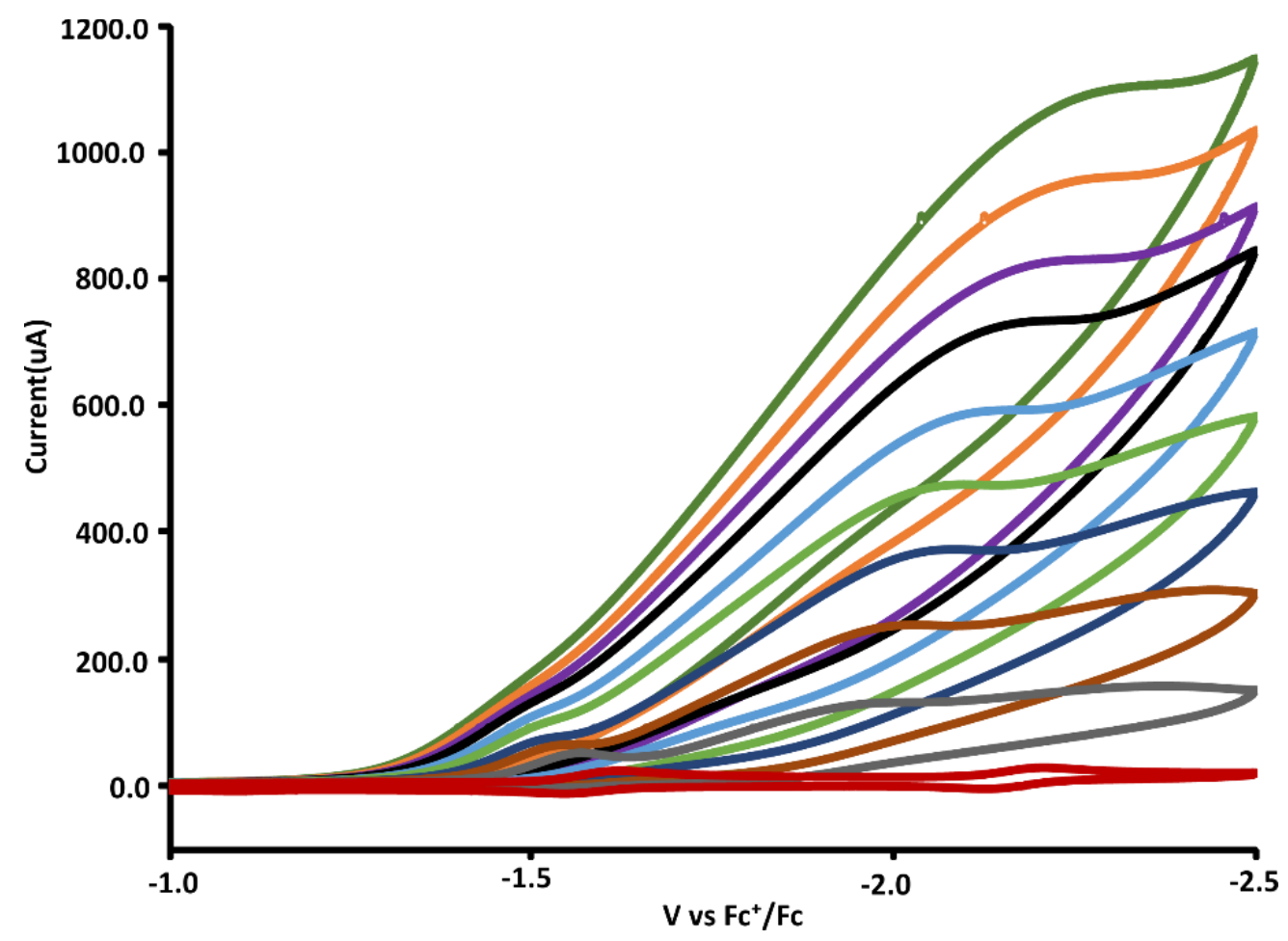

Figure 4.9 Cyclic voltammograms of $0.30 \mathrm{mM} \mathrm{NiL}^{3}$ in $25 \mathrm{ml}$ acetonitrile solution collected at scan rate of $500 \mathrm{mV} / \mathrm{s}$ with the increasing acetic acid concentrations of $0,1.4,2.8,4.2,5.6,7.0,8.4,9.8$, $11.2,12.6 \mathrm{mM}$ (top).

\subsubsection{Electrocatalytic hydrogen evolution reaction with $\mathrm{NiL}^{3}$ with acetic acid in dimethylformamide solutions}

The catalytic activity of $\mathrm{NiL}^{3}$ using acetic acid is also accessed in dimethylformamide solutions. An increase in the cathodic current at a potential of $-2.32 \mathrm{~V}$ 
vs $\mathrm{Fc}^{+} / \mathrm{Fc}^{0}$ is recorded with the successive additions of acetic acid at scan rates of 200,500 and $1000 \mathrm{mV} / \mathrm{s}$. The catalytic current becomes dependent of the acid concentration at an acid concentration of $9.80 \mathrm{mM}$, Figure 4.10. Using FOWA, at higher scan rate of 5000 $\mathrm{mV} / \mathrm{s}$, where the current demonstrates scan rate independence, a TOF of $1196 \mathrm{~s}^{-1}$ is calculated at an overpotential of $0.55 \mathrm{~V}$. The increase in the catalytic current shows the second-order dependence with respect to the acid concentration.

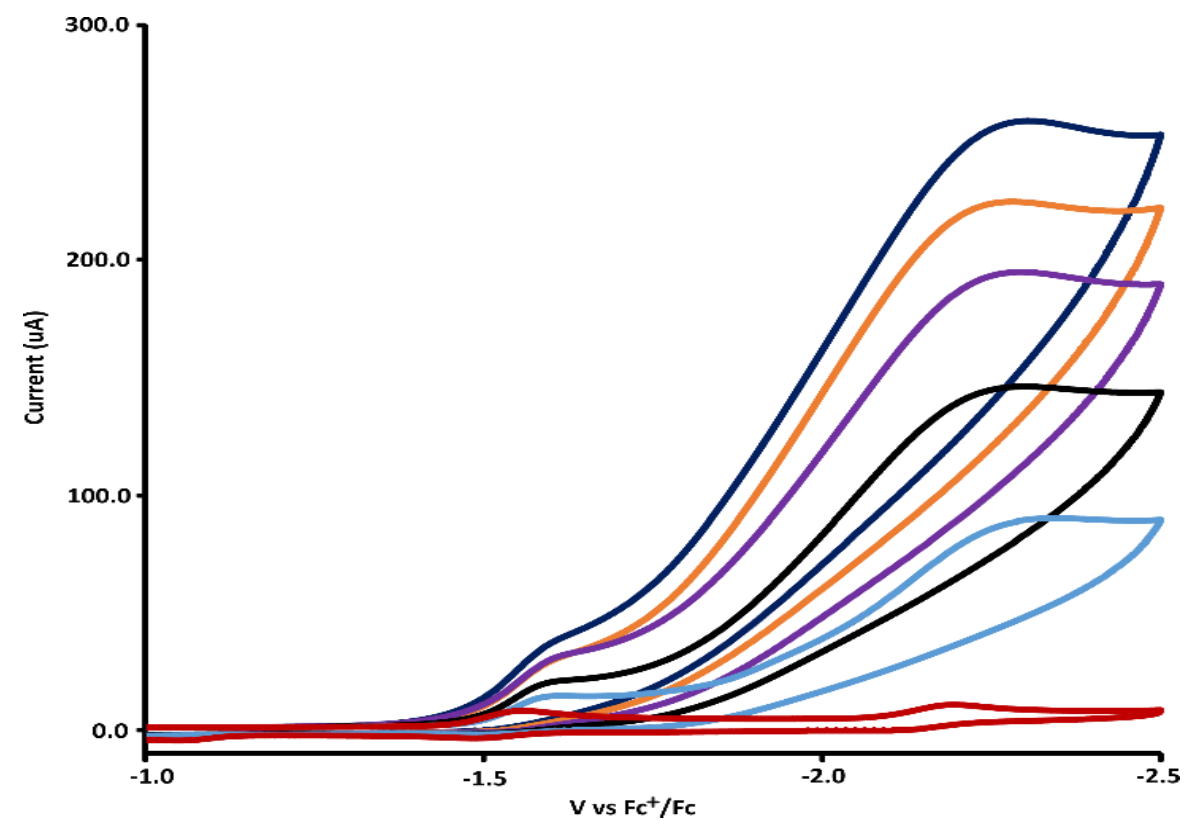

Figure 4.10 Cyclic voltammograms of $0.30 \mathrm{mM} \mathrm{NiL}^{3}$ in $25 \mathrm{ml}$ dimethylformamide solution collected at scan rate of $200 \mathrm{mV} / \mathrm{s}$ with the increasing acetic acid concentrations of $0,4.2,5.6,7$, 8.4, $9.8 \mathrm{mM}$ (top).

\subsubsection{Electrocatalytic hydrogen evolution reaction with $\mathrm{NiL}^{3}$ with trifluoroacetic acid in acetonitrile solutions}

The catalytic activity of $\mathrm{NiL}^{3}$ is also accessed using stronger acid trifluoroacetic acid in acetonitrile. In acetonitrile solutions, an increase in the cathodic current at $-2.11 \mathrm{~V}$ vs $\mathrm{Fc}^{+} / \mathrm{Fc}^{0}$ is attributed to the catalytic reduction and the current becomes independent of 
the acid concentration at an acid concentration of $18.0 \mathrm{mM}$, Figure 4.11. The TOF of 1324 $\mathrm{s}^{-1}$ is recorded at a scan rate of $7000 \mathrm{mV} / \mathrm{s}$. The second order dependence on acid concentration is found when $i_{d} i_{p}$ is plotted with respect to the acid concentration. The overpotential of $0.67 \mathrm{~V}$ is recorded using trifluoroacetic acid in acetonitrile solutions.

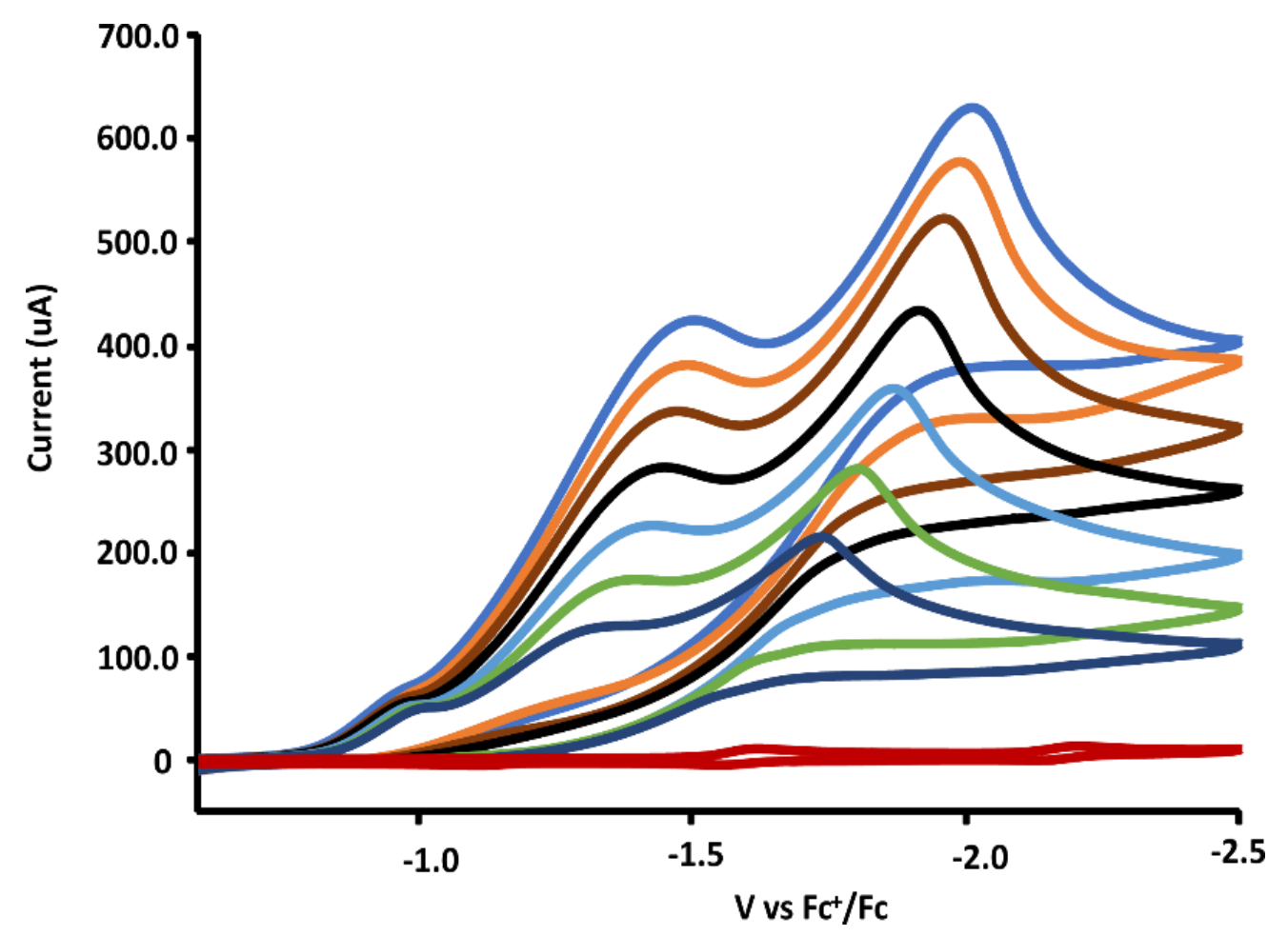

Figure 4.11 Cyclic voltammograms of $0.30 \mathrm{mM} \mathrm{NiL}^{3}$ in $25 \mathrm{ml}$ acetonitrile solution collected at scan rate of $200 \mathrm{mV} / \mathrm{s}$ with the increasing trifluoroacetic acid concentrations of $0,6,8,10,12,14$, $16,18 \mathrm{mM}$ (top).

\subsubsection{Electrocatalytic hydrogen evolution reaction with $\mathrm{NiL}^{3}$ with trifluoroacetic acid in dimethylformamide solutions}

When analyzed in dimethylformamide solutions, catalytic current is observed at $1.80 \mathrm{vs} \mathrm{Fc}^{+} / \mathrm{Fc}^{0}$, upon the addition of trifluoroacetic acid. The acid-independent region is 
observed at an acid concentration of $32.0 \mathrm{mM}$, Figure 4.12 . The TOF of $115 \mathrm{~s}^{-1}$ is recorded at scan rate of $5000 \mathrm{mV} / \mathrm{s}$. The second-order acid dependence is established.

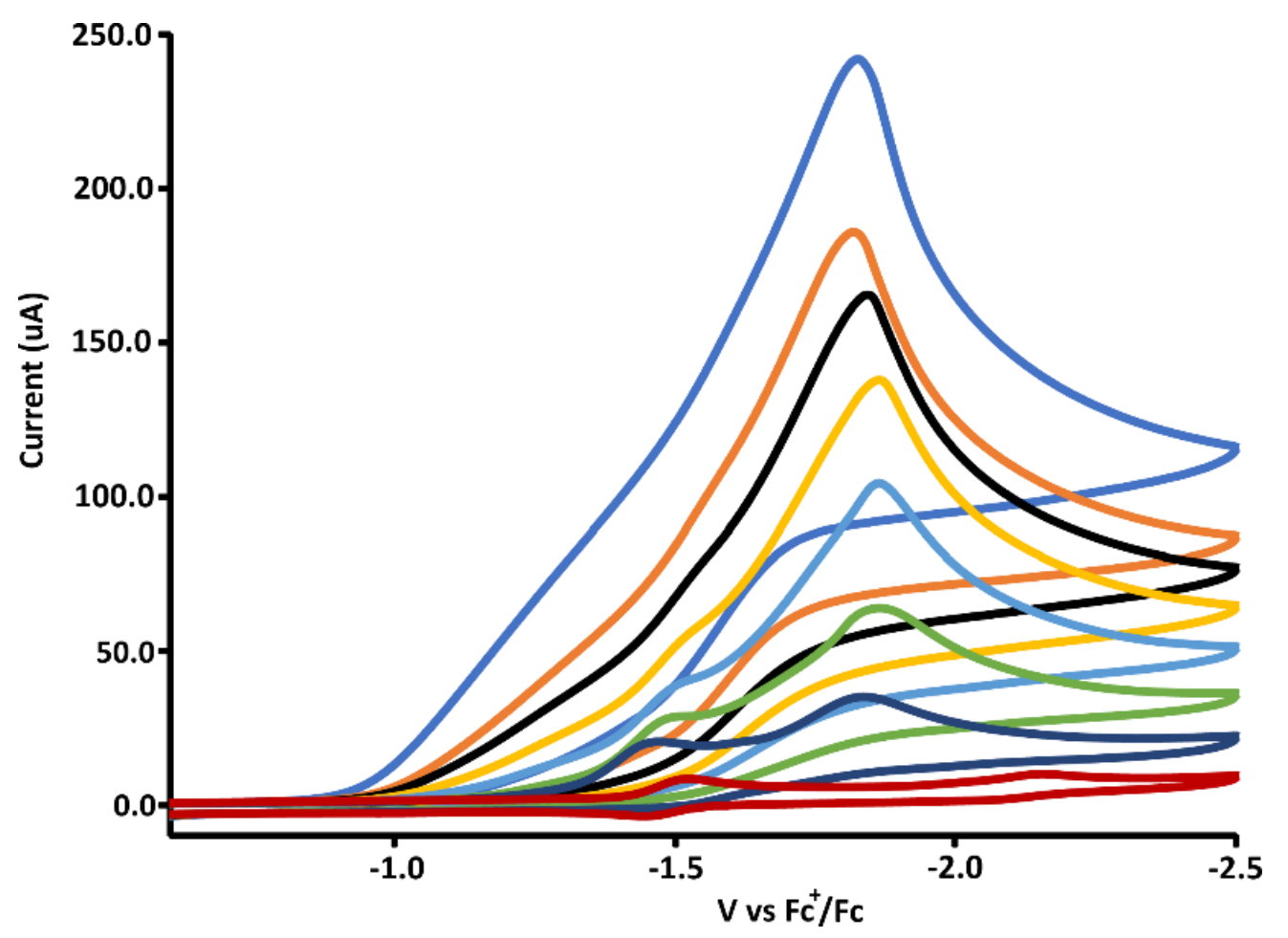

Figure 4.12 Cyclic voltammograms of $0.30 \mathrm{mM} \mathrm{NiL}^{3}$ in $25 \mathrm{ml}$ dimethylformamide solution collected at scan rate of $200 \mathrm{mV} / \mathrm{s}$ with the increasing trifluoroacetic acid concentrations of $0,4,8$, $12,16,20,24,32 \mathrm{mM}$ (top).

Control experiments performed in the absence of $\mathrm{NiL}^{3}$ with acetic acid and trifluoracetic acid in acetonitrile and dimethylformamide solutions showed no significant current at corresponding catalytic potentials mentioned above. CVs were also collected by taking the working electrode (glassy carbon electrode) out of the solution after performing the acid dependent studies. Glassy carbon electrode is then polished with the working solvent and is used again with the fresh solutions containing acid and electrolyte. The 
absence of any catalytic current indicates that there is no adsorbed species or any degraded product on the electrode surface is deposited that might be responsible for catalytic current. This indicates that the catalytic increment observed is entirely obtained from homogenous solutions (see appendix for CVs of control experiments).

The robustness of the catalyst $\mathrm{NiL}^{3}$ is evaluated using controlled potential coulometry (CPC) experiments for 18 hours. The experiments were conducted in acetonitrile and dimethylformamide solutions using acetic acid and trifluoroacetic acid. In acetonitrile solutions containing $0.1 \mathrm{M} \mathrm{Bu}_{4} \mathrm{NPF}_{6}, \mathrm{CPC}$ experiment is performed $0.30 \mathrm{mM}$ $\mathrm{NiL}^{3}$ and $12.60 \mathrm{mM}$ acetic acid. The potential is hold at $-1.75 \mathrm{vs} \mathrm{Fc}^{+} / \mathrm{Fc}^{0}$. The TON of 159 is calculated based on the total charge of $92 \mathrm{C}$., Figure 4.13. Similar studies using $18.0 \mathrm{mM}$ trifluoroacetic acid with $0.30 \mathrm{mM} \mathrm{NiL}{ }^{3}$ in acetonitrile solutions at an applied potential of $1.32 \mathrm{vs} \mathrm{Fc}^{+} / \mathrm{Fc}^{0}$ for 18 hours yielded a TON of 63 based on the total charge of $36 \mathrm{C}$.

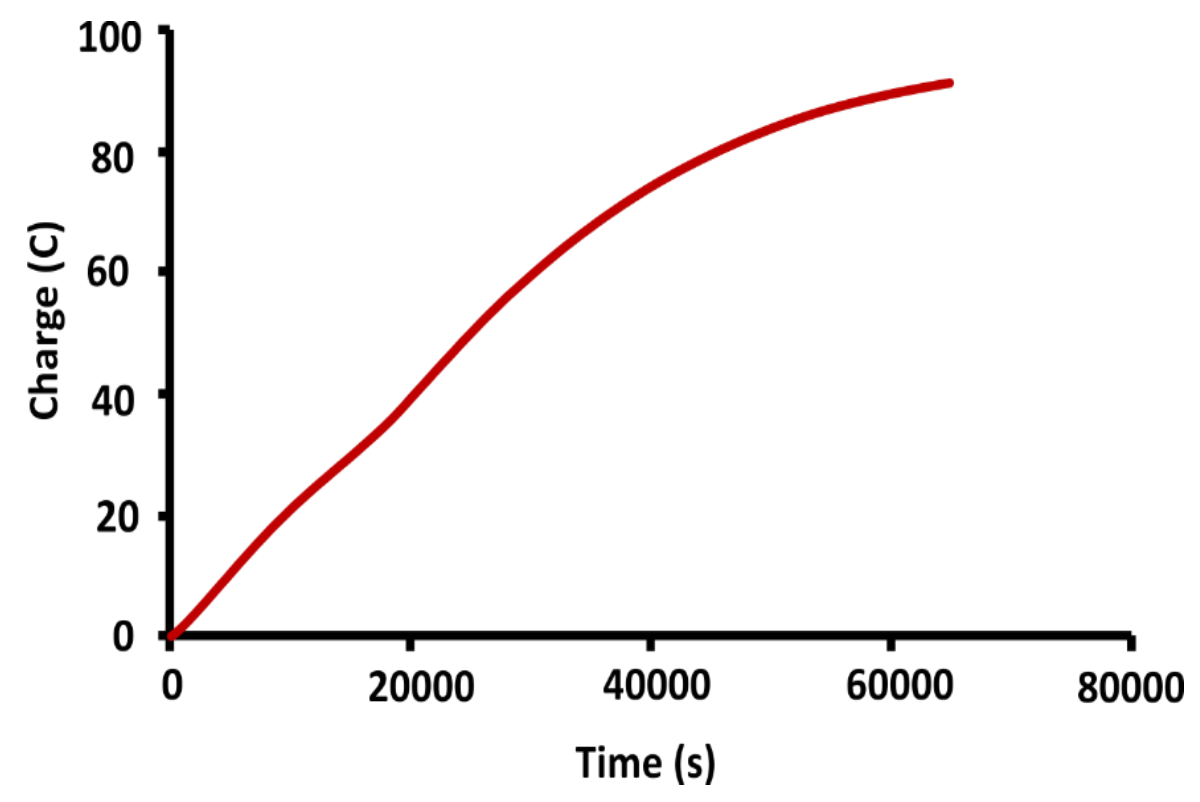

Figure 4.13 Controlled potential coulometry of $0.30 \mathrm{mM} \mathrm{NiL}^{3}$ in $0.1 \mathrm{M} \mathrm{Bu}_{4} \mathrm{NPF}_{6}$ with $12.6 \mathrm{mM}$ acetic acid added in acetonitrile solutions. 
In dimethylformamide solution containing $0.1 \mathrm{M} \mathrm{Bu}_{4} \mathrm{NPF}_{6}$, the $\mathrm{CPC}$ experiment is performed at a constant potential of $-1.95 \mathrm{vs} \mathrm{Fc}^{+} / \mathrm{Fc}^{0}$ using $0.30 \mathrm{mM} \mathrm{NiL}$ and $9.80 \mathrm{mM}$ acetic acid. The total charge of $37 \mathrm{C}$ is obtained over the period of 18 hours which accounted for the TON of 64. Similar results were obtained using $0.30 \mathrm{mM} \mathrm{NiL}^{3}$ at a constant potential of $-1.48 \mathrm{vs} \mathrm{Fc}^{+} / \mathrm{Fc}^{0}$ using $32 \mathrm{mM}$ trifluoroacetic acid in dimethylformamide solution, the charge of $23 \mathrm{C}$ is obtained which accounted for the total TON of 40 .

\subsection{Mechanistic studies}

To evaluate the mechanism of HER with $\mathrm{NiL}^{3}$ catalyst dependence, acid dependence, kinetic isotope effect and DFT studies were carried out, that has been described below.

\subsubsection{Catalyst dependent studies at a fixed acid concentration in acetonitrile solutions}

The order of the reaction is determined with respect to the concentration of the catalyst. At fixed acetic acid concentration of $12.6 \mathrm{mM}$ in acetonitrile solutions, the concentration of $\mathrm{NiL}^{3}$ is varied, and the catalytic current is recorded at different catalyst concentrations of $0.125 \mathrm{mM}, 0.25 \mathrm{mM}, 0.50 \mathrm{mM}$ and $1.00 \mathrm{mM}$. When the cathodic current obtained is plotted against the catalyst concentration, a linear relationship is established. This corresponds to the first-order dependence on the concentration of the catalyst, Figure 4.14 . 


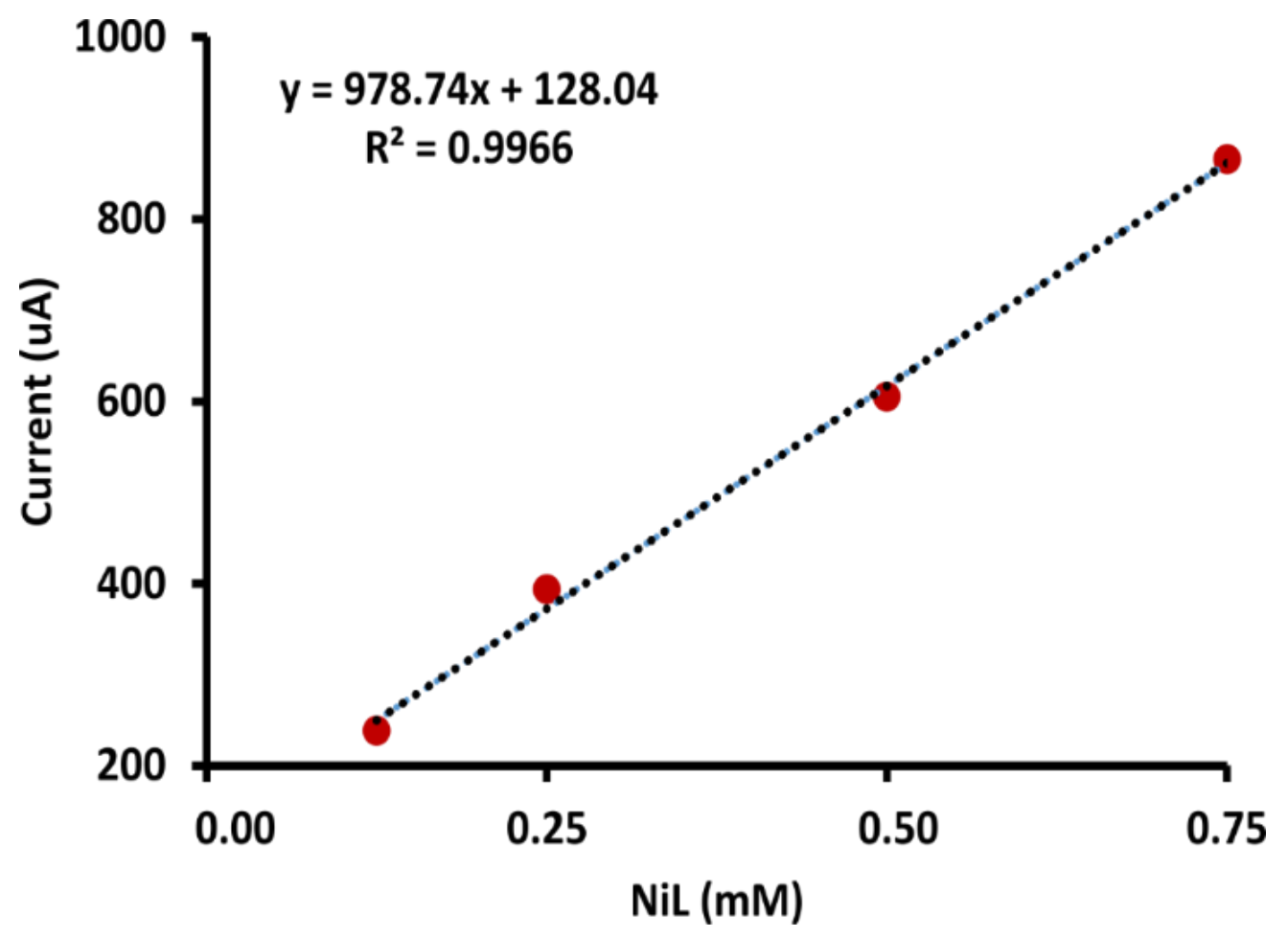

Figure 4.14 Catalyst dependence studies. Plot of catalytic current catalyst concentration at a constant acid concentration of $12.6 \mathrm{mM}$ in acetonitrile solutions.

\subsubsection{Acid dependent studies in acetonitrile solutions}

The order of the reaction with respect to acid is obtained by plotting the $i_{c a t} / i_{p}$ with respect to the acid concentrations. The values of $i_{c a t}$ is obtained by the cyclic voltammograms recorded under different acid concentrations. Herein, we report the acid dependent studies with acetic acid and trifluoroacetic acid in acetonitrile and dimethylformamide solutions. In all the cases, the second-order dependence with respect to acid is recorded. Figure 4.15 shows the plot of acid dependent studies with acetic acid in acetonitrile solutions at $500 \mathrm{mV} / \mathrm{s}$. Figure 4.16 shows the plot of acid dependent studies with acetic acid in dimethylformamide solutions at $200 \mathrm{mV} / \mathrm{s}$. Figure 4.17 shows the plot of acid dependent studies with trifluoroacetic acid in acetonitrile solutions at $200 \mathrm{mV} / \mathrm{s}$. 
Figure 4.18 shows the plot of acid dependent studies with trifluoroacetic acid in dimethylformamide solutions at $500 \mathrm{mV} / \mathrm{s}$.

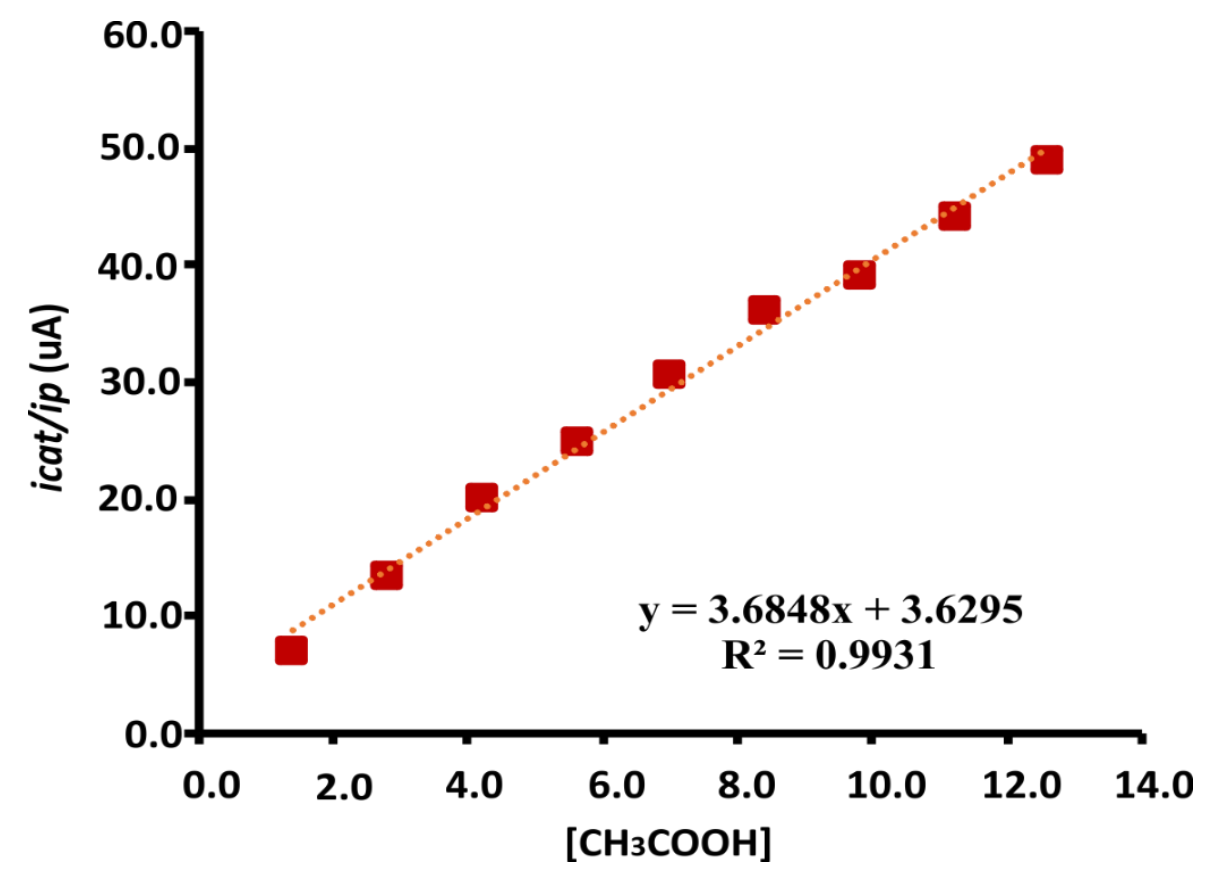

Figure 4.15 Acid dependence studies. Plot of $i_{c a} / i_{p}$ vs $\left[\mathrm{CH}_{3} \mathrm{COOH}\right]$ in acetonitrile solutions at 500 $\mathrm{mV} / \mathrm{s}$.

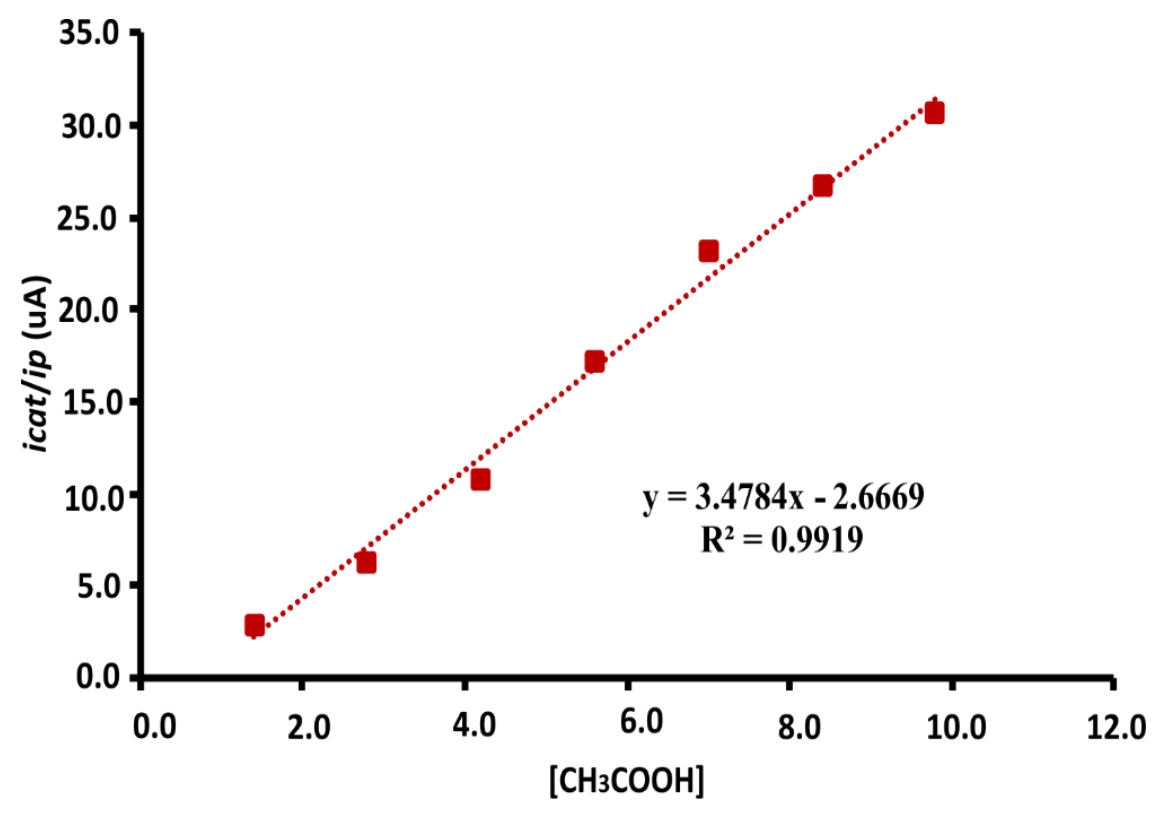

Figure 4.16 Acid dependence studies. Plot of $i_{c a l} / i_{p}$ vs $\left[\mathrm{CH}_{3} \mathrm{COOH}\right]$ in dimethylformamide solutions. 


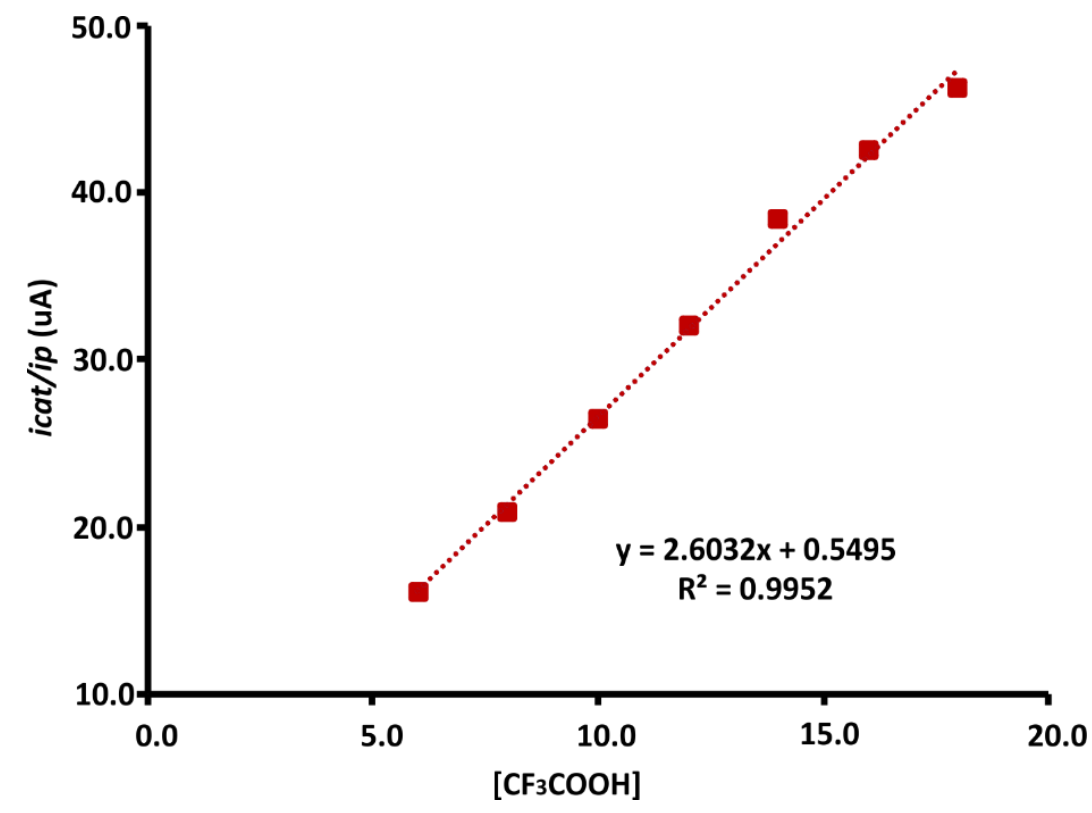

Figure 4.17 Acid dependence studies. Plot of $i_{c a} / i_{p}$ vs $\left[\mathrm{CF}_{3} \mathrm{COOH}\right]$ in acetonitrile solutions.

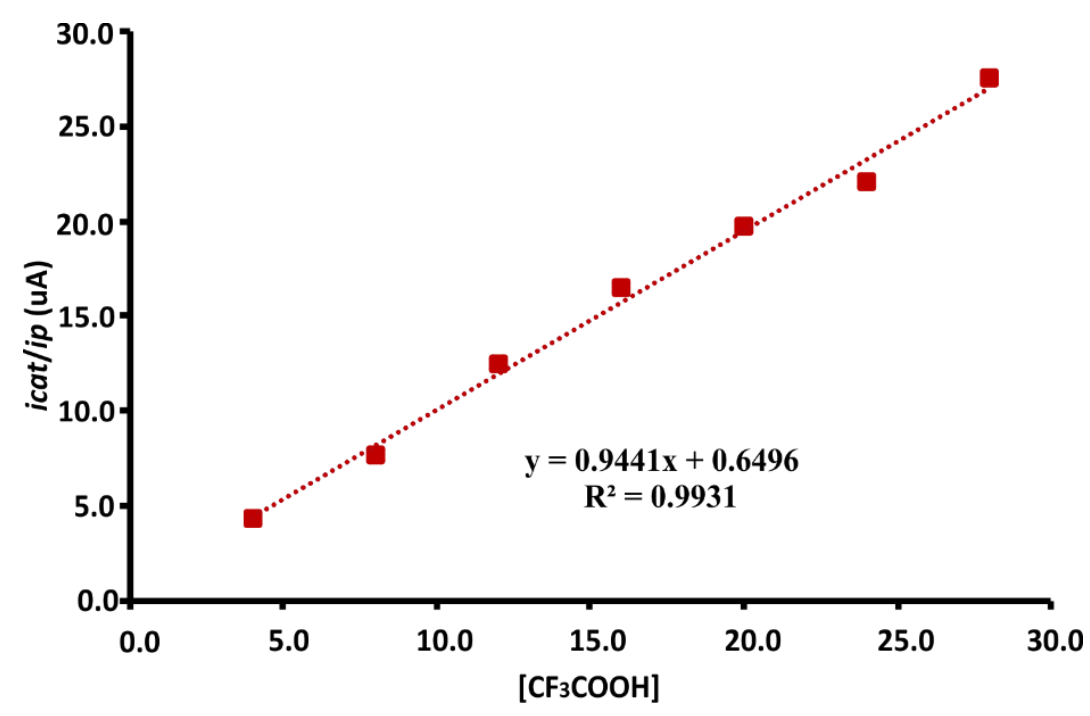

Figure 4.18 Acid dependence studies. Plot of $i_{c a t} / i_{p}$ vs $\left[\mathrm{CF}_{3} \mathrm{COOH}\right]$ in dimethylformamide solutions. 


\subsubsection{Kinetic isotope effect (KIE) studies}

To get more insights into the mechanism, the acetonitrile and dimethylformamide solutions of $\mathrm{NiL}^{3}$ were titrated with deuterated acids $\mathrm{CD}_{3} \mathrm{COOD}$ and $\mathrm{CF}_{3} \mathrm{COOD}$ and analyzed for HER. The KIE $\left(\mathrm{CH}_{3} \mathrm{COOH} / \mathrm{CD}_{3} \mathrm{COOD}\right)$ observed for HER in acetonitrile solutions is 0.75 indicating inverse isotope effect which is consistent with the formation of metal hydride as suggested by reports from Gray and Fukuzumi. ${ }^{53-54}$ In dimethylformamide solutions, $\mathrm{KIE}\left(\mathrm{CH}_{3} \mathrm{COOH} / \mathrm{CD}_{3} \mathrm{COOD}\right)$ of 0.64 is observed for HER. On screening $\mathrm{CF}_{3} \mathrm{COOD}$, KIE of 0.54 and 0.57 is recorded in acetonitrile and dimethylformamide solutions respectively.

\subsubsection{Computational studies}

To have better insights into the mechanism for HER with $\mathrm{NiL}^{3}$, density functional theory (DFT) calculations were carried out using the B3LYP functional and the 6-311g (d,p) basis set and BP86 functional and TZV/P basis set. The geometry optimization is performed in both gas phase as well as in solvent phase using polarizable continuum model (PCM) calculations. All the input coordinates used for optimizing the geometries have been provided in appendix. Gas phase calculations carried out using B3LYP functional and the 6-311g (d,p) basis set and BP86 functional and TZV/P basis set showed similar results as discussed by Straistari.

The hydrogen evolution reaction with $\mathrm{NiL}^{3}$ is found to follow different route with the input of solvent effects. Herein, the description of geometry optimization in acetonitrile using polarizable continuum model (PCM) calculations is given.

The input coordinates were taken from the previously reported crystal structure of $\mathrm{NiL}^{3}$. In the first step, the neutral $\mathrm{NiL}^{3}$ complex is optimized as shown in Figure 4.19. 
The ground state of $\mathrm{NiL}^{3}$ is best described as a restricted singlet $\mathrm{Ni}(\mathrm{II})\left(\mathrm{d}^{8}, M s=1\right)$ coordinated to two nitrogens and two sulfur centers.

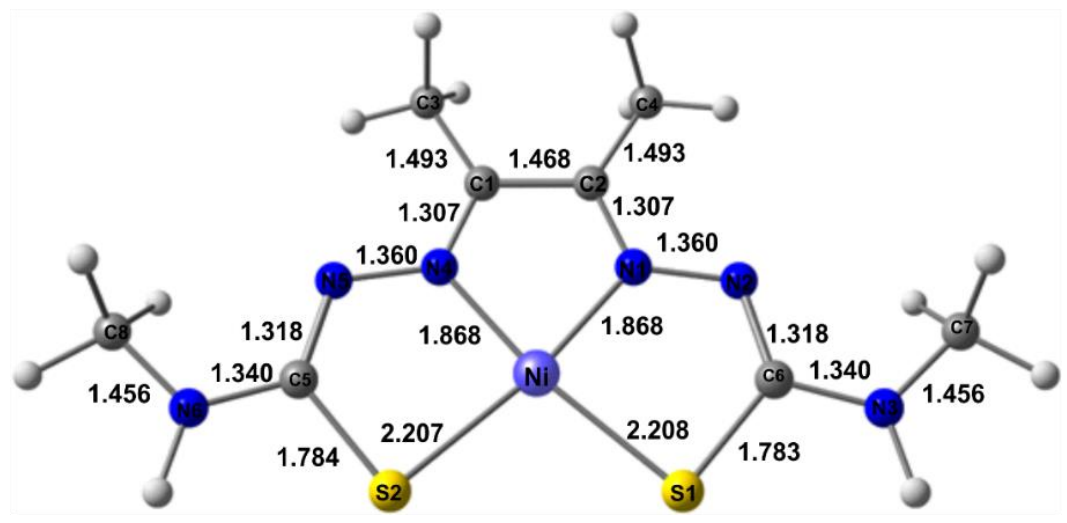

Figure 4.19 Optimized structure of $\mathrm{NiL}^{3}$ with B3LYP/6311g (d, p), $(M s=1, q=0)$.

Table 4.1 shows the comparison of the bond distances obtained from the optimized structure and experimentally determined from X-ray crystallography. ${ }^{90}$ In the optimized structure metal sulfur bond lengths are $0.05 \AA$ longer than the experimental values. The S$\mathrm{Ni}-\mathrm{N}$ bond angles in the optimized geometry are found to be approximately $0.10-0.48$ degrees smaller than the experimentally reported values.

Table 4.1 Comparison of optimized and experimental bond distances $(\AA)$ and Bond Angles $\left(^{\circ}\right)$ for $\mathrm{NiL}^{3}$.

\begin{tabular}{|c|c|c|}
\hline & $\mathrm{NiL}^{3}$ (optimized) & $\mathrm{NiL}^{3}$ (Experimental) \\
\hline Ni-S1 & 2.208 & 2.155 \\
\hline Ni-S2 & 2.207 & 2.159 \\
\hline Ni-N1 & 1.868 & 1.861 \\
\hline Ni-N4 & 1.868 & 1.855 \\
\hline N1-N2 & 1.360 & 1.378 \\
\hline N4-N5 & 1.360 & 1.375 \\
\hline N1-Ni-N4 & 84.15 & 83.59 \\
\hline S2-Ni-N4 & 87.08 & 86.55 \\
\hline S1-Ni-N1 & 87.06 & 87.07 \\
\hline S2-Ni-S1 & 101.71 & 101.81 \\
\hline
\end{tabular}


Next, the optimized structure of $\mathrm{NiL}^{3}$ with $\mathrm{B} 3 \mathrm{LYP} / 6311 \mathrm{~g}(\mathrm{~d}, \mathrm{p})$ is taken and electron is added to $\mathrm{NiL}^{3}$ species giving one electron reduced $\left[\mathrm{NiL}^{3}\right]^{-}$species $(M s=2, q=-1)$. Most of the spin density is found to be on the ligand backbone, Figure 4.20. This is accordance with the assignment of the first cathodic event observed in the $\mathrm{CVs}$ of $\mathrm{NiL}^{3}$ to be a ligand centered reduction. Similar spin density is observed when the one electron reduced species $\left[\mathrm{NiL}^{3}\right]^{-}$is optimized in gas phase and solvent phase with B3LYP/6311g (d, p) and BP86/ TZV/P. (see appendix)
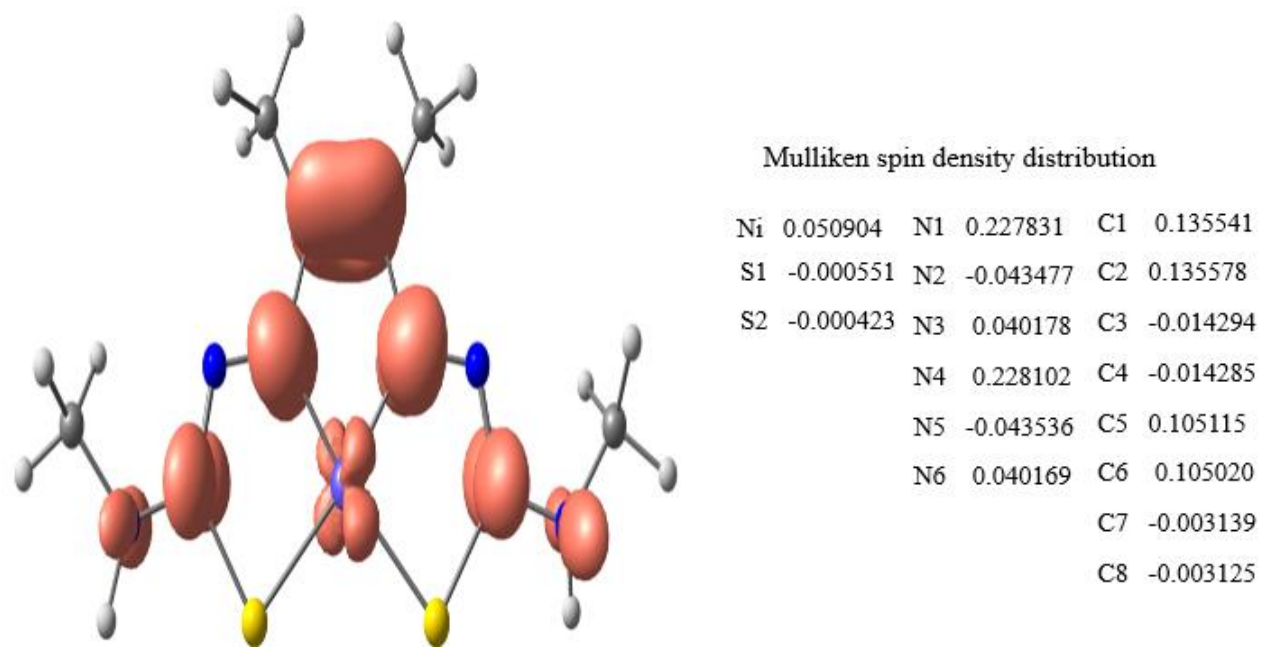

Figure 4.20 Spin density plot of $\left[\mathrm{NiL}^{3}\right]^{-}(M s=2, q=-1)$. Spin density on the $\mathrm{H}$-atoms has not been included in the figure.

In the optimized $\left[\mathrm{NiL}^{3}\right]^{-}$, the Ni-S distances are found to be $0.021 \AA$ longer than in $\mathrm{NiL}^{3}$. The bond lengths of $\mathrm{Ni}-\mathrm{N}$ are found to be decreased by $0.014 \AA$ in the one electron reduced species, $\left[\mathrm{NiL}^{3}\right]^{-}$. S-Ni-S bond angle is increased by $1.72^{\circ}$ from $101.71^{\circ}$ to $103.43^{\circ}$. The S-Ni-N bond angle is increased from $87.08^{\circ}$ to $87.56^{\circ}$. The results have been summarized in Table 4.2. 
Table 4.2 Comparison of optimized bond distances $(\AA)$ and Bond Angles $\left(^{\circ}\right)$ for $\mathrm{NiL}^{3}$ and $\left[\mathrm{NiL}^{3}\right]^{-}$

\begin{tabular}{|c|c|c|}
\hline & $\mathrm{NiL}^{3}$ (optimized) & {$\left[\mathrm{NiL}^{3}\right]^{-}$(optimized) } \\
\hline Ni-S1 & 2.208 & 2.229 \\
\hline Ni-S2 & 2.207 & 2.229 \\
\hline Ni-N1 & 1.868 & 1.854 \\
\hline Ni-N4 & 1.868 & 1.854 \\
\hline N1-N2 & 1.360 & 1.372 \\
\hline N4-N5 & 1.360 & 1.372 \\
\hline N1-Ni-N4 & 84.15 & 83.59 \\
\hline S2-Ni-N4 & 87.08 & 87.56 \\
\hline S1-Ni-N1 & 87.06 & 86.54 \\
\hline S2-Ni-S1 & 101.71 & 103.43 \\
\hline
\end{tabular}

Using the optimized structure of $\left[\mathrm{NiL}^{3}\right]^{-}$, a proton is added at various positions including $\mathrm{Ni}, \mathrm{S}$ and each $\mathrm{N}$ to evaluate the most likely site of protonation in the neutral complex $\left[\mathrm{NiL}^{3} \mathrm{H}\right](M s=2, q=0)$. For $\left[\mathrm{NiL}^{3} \mathrm{H}\right]$, the hydrazino protonated moiety is found to be energetically favored species in the PCM calculations using acetonitrile as a solvent. The energetic stability of the reduced/ protonated species $\left[\mathrm{NiL}^{3} \mathrm{H}\right](M s=2, q=0)$ has been shown in Figure 4.21. Species with protonation at the coordinated nitrogen N1 is found to be energetically similar to the hydrazino protonated moiety with the energy difference of only $2.85 \mathrm{kcal} / \mathrm{mol}$. The species protonated at the amine nitrogen is found to be 12.56 $\mathrm{kcal} / \mathrm{mol}$ higher in energy than the protonated hydrazine species. The sulfur protonation is disfavored by $13.62 \mathrm{kcal} / \mathrm{mol}$. The formation of metal hydride is found to be least likely at this stage with the energy difference of $15.72 \mathrm{kcal} / \mathrm{mol}$ from the most stable hydrazino protonated moiety. 


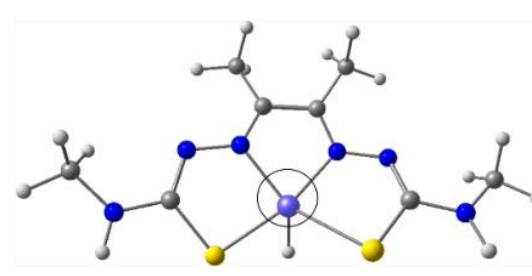

$\mathrm{Ni}-\mathrm{H}$

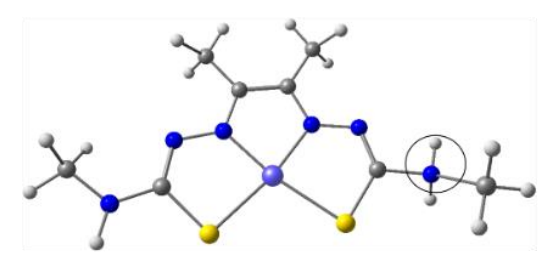

\section{$\mathbf{N i}-\mathbf{N}^{3} \mathbf{H}$}

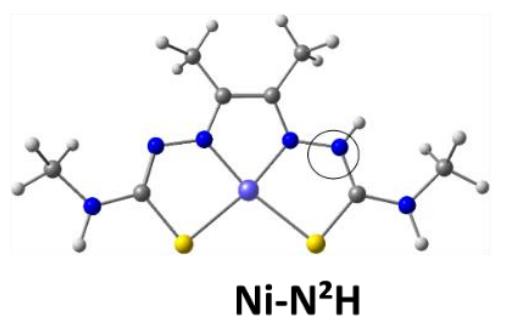

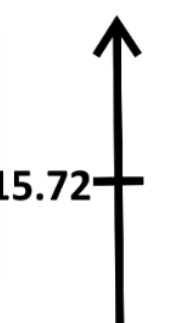

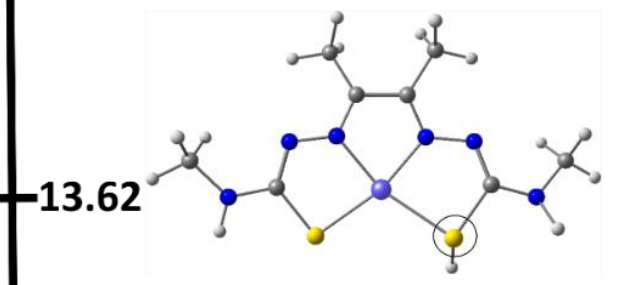

Ni-SH

12.56

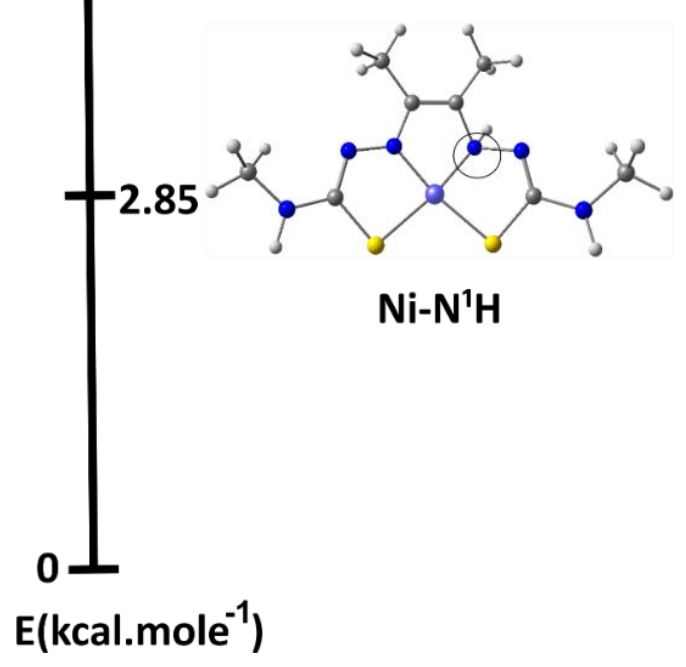

Figure 4.21 Energetic stability of the reduced/ protonated species $\left[\mathrm{NiL}^{3} \mathrm{H}\right]$ using B3LYP/6311g (d, p) $(M s=2, q=0)$, using PCM calculations in acetonitrile solvent.

After optimizing all the possible sites for the first protonation, the electron is added in the next step to all the optimized structures obtained from Step 3. Energy minimizations of the doubly reduced and singly protonated species were performed in both the triplet $(M s$ $=3, q=-1)$ and singlet $(M s=1, q=-1)$ states. Figure 4.22 shows the energetic stability of the reduced/protonated/reduced species in the triplet state. The doubly reduced, singly 
protonated species with the protonation at the nickel is found to be the energetically most favorable species in the triplet state. When compared to the species protonated at the coordinated and hydrazine nitrogen, nickel protonated species is found to be lower in energy by 4.43 and $14.93 \mathrm{kcal} / \mathrm{mol}$ respectively. Triplet electronic state with the protonated amine $\mathrm{N}$, is found to be energetically disfavored by $30.61 \mathrm{kcal} / \mathrm{mol}$.

Figure 4.23 shows the energetic stability of the reduced/protonated/reduced species in the singlet state. In the singlet state, the doubly reduced, singly protonated species with the protonation at the coordinated nitrogen is found to be the energetically most favorable species. Species protonated at the hydrazine nitrogen is found to be higher in energy by $12.41 \mathrm{kcal} / \mathrm{mol}$. Attempts to optimize the species protonated at the nickel center in the singlet state, leads to the break of the structure which is indicative of the fact that in singlet state when both the electrons are on the nickel, it will prefer square planar geometry. The species with the protonation on the amine nitrogen is found to be the highest in energy in the singlet state. Open shell singlet calculations were also carried out using unrestricted B3LYP functional to obtain the broken symmetry solutions where the electron density is on the ligand as well as on the metal. Out of all the geometries optimized for reduced/protonated/reduced species, $\left[\mathrm{NiL}^{3}\right]^{-}$. These studies are in progress. 


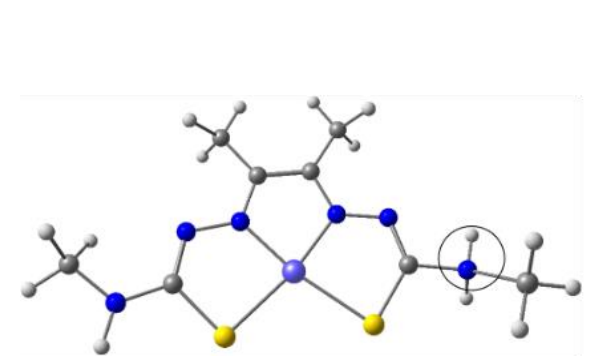

$\mathrm{Ni}-\mathrm{N}^{3} \mathrm{H}$

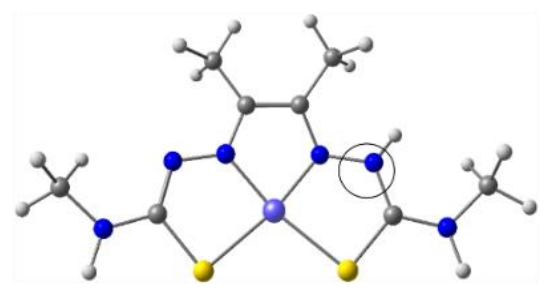

$\mathrm{Ni}-\mathrm{N}^{2} \mathrm{H}$

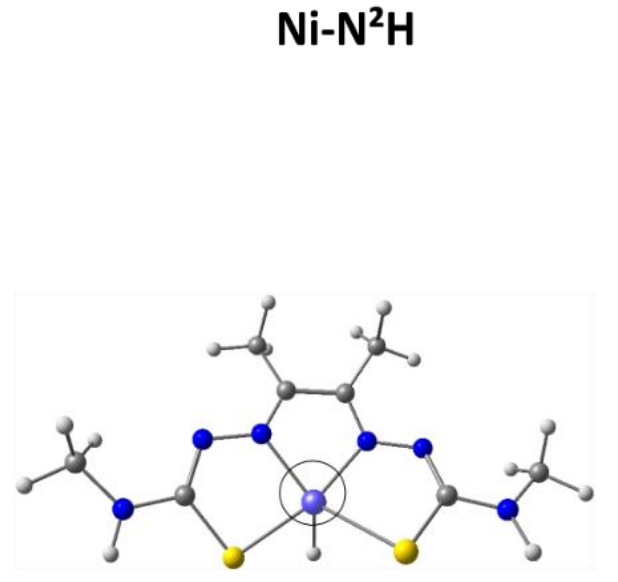

$\mathrm{Ni}-\mathrm{H}$

Ni-H

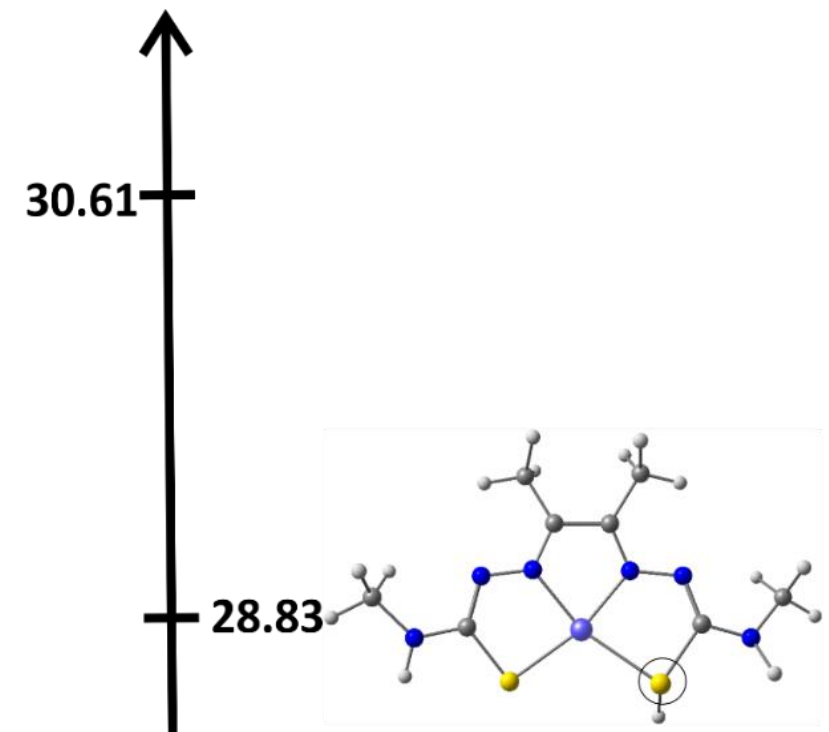

$\mathrm{Ni}-\mathrm{SH}$

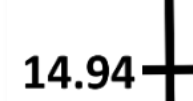

Figure 4.22 Energetic stability of the reduced/ protonated species/ reduced $\left[\mathrm{NiL}^{3} \mathrm{H}\right]^{-}$ B3LYP/6311g (d, p) (Ms = 3, $q=-1)$, using PCM calculations in acetonitrile solvent. 


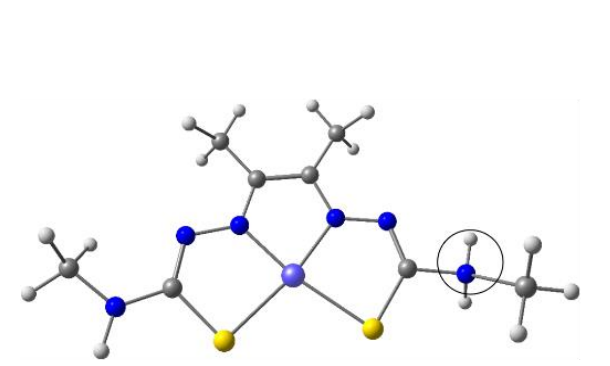

$\mathrm{Ni}-\mathrm{N}^{3} \mathrm{H}$

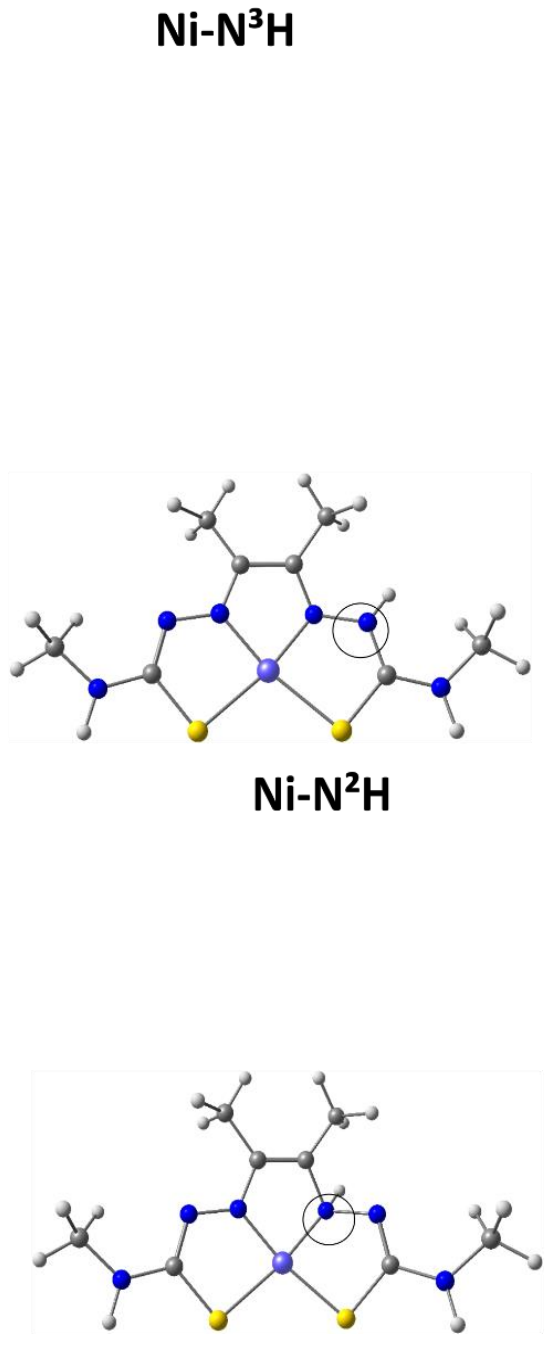

$\mathbf{N i}-\mathbf{N}^{1} \mathbf{H}$

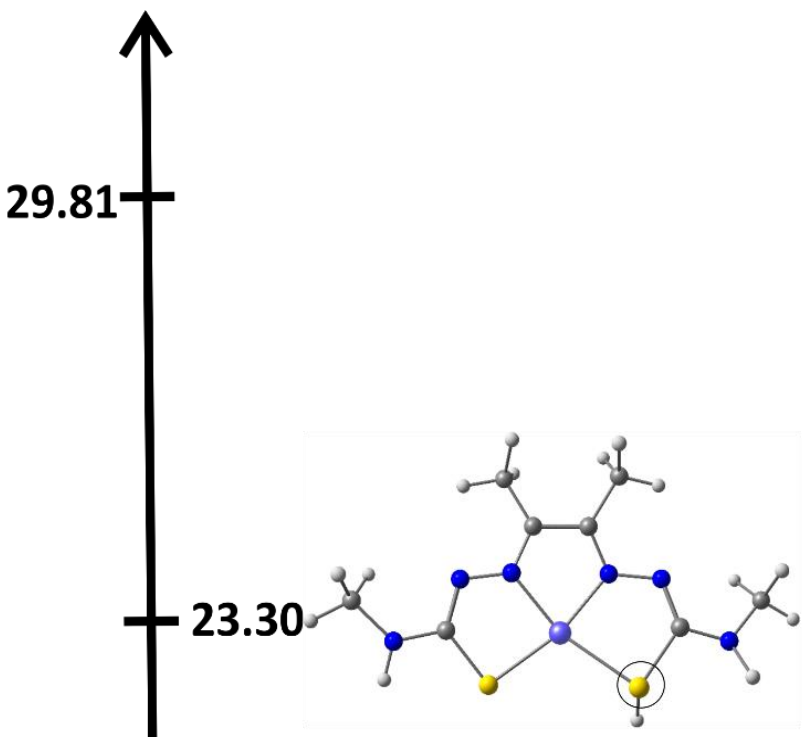

Ni-SH

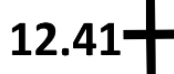

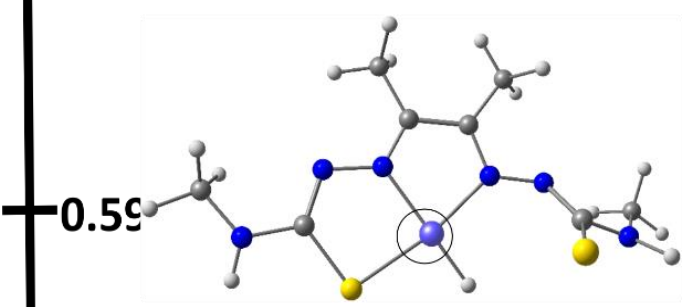

$\mathrm{Ni}-\mathrm{H}$

Figure 4.23 Energetic stability of the reduced/ protonated species/ reduced $\left[\mathrm{NiL}^{3} \mathrm{H}\right]^{-}$ B3LYP/6311g (d, p) $(M s=1, q=-1)$, using PCM calculations in acetonitrile solvent. 


\subsubsection{Proposed mechanism for HER with $\mathrm{NiL}^{3}$}

The DFT studies are still in progress. Based on the experimental and theoretical studies so far, hydrogen evolution with $\mathrm{NiL}^{3}$ is proposed to occur through ECEC type. In the first step, electron addition takes place, which is a ligand centered reduction. Second step is the chemical step involving the addition of proton on the ligand framework at the hydrazino nitrogen, $\mathrm{N}^{2}$ leading to the formation of protonated species $\mathrm{Ni}-\mathrm{N}^{2} \mathrm{H}$. Third step is the reduction step and involves the addition of electron to the protonated species which leads to the migration of the proton from the hydrazino nitrogen, $\mathrm{N}^{2}$ of the ligand to the metal center making $\mathrm{Ni}(\mathrm{III})$ hydride. In the Step 4 is the chemical step which involves the addition of the proton to the coordinated nitrogen. In the final step, homolytic cleavage of the $\mathrm{Ni}(\mathrm{III})-\mathrm{H}$ and the $\mathrm{N}-\mathrm{H}$ bonds evolves hydrogen and the $\mathrm{NiL}^{3}$ is regenerated to be used for the next cycle, Figure 4.24.

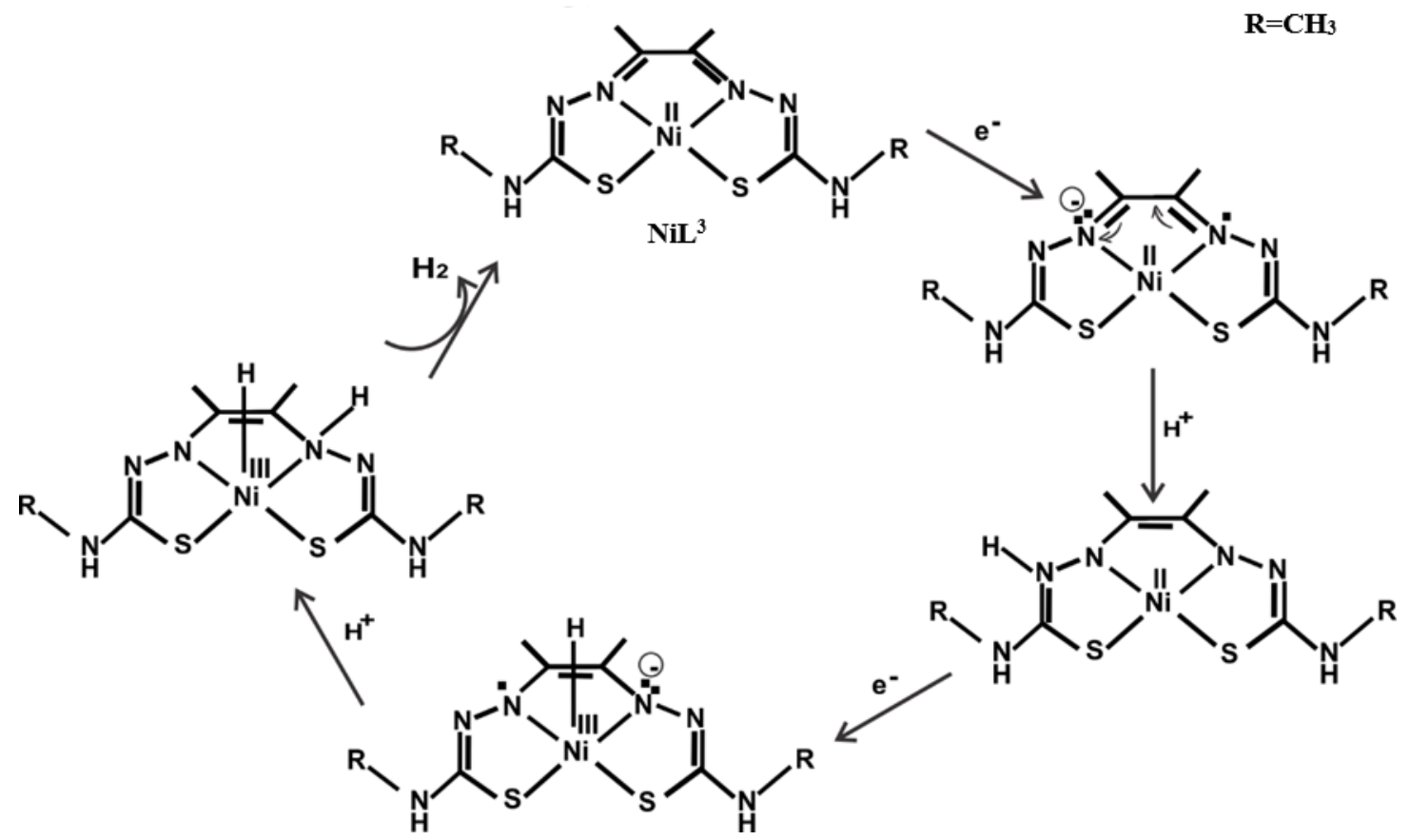

Figure 4.24 Proposed mechanism for hydrogen evolution reaction with $\mathrm{NiL}^{3}$. 


\subsection{Conclusions}

In the search of the low-cost catalysts to generate hydrogen electrocatalytically, redox noninnocence ligand bis(thiosemicarbazone) has been complexed with $\mathrm{Ni}(\mathrm{II})$ and the $\mathrm{NiL}^{3}$ complex thus synthesized has been evaluated for its ability to evolve hydrogen in the acetonitrile and dimethylformamide solutions using acetic acid and trifluoroacetic acid as the external proton source. The maximum TOF frequency reported for $\mathrm{NiL}^{3}$ is $4161 \mathrm{~s}^{-1}$ at an overpotential of $0.52 \mathrm{~V}$ in acetonitrile solutions. Kinetic isotope effect studies revealed the inverse KIE indicating towards the possibility of formation of the metal hydride in the reaction pathway. Mechanistic dependent studies revealed the second-order dependence on the acid concentration. The order of the reaction is also found to be first-order with respect to the catalyst concentration by varying the catalyst concentrations at fixed acid concentration. With the support of DFT calculations, an ECEC type of mechanism for HER has been proposed. 


\section{CHAPTER V}

\section{COPPER CATALYSED AEROBIC OXIDATION OF BENZYLIC ALCOHOLS IN AN}

\section{IMIDAZOLE CONTAINING N 4 LIGAND FRAMEWORK}

\subsection{Background}

In organic synthesis, alcohol oxidation to aldehydes has traditionally employed various stoichiometric oxidants like chromium, ${ }^{130-131}$ manganese, ${ }^{132-133}$ hypervalent iodine, ${ }^{134-135}$ and activated DMSO. ${ }^{135-137}$ Molecular oxygen can serve as an alternative oxidant, but this requires activation via a catalyst. ${ }^{138-143}$ Galactose oxidase is a naturally occurring fungal enzyme that uses oxygen to oxidizes D-galactose. The active site contains a copper (II) ion in a distorted square pyramidal geometry coordinated with two tyrosines, two histidines and a solvent molecule (i.e. water). ${ }^{144-147}$

The research described in Chapters 3 and 4 of this dissertation focused on catalytic hydrogen evolution and hydrogen oxidation, which mimics the activity of the hydrogenase enzymes. In contrast, the work in this chapter centers on catalytic alcohol oxidation, which mimics galactose oxidase. On comparison, the active sites of iron-only hydrogenase and galactose oxidase are similar as both contain redox active ligands and/or cofactors and perform multielectron reactions under physiological conditions near thermodynamic potentials. ${ }^{148-155}$ The active metal site performs these multielectron transformations synergistically with a redox active moiety positioned in its vicinity to promote the redox reactions with ease. ${ }^{148-155}$ The iron-only hydrogenase enzyme is capable of cleaving 
hydrogen and has a non-innocent, redox active pyridyl unit and pterin cofactor in the proximity of Fe center. ${ }^{153}$ In galactose oxidase, the phenoxyl radical on Tyr 272 is coordinated to the copper center in the axial or equatorial arrangement. The resonance stabilization of the radical occurs due to the antiferromagnetic coupling with copper center, ${ }^{156-157}$ Figure 5.1.
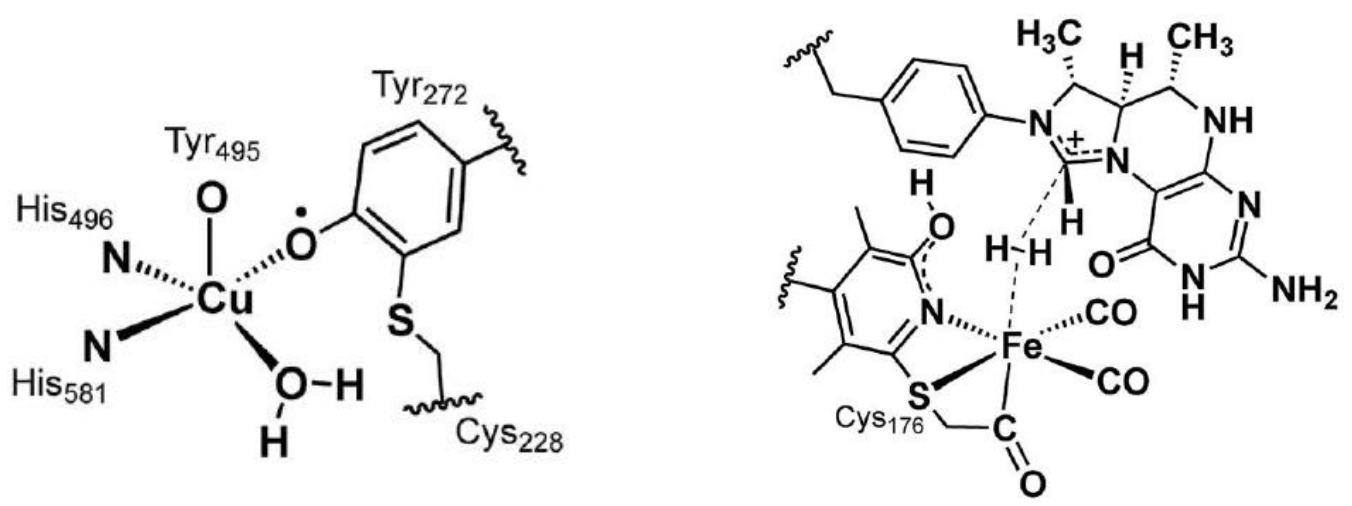

Figure 5.1 Active site of galactose oxidase (left) and iron-only hydrogenase (right). ${ }^{152-153}$

\subsubsection{Mechanism of alcohol oxidation by galactose oxidase}

The proposed mechanism for galactose oxidase is shown in Figure 5.2. The first step consists of the proton transfer between a metal coordinated alcohol and metal-bound Try495. After the acceptance of the proton, Try495 dissociates from the metal making the alcohol more susceptible to oxidation. In the next step, Tyr 272 abstracts the $\mathrm{H} \cdot$ from the $\alpha$ - carbon bound to the alkoxide which is followed by the rearrangement of electrons. The $\mathrm{Cu}$ (II) center gets reduced to $\mathrm{Cu}(\mathrm{I})$ and the alcohol gets oxidized to aldehyde. Release of aldehyde takes place which is then followed by the coordination of the oxygen molecule to $\mathrm{Cu}$ (II) center as a superoxide radical in the third step. Superoxide radical abstracts the $H \cdot$ from the Tyr272, generating back Tyr272 radical. In the final step, hydroperoxide abstracts the proton from the Tyr495 and leaves as $\mathrm{H}_{2} \mathrm{O}_{2}$ molecule. In the later step, 
coordination of the Tyr495 in the axial position generates back the catalytic center to be used in the next cycle. ${ }^{93,158-161}$
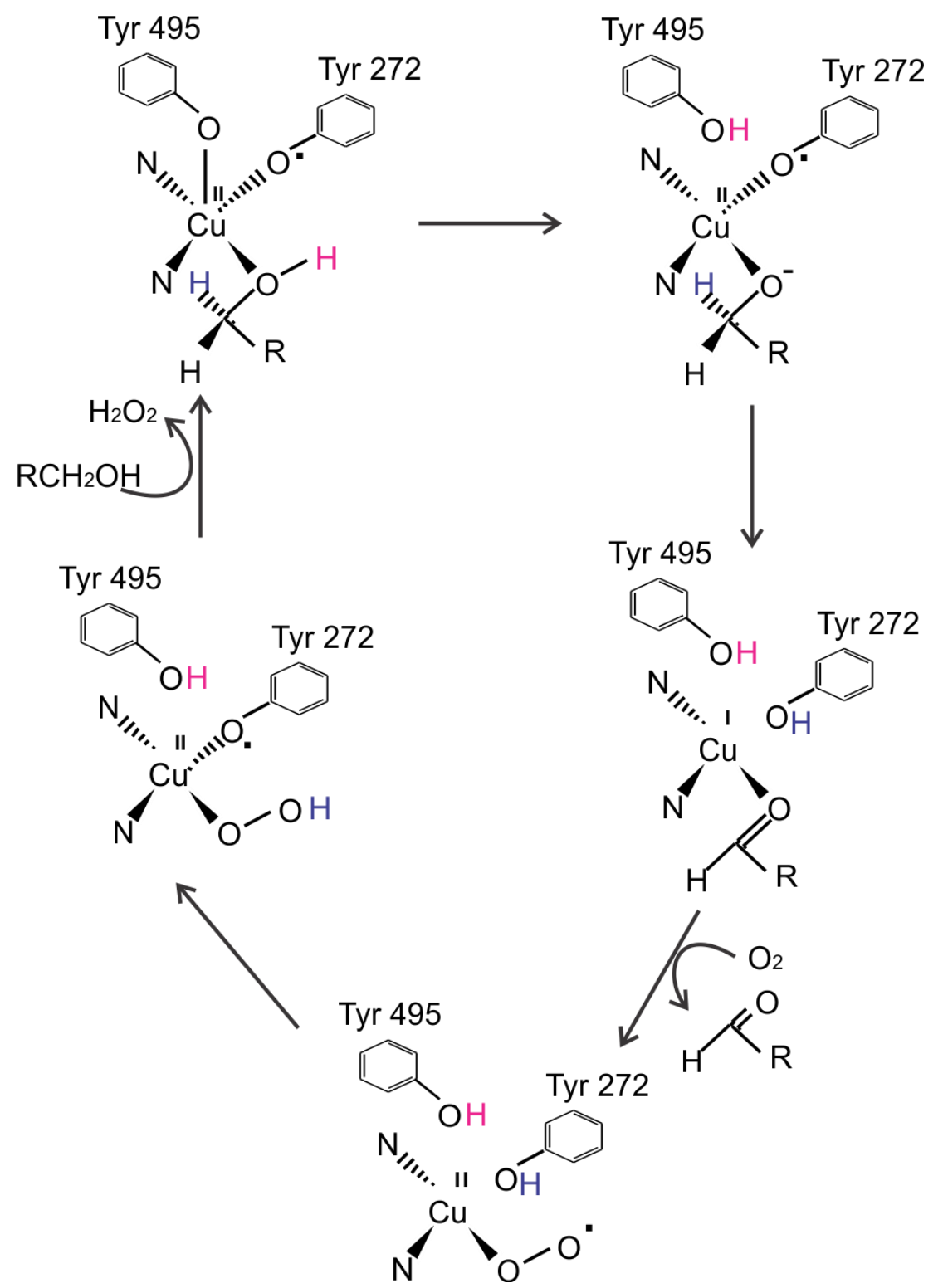

Figure 5.2 Mechanism of alcohol oxidation by galactose oxidase. ${ }^{160}$

\subsubsection{Copper complexes for oxidation of alcohols to aldehydes}

The first use of simple copper complexes in the oxidation of alcohols to aldehydes was reported by Brackman and Gaasbeek in $1966 .{ }^{162}$ In that report, di-tert-butyl nitroxide 
was used as a nitroxyl co-catalyst with phenanthroline/ $\mathrm{Cu}$ II complex to oxidize methanol to formaldehyde. This approach was further developed and refined by Semmelhack and Sheldon, who are considered pioneers in the field of $\mathrm{Cu} /$ nitroxyl-catalyzed aerobic alcohol oxidation. ${ }^{163-166}$ Semmelhack reported the oxidation of primary allylic and benzylic alcohols with $\mathrm{CuCl}$ and TEMPO in the presence of air in dimethylformamide solutions. ${ }^{163}$ Sheldon, in his studies showed that use of external base $\mathrm{KO}^{\mathrm{t}} \mathrm{Bu}$ in the presence of nitroxyl radical initiator TEMPO enhances the aerobic oxidation of allylic and benzylic alcohols at room temperature. ${ }^{164}$ Potential use of 1,8-diazabicycloundec-7-ene (DBU) and $N$-methyl imidazole (NMI) as external bases in combination with $\mathrm{Cu}$ (II) salts and TEMPO to enhance the product yields have been explored vastly in recent years. ${ }^{167}$ In the past decade, Stahl has perfected these studies with the use of $\mathrm{Cu}^{\mathrm{I} O T f} / \mathrm{TEMPO}$, bipyridine, and NMI for the oxidation of wide variety of alcohols in the various solvents. ${ }^{168-171}$

Figure 5.3 shows a mechanism for alcohol oxidation with $\mathrm{Cu}(\mathrm{I}) \mathrm{OTf} / \mathrm{TEMPO}$, bipyridine, and NMI as proposed by Stahl. ${ }^{169}$ In the first step, aerobic oxidation of $\mathrm{Cu}(\mathrm{I})$ generates a peroxo-bridged, dinuclear $\mathrm{Cu}$ (II) complex. This is followed by $\mathrm{H}$-atom transfer from TEMPOH to the $\mathrm{Cu}_{2} \mathrm{O}_{2}$ species to afford $\mathrm{LCu}(\mathrm{II})-\mathrm{OH}$. The $\mathrm{Cu}$ (II)-OH species thus formed reacts with the alcohol substrate producing alkoxide bound $\mathrm{Cu}(\mathrm{II})$ complex and releasing $\mathrm{H}_{2} \mathrm{O}$ as the by-product. In the final step, the alkoxide species reacts with the TEMPO radical previously formed to abstracts the $\mathrm{H}$-atom from the alkoxide species along with the concomitant reduction of $\mathrm{Cu}(\mathrm{II})$ to $\mathrm{Cu}(\mathrm{I})$, thus releasing aldehyde product and TEMPOH to complete the catalytic cycle. 


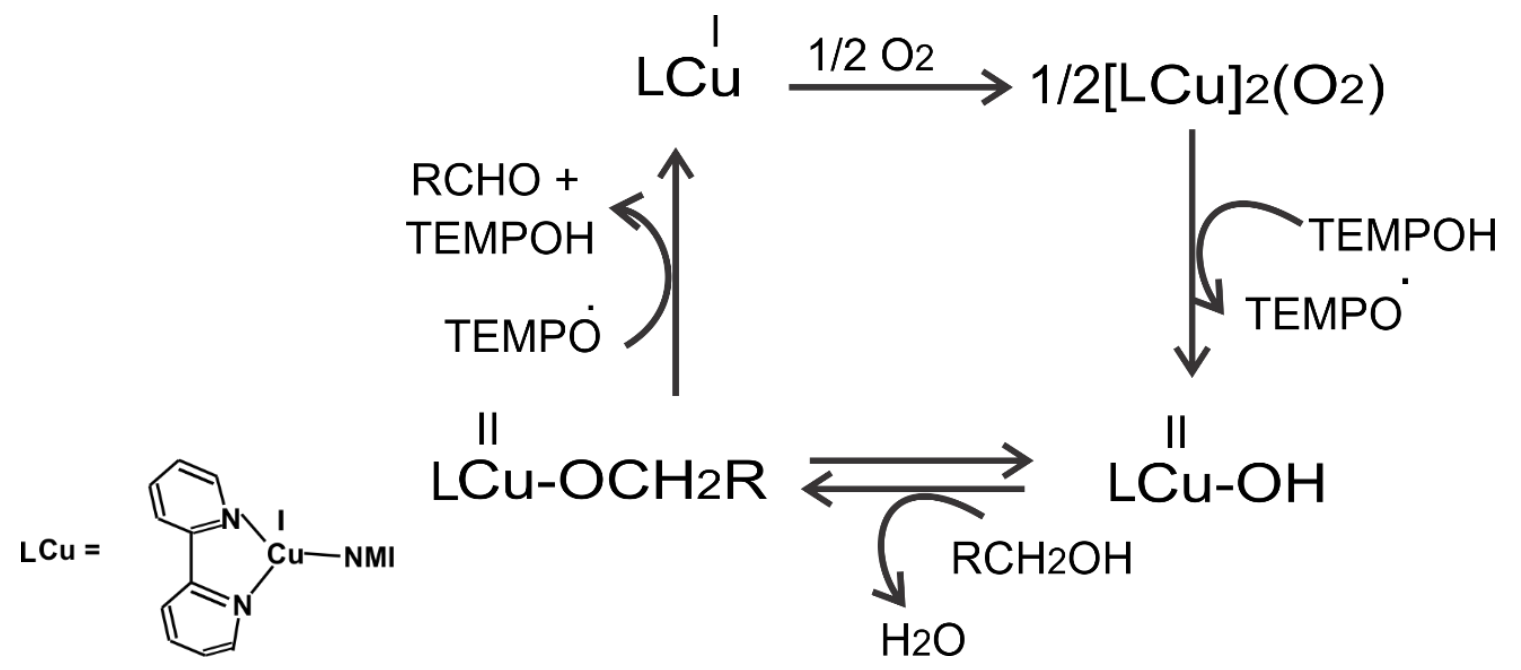

Figure 5.3 Proposed mechanism of alcohol oxidation by $\mathrm{Cu}^{\mathrm{I} O T f} / \mathrm{TEMPO} / \mathrm{bpy}$ system. ${ }^{169}$

The $\mathrm{Cu}^{\mathrm{I} O T f} / \mathrm{TEMPO} / \mathrm{bpy}$ system works best in the presence of two equivalents of NMI, thus making $\mathrm{N}_{4}$ ligand framework if both NMI and bpy are coordinated to copper center. Several reports in the literature showed that $\mathrm{N}_{4}$ and/or $\mathrm{N}_{2} \mathrm{O}_{2}$ chelated $\mathrm{Cu}$ (II) complexes in conjunction with niroxyl radicals like TEMPO are active aerobic oxidation catalysts for alcohol oxidation. ${ }^{165,172-174} \mathrm{Gamba}$ studied $\mathrm{Cu}(\mathrm{II})$ coordinated with the neutral tetra-pyridyl ligand for the benzyl alcohol oxidation in the presence of TEMPO. ${ }^{175}$ Punniyamurthy reported $\mathrm{N}_{2} \mathrm{O}_{2}$ chelated $\mathrm{Cu}$ (II) complex for the aerobic oxidation of variety of alcohols in toluene as a solvent at elevated temperatures. ${ }^{176}$

In this chapter, two copper (II) complexes with $\mathrm{N}_{4}$ ligand frameworks are evaluated for their ability to catalyse the aerobic oxidation of benzylic alcohols. The copper Schiff base complex $\left[\mathrm{CuL}^{4}\right]^{2+}$ was found to reversibly bind the methanol across the metal as well as across ligand through the azomethine $\mathrm{C}=\mathrm{N}$ bond. ${ }^{177}$ This complex was found to be inactive for the oxidation of benzylic alcohols. The reduced Schiff base complex $\left[\mathrm{CuL}^{5}\right]^{2+}$ was found to be an active catalyst in the presence of TEMPO and NMI for the aerobic oxidation of benzylic alcohols to benzylic aldehydes with the maximum yields up to $99 \%$ 
in 4 hours. ${ }^{178}$ The comparison of the reactivity of the complexes $\left[\mathrm{CuL}^{4}\right]^{2+}$ and $\left[\mathrm{CuL}^{5}\right]^{2+}$ is shown in Figure 5.4.

reversible ligand-centered alcohol addition

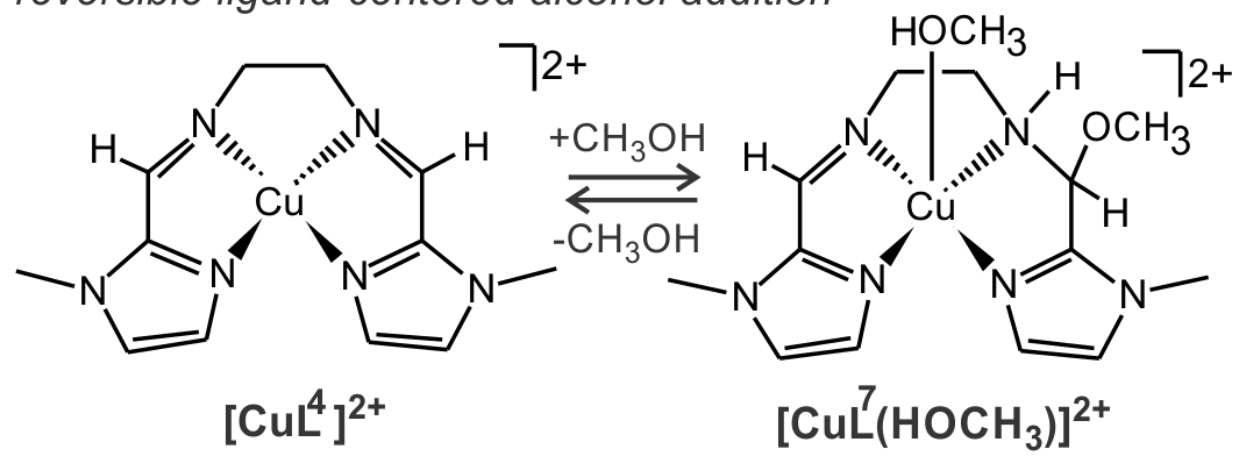

catalytic aerobic alcohol oxidation

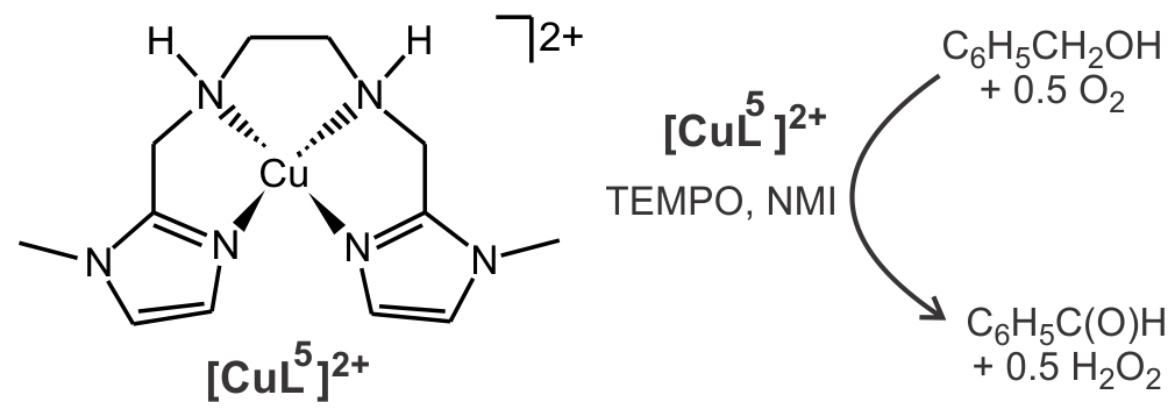

Figure 5.4 Comparison of alcohol reactivity of $\left[\mathrm{CuL}^{4}\right]^{2+}$ and $\left[\mathrm{CuL}^{5}\right]^{2+} .{ }^{178}$

\subsection{Synthesis and characterization of $\left[\mathrm{CuL}^{5}\right]^{2+}$}

The Schiff base ligand 1,2-bis[(1-methyl-2-imidazolyl)methyleneamino]ethane $\left(\mathrm{L}^{4}\right)$ and reduced Schiff base ligand [(1-methyl-4,5-dihydro-1H-imidazol-2-yl)methyl](2ethyl)amine] $\left(\mathrm{L}^{5}\right)$ were prepared as previously reported by Moreno-Esparza. ${ }^{61}$ Addition of $\mathrm{Cu}(\mathrm{II})$ perchlorate to methanol solutions of $\mathrm{L}^{5}$ yields a blue coloured precipitate of $\left[\mathrm{CuL}^{5}\right]^{2+}$ upon the addition of ice cold diethyl ether. The reaction mixture was filtered, and the solid product was washed with methanol. The (+) ESI-MS showed a parent peak at $m / z=155.54$ as expected for the dicationic reduced Schiff base complex. The low temperature $(77 \mathrm{~K}$ ) EPR spectrum in frozen acetonitrile displayed an axial signal with $\mathrm{g}_{\perp}=2.24\left(\mathrm{~A}_{\perp}=\right.$ 
$\left.0.000285 \mathrm{~cm}^{-1}\right)$ and $g_{/ /}=2.07\left(\mathrm{~A} / /=0.0163 \mathrm{~cm}^{-1}\right)$ consistent with square planar/pyramidal $\mathrm{Cu}(\mathrm{II})$.

The electronic spectrum of $\left[\mathrm{CuL}^{5}\right]^{2+}$ in acetonitrile showed charge transfer bands at 212 and $302 \mathrm{~nm}$ and a d-d transition at $630 \mathrm{~nm}$. The bands were similar to those reported at 208, 292, $640 \mathrm{~nm}$ for $\left[\mathrm{CuL}^{4}\left(\mathrm{ClO}_{4}\right)\right]\left[\mathrm{ClO}_{4}\right]$ and 212, 288, and $620 \mathrm{~nm}$ for $\left[\mathrm{Cu}(\mathrm{L})\left(\mathrm{HOCH}_{3}\right)\right]\left[\mathrm{ClO}_{4}\right]_{2}$ indicating highly similar electronic environments. On the addition of perchloric acid to acetonitrile solutions of $\left[\mathrm{CuL}^{5}\right]^{2+}$, two concurrent protonation events are observed, Figure 5.5. The first protonation event results in the blue shift of the charge transfer bands to 216 and $308 \mathrm{~nm}$ and the appearance of a shoulder at $236 \mathrm{~nm}$. This has been assigned to the protonation of the pendent NMI donors yielding $\left[\left(\mathrm{Cu}\left(\mathrm{HL}^{5}\right)\left(\mathrm{CH}_{3} \mathrm{CN}\right)_{2}\right]^{3+}\right.$. This species has been isolated and characterized by $\mathrm{x}$-ray crystallography. The second protonation resulted in the appearance of new bands at 216, 270 and $304 \mathrm{~nm}$. This event has been assigned to the protonation of the second ligated pendent NMI to the copper metal resulting in the formation of $\left[\mathrm{Cu}\left(\mathrm{H}_{2} \mathrm{~L}^{5}\right)\left(\mathrm{ClO}_{4}\right)_{2}\right]^{+}$, which is proposed to demetallize in solution. 


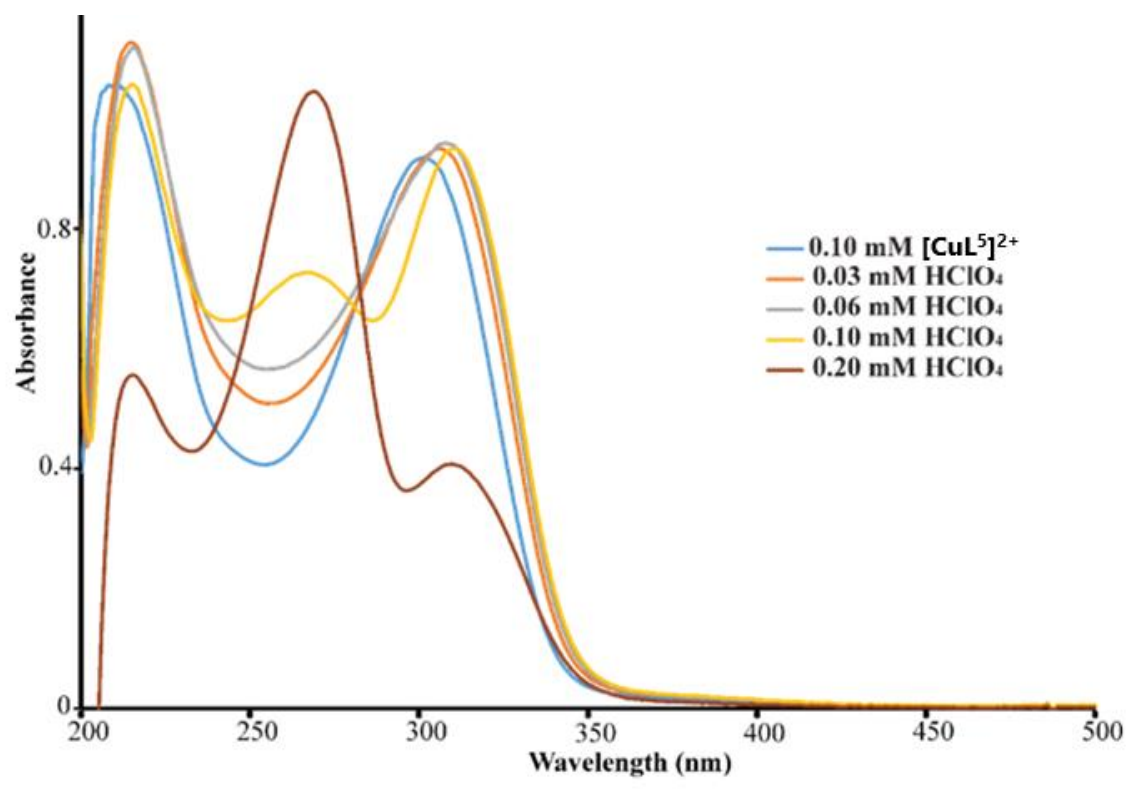

Figure 5.5 UV-Vis spectra collected with the titrations of $\left[\mathrm{CuL}^{5}\right]^{2+}$ with perchloric acid in acetonitrile. $^{178}$

\subsection{Structural determinations of $\left[\mathrm{CuL}^{5}\right]^{2+}$ and $\left[\mathrm{Cu}\left(\mathrm{HL}^{5}\right)\left(\mathrm{CH}_{3} \mathrm{CN}\right)_{2}\right]^{3+}$}

Using single crystal $x$-ray diffraction technique, the solid state structure of $\left[\mathrm{CuL}^{5}\right]\left[\mathrm{ClO}_{4}\right]_{2}$ and its mono-protonated derivative $\left[\mathrm{Cu}\left(\mathrm{HL}^{5}\right)\left(\mathrm{CH}_{3} \mathrm{CN}\right)_{2}\right]\left[\mathrm{ClO}_{4}\right]_{3}$ were determined. X-ray quality royal blue prism shaped crystals of $\left[\mathrm{CuL}^{5}\right]\left[\mathrm{ClO}_{4}\right]_{2}$ in the monoclinic space group $P 2_{1} / c$ were obtained by the liquid diffusion of methanol/ether solution. The asymmetric unit contains a single $\mathrm{Cu}(\mathrm{II})$ ion coordinated by four $\mathrm{N}$-atoms $\left(\mathrm{N}_{1}, \mathrm{~N}_{3}, \mathrm{~N}_{4}, \mathrm{~N}_{5}\right)$ in a pseudo-square planar environment, Figure 5.6. X-ray quality sapphire blue crystals of $\left[\mathrm{Cu}\left(\mathrm{HL}^{5}\right)\left(\mathrm{CH}_{3} \mathrm{CN}\right)_{2}\right]\left[\mathrm{ClO}_{4}\right]_{3}$ in the monoclinic space group $P 2_{1} / c$ were obtained by the liquid diffusion of acetonitrile/ether solution. The asymmetric unit contains a $\mathrm{Cu}(\mathrm{II})$ coordinated in a distorted-square pyramidal environment by three $\mathrm{N}$-atoms from the $\mathrm{L}^{5} \mathrm{H}^{+}\left(\mathrm{N}_{1}, \mathrm{~N}_{3}, \mathrm{~N}_{4}\right)$ and two acetonitrile donors (N7, N8), Figure 5.6. One of the 
imidazole nitrogen, $\mathrm{N}_{5}$ is protonated in $\mathrm{L}^{5} \mathrm{H}^{+}$and is found to be not coordinated to the metal centre.
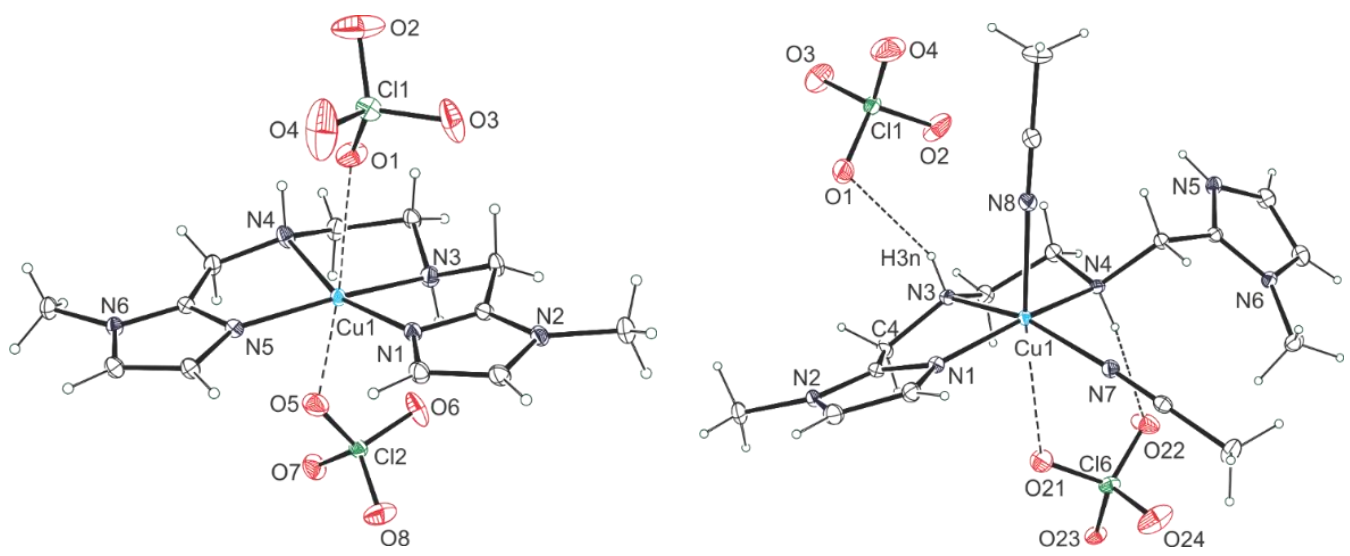

Figure 5.6 ORTEP ${ }^{106}$ representation of $\left[\mathrm{CuL}^{5}\right]\left[\mathrm{ClO}_{4}\right]_{2}$ (left) and $\left[\mathrm{Cu}\left(\mathrm{HL}^{5}\right)\left(\mathrm{CH}_{3} \mathrm{CN}\right)_{2}\right]\left[\mathrm{ClO}_{4}\right]_{3}$ (right). ${ }^{178}$

Selected metric parameters of $\left[\mathrm{CuL}^{5}\right]^{2+}$ and $\left[\mathrm{Cu}\left(\mathrm{HL}^{5}\right)\left(\mathrm{CH}_{3} \mathrm{CN}\right)_{2}\right]\left[\mathrm{ClO}_{4}\right]_{3}$ are compared in Table 5.1. The parameters for $\mathrm{N}_{4}-\mathrm{Cu}$ complex $\left[\mathrm{CuL}^{6}\right]\left[\mathrm{ClO}_{4}\right]_{2}\left(\mathrm{~L}^{6}=1,6-\mathrm{bis}(2-\right.$ pyridyl)-2,5-diazahexane) which has similar ligand framework as $\mathrm{L}^{5}$ previously reported by Robinson. ${ }^{179}$ has also been included for comparison. The $\mathrm{Cu}-\mathrm{N}_{\text {amine }}$ distances $\mathrm{Cu} 1-\mathrm{N} 3$ and $\mathrm{Cu} 1-\mathrm{N} 4$ of 2.019(2) and 2.024(2) $\AA$ for $\left[\mathrm{CuL}^{5}\right]^{2+}$ and 2.030(2) and 2.0419(19) $\AA$ for $\left[\mathrm{Cu}\left(\mathrm{HL}^{5}\right)\left(\mathrm{CH}_{3} \mathrm{CN}\right)_{2}\right]^{3+}$ are slightly longer than the corresponding distances of 1.980(4) and 1.992(4) $\AA$ in $\left[\mathrm{CuL}^{6}\right]^{2+}$. The $\mathrm{Cu}-\mathrm{N}_{\text {imidazole }}$ distances Cu1-N1 and Cu1-N5 of 1.957(2) and 1.955(2) $\AA$ for $\left[\mathrm{CuL}^{5}\right]^{2+}$ and the $\mathrm{Cu} 1-\mathrm{N} 1$ distance of $1.9565(19)$ for $\left[\mathrm{Cu}\left(\mathrm{HL}^{5}\right)\left(\mathrm{CH}_{3} \mathrm{CN}\right)_{2}\right]^{3+}$ are shorter than the corresponding $\mathrm{Cu}-\mathrm{N}_{\mathrm{pyridyl}}$ distances of $1.992(4)$ and $1.992(3) \AA$ in $\left[\mathrm{CuL}^{4}\right]^{2+}$. The Cu-N $\mathrm{N}_{\text {nitrile }}$ distances to the equatorial (N7) and axial (N8) acetonitrile donors of $\left[\mathrm{Cu}\left(\mathrm{HL}^{5}\right)\left(\mathrm{CH}_{3} \mathrm{CN}\right)_{2}\right]^{3+}$ are 2.0047(19) and 2.209(2) $\AA$, respectively. Due to the difference in ligand backbones in $\left[\mathrm{CuL}^{5}\right]^{2+}$ and $\left[\mathrm{CuL}^{6}\right]^{2+}$ as $\left[\mathrm{CuL}^{5}\right]^{2+}$ contains ethylene diamine whereas $\left[\mathrm{CuL}^{6}\right]^{2+}$ has diaminohexane, a variation in $\mathrm{N}-\mathrm{Cu}-\mathrm{N}$ bond angles is 
observed. Notably, for $\left[\mathrm{CuL}^{5}\right]^{2+}$ and $\left[\mathrm{CuL}^{6}\right]^{2+}$ the N1-Cu1-N5 angles are statistically equivalent, these angles are associated with the open end of the chelate with values of $110.3(9)$ and $110.34(14)^{\circ}$, respectively.

\begin{tabular}{|c|c|c|c|}
\hline \multicolumn{4}{|c|}{ 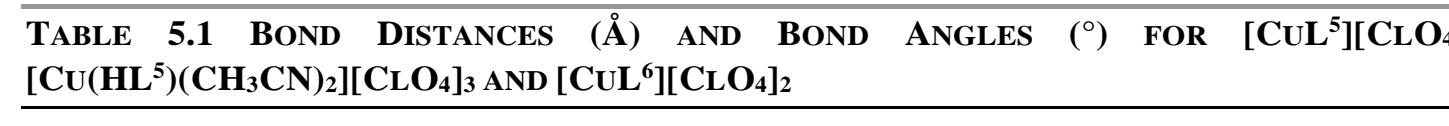 } \\
\hline DistanCE & {$\left[\mathrm{CUL}^{5}\right]\left[\mathrm{CLO}_{4}\right]_{2}$} & {$\left[\mathrm{CU}\left(\mathrm{HL}^{5}\right)\left(\mathrm{CH}_{3} \mathrm{CN}\right)_{2}\right]\left[\mathrm{CLO}_{4}\right]_{3}$} & {$\left[\mathrm{CUL}^{6}\right]\left[\mathrm{CLO}_{4}\right]_{2^{\mathrm{A}}}$} \\
\hline Cu1-N1 & $1.957(2)$ & $1.9565(19)$ & $1.992(4)$ \\
\hline Cu1-N3 & $2.019(2)$ & $2.030(2)$ & $1.980(4)$ \\
\hline Cu1-N4 & $2.024(2)$ & $2.0419(19)$ & $1.992(4)$ \\
\hline Cu1-N5 & $1.955(2)$ & - & $1.992(3)$ \\
\hline Cu1-N7 & - & $2.0047(19)$ & - \\
\hline $\mathrm{Cu} 1-\mathrm{N} 8$ & - & $2.209(2)$ & - \\
\hline \multirow{2}{*}{$\mathrm{Cu} 1 \cdots \mathrm{OClO}_{3}$} & $2.589(2)^{\mathrm{B}}$ & $3.0573(1)^{\mathrm{D}}$ & $2.610^{\mathrm{E}}$ \\
\hline & $2.707(2)^{\mathrm{C}}$ & & $2.610^{\mathrm{F}}$ \\
\hline \multicolumn{4}{|l|}{ ANGLE } \\
\hline N1-Cu1-N3 & $84.02(9)$ & $82.11(8)$ & $82.52(15)$ \\
\hline $\mathrm{N} 1-\mathrm{Cu} 1-\mathrm{N} 4$ & $162.84(9)$ & $162.14(8)$ & $167.85(15)$ \\
\hline N3-Cu1-N4 & $85.12(9)$ & $83.96(8)$ & $85.43(15)$ \\
\hline $\mathrm{N} 5-\mathrm{Cu} 1-\mathrm{N} 1$ & $110.33(9)$ & - & $110.34(14)$ \\
\hline N5-Cu1-N3 & $161.36(9)$ & - & $166.53(15)$ \\
\hline N5-Cu1-N4 & $83.30(2)$ & - & $81.79(14)$ \\
\hline N3-Cu1-N7 & - & $162.21(8)$ & - \\
\hline N3-Cu1-N8 & - & $98.61(8)$ & - \\
\hline
\end{tabular}

${ }^{\mathrm{A}}\left[\mathrm{CuL}^{6}\right]\left[\mathrm{ClO}_{4}\right]_{2}$ atoms are renumbered according to $\left[\mathrm{CuL}^{5}\right]\left[\mathrm{ClO}_{4}\right]_{2} \cdot{ }^{\mathrm{B}-\mathrm{F}}$ respective distances to perchlorate oxygens $\mathrm{O} 1, \mathrm{O} 5, \mathrm{O} 21$, and $\mathrm{O} 11$.

\subsection{Catalytic oxidations: Identification of system components}

All reported values are an average of at least three trials. In a typical trial, $5 \mathrm{mmol}$ $(0.5 \mathrm{~mL})$ of benzyl alcohol was dissolved in $10 \mathrm{~mL}$ of acetonitrile in a vial. To this solution was added $5 \mathrm{~mol} \%$ (with respect to substrate = w.r.t. substrate) TEMPO, $5 \mathrm{~mol} \%$ (w.r.t. substrate) copper catalyst, and 5 mol\% (w.r.t. substrate) NMI. Toluene (0.10 M) was added as an internal standard. The reaction was stirred at room temperature open to air for 4 hours during which time the color of the stock solution changed from blue to green. After $4 \mathrm{hrs}$., 
a $10 \mu \mathrm{L}$ aliquot was taken from the solution, diluted with acetonitrile, and analyzed by GCMS.

To probe the dependence of the individual components on turnover number (TON) and yield, the composition of the catalyst mixture was systematically varied. For substrate concentration studies, the moles of benzyl alcohol were varied from $1 \mathrm{mmol}$ to $20 \mathrm{mmol}$ while keeping the quantities of $\left[\mathrm{CuL}^{5}\right]^{2+}$, TEMPO, and $\mathrm{NMI}$ at $250 \mu \mathrm{mol}$, i.e. $5 \mathrm{~mol} \%$ with respect to $5 \mathrm{mmol}$ substrate solution in $10 \mathrm{~mL} \mathrm{CH}_{3} \mathrm{CN}$. Similarly, for catalyst concentration studies, the moles of catalyst were varied from 0.1 to 10 mol\% w.r.t. substrate with TEMPO and NMI held constant at $5 \mathrm{~mol} \%$ w.r.t. substrate. For TEMPO and NMI concentration studies, the equivalents of the TEMPO and NMI were varied from 0.05 to 2 and 0.5 to 10 equivalents w.r.t. $\left[\mathrm{CuL}^{5}\right]^{2+}$, respectively, with all other components held at $5 \mathrm{~mol} \%$ w.r.t substrate. To investigate the effect of $\mathrm{O}_{2}$ flowrate the typical reaction conditions were employed at flowrates ranging from 0.05 to $1 \mathrm{ml} / \mathrm{sec}$.

To evaluate the catalytic activity of $\left[\mathrm{CuL}^{5}\right]^{2+}$ for its ability to oxidize benzylic alcohols under aerobic conditions we employed a series of reaction conditions. The formation of the product was analyzed using toluene as an internal standard by GC-MS. TEMPO, a co-catalyst used in the reaction mixture prevents the formation of any carboxylic acid product due to its internal ability to scavenge free radicals and avoids autoxidation. ${ }^{166}$

The reaction trials were conducted using $10 \mathrm{ml}$ acetonitrile as a solvent for 4 hours using $5 \mathrm{mmol}$ of substrate and $250 \mu \mathrm{mol}\left(5 \mathrm{~mol} \%\right.$ with respect to substrate) of $\left[\mathrm{CuL}^{5}\right]^{2+}$, base, and/or radical initiator. All the reactions were monitored at room temperature i.e. 298 K. Addition of NMI as an external base to the mixture of $\left[\mathrm{CuL}^{5}\right]^{2+}$, substrate and TEMPO 
enhances the reaction yields. The highest activity with $76 \pm 3.6 \%$ yield is observed for the benzyl alcohol to benzaldehyde. The oxidation of selected benzylic alcohols has been summarized below in Table 5.2.

A series of control experiments have been performed to understand the catalytic efficiency of the system better. Absence of metal complex do not yield any product formation, in the presence of radical initiator TEMPO or in the presence of NMI and TEMPO (Entry 1-2). The presence of metal precursor $\mathrm{Cu}\left(\mathrm{ClO}_{4}\right)_{2} \cdot 6 \mathrm{H}_{2} \mathrm{O}$ is active with lower yields of $1.5 \pm 2.6 \%$ in the presence of radical initiator and base. (Entry 6). Absence of base or initiator resulted in no product yield. Also, the presence of air is necessary to achieve the good turnover numbers. The catalytic trial run in the presence of nitrogen atmosphere resulted in no conversion of substrate to the product (Entry 8).

\begin{tabular}{l} 
TABLE 5.2 OXIDATION OF THE SELECTED BENZYLIC ALCOHOLS TO THE CORRESPONDING CARBONYL COMPOUNDS AT \\
298 K. \\
ENTRY \\
\hline
\end{tabular}

Entries 1-20 were recorded under air, except entry 8 . The reaction in entry 8 was performed under nitrogen atmosphere. 
The Schiff base complex $\left[\mathrm{CuL}^{4}\right]^{2+}$ and the reduced Schiff base complex $\left[\mathrm{CuL}^{5}\right]^{2+}$ have been evaluated for their catalytic ability to oxidize benzyl alcohol in aerobic conditions in the presence of NMI and TEMPO., $\left[\mathrm{CuL}^{4}\right]^{2+}$ was found to be inadequate to catalyze benzyl alcohol to benzaldehyde whereas, $\left[\mathrm{CuL}^{5}\right]^{2+}$ was found to be the active catalyst for the conversion of benzylic alcohols to benzylic aldehyde (Entry 7-8).

The entries 10- 13 shows the effect of external base to the reaction mixture. The bases differing in nucleophilicity and basicity in acetonitrile was examined and the highest catalytic activity was recorded for weakest base, NMI which has a $p K$ a value of 17.1. The non-coordinating base DBU which is 1,8 -diazabicycloundec-7-ene, $\left(p K_{a}=24.13\right)$ was found to be active for catalytic activity resulting in the product yield of $56 \pm 5.5$, less than the yield recorded with NMI. This is in contrast to previous results by Stahl. ${ }^{173}$ Bases like $\mathrm{Et}_{3} \mathrm{~N}\left(p K_{a}=18.5\right)$ and $N, N$-diisopropylethylamine (DIPEA), $p K_{a} 18.6$, which has lower nucleophilicity than NMI have been found to yield less product formation (Entry 10-13). These results indicate that during the catalytic turnover coordination of an external base is not necessary to the active metal centre of the catalyst, $\left[\mathrm{CuL}^{5}\right]^{2+}$. However, the better catalytic yields in the presence of NMI as an external base indicates the complementation of the basicity between NMI and imidazole donors of $\mathrm{L}_{5}$ ligand framework, thus permitting fast proton exchange during catalytic cycle.

TEMPO, a nitroxyl radical initiator is vastly employed to study the oxidation of benzylic alcohols. In this study, hydroxyl radical sources like $\mathrm{H}_{2} \mathrm{O}_{2}$ and tert-butyl hydroperoxide (TBHP) have been employed. ${ }^{172,}$ 180-181 The results have been summarised in entries 14 and 15. The hydroxyl radicals $\mathrm{H}_{2} \mathrm{O}_{2}$ and TBHP found to be inactive towards the initiation of the catalysis. This can be attributed to the non-coordinating behaviour of 
the hydroxyl radicals to the metal atom, in contrast to the nitroxyl radical like TEMPO. Attempts were made to increase the temperature up to $323 \mathrm{~K}$ in the presence to hydroxyl radicals but still no detectable formation of product is observed.

The variety of substrates has been screened to evaluate the catalytic efficiency of $\left[\mathrm{CuL}^{5}\right]^{2+}$. Entries 16-18 lists the different benzylic alcohols. The \% yield of the aldehyde product was found to improve with the substitution of the electron withdrawing group like $-\mathrm{NO}_{2}$ and $-\mathrm{Br}$, in contrast to the electron releasing group like $-\mathrm{OCH}_{3}$. No product yield was recorded for the acyclic alcohols like cyclohexanol (entry 19). Also, the catalytic system was found to be inactive towards the aerobic oxidation of secondary benzylic alcohols, 1phenyl-2-propanol (entry 20).

\subsection{Catalytic oxidations: Mechanistic studies}

The relative concentrations of each of the components in the reaction mixture were varied to have the better understanding of the mechanism. The impact on percent yield (100 x moles product per moles of substrate) and turnover number, TON (moles product per moles of catalyst) was studied.

Variation in Substrate Concentration. In the reaction mixture volume of the substrate, benzyl alcohol was varied from $1 \mathrm{mmol}$ to $20 \mathrm{mmol}$ while keeping the constant molar quantities of $\left[\mathrm{CuL}^{5}\right]^{2+}$, TEMPO, and NMI at $250 \mu \mathrm{mol}$ each under an aerobic atmosphere. Figure 5.7 shows a plot of TON (left axis) and \% Yield (right axis) versus alcohol concentrations. At concentrations equal to or less than $2.5 \mathrm{mmol}$ of benzyl alcohol, the percent yield of $92.7 \pm 6.5 \%$ is obtained. At higher concentrations of substrate, the TON shows a decrease with the maximum value recorded between $11.8 \pm 1.1$ and $15.3 \pm 0.7$. 
The equimolar ratios of $\left[\mathrm{CuL}^{5}\right]^{2+}$, TEMPO, and NMI are required to obtain the high yields and TON of the product. The maximum $\%$ yield of $76 \pm 3.7 \%$ is recorded for $5 \mathrm{mmol}$ of the substrate. The $\%$ yield drops down to $33 \pm 1.4 \%$ on using $10 \mathrm{mmol}$ of the substrate. Quantitative conversion with the maximum TON are obtained when 3-4 mmol of alcohol which ranges between ( $0.5 \mathrm{~mol} \%$ to $5.0 \mathrm{~mol} \%$ catalysts) is used.

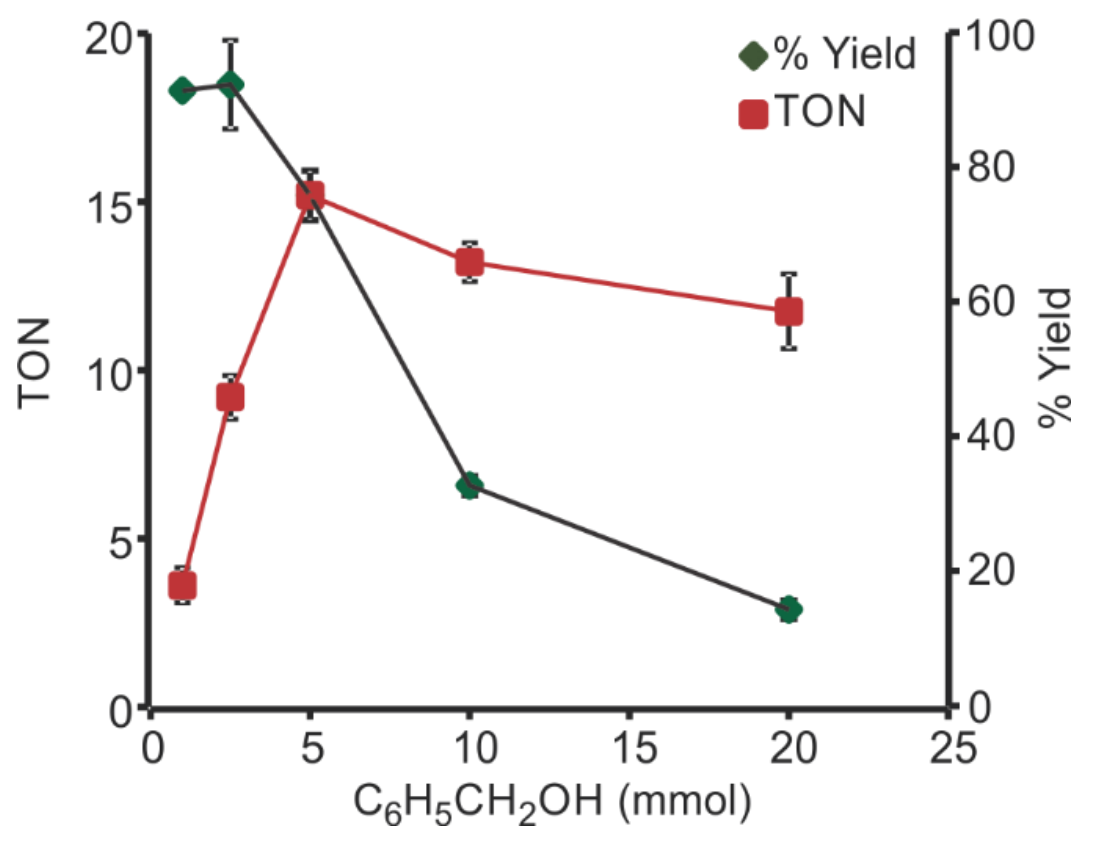

Figure 5.7 Plot of TON (red squares, left axis) and \% yield (green diamonds, right axis) versus substrate quantity. $\left[\mathrm{CuL}^{5}\right]^{2+}=\mathrm{NMI}=\mathrm{TEMPO}=250 \mu \mathrm{mol}, 10 \mathrm{~mL} \mathrm{CH} \mathrm{CHN}_{3}$, aerobic conditions.

Variation in $\left[\mathrm{CuL}^{5}\right]^{2+}$ Concentration. In the reaction mixture $\left[\mathrm{CuL}^{5}\right]^{2+}$ concentrations were varied from 0.1 to $10 \mathrm{~mol} \%$ with respect to substrate. The percent yield and TON were plotted as a function of catalyst mole percent, Figure 5.8. The concentrations of base, NMI, and radical initiator TEMPO were kept constant at $5 \mathrm{~mol} \%$ with respect to benzyl alcohol. At $5 \mathrm{~mol} \%$ of the catalyst loading the maximum percent yield of $76 \pm 3.7 \%$ is obtained. Catalyst loading lower or higher than $5 \mathrm{~mol} \%$ with respect to substrate results in decrease in the product yield. At higher catalyst loading of $10 \mathrm{~mol} \%$ lowest TON of $1.1 \pm 0.1$ is 
obtained indicating that both TEMPO and NMI is inadequate in the reaction mixture to achieve high TON. At lower catalyst loadings, limited by concentrations of $\left[\mathrm{CuL}^{5}\right]^{2+}$ yields lower TON although the relative quantities of TEMPO, NMI, and/or $\mathrm{O}_{2}$ are sufficient. The most efficient conversion occurs at $5 \mathrm{~mol} \%\left[\mathrm{CuL}^{5}\right]^{2+}$ with respect to substrate.

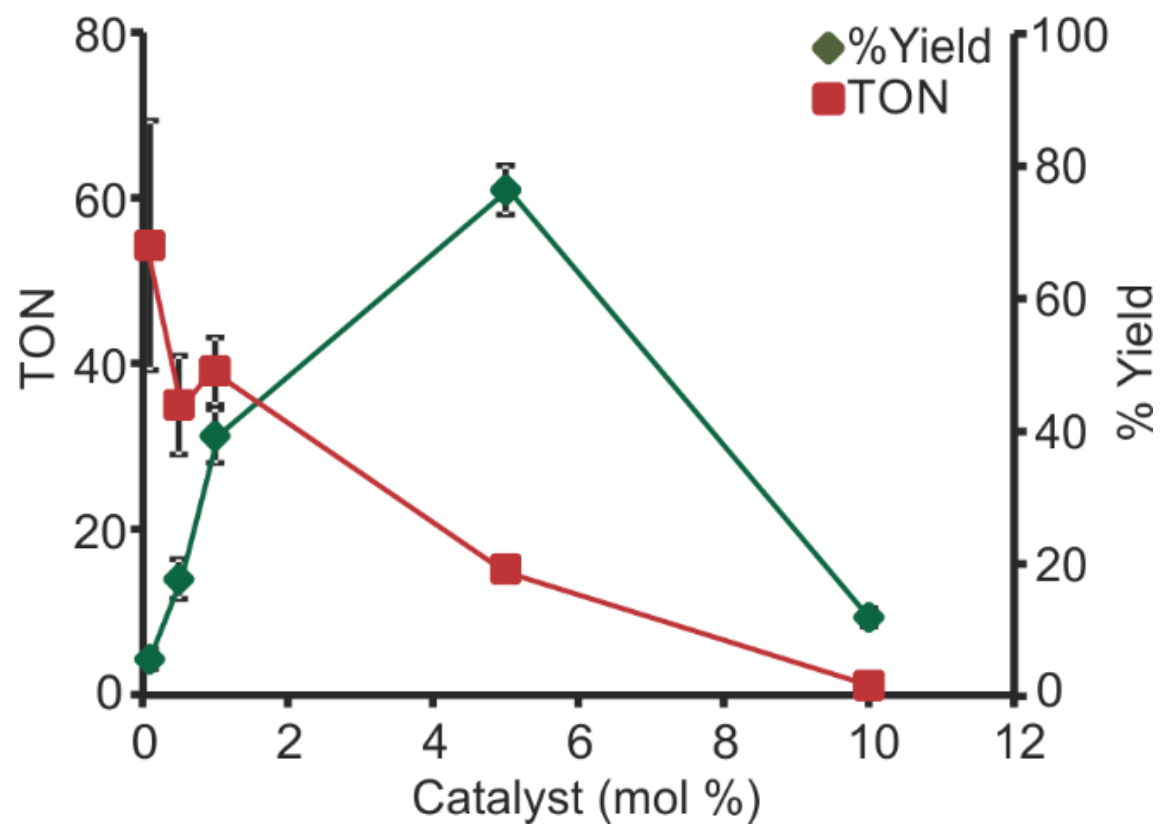

Figure 5.8 Plot of TON (red squares, left axis) and \% yield (green diamonds, right axis) versus

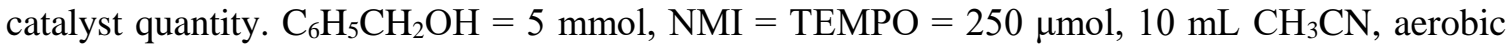
conditions.

Variations in TEMPO Concentrations. In the further studies, loadings of the co-catalyst TEMPO were varied keeping the concentrations of $\left[\mathrm{CuL}^{5}\right]^{2+}$ and NMI at $5 \mathrm{~mol} \%$ with respect to substrate. On adding one equivalent i.e. 5 mol\% of TEMPO with respect to substrate maximum turnover is obtained. At lower concentrations of TEMPO, insufficient amounts of co-catalyst with respect to other components suggests lowering in TON whereas while increasing the relative TEMPO concentrations indicates the blocking of substrate binding site, Figure 5.9. 


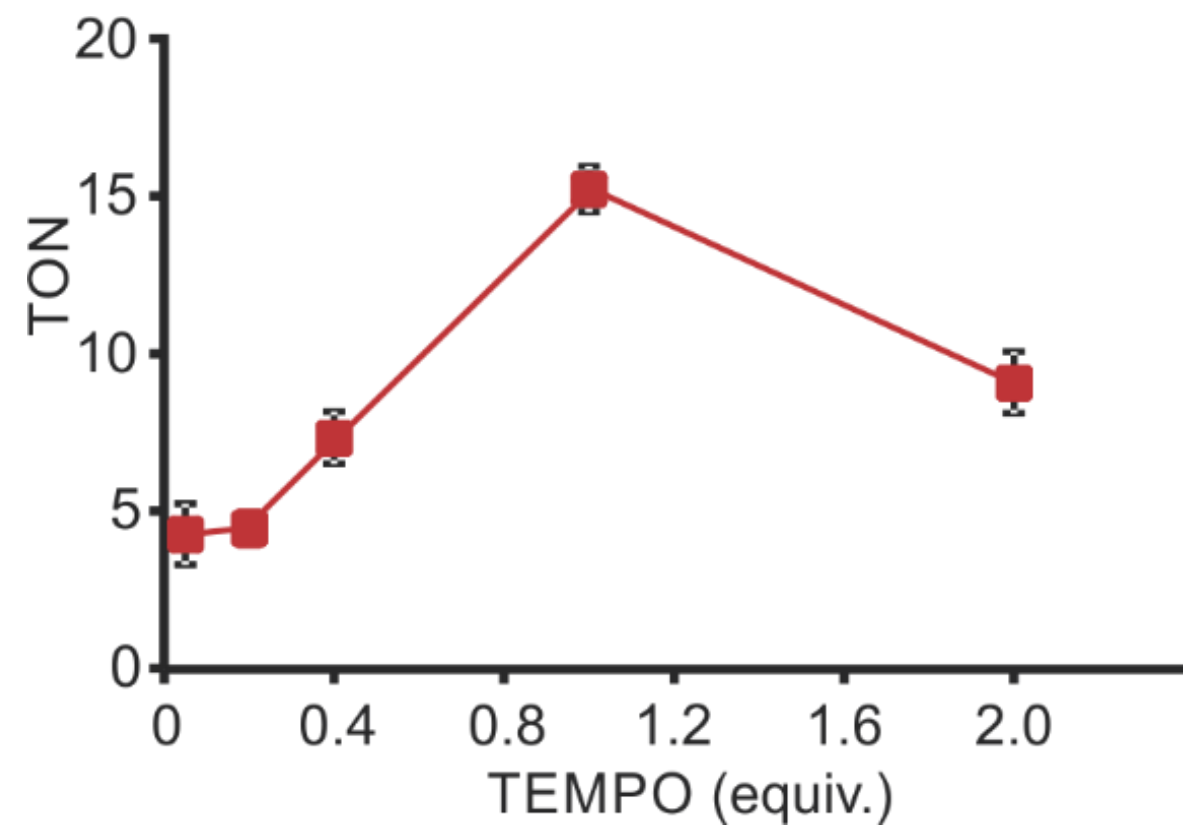

Figure 5.9 Plot of TON versus TEMPO equivalents relative to $\left[\mathrm{CuL}^{5}\right]^{2+} . \mathrm{C}_{6} \mathrm{H}_{5} \mathrm{CH}_{2} \mathrm{OH}=5 \mathrm{mmol}$, $\left[\mathrm{CuL}^{5}\right]^{2+}=\mathrm{NMI}=250 \mu \mathrm{mol}, 10 \mathrm{~mL} \mathrm{CH}_{3} \mathrm{CN}$, aerobic conditions.

Variations in NMI Concentrations. To get more insights, the concentration of external base NMI was varied keeping the $\left[\mathrm{CuL}^{5}\right]^{2+}$ and TEMPO loadings of $5 \mathrm{~mol} \%$ with respect to substrate. On increasing the NMI loading from 1 equivalent to 2 TON increases. Further increases in the concentration of NMI causes the TON to drop down, which is a trend similar to that observed with increases in the concentration of TEMPO. This suggests binding of excess base to the active site hinders the binding of the TEMPO moiety required to initiate the catalysis, Figure 5.10. 


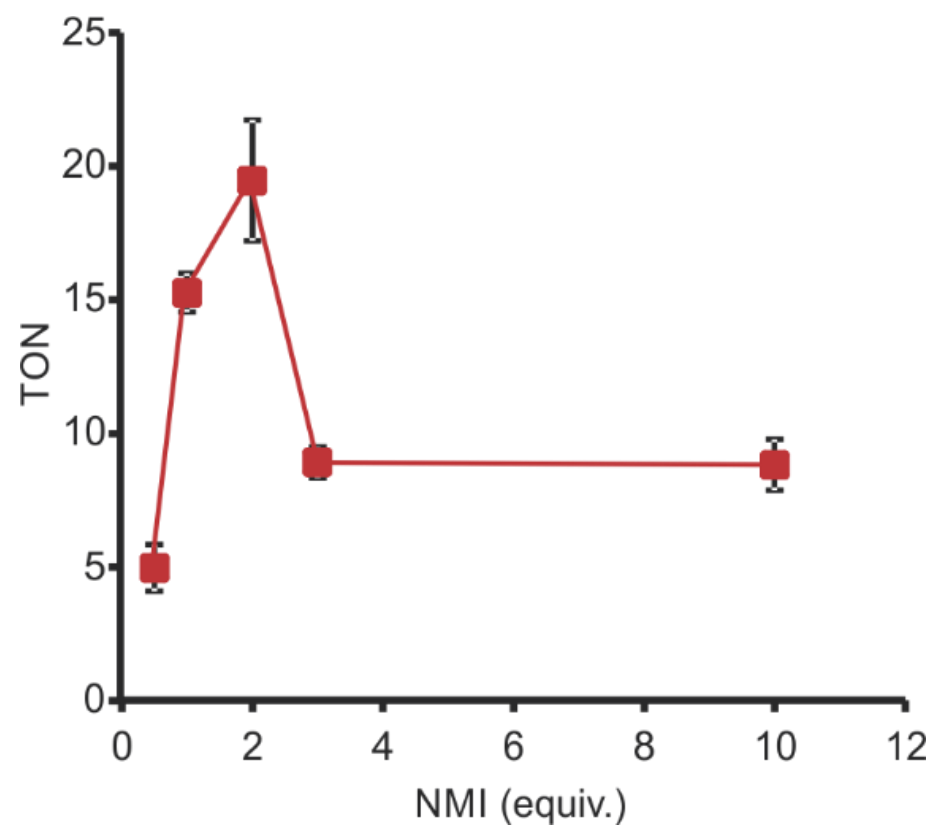

Figure 5.10 Plot of TON versus NMI equivalents relative to $\left[\mathrm{CuL}^{5}\right]^{2+} \cdot \mathrm{C}_{6} \mathrm{H}_{5} \mathrm{CH}_{2} \mathrm{OH}=5 \mathrm{mmol}$, $\left[\mathrm{CuL}^{5}\right]^{2+}=\mathrm{TEMPO}=250 \mu \mathrm{mol}, 10 \mathrm{~mL} \mathrm{CH} \mathrm{CHN}_{3}$, aerobic conditions.

Solvent screening. The catalytic trials were also conducted in common solvents like tetrahydrofuran (THF) and water. ${ }^{182-184}$ However, the yields found to drop dramatically when going from acetonitrile to these solvents. In THF, \% yields of $24.04 \pm 1.22$ were recorded whereas using water as a solvent yield $18.93 \pm 2.32 \%$ of the product. This might be attributed to possible coordination of the oxygen containing solvent to the metal centre of the catalyst as described in the mechanism. There is a chance of competitive binding between the solvent and substrate molecule.

Variation in oxygen flow rate. To evaluate the effect of flow of oxygen on the product yield, the reaction mixture was stirred under the continuous flow of oxygen at one atmospheric pressure at different flowrates for two hours. With the increase in the flowrate of the oxygen, a linear increase in the TON is observed with the maximum TON of 17.3 at 
an oxygen flowrate of $1 \mathrm{~mL} / \mathrm{sec}$ for 2 hours. This is indicative of the fact that reoxidation of the catalyst by oxygen is a kinetically important step, Figure 5.11.

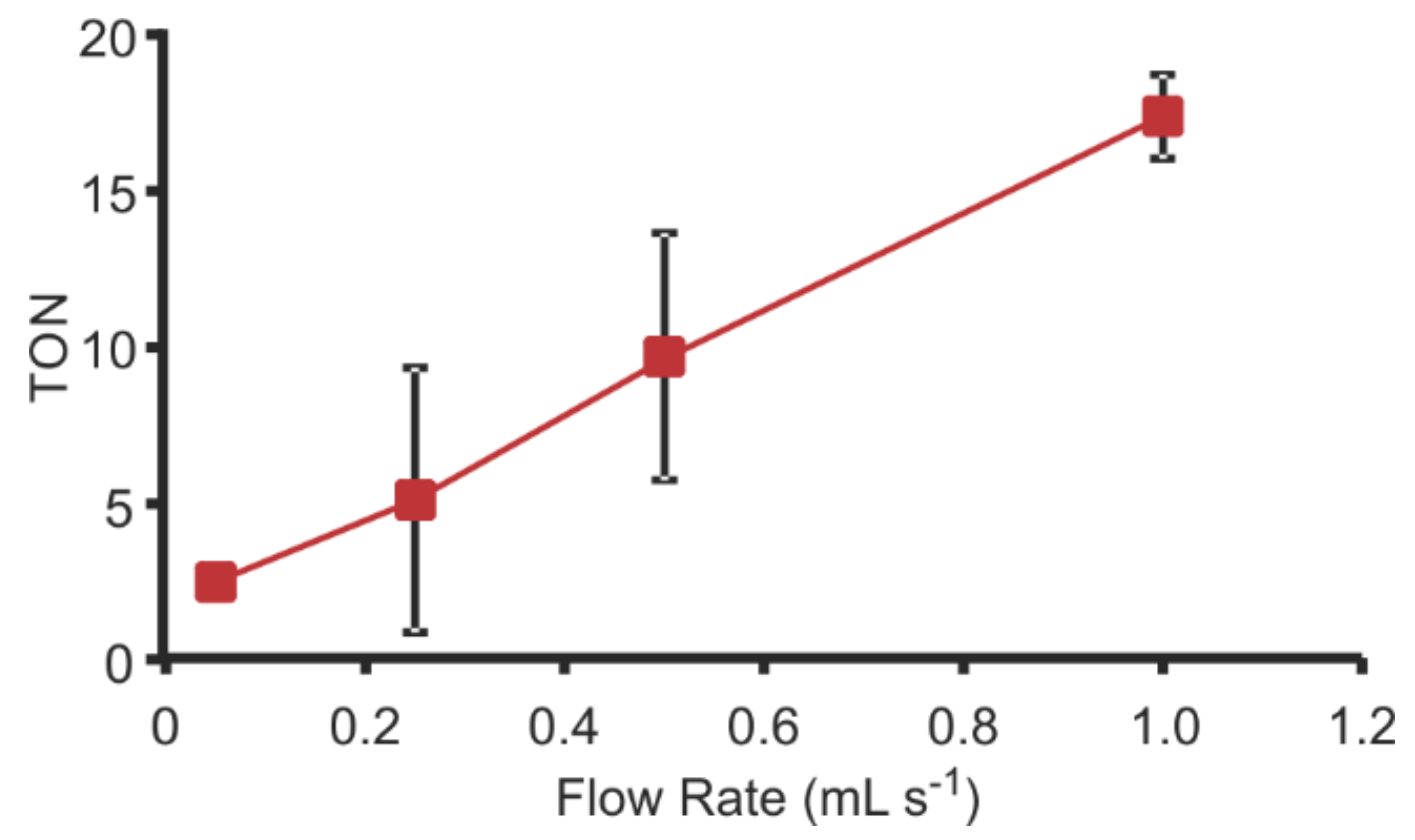

Figure 5.11 Plot of TON versus $\mathrm{O}_{2}$ flowrate. $\mathrm{C}_{6} \mathrm{H}_{5} \mathrm{CH}_{2} \mathrm{OH}=5 \mathrm{mmol},\left[\mathrm{CuL}^{5}\right]^{2+}=\mathrm{NMI}=\mathrm{TEMPO}$ $=250 \mu \mathrm{mol}, 10 \mathrm{~mL} \mathrm{CH}{ }_{3} \mathrm{CN}$.

\subsection{Proposed mechanism for aerobic oxidation of benzylic alcohols with $\left[\mathrm{CuL}^{5}\right]^{2+}$}

Based on above results, Figure 5.12 shows a proposed mechanism for $\left[\mathrm{CuL}^{5}\right]^{2+}$ catalysed aerobic oxidation of benzyl alcohol. In the first step, binding of the benzyl alcohol to the $\mathrm{Cu}^{2+}$ centre takes place. This makes the alcohol more acidic by lowering its $\mathrm{pKa}$, thus enables the external base NMI to abstract the acidic proton from the alcohol. The protonated $\mathrm{H}(\mathrm{NMI})^{+}$is in equilibrium with one of the imidazole arms in the N4- ligand framework. In the next stage, one of the imidazole arms gets protonated and opens the site for the TEMPO to coordinate with the metal centre. This results in the formation of fivecoordinate intermediate that resembles $\left[\mathrm{Cu}\left(\mathrm{HL}^{5}\right)\left(\mathrm{NCCH}_{3}\right)_{2}\right]^{3+}$. H-atom transfer from the substrate to $\eta^{1}$-nitroxyl leads to the formation of TEMPOH. ${ }^{174}$ In the next stage, aldehyde 
product dissociation yields $\mathrm{Cu}(\mathrm{I})$ complex $\left[\mathrm{Cu}\left(\mathrm{HL}^{5}\right)\right]^{2+}$. In the presence of TEMPOH and $\mathrm{O}_{2}$, deprotonation of $\left[\mathrm{Cu}\left(\mathrm{HL}^{5}\right)\right]^{2+}$ takes place. In the final step, $\mathrm{Cu}(\mathrm{I})$ is aerobically gets oxidized to regenerate $\mathrm{Cu}(\mathrm{II})$ catalyst.

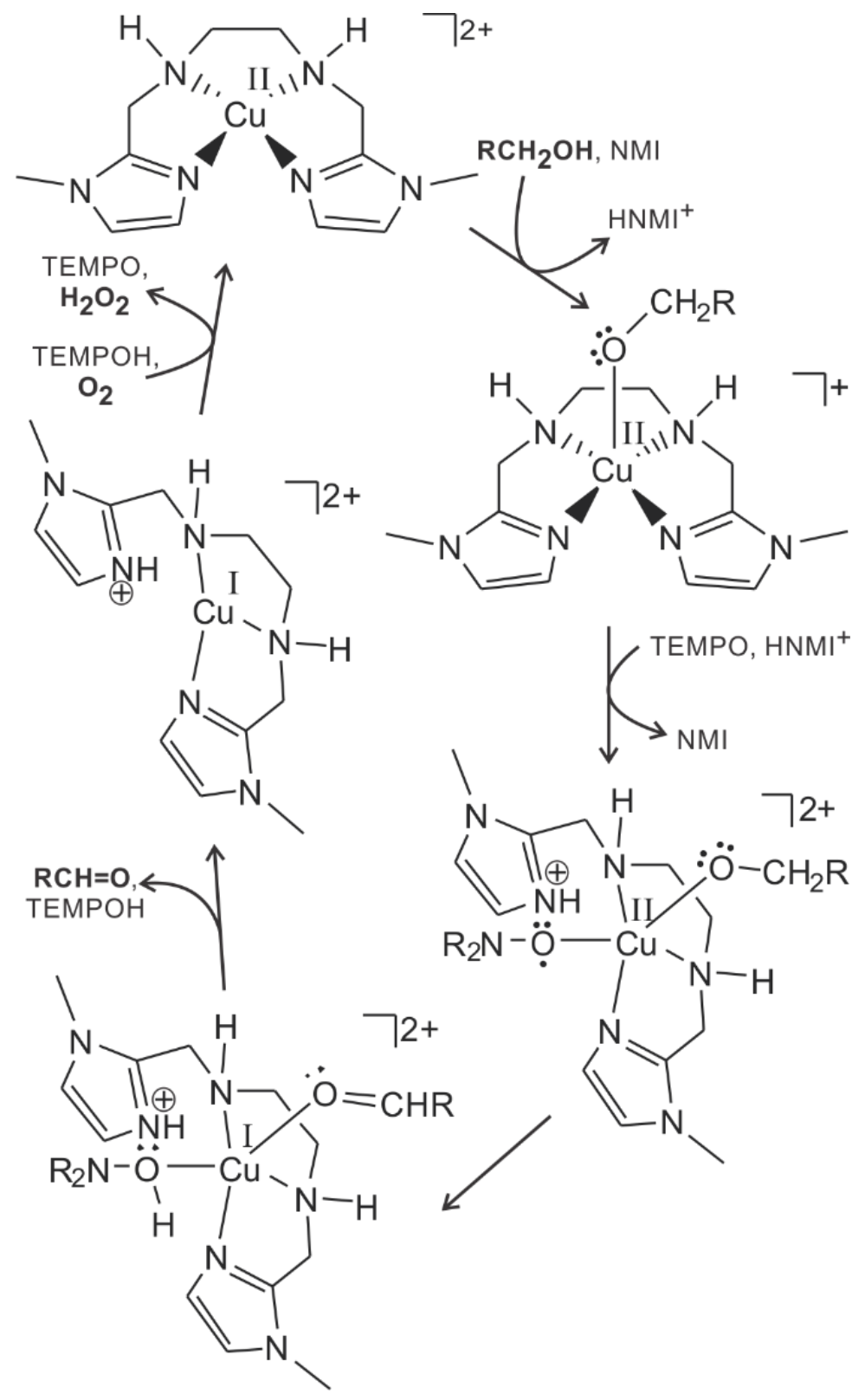

Figure 5.12 A proposed mechanism for alcohol oxidation with $\left[\mathrm{CuL}^{5}\right]^{2+} .{ }^{178}$ 


\subsection{Conclusions}

The tetradentate copper(II) complexes with $\mathrm{N}_{4}$ ligand framework having an imidazole in the ligand framework has been synthesized, characterized and evaluated for its catalytic ability to oxidize benzylic alcohols to corresponding aldehydes. The optimum conditions to achieve quantitative yields require the combination of $5 \mathrm{mmol}$ of substrate, 5 mol\% catalyst with respect to substrate, $5 \mathrm{~mol} \%$ radical initiator TEMPO with respect to substrate, $5 \mathrm{~mol} \%$ external base NMI with respect to substrate in $10 \mathrm{ml}$ of acetonitrile. Additional NMI enhances the turnover with yields up to $99 \%$ within 4 hours. The key role of the base is shown in the proposed mechanism where the base helps in the deprotonation of the coordinated substrate with subsequent proton transfer to the pendent NMI of the ligand framework. This eventually helps in the opening of the ligand framework and thus helping in the radical initiator TEMPO in binding to the copper centre. 


\section{CHAPTER VI \\ CONCLUSIONS AND FUTURE DIRECTIONS}

This dissertation detailed the evaluation of the ligand assisted activation of small molecules through proton reduction and alcohol oxidation. First-row earth abundant transition metals $\mathrm{Ni}, \mathrm{Cu}$ and $\mathrm{Zn}$ have been employed to develop the economically viable molecular catalysts. The ligand backbone and orientation of the ligand framework around the metal center found to play a crucial role in the reactivity and mechanistic studies of the complexes.

In the efforts to develop economical electrocatalysts for hydrogen evolution reactions, earth abundant cheap transition metal nickel has been complexed with the redox non-innocent ligands, benzenethiols and bis(thiosemicarbazones). The dialkyl/diaryl benzenethiols in Chapter 3 are the redox active ligands that undergo ligand centered oxidation at the sulfur. The orientation of the benzenetiolate ligands on the metal atom directs the coordination of the incoming proton on to the molecule. In contrast to benezenethiol ligands which undergo a one electron oxidation, the bis(thiosemicarbazone) ligand framework described in Chapter 4 undergo reduction due to presence of terminal $\alpha$ diimine unit. The redox non-innocence nature of the bis(thiosemicarbazone) ligand has been exploited for the proton reduction studies. In Chapter 5, the $\mathrm{N}_{4}$-ligand framework with imidazole integrated as the part of the ligand framework was established that has been used 
to oxidize benzylic alcohols to benzaldehydes under aerobic conditions. The three projects described in this dissertation has been summarized below.

\section{Electrocatalytic hydrogen evolution and hydrogen oxidation with $\mathrm{Ni}(\mathrm{PS})_{2}$ complex}

Chapter 3 described the syntheses, characterization, and electrocatalytic studies of four complexes $\mathrm{Ni}\left(\mathrm{L}^{1}\right)_{2}, \mathrm{Ni}\left(\mathrm{L}^{2}\right)_{2}, \mathrm{Zn}\left(\mathrm{L}^{1}\right)_{2}$ and $\mathrm{Zn}\left(\mathrm{L}^{2}\right)_{2}$. $\mathrm{Ni}\left(\mathrm{L}^{1}\right)_{2}$ was found to be electrocatalytically active for hydrogen evolution and hydrogen oxidation, whereas $\mathrm{Ni}\left(\mathrm{L}^{2}\right)_{2}$ was found to be electrocatalytically active for hydrogen oxidation. $\mathrm{Zn}\left(\mathrm{L}^{1}\right)_{2}$ and $\mathrm{Zn}\left(\mathrm{L}^{2}\right)_{2}$ were found to be inadequate for both HER and HOR. The $\operatorname{Re}\left(\mathrm{L}^{1}\right)_{3}$ complex previously reported by our group was found to evolve hydrogen in the presence of external acids as well as cleave dihydrogen in the presence of external base under $1 \mathrm{~atm} . \mathrm{H}_{2}$. The drawback of $\operatorname{Re}\left(\mathrm{L}^{1}\right)_{3}$ was the high cost of the Re metal to develop catalytic systems for HER and HOR. This lead us to exploit cheap first row transition metals like nickel and zinc and complexing them with the ligand $\mathrm{L}^{1}$. The ligand $\mathrm{L}^{2}$ was also synthesized which has electron releasing isopropyl groups on phosphorus instead of electron withdrawing phenyl groups.

Out of the four complexes investigated in Chapter 3, only $\mathrm{Ni}\left(\mathrm{L}^{1}\right)_{2}$ was found to evolve hydrogen in the dichloromethane solutions with the maximum TOF of $140 \mathrm{~s}^{-1}$ using $\mathrm{HCl}$ as an external acid source at an overpotential of $1.1 \mathrm{~V} . \mathrm{Ni}\left(\mathrm{L}^{1}\right)_{2}$ also found to be electrocatalytically active for HER with weak acid $\mathrm{CH}_{3} \mathrm{COOH}$ with TOF of $51 \mathrm{~s}^{-1}$. Mechanistic studies revealed the first-order dependence on acid and first-order dependence on the catalyst concentration. The KIE studies shows the inverse isotope effect indicating towards the formation of metal hydride during the catalysis. The mechanism for HER with weak acid is postulated to be ECEC type. In the initial step, the electron addition takes place that reduces $\mathrm{Ni}(\mathrm{II})$ species to $\mathrm{Ni}(\mathrm{I})$ species. This is followed by protonation in the 
second step making $\mathrm{Ni}(\mathrm{III})$ hydride species. In the next step, the second electron addition takes place thus, reducing the $\mathrm{Ni}(\mathrm{III})$-hydride to $\mathrm{Ni}(\mathrm{II})$-hydride species. In this final step, the external proton from the solution interacts with the $\mathrm{Ni}(\mathrm{II})$ - hydride species to evolve hydrogen and regenerating original $\mathrm{Ni}\left(\mathrm{L}^{1}\right)_{2}$ catalyst. In electrocatalytic studies with strong acid $\mathrm{HCl}$, an additional protonation event is observed in the HER studies prior to reduction of $\mathrm{Ni}$ (II) species to $\mathrm{Ni}(\mathrm{I})$ species. This suggests that the other route for HER mechanism can be CEEC type in which first step is the chemical step leading to the formation of $[\mathrm{Ni}(\mathrm{II})-\mathrm{H}]^{+}$species. In the next step, addition of electron takes place to form $\mathrm{Ni}$ (III) hydride species which in the final step interacts with external proton to form hydrogen. $\mathrm{Ni}\left(\mathrm{L}^{1}\right)_{2}$ is found to cleave dihydrogen in the presence of external base $\mathrm{Et}_{3} \mathrm{~N}$ under 1 atm. $\mathrm{H}_{2}$ with the TOF of $23 \mathrm{~s}^{-1}$ at an overpotential of $0.33 \mathrm{~V} . \mathrm{Ni}\left(\mathrm{L}^{2}\right)_{2}$ showed no activity for hydrogen evolution due to inaccessible $\mathrm{Ni}(\mathrm{II} / \mathrm{I})$ reduction but cleaves dihydrogen with the TOF of 19 $\mathrm{s}^{-1}$ at an overpotential of $0.49 \mathrm{~V}$.

Future studies with these systems include the complexation of the benzenethiol ligands with different metals like $\mathrm{Cu}$ and Fe for the ability to catalyze HER and HOR. Also, modification of the ligand framework by changing the R-groups on the Phosphorus atom and substitution on the benzene ring can be taken into consideration. The future studies can include the choice of different solvent like dimethylformamide and use of other acids like $\mathrm{HBF}_{4}, \mathrm{CF}_{3} \mathrm{COOH}, \mathrm{Et}_{3} \mathrm{NH}^{+}, \mathrm{DMFH}^{+}$etc.

Electrocatalytic hydrogen evolution with bis(thiosemicarbazonato) Ni(II)complex

The synthesis of PS-ligands requires lot of effort as the organic ligands are air, moisture and light sensitive. In the search of simple and cost-effective systems for energy production, we have explored bis(thiosemicarbazones) as potential ligand frameworks for 
hydrogen evolution complexes. These $\mathrm{N}_{2} \mathrm{~S}_{2}$ ligand moieties employed in Chapter 4 are easy to synthesize and are stable under atmospheric conditions. Our group has previously reported $\mathrm{Zn}(\mathrm{II})$ and $\mathrm{Cu}(\mathrm{II})$ complexes with bis(thiosemicarbazones) as active electrocatalysts for HER. In chapter 4, the electrocatalytic hydrogen evolution with bis(thiosemicarbazonato) $\mathrm{Ni}(\mathrm{II})\left(\mathrm{NiL}^{3}\right)$ has been described. $\mathrm{NiL}^{3}$ was found to evolve hydrogen in the acetonitrile solutions with the maximum TOF of $4100 \mathrm{~s}^{-1}$ using $\mathrm{CH}_{3} \mathrm{COOH}$ as an external acid source at an overpotential of $0.52 \mathrm{~V}$. The catalytic studies were also conducted using strong acid $\mathrm{CF}_{3} \mathrm{COOH}$ in acetonitrile and dimethylformamide solutions. Mechanistic investigations first order dependence on the catalyst and second order dependence on the acid concentration. An inverse KIE values has been recorded which was indicative of the formation of metal hydride. DFT studies were conducted using functionals, B3LYP/6311 $\mathrm{g}$ and BP-86/TZV/P. The calculations were performed in gas phase and by applying Polarizable Continuum Model (PCM) calculations of solvent effects. The mechanism for HER with $\mathrm{NiL}^{3}$ based on experimental and theoretical calculations was proposed to be ECEC type.

Future studies involve the modification of the ligand framework with substituting the R-groups on the amine nitrogen with electron withdrawing groups like $-\mathrm{CF}_{3}$ to modulate the overpotential. Ligand backbone can be altered by the condensation of the different dione group other than butanedione with the modified thiosemicarbazide. Replacement of the alkyl groups in the butanedione with the aryl groups can affect the electron density observed on the ligand framework. The modified ligands complexed with first row transition metals like $\mathrm{Ni}, \mathrm{Zn}, \mathrm{Cu}, \mathrm{Mn}$ can be screened for the ability to generate hydrogen with the external acids. 
Copper catalyzed aerobic oxidation of benzylic alcohols in an imidazole containing $N_{4}$ ligand framework

This project describes the syntheses, characterization and catalytic behavior of $\mathrm{N}_{4}$ $-\mathrm{Cu}(\mathrm{II})$ complexes for oxidation of the benzylic alcohols to benzaldehydes under aerobic conditions. The galactose oxidase, is a copper containing fungal enzyme that catalyzes alcohol oxidation in nature. Various reports in literature describes the synthesis of copper coordinated systems that has been used for this purpose. Stahl group reported a simple $\mathrm{Cu}(\mathrm{I}) / \mathrm{bpy} / \mathrm{NMI}$ system for oxidation of variety of alcohols. In this one pot reaction, NMI was added as an external base to enhance the product yield. Taking an inspiration from this work, we synthesized two $\mathrm{Cu}(\mathrm{II})$ complexes containing NMI as an integral part of the ligand framework. The thought process behind the design of this ligand framework was to evaluate the effect on the oxidation reaction if NMI was present as a part of ligand. The $\mathrm{N}_{4}-\mathrm{Cu}$ (II) Schiff base complex is found to be inactive towards the oxidation of the benzylic alcohols whereas the $\mathrm{N}_{4}-\mathrm{Cu}$ (II) reduced Schiff base complex found to be active for the reaction. The optimum conditions to achieve the best results under aerobic conditions were found to be: $5 \mathrm{mmol}$ substrate, $5 \mathrm{~mol} \%$ catalyst w.r.t. substrate, $5 \mathrm{~mol} \%$ TEMPO w.r.t. substrate, $10 \mathrm{~mol} \%$ base w.r.t. substrate. Control experiments suggests that presence of $\mathrm{Cu}$ (II) source, TEMPO, NMI and air are required to initiate the oxidation. Absence of any of these results in no conversion. The electron withdrawing substituted benzylic alcohols like nitrobenzylic alcohols were found to works best with $\left[\mathrm{CuL}^{5}\right]^{2+}$ catalyst. The aliphatic alcohols and secondary benzylic alcohols found to be inactive towards their oxidation. The external base NMI founds to works best as compared to other bases like DBU and DIPEA. This can be attributed to the equilibrium established between protonated NMI and the 
coordinated NMI in the ligand framework, as described in the mechanism. The hydroxyl radical initiators $\mathrm{H}_{2} \mathrm{O}_{2}$ and $\mathrm{TBHP}$ found to be insufficient to initiate the reactions as compared to nitroxyl radical, TEMPO.

Mechanistic studies detail the study of the variation in the one of the components of the reaction mixture at a time keeping the mass of the other substituents constant. The excess or deficiency of any of the components decrease the percentage yield suggesting that all the components must be present in the specific quantities with respect to each other to achieve high conversions. For example, excess of catalyst with respect to substrate suggests that there was not enough TEMPO and NMI to come and interact with it to get better yields and deficiency of the catalyst indicates that now although TEMPO and NMI are present but no catalyst for binding to them to get better yields. The proposed mechanism involves the binding of alcohol in the first step, thus lowering its $\mathrm{p} K \mathrm{a}$, thus facilitating the external base NMI to abstracts the proton in the first step. In the second step, the protonated NMI establishes an equilibrium with the coordinated NMI and transfer of proton takes place, thus opening the site for the TEMPO to come and bind to the copper center. Transfer of electrons in the following step takes place and thus $\mathrm{Cu}(\mathrm{II})$ alkoxide is formed. The next step, yields TEMPOH and the aldehyde product and leaving behind $\mathrm{Cu}(\mathrm{I})$ complex. Final step, involves the formation of $\mathrm{H}_{2} \mathrm{O}_{2}$ by the abstraction of proton from the protonated coordinated NMI and TEMPOH and the regeneration of the catalyst by aerobic oxidation of $\mathrm{Cu}(\mathrm{I})$ to $\mathrm{Cu}(\mathrm{II})$, for use in the next cycle.

Future studies involve the use of $\mathrm{Cu}(\mathrm{I})$ source in place of $\mathrm{Cu}(\mathrm{II})$ to synthesize the complex. The modification of the ligand framework with various substitutions on the imidazole framework and its effect on the alcohol oxidation. To expand the horizon of 
oxidation studies with these systems, variety of other alcohol substrates can be tested for oxidation. 


\section{REFERENCES}

1. U.S. EIA, M. E. R., Table 1.3 and 10.1, April 2017, prelim. data.

2. Chaubey, R.; Sahu, S.; James, O. O.; Maity, S., Renew. Sust. Energ. Rev. 2013, 23, 443-462.

3. Cook, T. R.; Dogutan, D. K.; Reece, S. Y.; Surendranath, Y.; Teets, T. S.; Nocera, D. G., Chem. Rev. 2010, 110, 6474-6502.

4. DuBois, D. L., Inorg. Chem. 2014, 53, 3935-3960.

5. Nagarajan, D.; Lee, D.-J.; Kondo, A.; Chang, J.-S., Bioresour. Technol. 2017, 227, 373-387.

6. $\quad$ Ozmihci, S.; Kargi, F., Int. J. of Hydrog. Energy 2010, 35, 6674-6680.

7. Hay, J. X. W.; Wu, T. Y.; Juan, J. C.; Md. Jahim, J., Biofuels, Bioproducts and Biorefining 2013, 7, 334-352.

8. Stephenson, M.; Stickland, L. H., Biochem. J. 1931, 25, 205-214.

9. Vignais, P. M.; Billoud, B.; Meyer, J., FEMS Microbiol. Rev. 2001, 25, 455-501.

10. Vignais, P. M.; Billoud, B., Chem. Rev. 2007, 107, 4206-4272.

11. Fontecilla-Camps, J. C.; Amara, P.; Cavazza, C.; Nicolet, Y.; Volbeda, A., Nature 2009, 460, 814.

12. Volbeda, A.; Garcin, E.; Piras, C.; de Lacey, A. L.; Fernandez, V. M.; Hatchikian, E. C.; Frey, M.; Fontecilla-Camps, J. C., J. Am. Chem. Soc. 1996, 118, 1298912996.

13. Volbeda, A.; Charon, M.-H.; Piras, C.; Hatchikian, E. C.; Frey, M.; FontecillaCamps, J. C., Nature 1995, 373, 580.

14. Winkler, M.; Esselborn, J.; Happe, T., Biochim. Biophys. Acta, - Bioenerg. 2013, 1827, 974-985.

15. Lubitz, W.; Ogata, H.; Rüdiger, O.; Reijerse, E., Chem. Rev. 2014, 114, 4081-4148.

16. Rand, D. A. J., Dell, R. M., Hydrogen economy. Challenges and Prospects 2008.

17. Mehta, V.; Cooper, J. S., J. Power Sources 2003, 114, 32-53.

18. Jones, A. K.; Sillery, E.; Albracht, S. P. J.; Armstrong, F. A., Chem. Commun. 2002, 866-867.

19. Vincent, K. A.; Cracknell, J. A.; Lenz, O.; Zebger, I.; Friedrich, B.; Armstrong, F. A., Proc. Natl. Acad. Sci. USA 2005, 102, 16951-16954.

20. Vincent, K. A.; Belsey, N. A.; Lubitz, W.; Armstrong, F. A., J. Am. Chem. Soc. 2006, 128, 7448-7449.

21. Goldet, G.; Wait, A. F.; Cracknell, J. A.; Vincent, K. A.; Ludwig, M.; Lenz, O.; Friedrich, B.; Armstrong, F. A., J. Am. Chem. Soc. 2008, 130, 11106-11113.

22. Pandelia, M.-E.; Infossi, P.; Giudici-Orticoni, M. T.; Lubitz, W., Biochem. 2010, 49, 8873-8881.

23. Lai, C.-H.; Reibenspies, J. H.; Darensbourg, M. Y., Angew. Chem. Int. Ed. 1996, 35, 2390-2393. 
24. Schilter, D.; Camara, J. M.; Huynh, M. T.; Hammes-Schiffer, S.; Rauchfuss, T. B., Chem. Rev. 2016, 116, 8693-8749.

25. Weber, K.; Krämer, T.; Shafaat, H. S.; Weyhermüller, T.; Bill, E.; van Gastel, M.; Neese, F.; Lubitz, W., J. Am. Chem. Soc. 2012, 134, 20745-20755.

26. Ogo, S.; Ichikawa, K.; Kishima, T.; Matsumoto, T.; Nakai, H.; Kusaka, K.; Ohhara, T., Science 2013, 339, 682-684.

27. Rakowski DuBois, M.; DuBois, D. L., Chem. Soc. Rev. 2009, 38, 62-72.

28. Chen, S.; Ho, M.-H.; Bullock, R. M.; DuBois, D. L.; Dupuis, M.; Rousseau, R.; Raugei, S., ACS Catal. 2014, 4, 229-242.

29. Tran, P. D.; Barber, J., Phys. Chem. Chem. Phys. 2012, 14, 13772-13784.

30. Chaudhuri, P.; Verani, C. N.; Bill, E.; Bothe, E.; Weyhermüller, T.; Wieghardt, K., J. Am. Chem. Soc. 2001, 123, 2213-2223.

31. Zanello, P.; Corsini, M., Coord. Chem. Rev. 2006, 250, 2000-2022.

32. de Bruin, B.; Bill, E.; Bothe, E.; Weyhermüller, T.; Wieghardt, K., Inorg. Chem. 2000, 39, 2936-2947.

33. Chirik, P. J.; Wieghardt, K., Science 2010, 327, 794-795.

34. Budzelaar, P. H. M.; de Bruin, B.; Gal, A. W.; Wieghardt, K.; van Lenthe, J. H., Inorg. Chem. 2001, 40, 4649-4655.

35. Stiefel, E. I.; Waters, J. H.; Billig, E.; Gray, H. B., J. Am. Chem.Soc. 1965, 87, 3016-3017.

36. Bart, S. C.; Lobkovsky, E.; Chirik, P. J., J. Am. Chem. Soc. 2004, 126, 1379413807.

37. Sylvester, K. T.; Chirik, P. J., J. Am. Chem.Soc. 2009, 131, 8772-8774.

38. Smith, A. L.; Hardcastle, K. I.; Soper, J. D., J. Am. Chem. Soc. 2010, 132, 1435814360.

39. Blackmore, K. J.; Lal, N.; Ziller, J. W.; Heyduk, A. F., J. Am. Chem. Soc 2008, 130, 2728-2729.

40. Heyduk, A. F.; Zarkesh, R. A.; Nguyen, A. I., Inorg. Chem. 2011, 50, 9849-9863.

41. Ashby, M. T.; Enemark, J. H.; Lichtenberger, D. L., Inorg. Chem. 1988, 27, 191197.

42. Grapperhaus, C. A.; Mullins, C. S.; Kozlowski, P. M.; Mashuta, M. S., Inorg. Chem. 2004, 43, 2859-2866.

43. Grapperhaus, C. A.; Mullins, C. S.; Mashuta, M. S., Inorg. Chim. Acta 2005, 358, 623-632.

44. Mullins, C. S.; Grapperhaus, C. A.; Kozlowski, P. M., J. Biol. Inorg. Chem. 2006, 11, 617-625.

45. Ouch, K.; Mashuta, M. S.; Grapperhaus, C. A., Inorg. Chem. 2011, 50, 9904-9914.

46. Sampson, K. O.; Kumar, D.; Mashuta, M. S.; Grapperhaus, C. A., Inorg. Chim. Acta 2013, 408, 1-8.

47. Dilworth, J. R.; Hutson, A. J.; Morton, S.; Harman, M.; Hursthouse, M. B.; Zubieta, J.; Archer, C. M.; Kelly, J. D., Polyhedron 1992, 11, 2151-2155.

48. Dilworth, J. R.; Zheng, Y.; Lu, S.; Wu, Q., Trans. Met. Chem. 1992, 17, 364-368.

49. Grapperhaus, C. A.; Poturovic, S., Inorg. Chem. 2004, 43, 3292-3298.

50. Grapperhaus, C. A.; Ouch, K.; Mashuta, M. S., J. Am. Chem. Soc. 2009, 131, 6465. 
51. Haddad, A. Z.; Kumar, D.; Ouch Sampson, K.; Matzner, A. M.; Mashuta, M. S.; Grapperhaus, C. A., J. Am. Chem. Soc. 2015, 137, 9238-9241.

52. Zhang, W.; Haddad, A. Z.; Garabato, B. D.; Kozlowski, P. M.; Buchanan, R. M.; Grapperhaus, C. A., Inorg. Chem. 2017, 56, 2177-2187.

53. Marinescu, S. C.; Winkler, J. R.; Gray, H. B., Proc. Natl. Acad. Sci. 2012, 109, 15127-15131.

54. Kotani, H.; Hanazaki, R.; Ohkubo, K.; Yamada, Y.; Fukuzumi, S., Chem. Eur. J. 2011, 17, 2777-2785.

55. Gordon, A. J., The Chemistry Companion, John Wiley \& Sons Inc., Canada 1972.

56. Stoll, S.; Schweiger, A., J. Magn. Reson. 2006, 178, 42-55.

57. Block, E.; Eswarakrishnan, V.; Gernon, M.; Ofori-Okai, G.; Saha, C.; Tang, K.; Zubieta, J., J. Am. Chem. Soc. 1989, 111, 658-665.

58. Block, E.; Ofori-Okai, G.; Zubieta, J., J. Am. Chem. Soc. 1989, 111, 2327-2329.

59. Morales-Morales, D.; Rodríguez-Morales, S.; Dilworth, J. R.; Sousa-Pedrares, A.; Zheng, Y., Inorg. Chim. Acta 2002, 332, 101-107.

60. Betts, H. M.; Barnard, P. J.; Bayly, S. R.; Dilworth, J. R.; Gee, A. D.; Holland, J. P., Angew. Chem. Intl. Ed. 2008, 47, 8416-8419.

61. Ortega-Villar, N.; Ugalde-Saldívar, V. M.; Flores-Pérez, B.; Flores-Alamo, M.; Real, J. A.; Moreno-Esparza, R., Inorg. Chim. Acta 2011, 375, 213-219.

62. Bard, A. J., Faulkner, L. R., Electrochemical Methods: Fundamentals and Applications (2 ed.).Wiley. ISBN 0-471-04372-9.

63. Heinze, J., Angew. Chem. Intl. Ed. 1984, 23, 831-847.

64. Appel, A. M.; Helm, M. L., ACS Catal. 2014, 4, 630-633.

65. Roberts, J. A. S.; Bullock, R. M., Inorg. Chem. 2013, 52, 3823-3835.

66. Fourmond, V.; Jacques, P.-A.; Fontecave, M.; Artero, V., Inorg. Chem. 2010, 49, 10338-10347.

67. Wilson, A. D.; Newell, R. H.; McNevin, M. J.; Muckerman, J. T.; Rakowski DuBois, M.; DuBois, D. L., J. Am. Chem. Soc. 2006, 128, 358-366.

68. Appel, A. M.; DuBois, D. L.; Rakowski DuBois, M., J. Am. Chem. Soc. 2005, 127, 12717-12726.

69. Elgrishi, N.; McCarthy, B. D.; Rountree, E. S.; Dempsey, J. L., ACS Catal. 2016, 6, 3644-3659.

70. Rountree, E. S.; McCarthy, B. D.; Eisenhart, T. T.; Dempsey, J. L., Inorg. Chem. 2014, 53, 9983-10002.

71. Elgrishi, N.; Chambers, M. B.; Fontecave, M., Chem. Sci. 2015, 6, 2522-2531.

72. Wiedner, E. S.; Bullock, R. M., J. Am. Chem. Soc. 2016, 138, 8309-8318.

73. Costentin, C.; Drouet, S.; Robert, M.; Savéant, J.-M., J. Am. Chem. Soc. 2012, 134, 11235-11242.

74. Costentin, C.; Robert, M.; Saveant, J.-M., Chem. Soc. Rev. 2013, 42, 2423-2436.

75. Costentin, C.; Savéant, J.-M., ChemElectroChem 2014, 1, 1226-1236.

76. DiRisio, R. J.; Armstrong, J. E.; Frank, M. A.; Lake, W. R.; McNamara, W. R., Dalton Trans. 2017, 46, 10418-10425.

77. $\quad$ Artero, V.; Saveant, J.-M., Energ. Environ. Sci. 2014, 7, 3808-3814.

78. Atkins, P., de Paula, J, Atkins' Physical Chemistry ISBN 978-0-19-870072-2 2006.

79. CrysAlis PRO (CCD and RED), V., Agilent Technologies 2013.

80. SCALE3 ABSPACK included in CrysAlis PRO RED, (V.1.171.36.32) 2013 
81. Sheldrick, G. M., Acta Crystallogr., Sect. A 2008, 64, 112-122.

82. Kumar, D., "Sulfur-oxidation enhances nitrile hydration in bioinspired ruthenium complexes : catalytic, kinetic, and DFT investigations." 2015, Electronic Theses and Dissertations. Paper 2098., https://doi.org/10.18297/etd/2098.

83. Levine; I. N. 5th ed. Prentice-Hall, I., NJ.

84. Pople, J. A.; Gill, P. M. W.; Johnson, B. G., Chem. Phys. Lett. 1992, 199, 557-560.

85. Perdew, J. P.; Chevary, J. A.; Vosko, S. H.; Jackson, K. A.; Pederson, M. R.; Singh, D. J.; Fiolhais, C., Phys. Rev. B 1992, 46, 6671-6687.

86. Gill, P. M. W.; Johnson, B. G.; Pople, J. A.; Frisch, M. J., Chem. Phys. Lett. 1992, 197, 499-505.

87. Becke, A. D., J. Chem. Phys. 1993, 98, 1372-1377.

88. Becke, A. D., Phys. Rev. A 1988, 38, 3098-3100.

89. Lee, C.; Yang, W.; Parr, R. G., Phys. Rev. B 1988, 37, 785-789.

90. Blower, P. J.; Castle, T. C.; Cowley, A. R.; Dilworth, J. R.; Donnelly, P. S.; Labisbal, E.; Sowrey, F. E.; Teat, S. J.; Went, M. J., Dalton Trans. 2003, 44164425.

91. Barton, B. E.; Whaley, C. M.; Rauchfuss, T. B.; Gray, D. L., J. Am. Chem. Soc. 2009, 131, 6942-6943.

92. Dilworth, J. R.; Wheatley, N., Coord. Chem. Rev. 2000, 199, 89-158.

93. Imola Sárosi, I., Silaghi-Dumitrescu, L., Hey-Hawkins, E., Maced. J. Chem. Chem. Eng. 2013, 32, 1-23.

94. Block, E.; Kang, H.; Oforiokai, G.; Zubieta, J., Inorg. Chim. Acta 1989, 166, 155157.

95. Bolzati, C.; Refosco, F.; Tisato, F.; Bandoli, G.; Dolmella, A., Inorg. Chim. Acta 1992, 201, 7-10.

96. Pérez-Lourido, P.; Romero, J.; García-Vázquez, J. A.; Sousa, A.; Maresca, K. P.; Zubieta, J., Inorg. Chem. 1999, 38, 1511-1519.

97. Dilworth, J. R.; Miller, J. R.; Wheatley, N.; Baker, M. J.; Sunley, J. G., J. Chem. Soc., Chem. Commun. 1995, 1579-1581.

98. Dahlenburg, L.; Herbst, K.; Kühnlein, M., Z. Anorg. Allg. Chem. 1997, 623, 250258.

99. Benefiel, A.; Roundhill, D. M.; Fultz, W. C.; Rheingold, A. L., Inorg. Chem. 1984, 23, 3316-3324.

100. Canseco-González, D.; Gómez-Benítez, V.; Hernández-Ortega, S.; Toscano, R. A.; Morales-Morales, D., J. Organomet. Chem. 2003, 679, 101-109.

101. Kim, J. S.; Reibenspies, J. H.; Darensbourg, M. Y., J. Am. Chem. Soc. 1996, 118, 4115-4123.

102. Kraikivskii, P. B.; Frey, M.; Bennour, H. A.; Gembus, A.; Hauptmann, R.; Svoboda, I.; Fuess, H.; Saraev, V. V.; Klein, H.-F., J. Organomet. Chem. 2009, 694, 1869-1876.

103. She, L.; Li, X.; Sun, H.; Ding, J.; Frey, M.; Klein, H.-F., Organometallics 2007, 26, 566-570.

104. Barry, B. M.; Stein, B. W.; Larsen, C. A.; Wirtz, M. N.; Geiger, W. E.; Waterman, R.; Kemp, R. A., Inorg. Chem. 2013, 52, 9875-9884.

105. Jain, R.; Mashuta, M. S.; Buchanan, R. M.; Grapperhaus, C. A., Eur. J. Inorg. Chem. 2017, 2017, 3714-3719. 
106. Farrugia, L., J. Appl. Crystallogr. 1997, 30, 565.

107. Martin, D. J.; McCarthy, B. D.; Donley, C. L.; Dempsey, J. L., Chem. Commun. 2015, 51, 5290-5293.

108. Xue, D.; Peng, Q.-X.; Zhan, S.-Z., Inorg. Chem. Commun. 2017, 82, 11-15.

109. Zhang, Y.-X.; Tang, L.-Z.; Deng, Y.-F.; Zhan, S.-Z., Inorg. Chem. Commun. 2016, 72, 100-104.

110. Lawrence, E. J.; Clark, E. R.; Curless, L. D.; Courtney, J. M.; Blagg, R. J.; Ingleson, M. J.; Wildgoose, G. G., Chem. Sci. 2016, 7, 2537-2543.

111. Morris, A. J.; Meyer, G. J.; Fujita, E., Acc. Chem. Res. 2009, 42, 1983-1994.

112. Thoi, V. S.; Kornienko, N.; Margarit, C. G.; Yang, P.; Chang, C. J., J. Am. Chem. Soc. 2013, 135, 14413-14424.

113. Pellegrin, Y.; Odobel, F., C. R. Chim 2017, 20, 283-295.

114. Palanimuthu, D.; Shinde, S. V.; Somasundaram, K.; Samuelson, A. G., J. Med. Chem. 2013, 56, 722-734.

115. Christlieb, M.; Dilworth, J. R., Chem. Eur. J. 2006, 12, 6194-6206.

116. McQuade, P.; Martin, K. E.; Castle, T. C.; Went, M. J.; Blower, P. J.; Welch, M. J.; Lewis, J. S., Nucl. Med. Biol. 2005, 32, 147-156.

117. Cater, M. A.; Pearson, H. B.; Wolyniec, K.; Klaver, P.; Bilandzic, M.; Paterson, B. M.; Bush, A. I.; Humbert, P. O.; La Fontaine, S.; Donnelly, P. S.; Haupt, Y., ACS Chem. Biol. 2013, 8, 1621-1631.

118. Cowley, A. R.; Davis, J.; Dilworth, J. R.; Donnelly, P. S.; Dobson, R.; Nightingale, A.; Peach, J. M.; Shore, B.; Kerr, D.; Seymour, L., Chem. Commun. 2005, 845-847.

119. Cowley, A. R.; Dilworth, J. R.; Donnelly, P. S.; Labisbal, E.; Sousa, A., J. Am. Chem. Soc. 2002, 124, 5270-5271.

120. Cowley, A. R.; Dilworth, J. R.; Donnelly, P. S.; White, J. M., Inorg.Chem. 2006, 45, 496-498.

121. Ashfield, L. J.; Cowley, A. R.; Dilworth, J. R.; Donnelly, P. S., Inorg. Chem. 2004, 43, 4121-4123.

122. Kochem, A.; Gellon, G.; Jarjayes, O.; Philouze, C.; du Moulinet d'Hardemare, A.; van Gastel, M.; Thomas, F., Dalton Trans. 2015, 44, 12743-12756.

123. Blanchard, S.; Bill, E.; Weyhermüller, T.; Wieghardt, K., Inorg. Chem. 2004, 43, 2324-2329.

124. Blanchard, S.; Neese, F.; Bothe, E.; Bill, E.; Weyhermüller, T.; Wieghardt, K., Inorg. Chem. 2005, 44, 3636-3656.

125. Haddad, A. Z.; Garabato, B. D.; Kozlowski, P. M.; Buchanan, R. M.; Grapperhaus, C. A., J. Am. Chem. Soc. 2016, 138, 7844-7847.

126. Haddad, A. Z.; Cronin, S. P.; Mashuta, M. S.; Buchanan, R. M.; Grapperhaus, C. A., Inorg. Chem. 2017, 56, 11254-11265.

127. Vuilleumier, R.; Borgis, D., Nat. Chem. 2012, 4, 432.

128. Haddad, A. Z., "Homogeneous ligand-centered hydrogen evolution and hydrogen oxidation : exploiting redox non-innocence to drive catalysis." 2017, Electronic Theses and Dissertations. Paper 2710.; https://doi.org/10.18297/etd/2710.

129. Straistari, T.; Fize, J.; Shova, S.; Réglier, M.; Artero, V.; Orio, M., ChemCatChem 2017, 9, 2262-2268.

130. Corey, E. J.; Suggs, J. W., Tetrahedron Lett. 1975, 16, 2647-2650.

131. Piancatelli, G.; Scettri, A.; D'Auria, M., Synthesis 1982, 1982, 245-258. 
132. Fatiadi, A. J., Synthesis 1976, 1976, 133-167.

133. Taylor, R. J. K.; Reid, M.; Foot, J.; Raw, S. A., Acc. Chem. Res. 2005, 38, 851-869.

134. Uyanik, M.; Ishihara, K., Chem. Commun. 2009, 2086-2099.

135. Pfitzner, K. E.; Moffatt, J. G., J. Am. Chem. Soc. 1963, 85, 3027-3027.

136. Mancuso, A. J.; Brownfain, D. S.; Swern, D., J. Org. Chem. 1979, 44, 4148-4150.

137. Tidwell, T. T., Synthesis 1990, 1990, 857-870.

138. Mallat, T.; Baiker, A., Chem. Rev. 2004, 104, 3037-3058.

139. Zhan, B.-Z.; Thompson, A., Tetrahedron 2004, 60, 2917-2935.

140. Schultz, M. J.; Sigman, M. S., Tetrahedron 2006, 62, 8227-8241.

141. Parmeggiani, C.; Cardona, F., Green Chem. 2012, 14, 547-564.

142. Matsumoto, T.; Ueno, M.; Wang, N.; Kobayashi, S., Chem. Asian J. 2008, 3, 196214.

143. MarkÓ, I. E.; Giles, P. R.; Tsukazaki, M.; ChellÉ-Regnaut, I.; Gautier, A.; Dumeunier, R.; Philippart, F.; Doda, K.; Mutonkole, J.-L.; Brown, S. M.; Urch, C. J., Adv. Inorg. Chem. 2004; 56, 211-240.

144. Whittaker, M. M.; Chuang, Y. Y.; Whittaker, J. W., J. Am. Chem. Soc. 1993, 115, 10029-10035.

145. Itoh, S.; Takayama, S.; Arakawa, R.; Furuta, A.; Komatsu, M.; Ishida, A.; Takamuku, S.; Fukuzumi, S., Inorg. Chem. 1997, 36, 1407-1416.

146. Ito, N.; Phillips, S. E. V.; Stevens, C.; Ogel, Z. B.; McPherson, M. J.; Keen, J. N.; Yadav, K. D. S.; Knowles, P. F., Nature 1991, 350, 87.

147. Thomas, F., Eur. J. Inorg. Chem. 2007, 2007, 2379-2404.

148. Denisov, I. G.; Makris, T. M.; Sligar, S. G.; Schlichting, I., Chem. Rev. 2005, 105, 2253-2278.

149. Groves, J. T., J. Inorg. Biochem. 2006, 100, 434-447.

150. Shaik, S.; Kumar, D.; de Visser, S. P.; Altun, A.; Thiel, W., Chem. Rev. 2005, 105, 2279-2328.

151. Jazdzewski, B. A.; Tolman, W. B., Coord. Chem. Rev. 2000, 200-202, 633-685.

152. Whittaker, J. W., Chem. Rev. 2003, 103, 2347-2364.

153. Hiromoto, T.; Warkentin, E.; Moll, J.; Ermler, U.; Shima, S., Angew. Chem. Intl. Ed. 2009, 48, 6457-6460.

154. Stubbe, J.; van der Donk, W. A., Chem. Rev. 1998, 98, 705-762.

155. Jurss, J. W.; Khnayzer, R. S.; Panetier, J. A.; El Roz, K. A.; Nichols, E. M.; HeadGordon, M.; Long, J. R.; Castellano, F. N.; Chang, C. J., Chem. Sci. 2015, 6, 49544972.

156. Lyons, C. T.; Stack, T. D. P., Coord. Chem. Rev. 2013, 257, 528-540.

157. Pratt, R. C.; Lyons, C. T.; Wasinger, E. C.; Stack, T. D. P., J. Am. Chem. Soc. 2012, 134, 7367-7377.

158. Gamez, P.; Koval, I. A.; Reedijk, J., Dalton Trans. 2004, 4079-4088.

159. Himo, F.; Siegbahn, P. E. M., Chem. Rev. 2003, 103, 2421-2456.

160. Xie, L.; van der Donk, W. A., Proc. Natl. Acad. Sci. 2001, 98, 12863-12865.

161. Tkac, J.; Vostiar, I.; Gemeiner, P.; Sturdik, E., Bioelectrochem. 2002, 56, 23-25.

162. Brackman, W.; Gaasbeek, C. J., Recl. Trav. Chim. Pays-Bas 1966, 85, 221-241.

163. Semmelhack, M. F.; Schmid, C. R.; Cortes, D. A.; Chou, C. S., J. Am. Chem. Soc. 1984, 106, 3374-3376. 
164. Gamez, P.; Arends, I. W. C. E.; Reedijk, J.; Sheldon, R. A., Chem. Commun. 2003, 2414-2415.

165. Gamez, P.; Arends, I. W. C. E.; Sheldon, R. A.; Reedijk, J., Adv. Synth. Catal. 2004, 346, 805-811.

166. Sheldon, R. A.; Arends, I. W. C. E., Adv. Synth. Catal. 2004, 346, 1051-1071.

167. Kumpulainen, E. T. T.; Koskinen, A. M. P., Chem. Eur. J. 2009, 15, 10901-10911.

168. Hoover, J. M.; Stahl, S. S., J. Am. Chem. Soc. 2011, 133, 16901-16910.

169. Hoover, J. M.; Ryland, B. L.; Stahl, S. S., J. Am. Chem. Soc. 2013, 135, 2357-2367.

170. Greene, J. F.; Hoover, J. M.; Mannel, D. S.; Root, T. W.; Stahl, S. S., Org. Process Res. Dev. 2013, 17, 1247-1251.

171. Ryland, B. L.; Stahl, S. S., Angew. Chem. Intl. Ed. 2014, 53, 8824-8838.

172. Ahmad, J. U.; Räisänen, M. T.; Leskelä, M.; Repo, T., Appl. Catal., A 2012, 411 412, 180-187.

173. Hoover, J. M.; Ryland, B. L.; Stahl, S. S., ACS Catalysis 2013, 3, 2599-2605.

174. McCann, S. D.; Stahl, S. S., Acc. Chem. Res. 2015, 48, 1756-1766.

175. Gamba, I.; Mutikainen, I.; Bouwman, E.; Reedijk, J.; Bonnet, S., Eur. J. Inorg. Chem. 2013, 2013, 115-123.

176. Velusamy, S.; Srinivasan, A.; Punniyamurthy, T., Tetrahedron Lett. 2006, 47, 923926.

177. Zhang, W.; Saraei, N.; Nie, H.; Vaughn, J. R.; Jones, A. S.; Mashuta, M. S.; Buchanan, R. M.; Grapperhaus, C. A., Dalton Trans. 2016, 45, 15791-15799.

178. Jain, R.; Gibson, T. J.; Mashuta, M. S.; Buchanan, R. M.; Grapperhaus, C. A., Dalton Trans. 2016, 45, 18356-18364.

179. Rybak-Akimova, E. V.; Nazarenko, A. Y.; Chen, L.; Krieger, P. W.; Herrera, A. M.; Tarasov, V. V.; Robinson, P. D., Inorg. Chim. Acta 2001, 324, 1-15.

180. Chattopadhyay, T.; Kogiso, M.; Asakawa, M.; Shimizu, T.; Aoyagi, M., Catal. Commun. 2010, 12, 9-13.

181. Islam, S. M.; Roy, A. S.; Mondal, P.; Mubarak, M.; Mondal, S.; Hossain, D.; Banerjee, S.; Santra, S. C., J. Mol. Catal. A: Chem. 2011, 336, 106-114.

182. Zhang, G.; Yang, C.; Liu, E.; Li, L.; Golen, J. A.; Rheingold, A. L., RSC Adv. 2014, 4, 61907-61911.

183. Zhang, G.; Proni, G.; Zhao, S.; Constable, E. C.; Housecroft, C. E.; Neuburger, M.; Zampese, J. A., Dalton Trans. 2014, 43, 12313-12320.

184. Kolahdoozan, M.; Kalbasi, R. J.; Hossaini, M., J. Chem. 2013, 2013, 7. 


\section{APPENDIX}

\section{LIST OF FIGURES}

Figure A1. Cyclic voltammogram of $\mathrm{Ni}\left(\mathrm{L}^{1}\right)_{2}$ after subraction of solvent background ...127

Figure A2. Cyclic voltammograms showing scan rate dependence of $\mathrm{Ni}\left(\mathrm{L}^{1}\right)_{2} \ldots \ldots \ldots \ldots . .128$

Figure A3. Plot of peak current versus square root of scan rate for $\mathrm{Ni}\left(\mathrm{L}^{1}\right)_{2} \ldots \ldots \ldots \ldots \ldots . .128$

Figure A4. Cyclic voltammograms of acid in the presence and absence of $\mathrm{Ni}\left(\mathrm{L}^{1}\right)_{2} \ldots . .129$

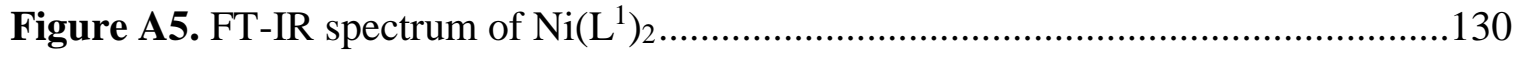

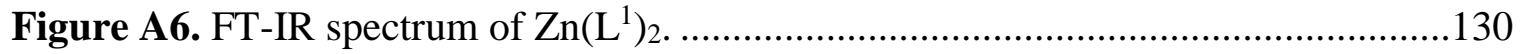

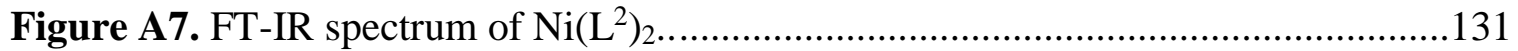

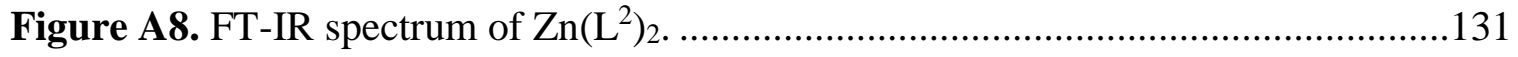

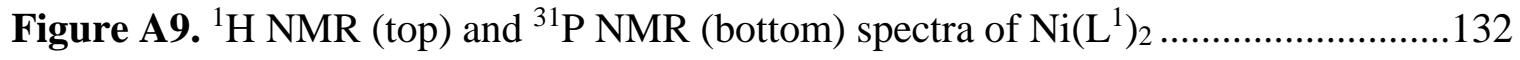

Figure A10. ${ }^{1} \mathrm{H}$ NMR (top) and ${ }^{31} \mathrm{P}$ NMR (bottom) spectra of $\mathrm{Zn}\left(\mathrm{L}^{1}\right)_{2} \ldots \ldots \ldots \ldots \ldots \ldots \ldots \ldots . . . . . . . . . . . .33$

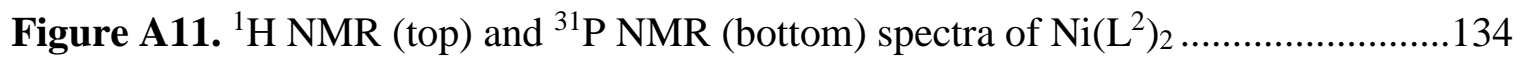

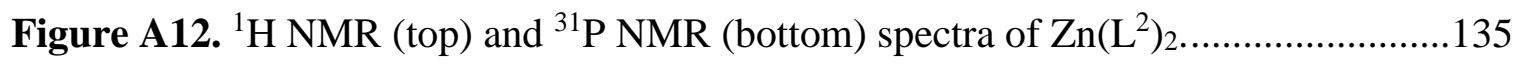

Figure A13. Cyclic voltammograms of $\mathrm{NiL}^{3}$ with increasing $\mathrm{CH}_{3} \mathrm{COOH}$ in acetonitrile at

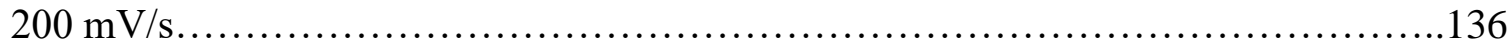

Figure A14. Cyclic voltammograms of $\mathrm{NiL}^{3}$ with increasing $\mathrm{CH}_{3} \mathrm{COOH}$ in acetonitrile at $1000 \mathrm{mV} / \mathrm{s}$.

Figure A15. Cyclic voltammograms of $\mathrm{NiL}^{3}$ with increasing $\mathrm{CH}_{3} \mathrm{COOH}$ in dimethylformamide at $500 \mathrm{mV} / \mathrm{s}$.

Figure A16. Cyclic voltammograms of $\mathrm{NiL}^{3}$ with increasing $\mathrm{CH}_{3} \mathrm{COOH}$ in dimethylformamide at $1000 \mathrm{mV} / \mathrm{s}$....

Figure A17. Cyclic voltammograms of $\mathrm{NiL}^{3}$ with increasing $\mathrm{CF}_{3} \mathrm{COOH}$ in dimethylformamide at $500 \mathrm{mV} / \mathrm{s}$

Figure A18. Cyclic voltammograms of $\mathrm{NiL}^{3}$ with increasing $\mathrm{CF}_{3} \mathrm{COOH}$ in dimethylformamide at $1000 \mathrm{mV} / \mathrm{s}$

Figure A19. Cyclic voltammograms of $\mathrm{NiL}^{3}$ with increasing $\mathrm{CF}_{3} \mathrm{COOH}$ in acetonitrile at $500 \mathrm{mV} / \mathrm{s}$ .142

Figure A20. Cyclic voltammograms of $\mathrm{NiL}^{3}$ with increasing $\mathrm{CF}_{3} \mathrm{COOH}$ in acetonitrile at $1000 \mathrm{mV} / \mathrm{s}$ 
Figure A21. Foot of wave analysis for $\mathrm{NiL}^{3}$ with acetic acid in acetonitrile solution ....144

Figure A22._Foot of wave analysis for $\mathrm{NiL}^{3}$ with acetic acid in dimethylformamide solution.

Figure A23. Foot of wave analysis for $\mathrm{NiL}^{3}$ with trifluoracetic acid in acetonitrile solution.

Figure A24. Foot of wave analysis for $\mathrm{NiL}^{3}$ with trifluoroacetic acid in dimethylformamide solution

Figure A25. Cyclic voltammograms of trifluoroacetic acid in the presence and absence of $\mathrm{NiL}^{3}$ in acetonitrile solution

Figure A26. Cyclic voltammograms of trifluoroacetic acid in the presence and absence of $\mathrm{NiL}^{3}$ in dimethylformamide solution

Figure A27. Cyclic voltammograms of acetic acid in the presence and absence of $\mathrm{NiL}^{3}$ in acetonitrile solution. .150

Figure A28. Cyclic voltammograms of acetic acid in the presence and absence of $\mathrm{NiL}^{3}$ in dimethylformamide solution.

Figure A29. Representation of Gas Chromatogram for the reaction mixture for oxidation of benzylic alcohols to benzylic aldehydes....

Figure A30. FT-IR spectrum of $\left[\mathrm{CuL}^{5}\right]\left[\mathrm{ClO}_{4}\right]_{2}$

Figure A31. Experimental and simulated EPR spectra of $\left[\mathrm{CuL}^{5}\right]\left[\mathrm{ClO}_{4}\right]_{2}$

\section{LIST OF TABLES}

Table T1. List of selected $\mathrm{H}$-bonding interactions in $\left[\mathrm{CuL}^{5}\right]\left(\mathrm{ClO}_{4}\right)_{2}$ and $\left[\mathrm{Cu}\left(\mathrm{HL}^{5}\right)\right]\left[\left(\mathrm{ClO}_{4}\right)_{3}\right]$

\section{COMPUTATIONAL INPUT COORDIATES FOR DFT CALCULATIONS}

A.1 Computational input coordinates for $\mathrm{NiL}^{3}$ and related compounds using B3LYP/ 6$311 \mathrm{~g}(\mathrm{~d}, \mathrm{p})$ in acetonitrile.

A.2 Computational input coordinates for $\mathrm{NiL}^{3}$ and related compounds using B3LYP/ 6$311 \mathrm{~g}(\mathrm{~d}, \mathrm{p})$ in gas phase. 

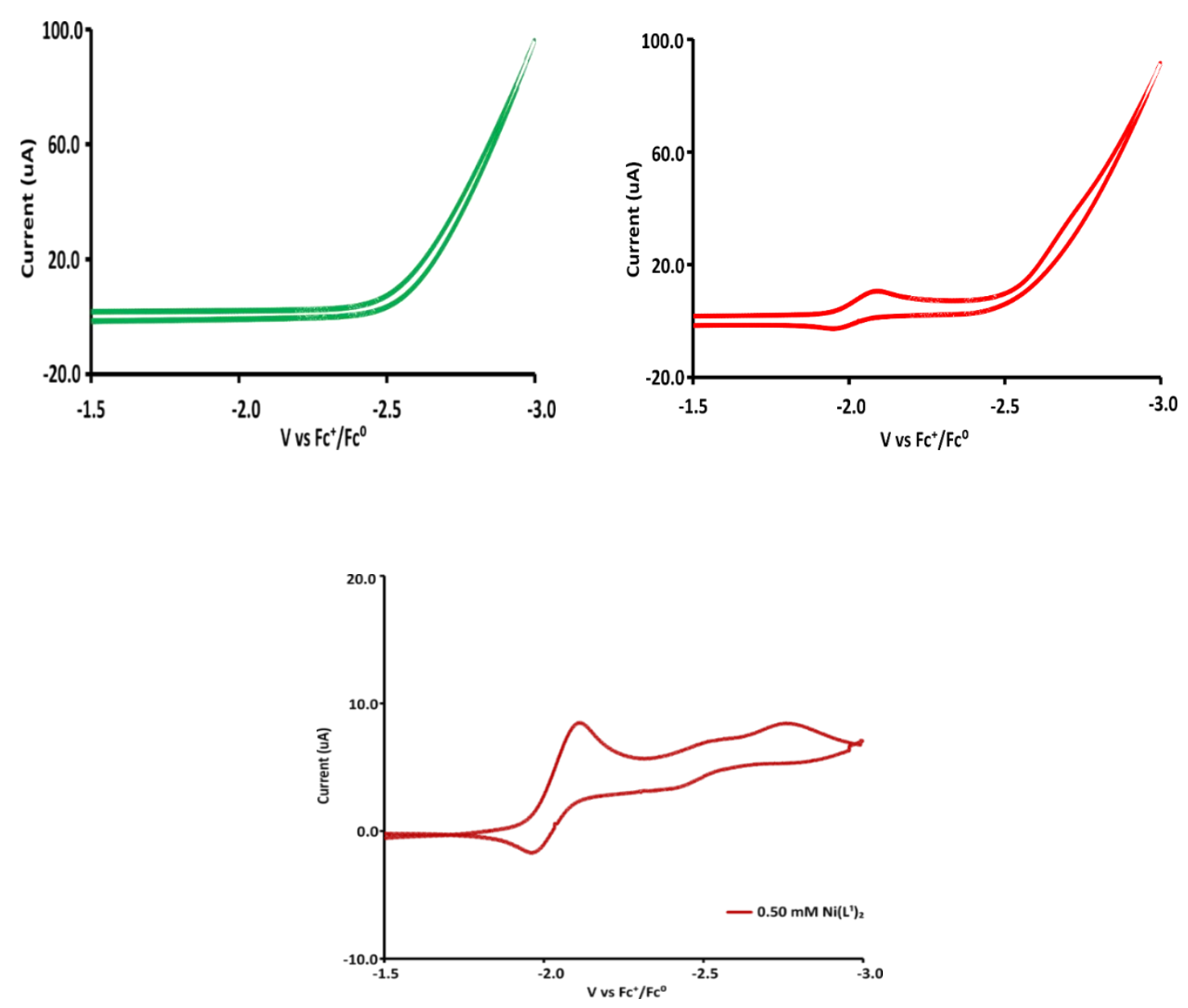

Figure A1. Cyclic Voltammograms $(\mathrm{CVs})$ of $\mathrm{Ni}\left(\mathrm{L}^{1}\right)_{2}$ scan over a larger window. Solvent background is collected with dichloromethane as a solvent (top left). Experimental voltammogram of $0.50 \mathrm{mM} \mathrm{Ni}\left(\mathrm{L}^{1}\right)_{2}$ (top right). Background corrected voltammogram of $\mathrm{Ni}\left(\mathrm{L}^{1}\right)_{2}$ obtained by the subtraction of solvent background CV from the experimental CV(bottom). Votammograms were recorded in dichloromethane solvent with $0.10 \mathrm{M} \mathrm{Bu}_{4} \mathrm{NPF}_{6}$ as supporting electrolyte using a glassy carbon working electrode, platinum counter electrode, and $\mathrm{Ag} / \mathrm{Ag}^{+}$reference electrode at a scan rate of $200 \mathrm{mV} / \mathrm{s}$. Potentials referenced versus ferrocenium/ferrocene $\left(\mathrm{Fc}^{+} / \mathrm{Fc}^{0}\right)$ using an internal standard. 


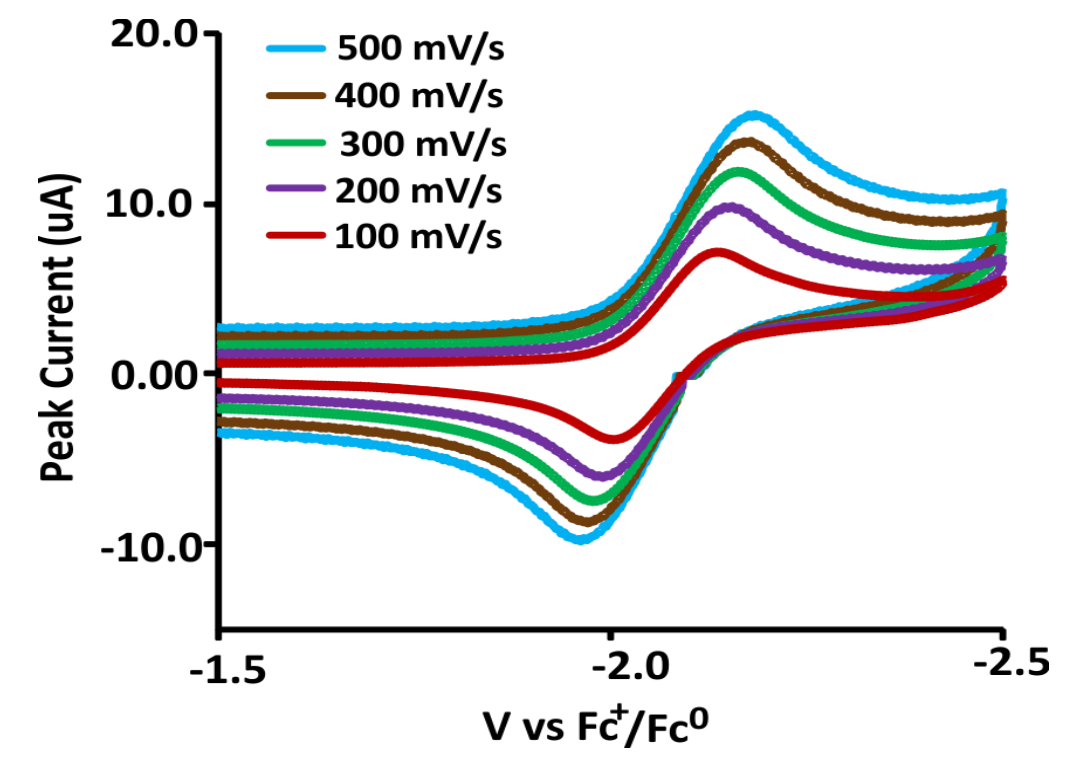

Figure A2. Cyclic Voltammograms showing scan rate dependence of $\mathrm{Ni}\left(\mathrm{L}^{1}\right)_{2}$ at scan rates from $100 \mathrm{mV} / \mathrm{s}$ to $500 \mathrm{mV} / \mathrm{s}$. Votammograms were recorded in dichloromethane solvent with $0.10 \mathrm{M}$ $\mathrm{Bu}_{4} \mathrm{NPF}_{6}$ as supporting electrolyte using a glassy carbon working electrode, platinum counter electrode, and $\mathrm{Ag} / \mathrm{Ag}^{+}$reference electrode at a scan rates from $100 \mathrm{mV} / \mathrm{s}$ to $500 \mathrm{mV} / \mathrm{s}$. Potentials referenced versus ferrocenium/ferrocene $\left(\mathrm{Fc}^{+} / \mathrm{Fc}^{0}\right)$ using an internal standard.

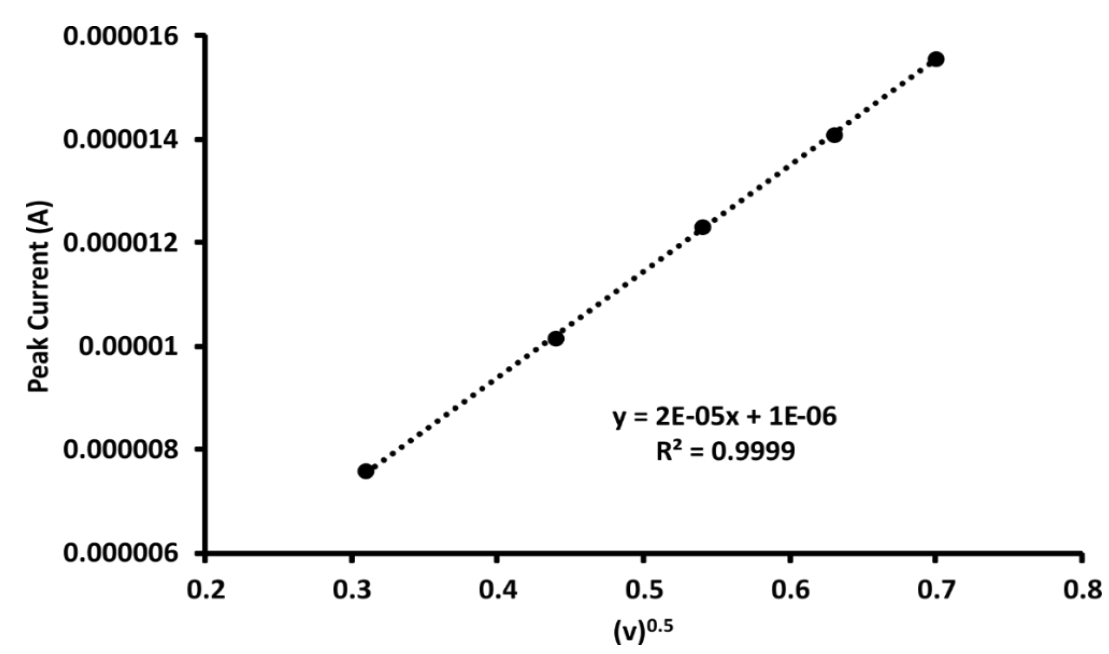

Figure A3. Plot of peak current $\left(i_{p}\right)$ versus the square root of scan rate. 


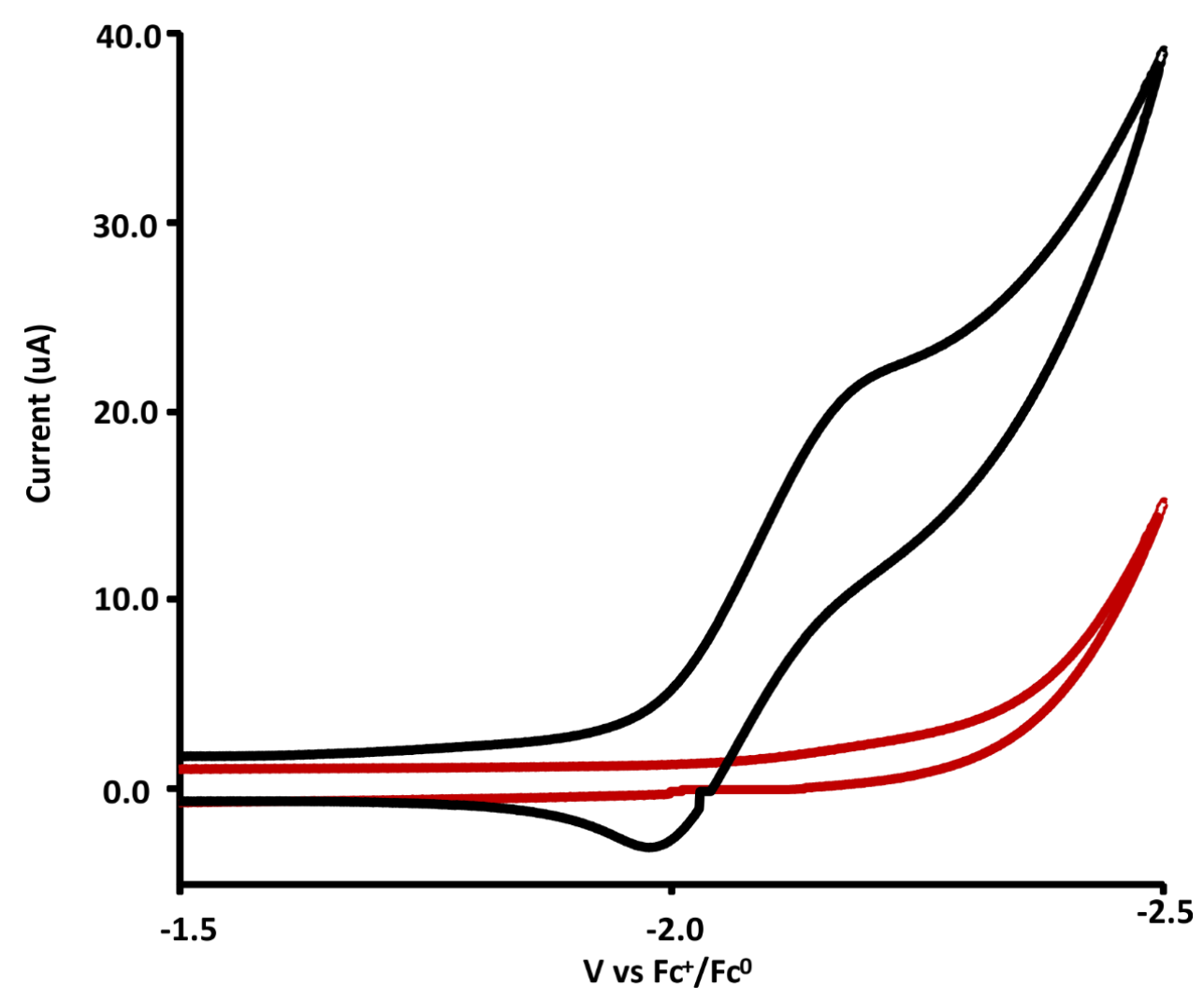

Figure A4. Control experiment for the catalysis of $\mathrm{Ni}\left(\mathrm{L}^{1}\right)_{2}$. Cyclic voltammogram of $0.50 \mathrm{mM}$ $\mathrm{Ni}\left(\mathrm{L}^{1}\right)_{2}$ with $3.5 \mathrm{mM}$ acetic acid (black) and blank dichloromethane with $3.5 \mathrm{mM}$ acetic acid in the absence of $\mathrm{Ni}\left(\mathrm{L}^{1}\right)_{2}$ (red) at a scan rate of $200 \mathrm{mV} / \mathrm{s}$. Votammograms were recorded in dichloromethane solvent with $0.10 \mathrm{M} \mathrm{Bu}_{4} \mathrm{NPF}_{6}$ as supporting electrolyte using a glassy carbon working electrode, platinum counter electrode, and $\mathrm{Ag} / \mathrm{Ag}^{+}$reference electrode at a scan rate 200 $\mathrm{mV} / \mathrm{s}$. Potentials referenced versus ferrocenium/ferrocene $\left(\mathrm{Fc}^{+} / \mathrm{Fc}^{0}\right)$ using an internal standard. 


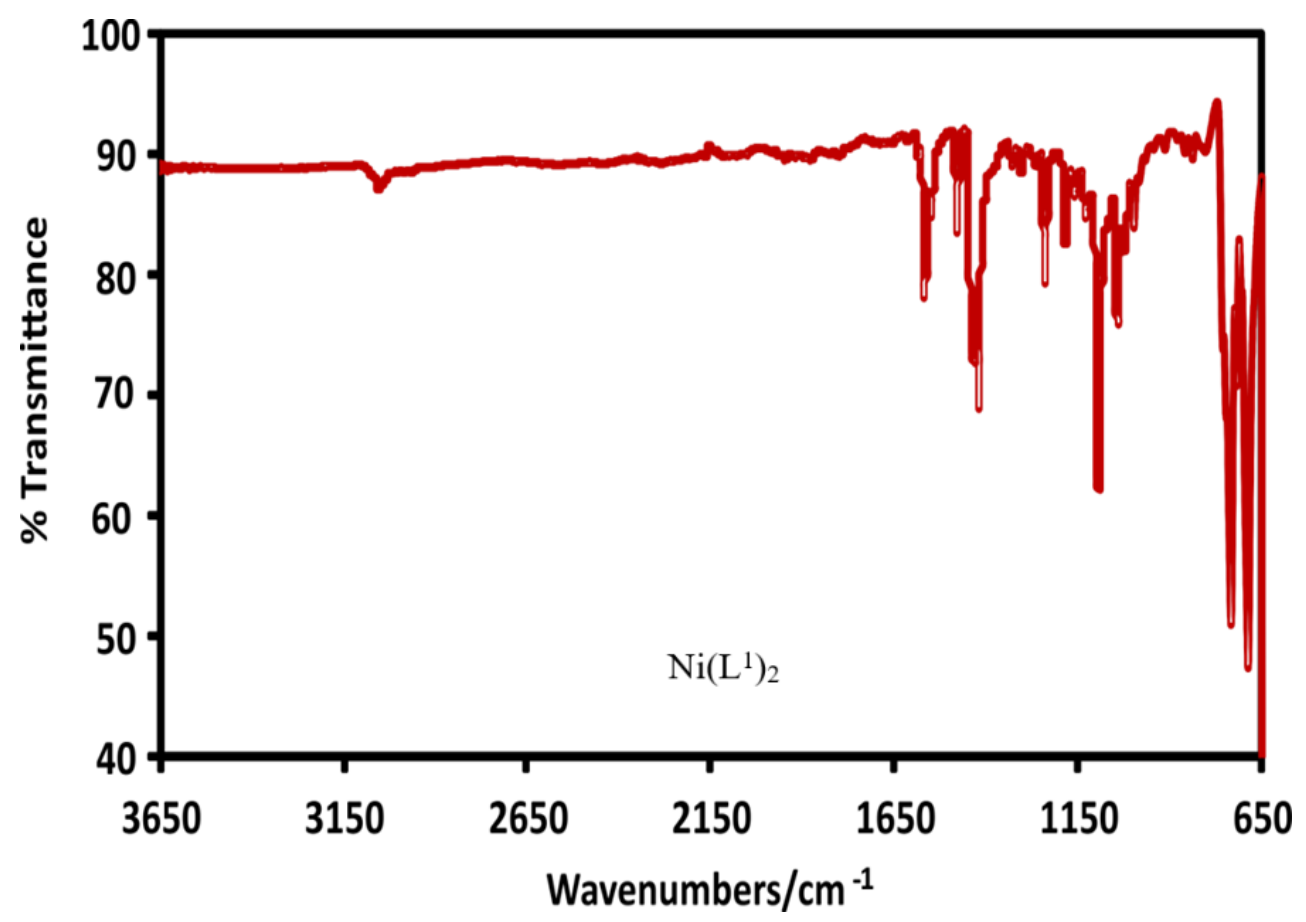

Figure A5. FT-IR spectrum of $\mathrm{Ni}\left(\mathrm{L}^{1}\right)_{2}$ collected on solid powder using an ATR attachment.

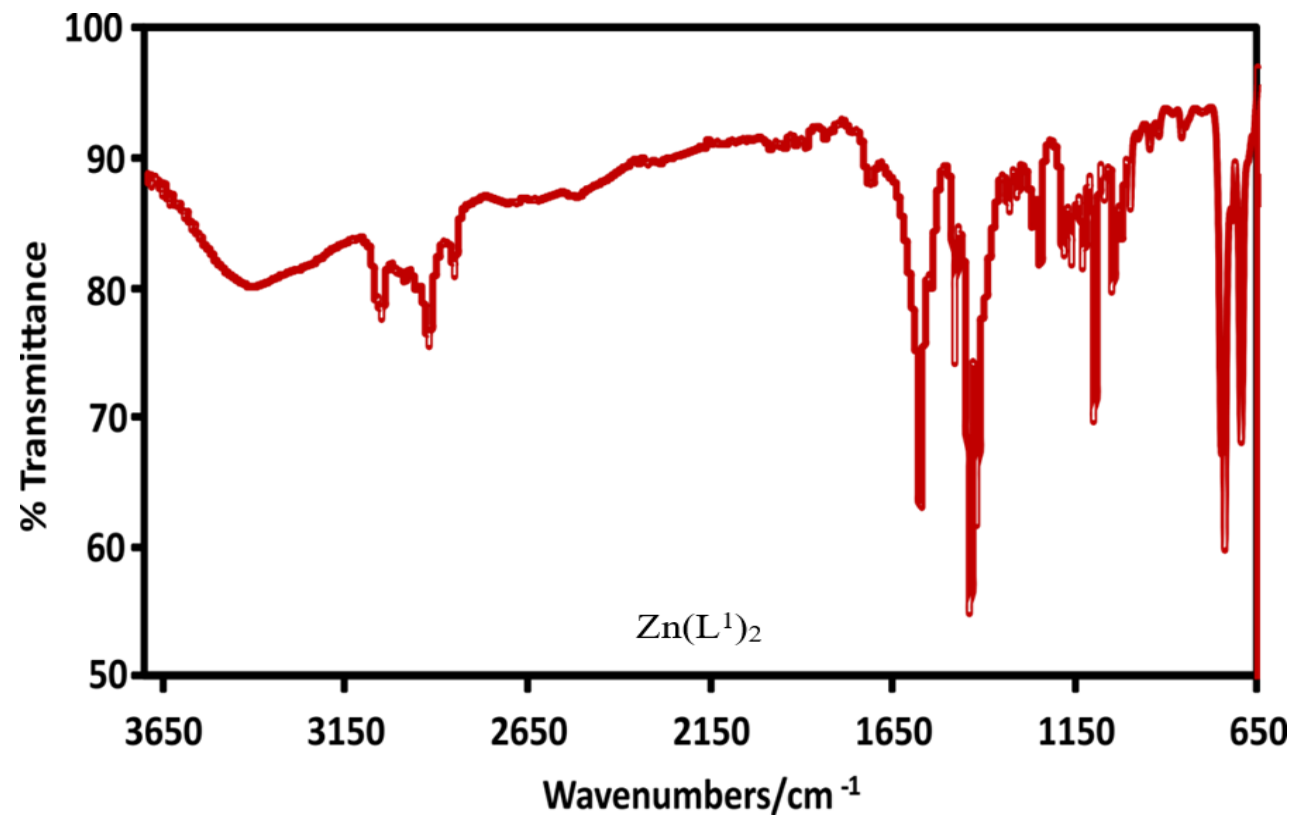

Figure A6. FT-IR spectrum of $\mathrm{Zn}\left(\mathrm{L}^{1}\right)_{2}$ collected on solid powder using an ATR attachment. 


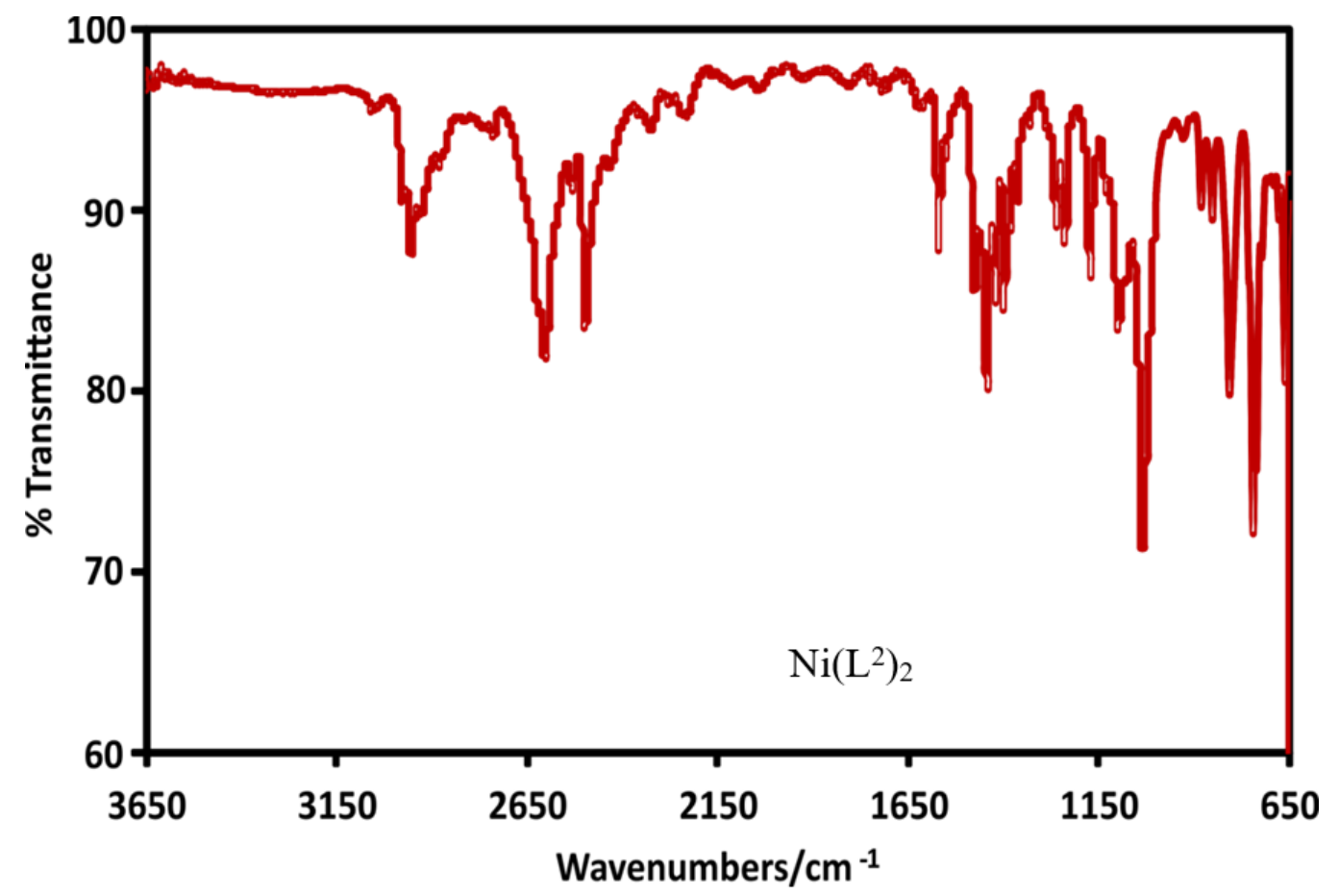

Figure A7. FT-IR spectrum of $\mathrm{Ni}\left(\mathrm{L}^{2}\right)_{2}$ collected on solid powder using an ATR attachment.

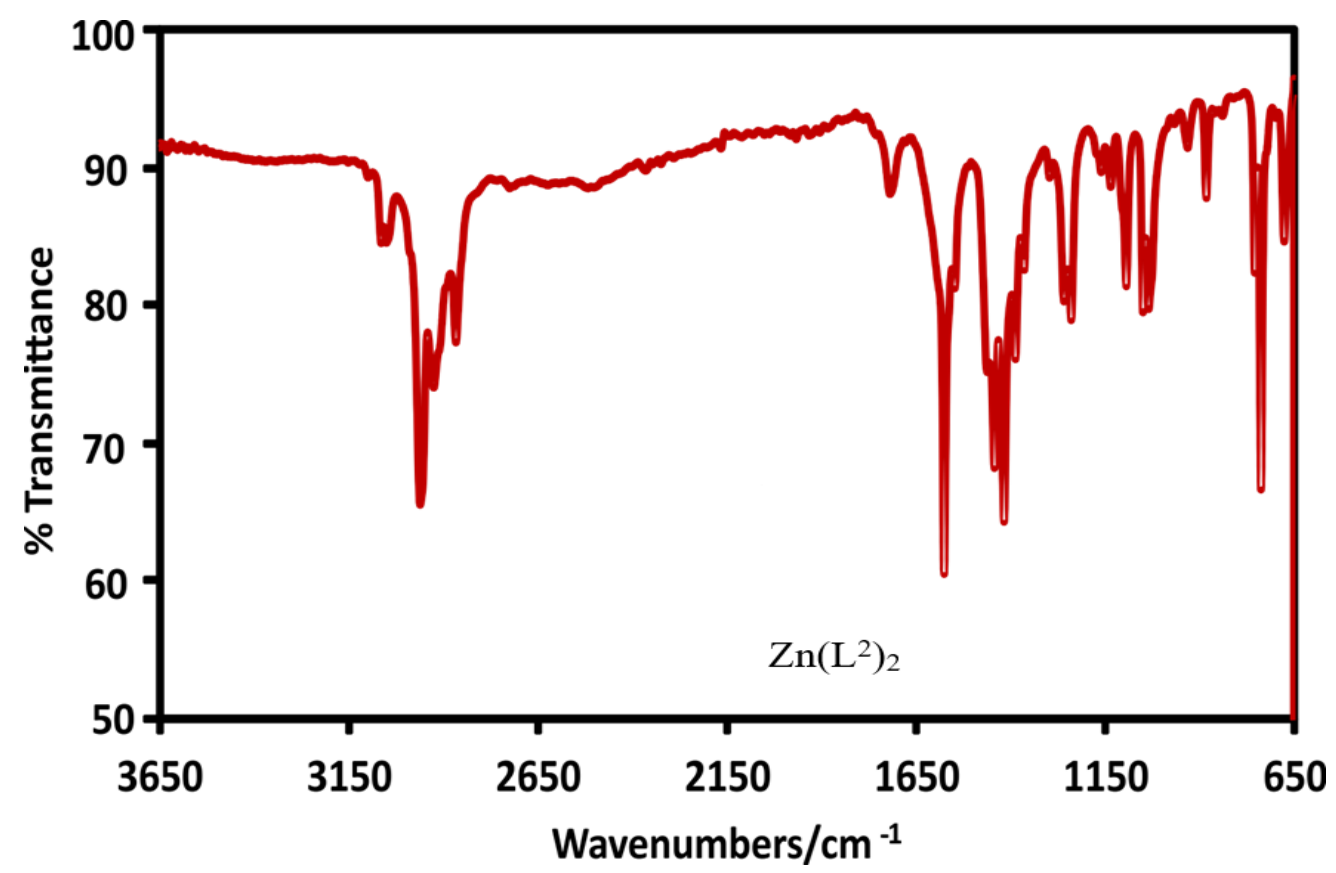

Figure A8. FT-IR spectrum of $\mathrm{Zn}\left(\mathrm{L}^{2}\right)_{2}$ collected on solid powder using an ATR attachment. 


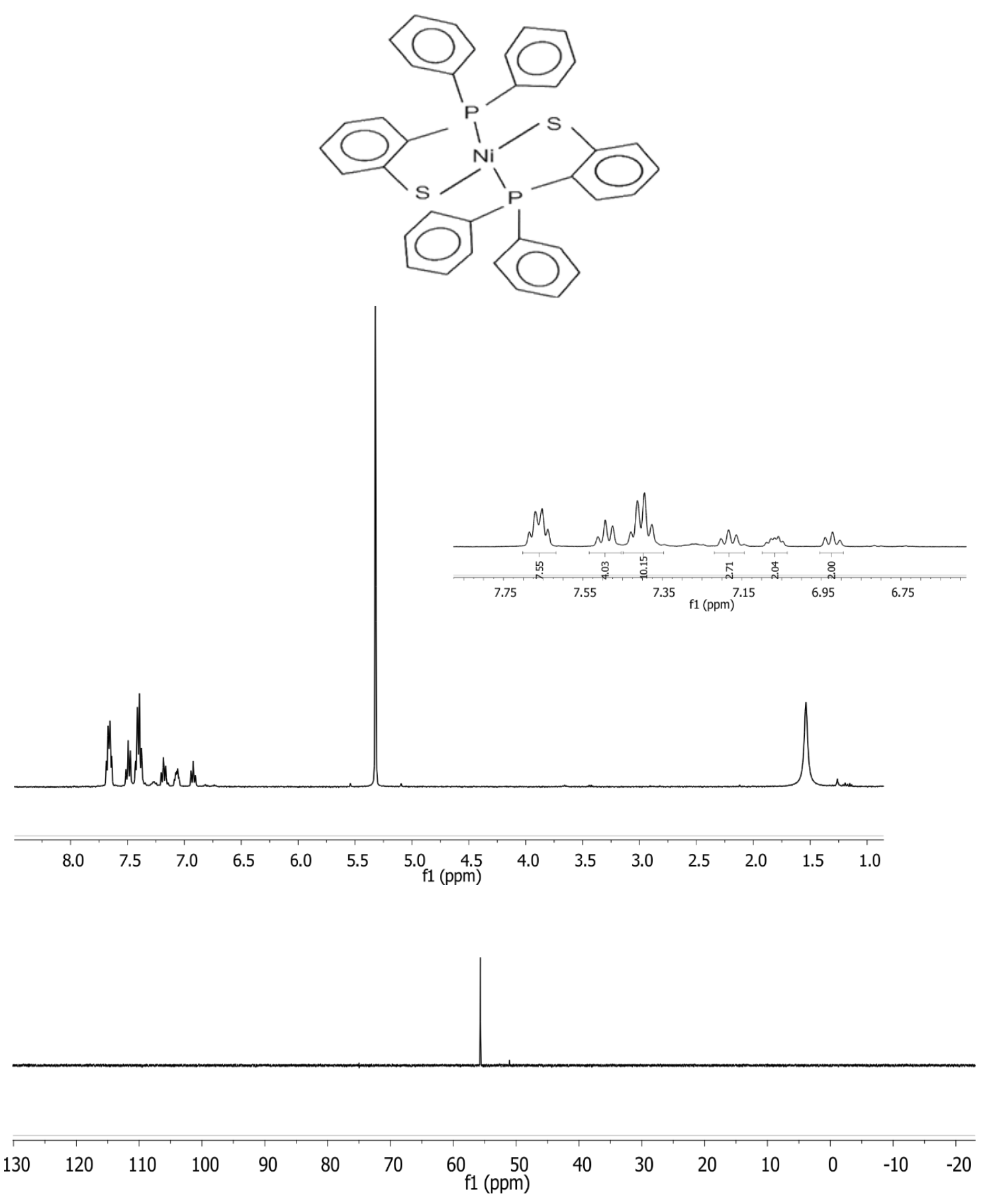

Figure A9. (Top) ${ }^{1} \mathrm{H}-\mathrm{NMR}$ and (bottom) ${ }^{31} \mathrm{P}-\mathrm{NMR}$ spectra of $\mathrm{Ni}\left(\mathrm{L}^{1}\right)_{2}$ collected in ddichloromethane at room temperature on $400 \mathrm{MHz}$ instrument. 

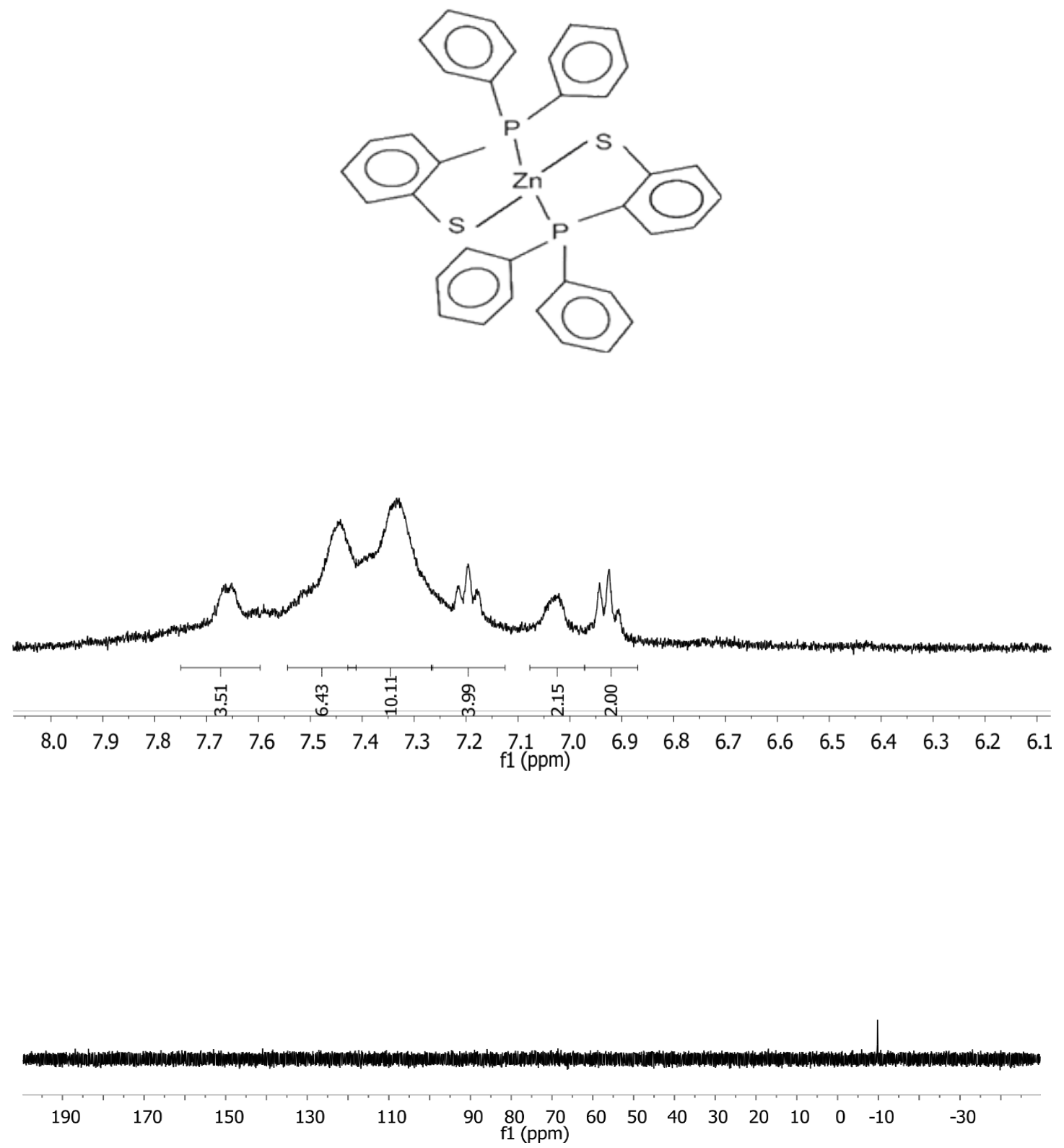

Figure A10. (Top) ${ }^{1} \mathrm{H}-\mathrm{NMR}$ and (bottom) ${ }^{31} \mathrm{P}$ - NMR spectra of $\mathrm{Zn}\left(\mathrm{L}^{1}\right)_{2}$ collected in $\mathrm{d}$ dichloromethane at room temperature on $400 \mathrm{MHz}$ instrument. 

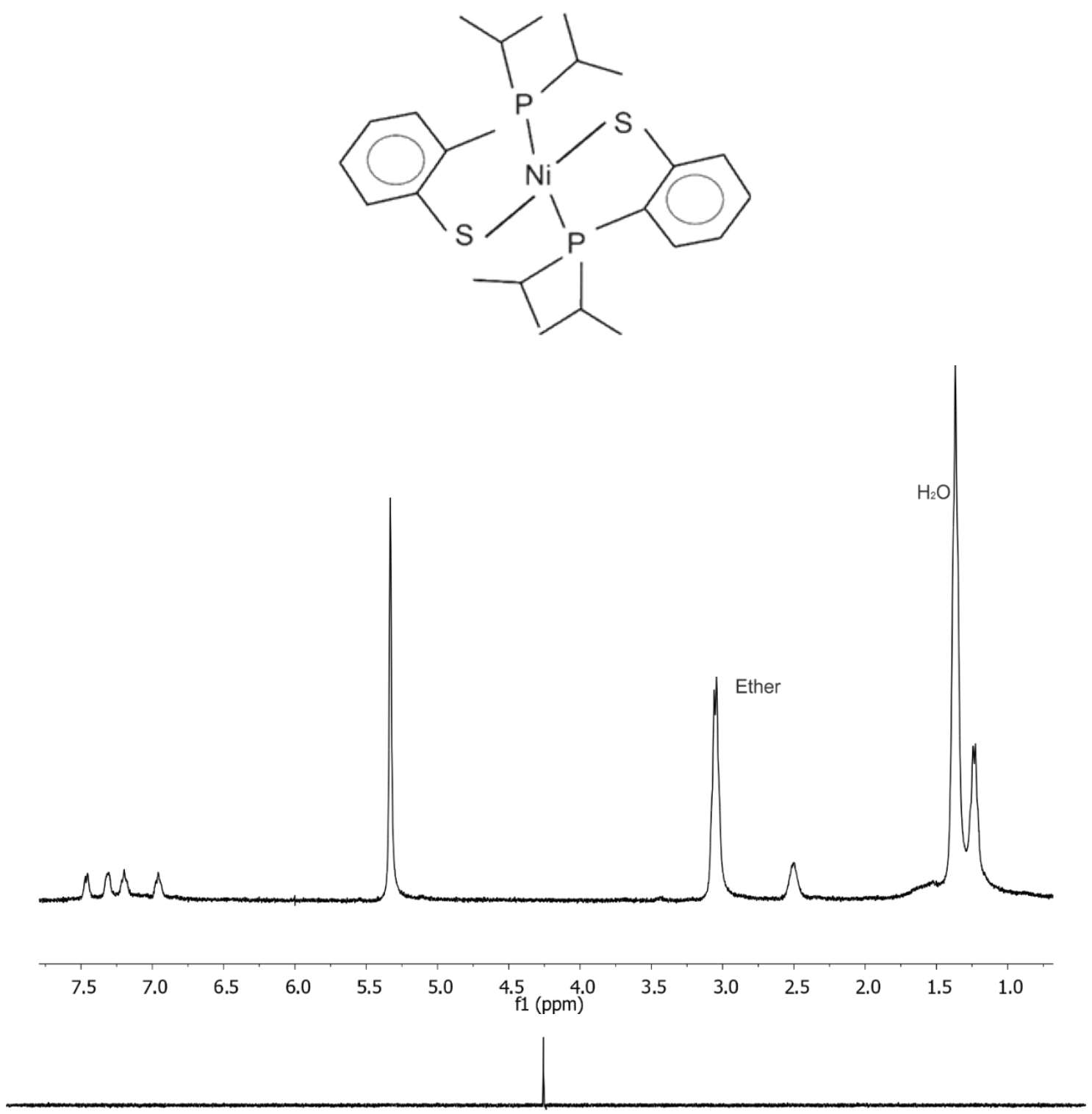

\begin{tabular}{|c|c|c|c|c|c|c|c|c|c|c|c|c|c|c|c|}
\hline 190 & 170 & 150 & 130 & 110 & 90 & $\begin{array}{c}80 \\
\mathrm{f} 1(\mathrm{ppm})\end{array}$ & 60 & 50 & 40 & 30 & 20 & 10 & 0 & -10 & -30 \\
\hline
\end{tabular}

Figure A11. (Top) ${ }^{1} \mathrm{H}-\mathrm{NMR}$ and (bottom) ${ }^{31} \mathrm{P}-\mathrm{NMR}$ spectra of $\mathrm{Ni}\left(\mathrm{L}^{2}\right)_{2}$ collected in ddichloromethane at room temperature on $400 \mathrm{MHz}$ instrument. 

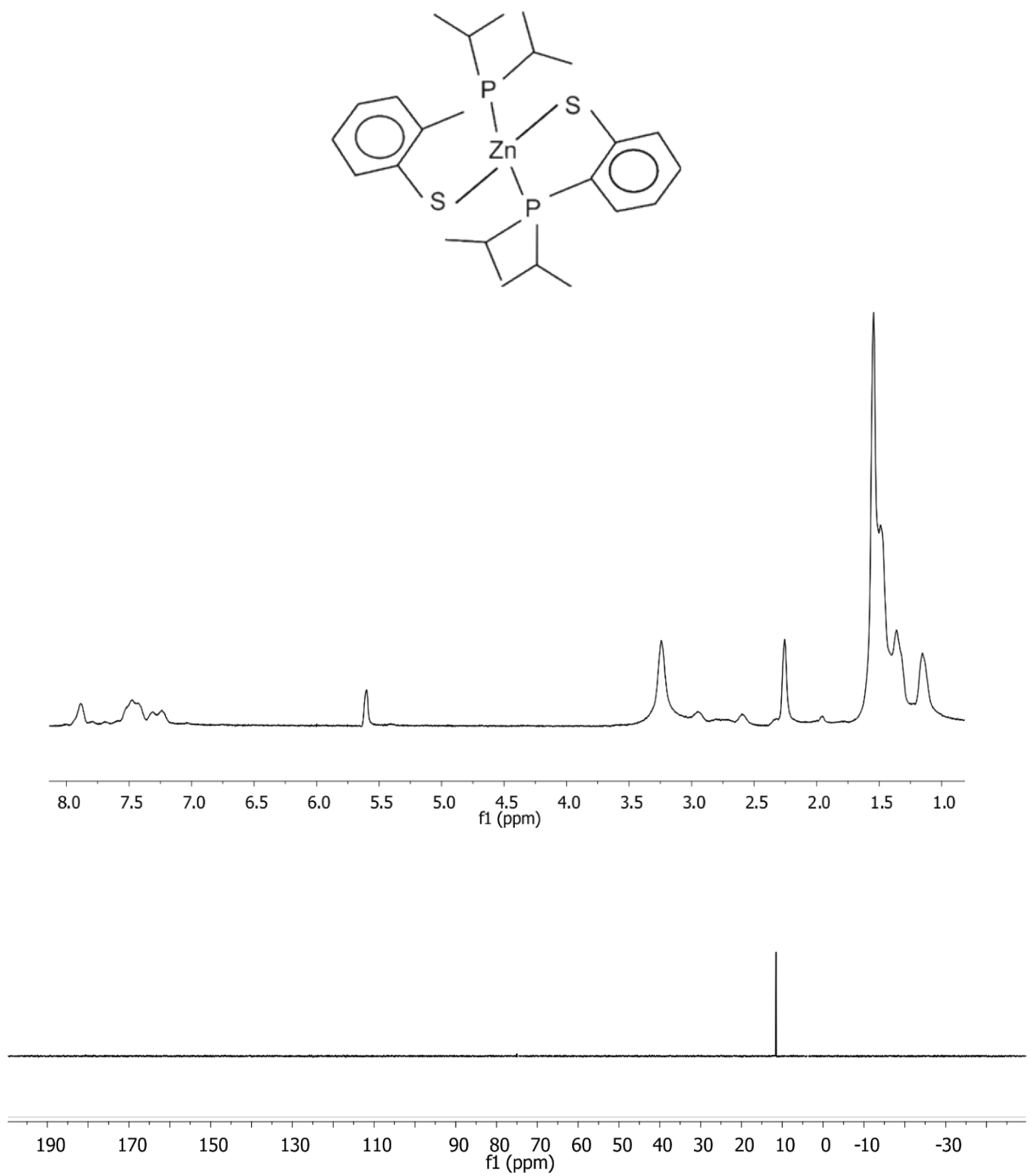

Figure A12. (Top) ${ }^{1} \mathrm{H}-\mathrm{NMR}$ and (bottom) ${ }^{31} \mathrm{P}$ - NMR spectra of $\mathrm{Zn}\left(\mathrm{L}^{2}\right)_{2}$ collected in ddichloromethane at room temperature on $400 \mathrm{MHz}$ instrument. 


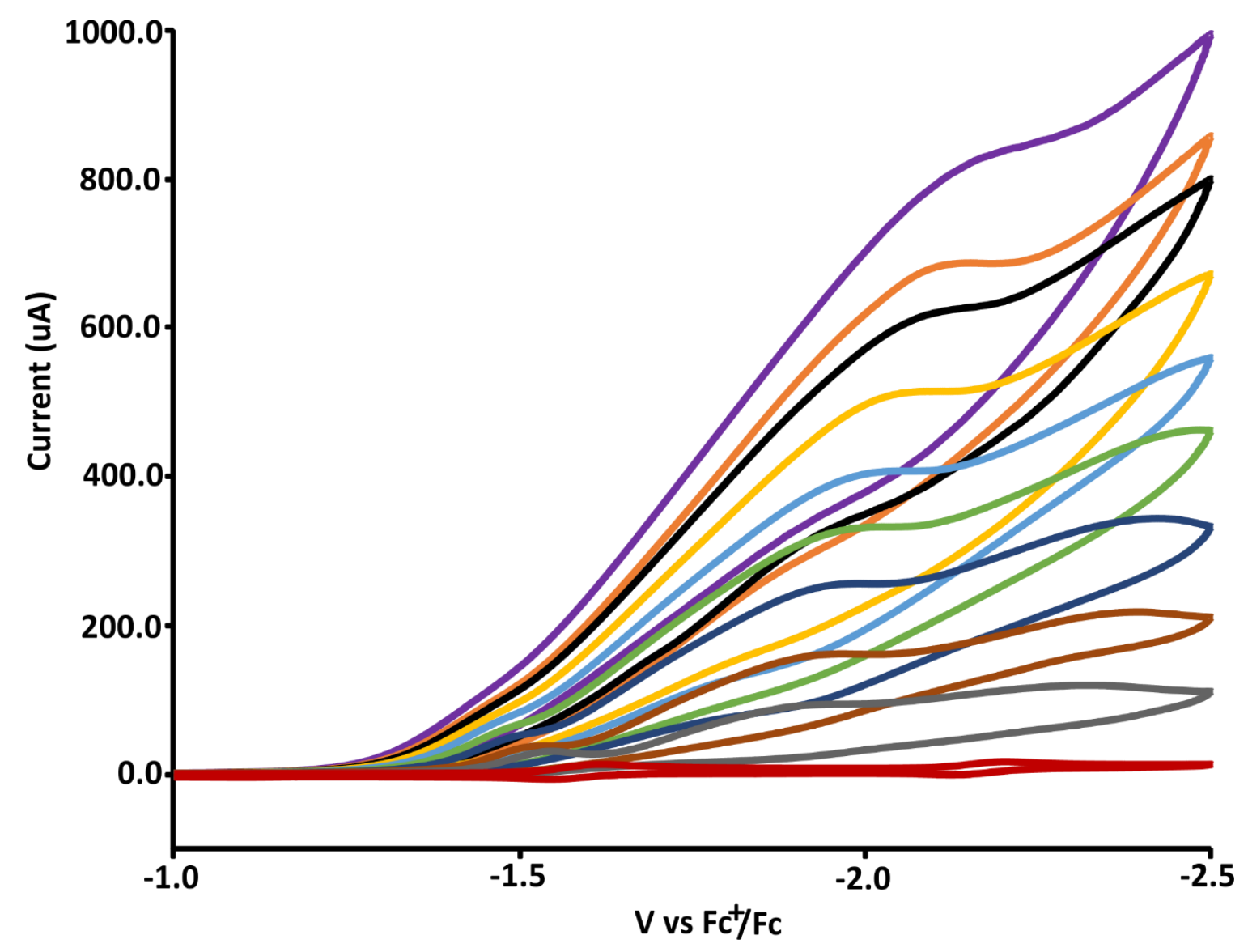

Figure A13. Electrocatalytic hydrogen evolution reaction. Cyclic voltammograms (CVs) of 0.30 $\mathrm{mM} \mathrm{NiL}{ }^{3}$ in acetonitrile solution with subsequent addition of acetic acid. CVs showing no acid, $1.4,2.8,4.2,5.6,7,8.4,9.8,11.2,12.6 \mathrm{mM}$ (top). Votammograms were recorded in acetonitrile solvent with $0.10 \mathrm{M} \mathrm{Bu}_{4} \mathrm{NPF}_{6}$ as supporting electrolyte using a glassy carbon working electrode, platinum counter electrode, and $\mathrm{Ag} / \mathrm{Ag}^{+}$reference electrode at a scan rate $200 \mathrm{mV} / \mathrm{s}$. Potentials referenced versus ferrocenium/ferrocene $\left(\mathrm{Fc}^{+} / \mathrm{Fc}^{0}\right)$ using an internal standard. 


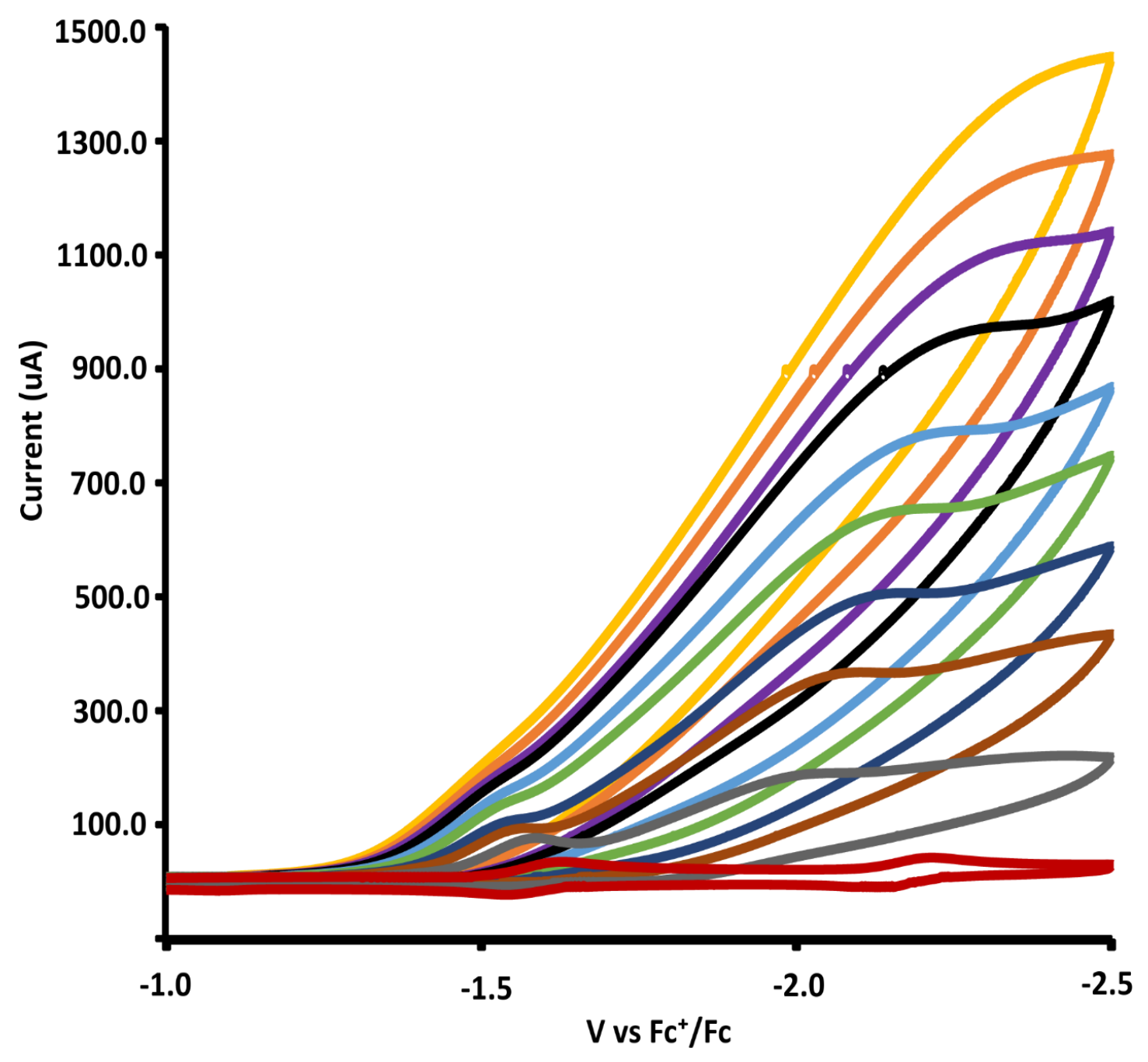

Figure A14. Electrocatalytic hydrogen evolution reaction. Cyclic voltammograms (CVs) of 0.30 $\mathrm{mM} \mathrm{NiL}^{3}$ in acetonitrile solution with subsequent addition of acetic acid at scan rate of $1000 \mathrm{mV} / \mathrm{s}$. CVs showing no acid, 1.4, 2.8, 4.2, 5.6, 7, 8.4, 9.8, 11.2, $12.6 \mathrm{mM}$ (top). Votammograms were recorded in acetonitrile solvent with $0.10 \mathrm{M} \mathrm{Bu}_{4} \mathrm{NPF}_{6}$ as supporting electrolyte using a glassy carbon working electrode, platinum counter electrode, and $\mathrm{Ag} / \mathrm{Ag}^{+}$reference electrode at a scan rate $1000 \mathrm{mV} / \mathrm{s}$. Potentials referenced versus ferrocenium/ferrocene $\left(\mathrm{Fc}^{+} / \mathrm{Fc}^{0}\right)$ using an internal standard. 


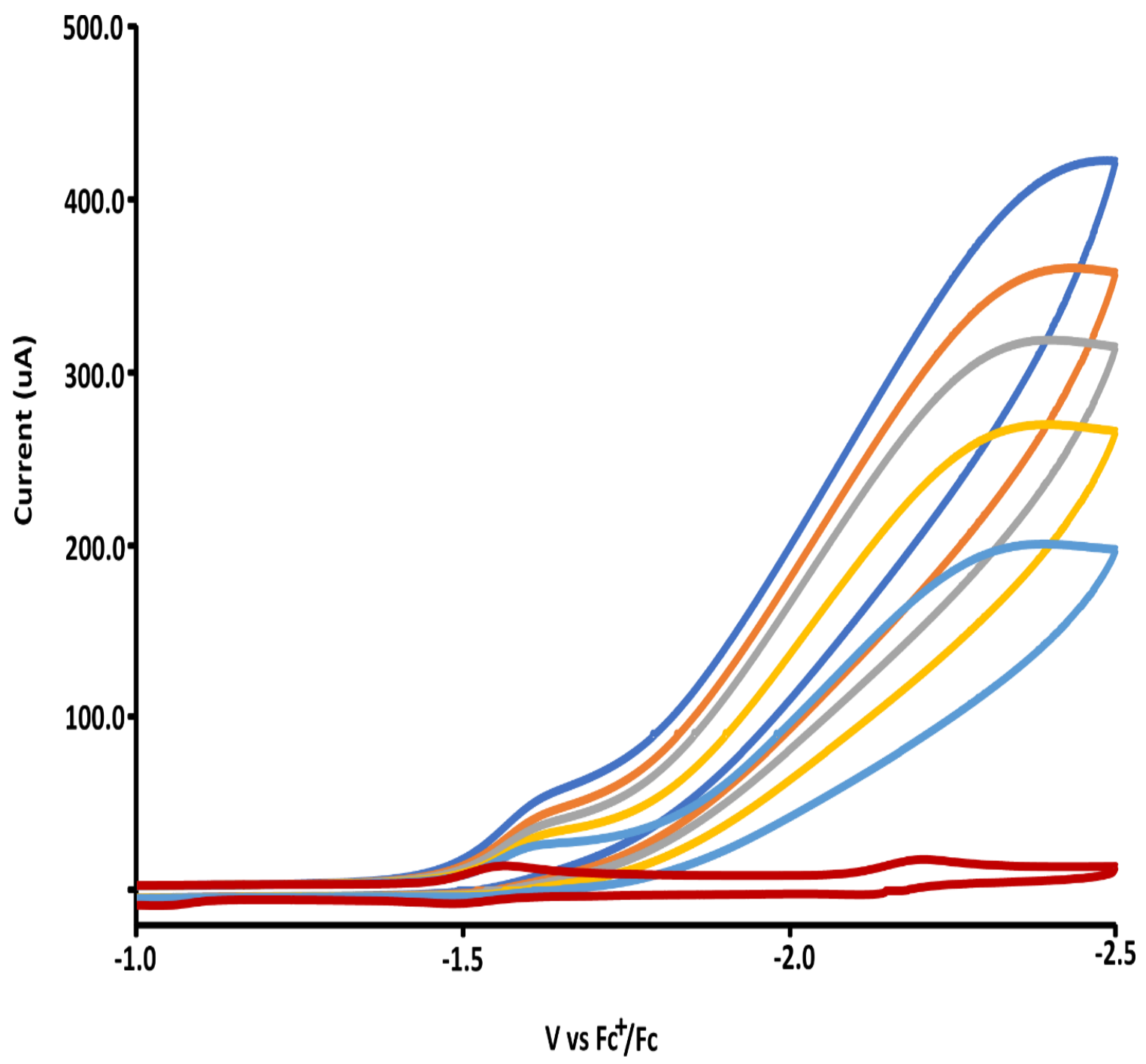

Figure A15. Cyclic voltammograms (CVs) of $0.30 \mathrm{mM} \mathrm{NiL}^{3}$ in dimethylformamide solution with subsequent addition of acetic acid. CVs showing no acid, 4.2, 5.6, 7, 8.4, $9.8 \mathrm{mM}$ (top). Votammograms were recorded in dimethylformamide solvent with $0.10 \mathrm{M} \mathrm{Bu}_{4} \mathrm{NPF}_{6}$ as supporting electrolyte using a glassy carbon working electrode, platinum counter electrode, and $\mathrm{Ag} / \mathrm{Ag}^{+}$ reference electrode at a scan rate $500 \mathrm{mV} / \mathrm{s}$. Potentials referenced versus ferrocenium/ferrocene $\left(\mathrm{Fc}^{+} / \mathrm{Fc}^{0}\right)$ using an internal standard. 


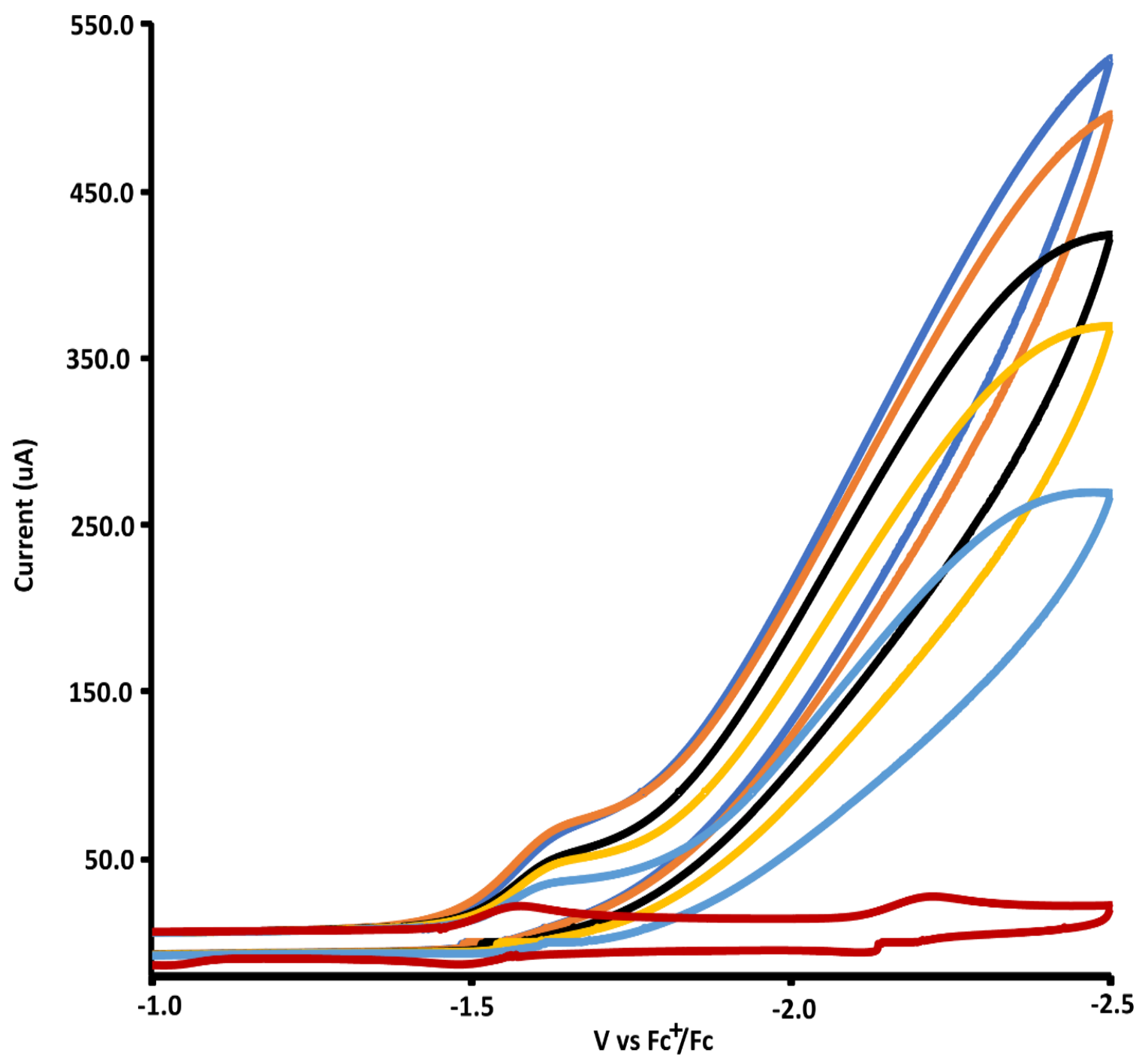

Figure A16. Cyclic voltammograms (CVs) of $0.30 \mathrm{mM} \mathrm{NiL}^{3}$ in dimethylformamide solution with subsequent addition of acetic acid. CVs showing no acid, 4.2, 5.6, 7, 8.4, $9.8 \mathrm{mM}$ (top) Votammograms were recorded in dimethylformamide solvent with $0.10 \mathrm{M} \mathrm{Bu}_{4} \mathrm{NPF}_{6}$ as supporting electrolyte using a glassy carbon working electrode, platinum counter electrode, and $\mathrm{Ag} / \mathrm{Ag}^{+}$ reference electrode at a scan rate $1000 \mathrm{mV} / \mathrm{s}$. Potentials referenced versus ferrocenium/ferrocene $\left(\mathrm{Fc}^{+} / \mathrm{Fc}^{0}\right)$ using an internal standard. 


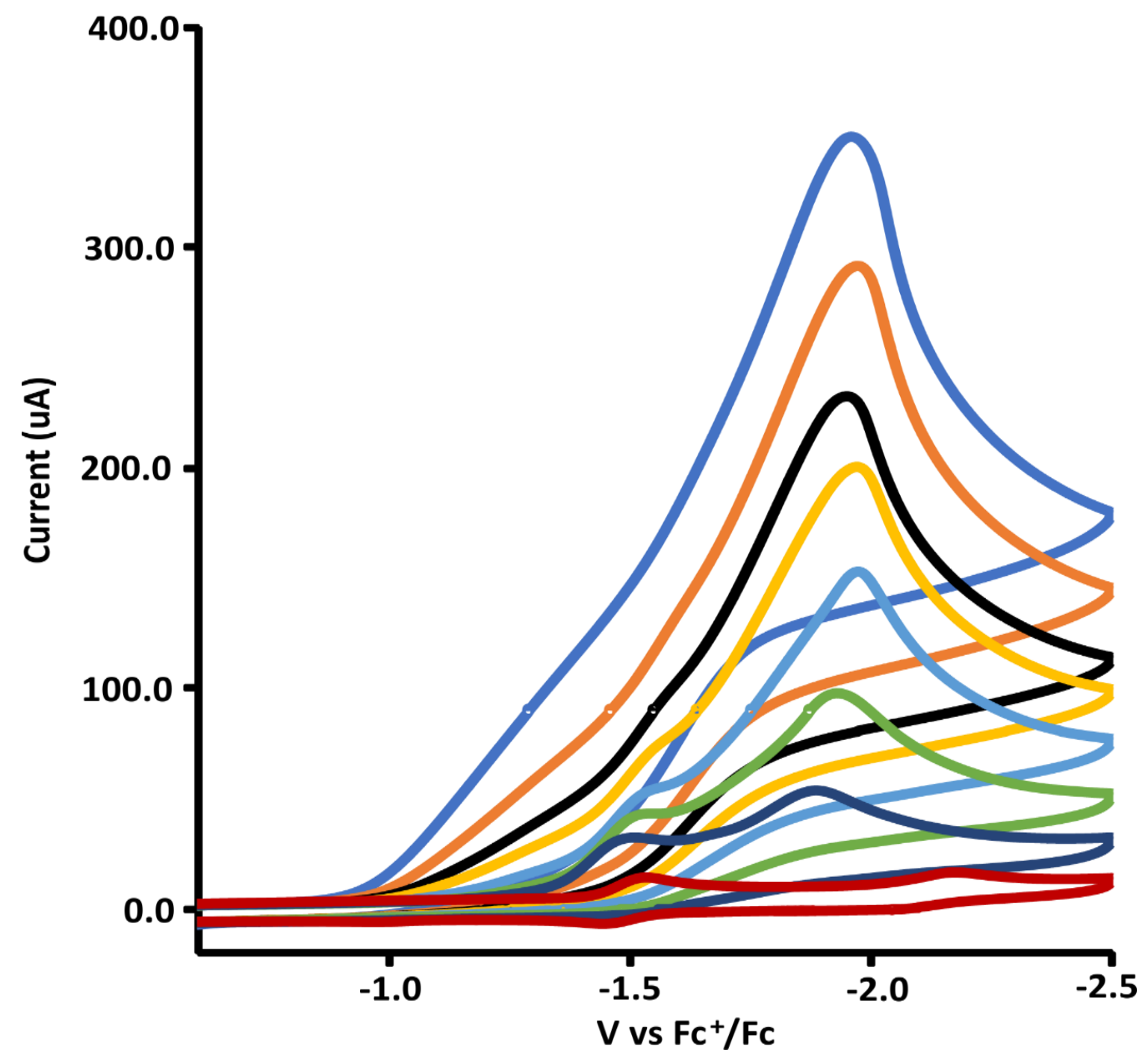

Figure A17. Cyclic voltammograms (CVs) of $0.30 \mathrm{mM} \mathrm{NiL}^{3}$ in dimethylformamide solution with subsequent addition of trifluoroacetic acid. CVs showing no acid, 4, 8, 12, 16, 20, 24, $32 \mathrm{mM}$ (top) Votammograms were recorded in dimethylformamide solvent with $0.10 \mathrm{M} \mathrm{Bu}_{4} \mathrm{NPF}_{6}$ as supporting electrolyte using a glassy carbon working electrode, platinum counter electrode, and $\mathrm{Ag} / \mathrm{Ag}^{+}$ reference electrode at a scan rate $500 \mathrm{mV} / \mathrm{s}$. Potentials referenced versus ferrocenium/ferrocene $\left(\mathrm{Fc}^{+} / \mathrm{Fc}^{0}\right)$ using an internal standard 


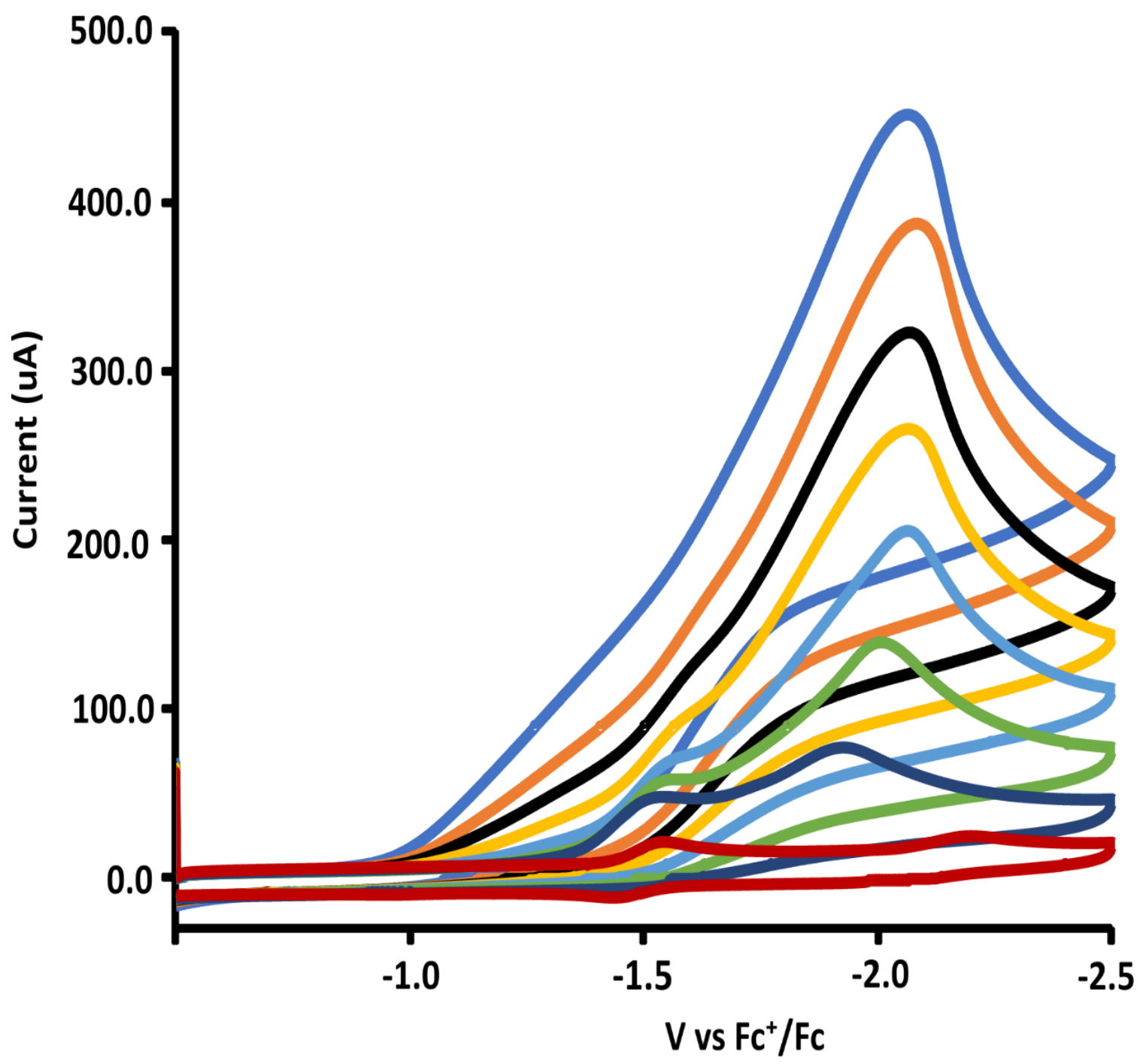

Figure A18. Cyclic voltammograms (CVs) of $0.30 \mathrm{mM} \mathrm{NiL}^{3}$ in dimethylformamide solution with subsequent addition of trifluoroacetic acid. CVs showing no acid, 4, 8, 12, 16, 20, 24, $32 \mathrm{mM}$ (top). Votammograms were recorded in dimethylformamide solvent with $0.10 \mathrm{M} \mathrm{Bu}_{4} \mathrm{NPF}_{6}$ as supporting electrolyte using a glassy carbon working electrode, platinum counter electrode, and $\mathrm{Ag} / \mathrm{Ag}^{+}$ reference electrode at a scan rate $1000 \mathrm{mV} / \mathrm{s}$. Potentials referenced versus ferrocenium/ferrocene $\left(\mathrm{Fc}^{+} / \mathrm{Fc}^{0}\right)$ using an internal standard. 


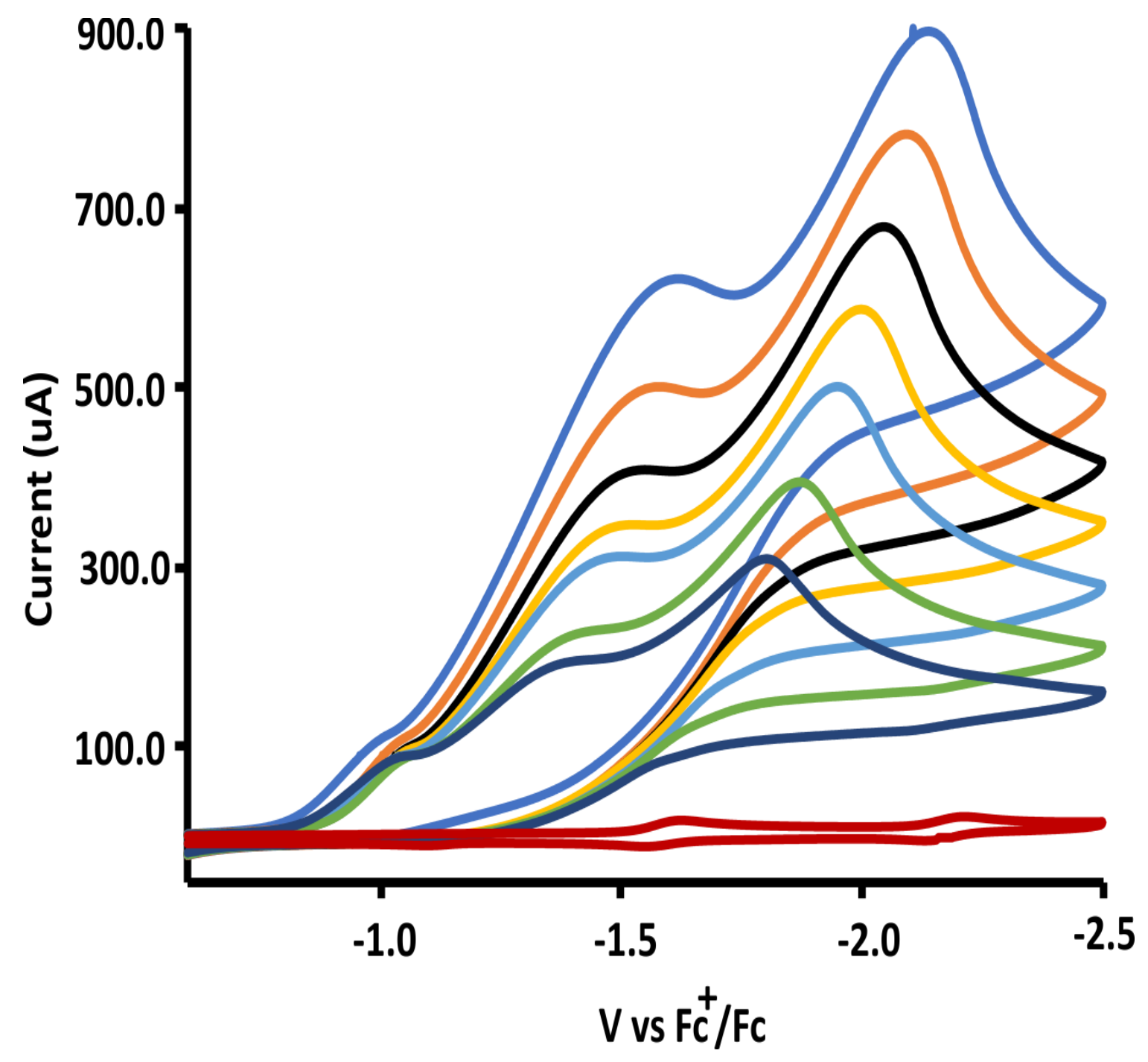

Figure A19. Cyclic voltammograms (CVs) of $0.30 \mathrm{mM} \mathrm{NiL}{ }^{3}$ in acetonitrile solution with subsequent addition of trifluoroacetic acid. CVs showing no acid, 6, 8, 10, 12, 14, 16, 18 mM (top). Votammograms were recorded in acetonitrile solvent with $0.10 \mathrm{M} \mathrm{Bu}_{4} \mathrm{NPF}_{6}$ as supporting electrolyte using a glassy carbon working electrode, platinum counter electrode, and $\mathrm{Ag} / \mathrm{Ag}^{+}$ reference electrode at a scan rate $500 \mathrm{mV} / \mathrm{s}$. Potentials referenced versus ferrocenium/ferrocene $\left(\mathrm{Fc}^{+} / \mathrm{Fc}^{0}\right)$ using an internal standard. 


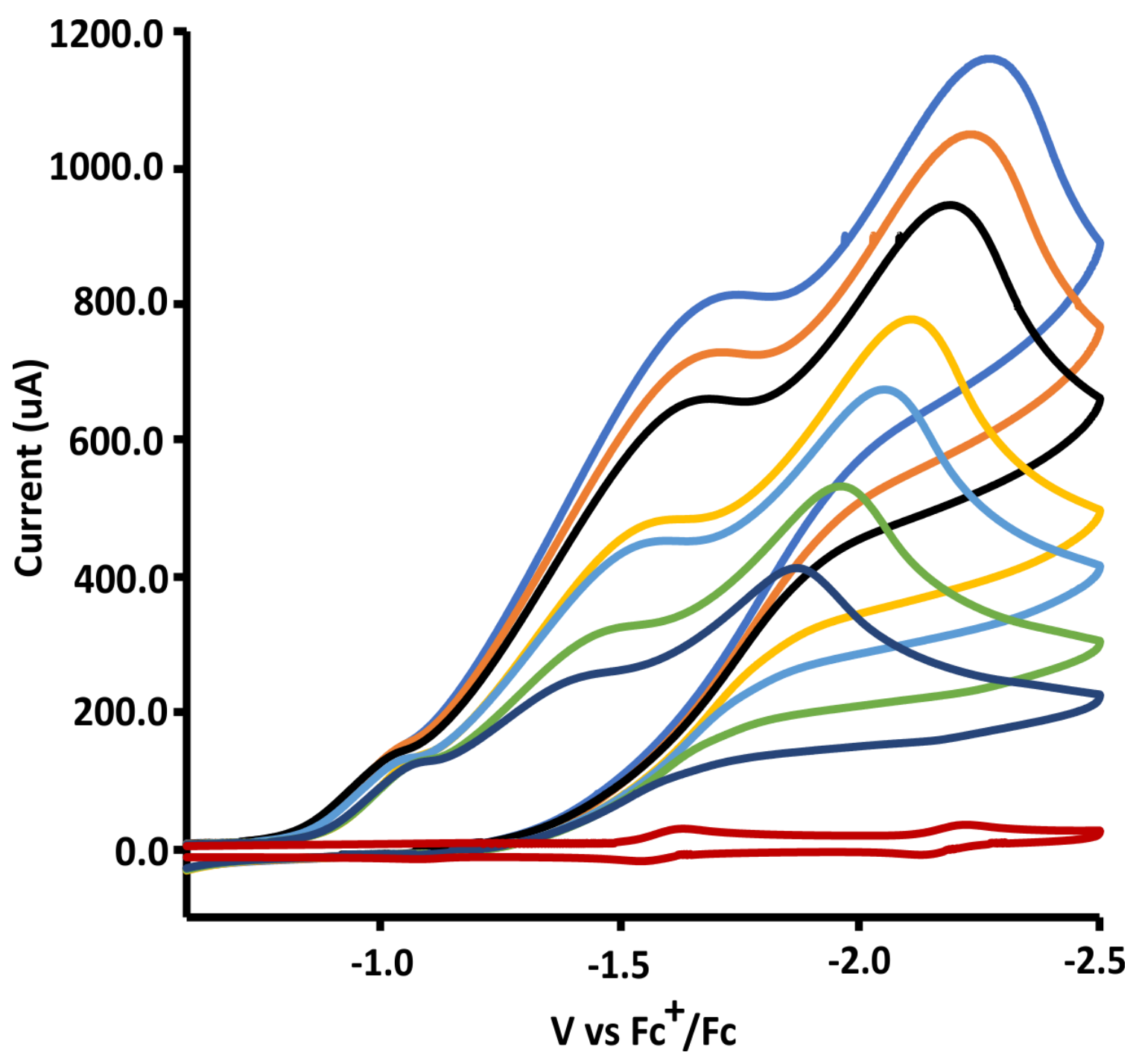

Figure A20. Cyclic voltammograms (CVs) of $0.30 \mathrm{mM} \mathrm{NiL}{ }^{3}$ in acetonitrile solution with subsequent addition of trifluoroacetic acid. CVs showing no acid, 6, 8, 10, 12, 14, 16, 18 mM (top). Votammograms were recorded in acetonitrile solvent with $0.10 \mathrm{M} \mathrm{Bu}_{4} \mathrm{NPF}_{6}$ as supporting electrolyte using a glassy carbon working electrode, platinum counter electrode, and $\mathrm{Ag} / \mathrm{Ag}^{+}$ reference electrode at a scan rate $1000 \mathrm{mV} / \mathrm{s}$. Potentials referenced versus ferrocenium/ferrocene $\left(\mathrm{Fc}^{+} / \mathrm{Fc}^{0}\right)$ using an internal standard. 


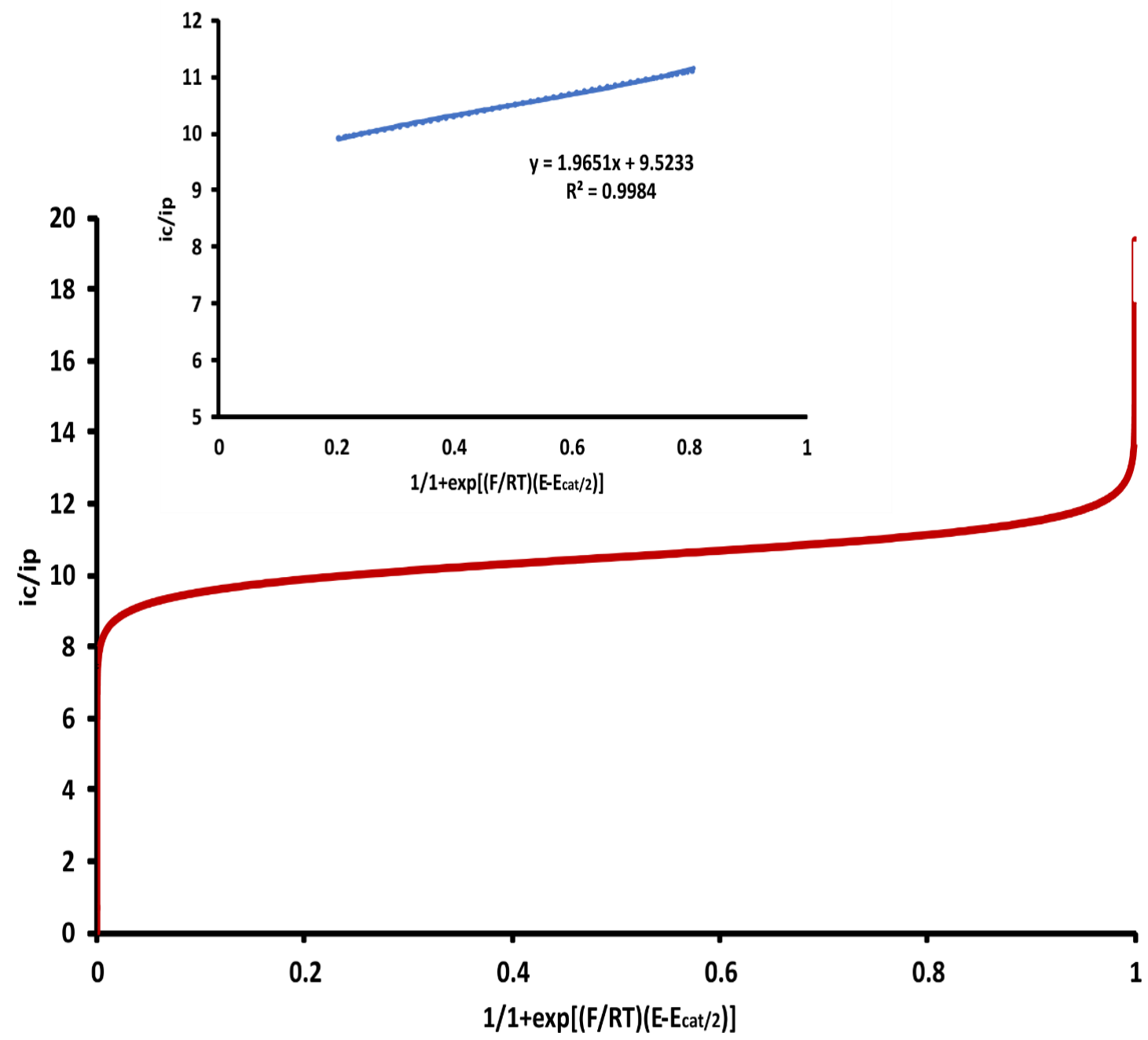

Figure A21. Foot of wave analysis for $\mathrm{NiL}^{3}$ with acetic acid in acetonitrile solution. Plot of $i_{c} / i_{p} \mathrm{vs}$ $1 / 1+\exp \left[(\mathrm{F} / \mathrm{RT})\left(\mathrm{E}_{-} \mathrm{E}_{\mathrm{cat} / 2}\right)\right]$. (Inset) Plot of Linear fit. 


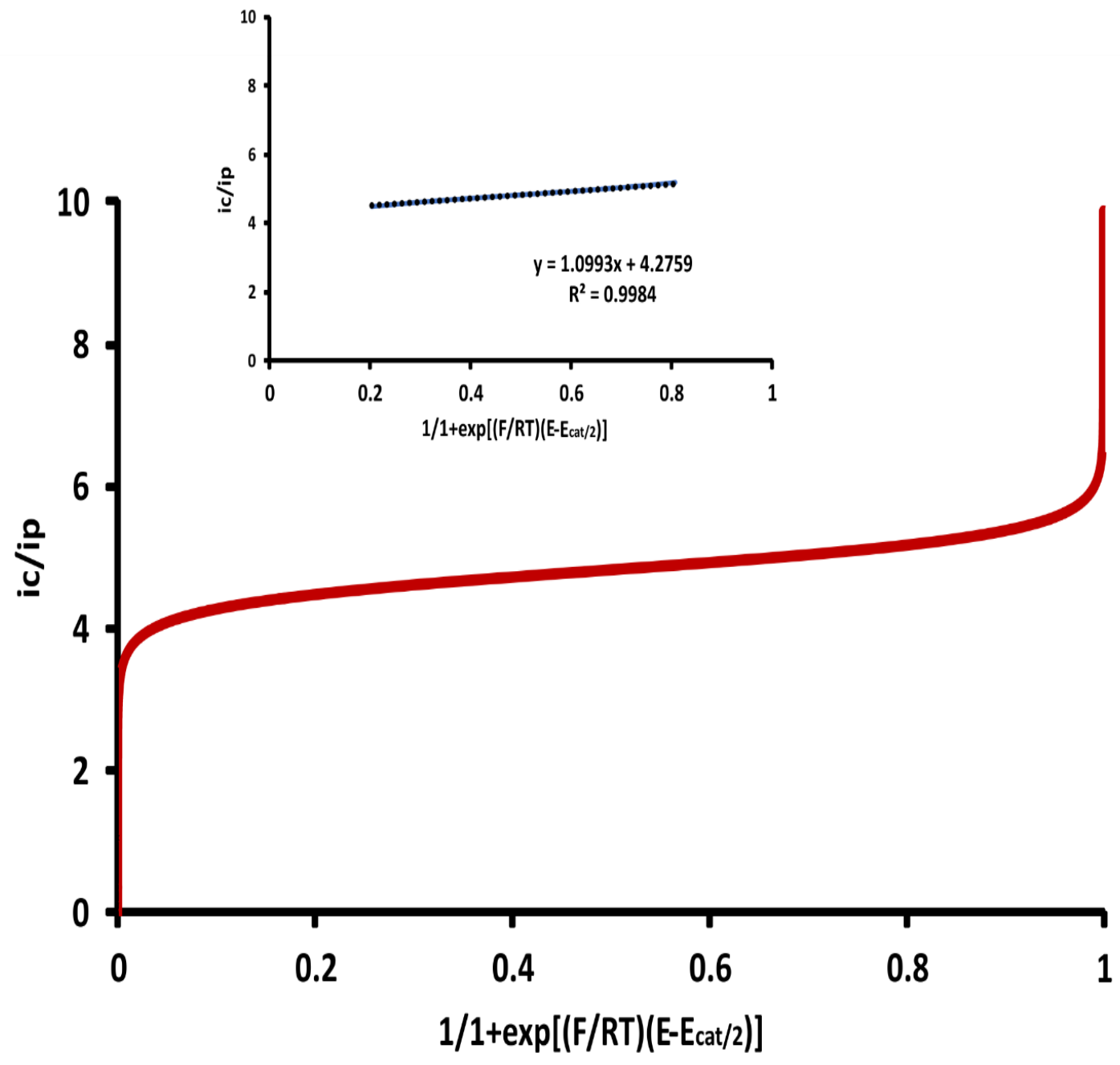

Figure A22. Foot of wave analysis for $\mathrm{NiL}^{3}$ with acetic acid in dimethylformamide solution. Plot of $i_{d} i_{p}$ vs $1 / 1+\exp \left[(\mathrm{F} / \mathrm{RT})\left(\mathrm{E}-\mathrm{E}_{\mathrm{cat} / 2}\right)\right]$. (Inset) Plot of Linear fit. 


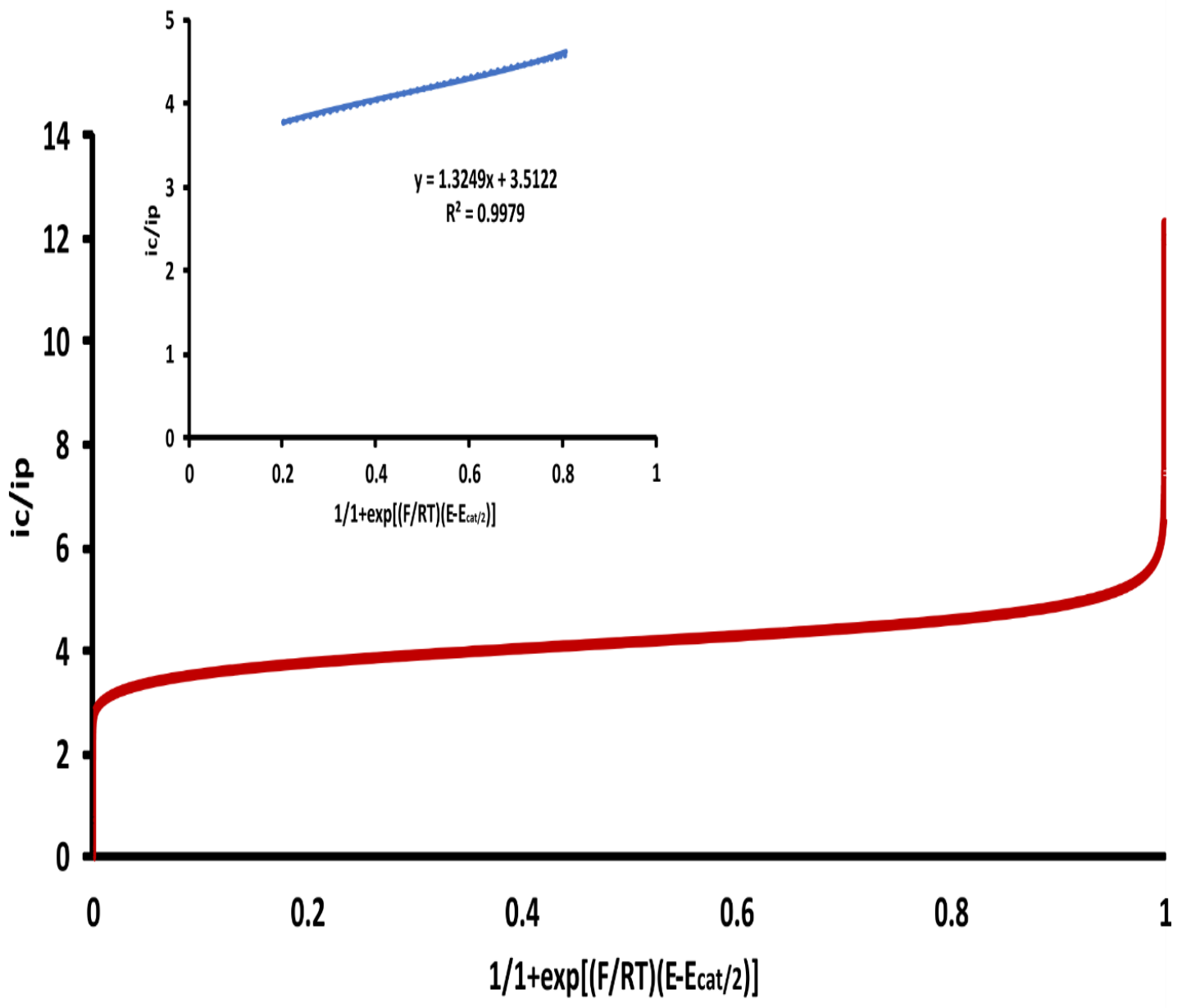

Figure A23. Foot of wave analysis for $\mathrm{NiL}^{3}$ with trifluoroacetic acid in acetonitrile solution. Plot of $i_{d} i_{p}$ vs $1 / 1+\exp \left[(\mathrm{F} / \mathrm{RT})\left(\mathrm{E}-\mathrm{E}_{\mathrm{cat} / 2}\right)\right]$. (Inset) Plot of Linear fit. 


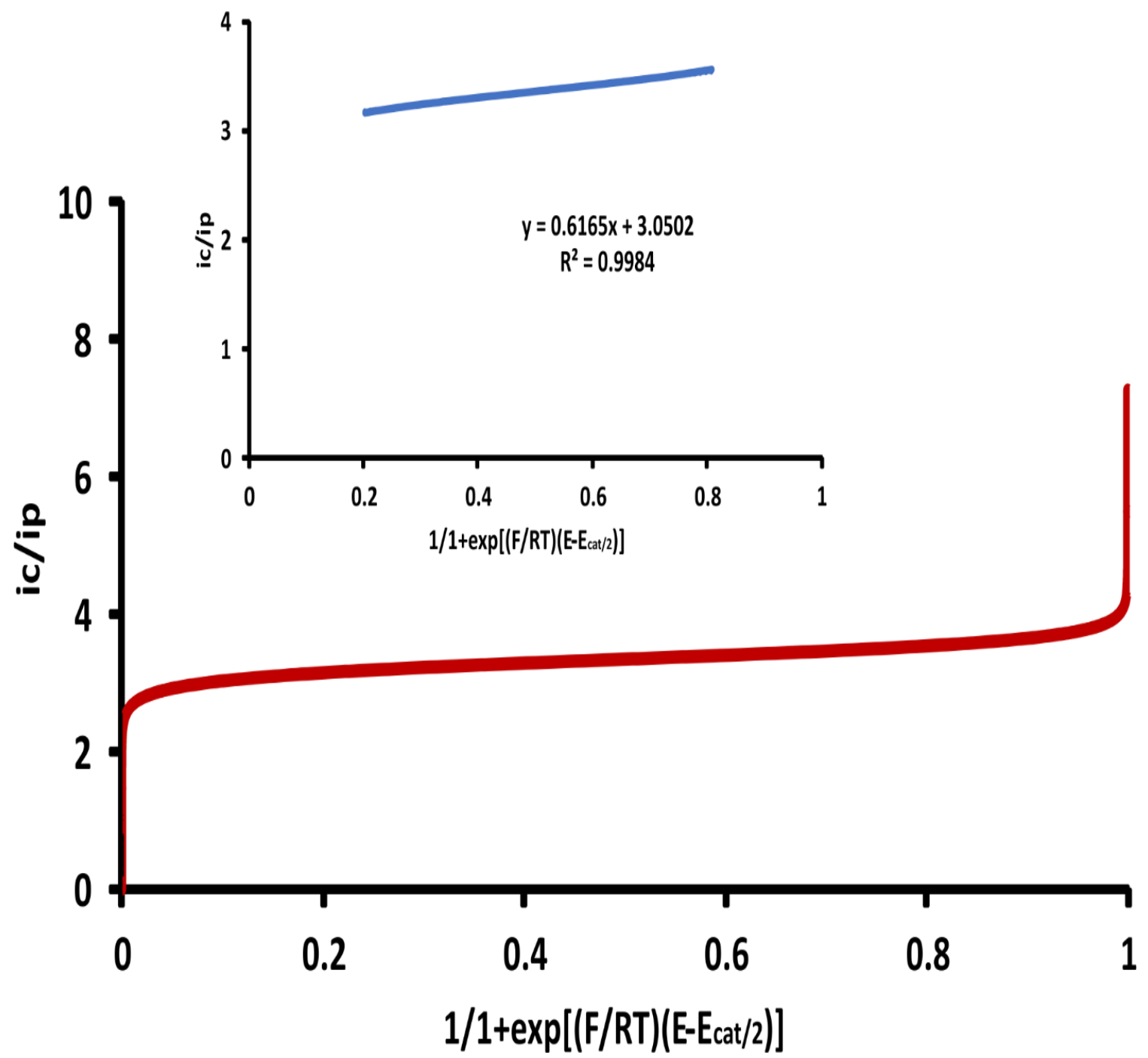

Figure A24. Foot of wave analysis for $\mathrm{NiL}^{3}$ with trifluoroacetic acid in dimethylformamide solution. Plot of $i_{d} / i_{p}$ vs $1 / 1+\exp \left[(\mathrm{F} / \mathrm{RT})\left(\mathrm{E}-\mathrm{E}_{\mathrm{cat} / 2}\right)\right]$. (Inset) Plot of Linear fit. 


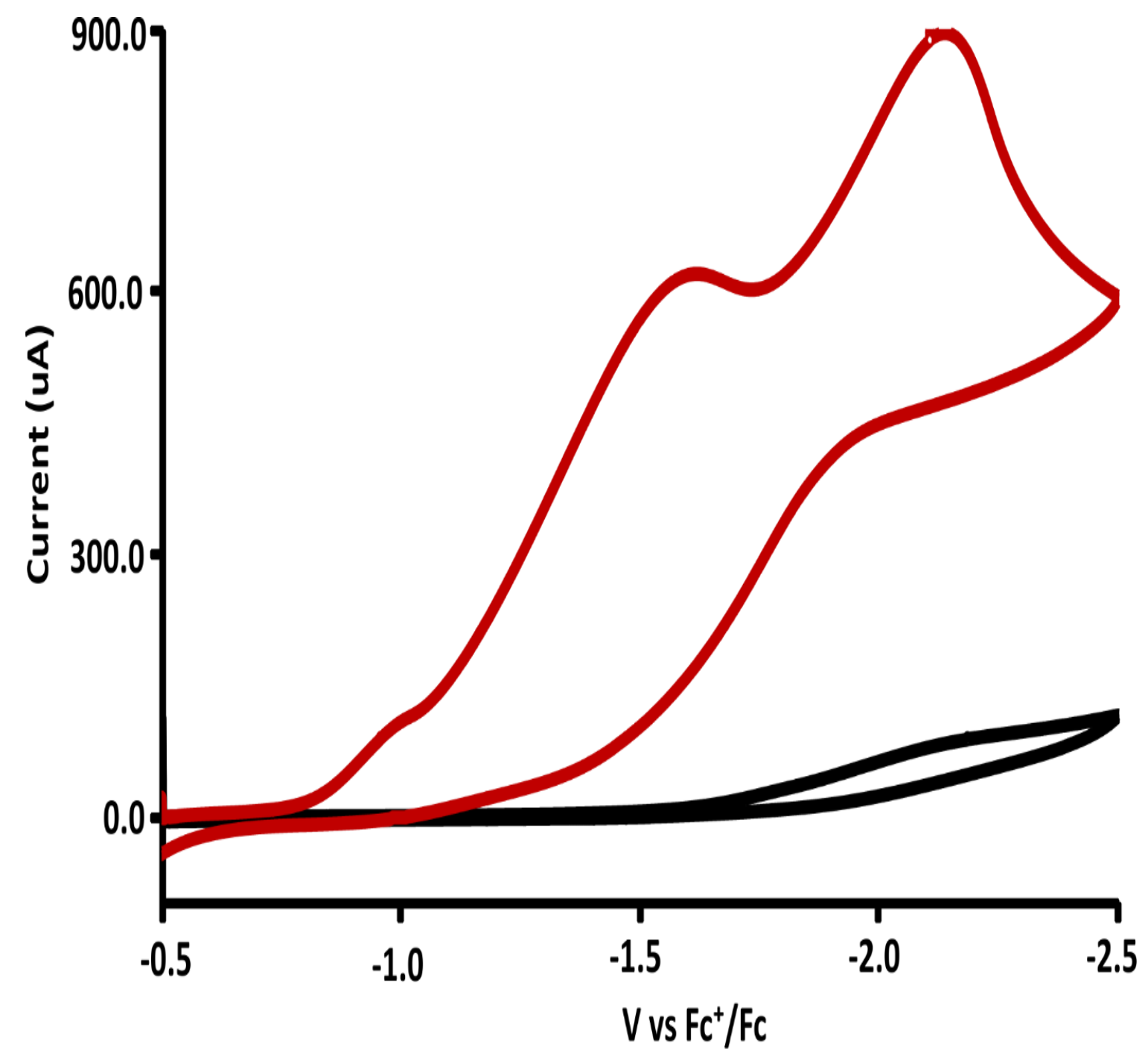

Figure A25. Control experiment for the catalysis of $\mathrm{NiL}^{3}$. Cyclic voltammogram of $0.30 \mathrm{mM} \mathrm{NiL}^{3}$ with $20 \mathrm{mM}$ trifluoroacetic acid (red) and blank acetonitrile with $20 \mathrm{mM}$ acetic acid in the absence of $\mathrm{NiL}^{3}$ (black). Votammograms were recorded in acetonitrile solvent with $0.10 \mathrm{M} \mathrm{Bu}_{4} \mathrm{NPF}_{6}$ as supporting electrolyte using a glassy carbon working electrode, platinum counter electrode, and $\mathrm{Ag} / \mathrm{Ag}^{+}$reference electrode at a scan rate $500 \mathrm{mV} / \mathrm{s}$. Potentials referenced versus ferrocenium/ferrocene $\left(\mathrm{Fc}^{+} / \mathrm{Fc}^{0}\right)$ using an internal standard. 


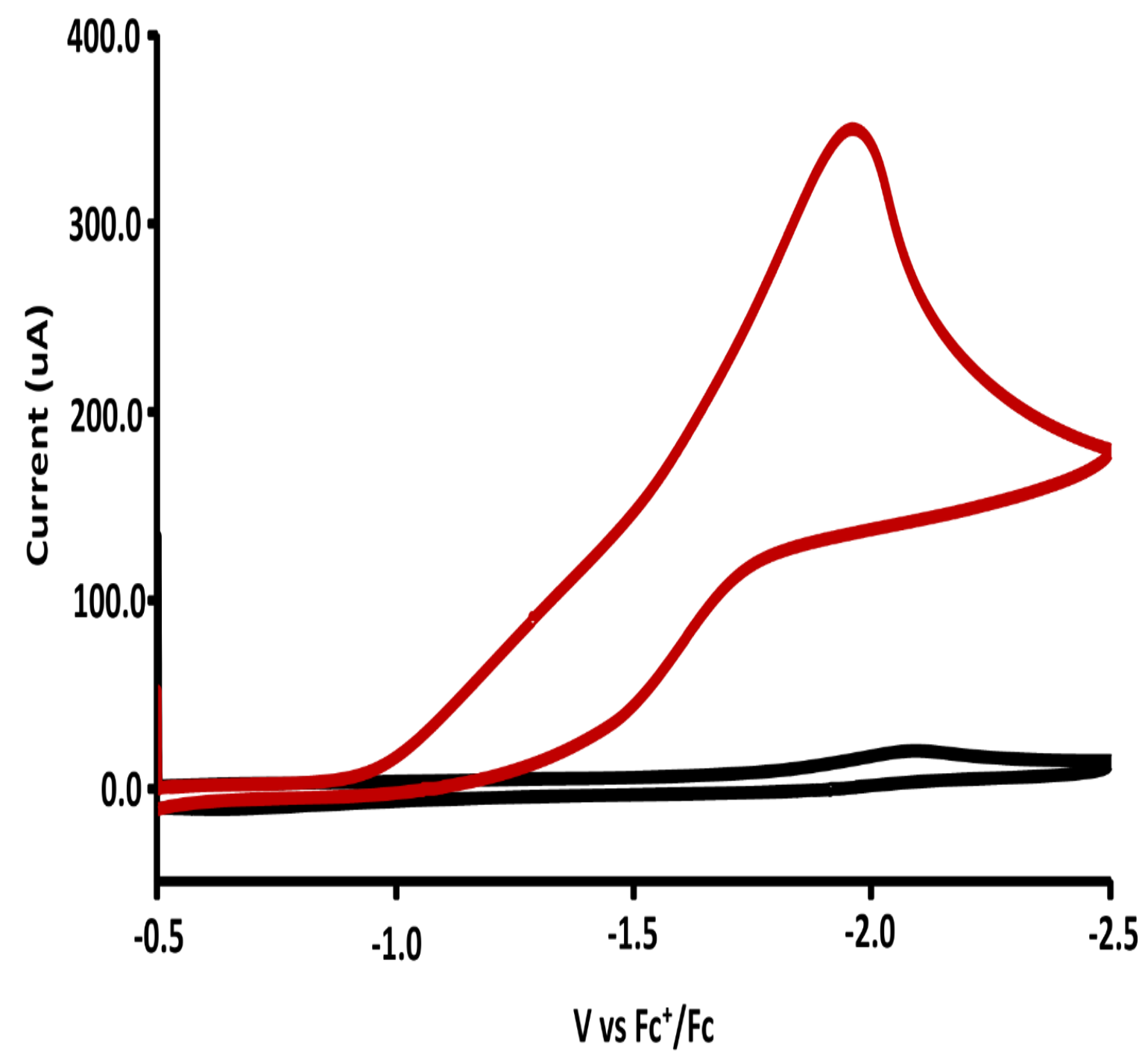

Figure A26. Control experiment for the catalysis of $\mathrm{NiL}^{3}$. Cyclic voltammogram of $0.30 \mathrm{mM} \mathrm{NiL}^{3}$ with $32 \mathrm{mM}$ trifluoroacetic acid (red) and blank dimethylformamide with $32 \mathrm{mM}$ trifuoroacetic acid in the absence of $\mathrm{NiL}^{3}$ (black). Votammograms were recorded in dimethylformamide solvent with $0.10 \mathrm{M} \mathrm{Bu}_{4} \mathrm{NPF}_{6}$ as supporting electrolyte using a glassy carbon working electrode, platinum counter electrode, and $\mathrm{Ag} / \mathrm{Ag}^{+}$reference electrode at a scan rate $500 \mathrm{mV} / \mathrm{s}$. Potentials referenced versus ferrocenium/ferrocene $\left(\mathrm{Fc}^{+} / \mathrm{Fc}^{0}\right)$ using an internal standard. 


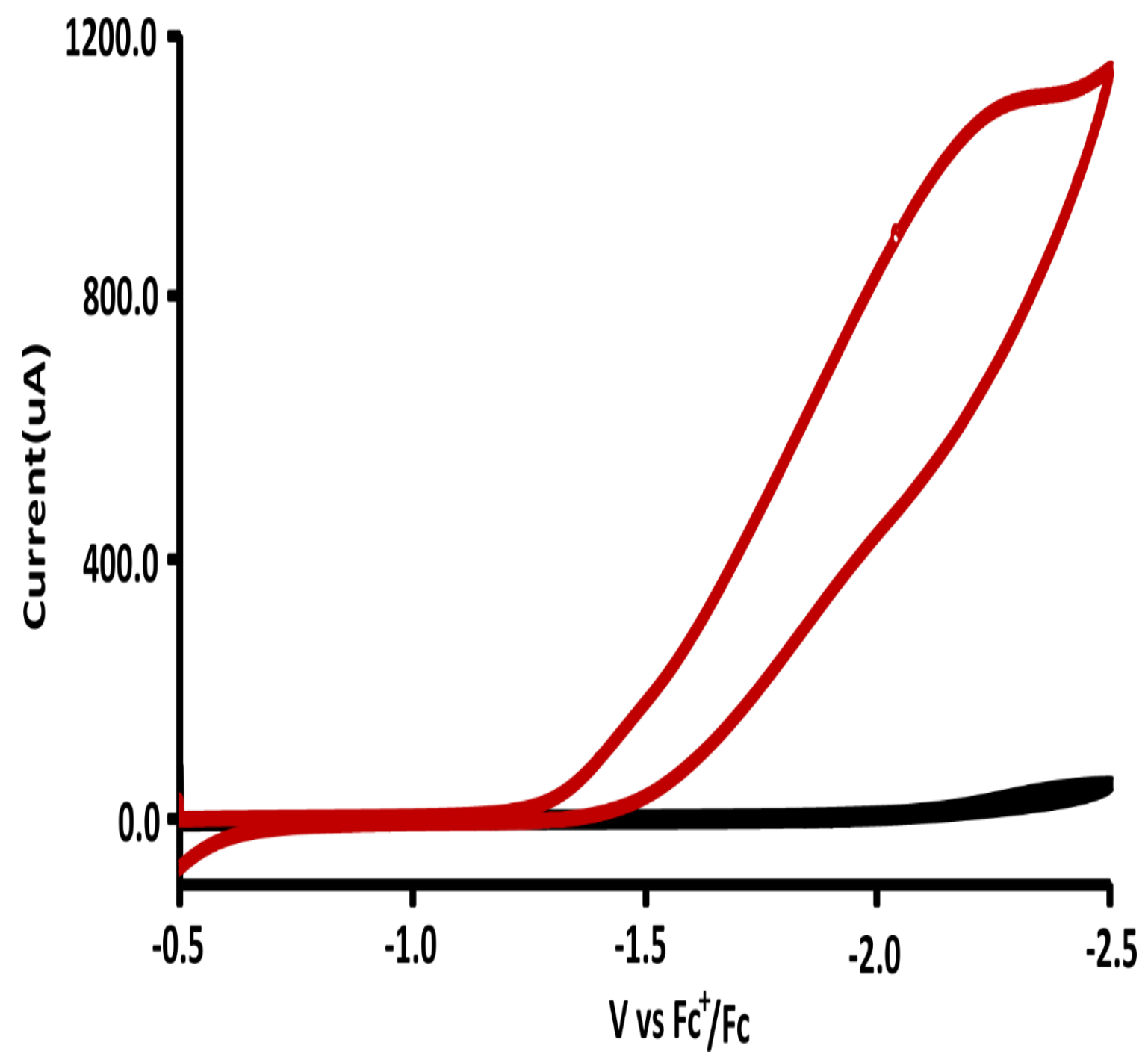

Figure A27. Control experiment for the catalysis of $\mathrm{NiL}^{3}$. Cyclic voltammogram of $0.30 \mathrm{mM} \mathrm{NiL}^{3}$ with $12.6 \mathrm{mM}$ acetic acid (red) and blank acetonitrile with $12.6 \mathrm{mM}$ acetic acid in the absence of $\mathrm{NiL}^{3}$ (black). Votammograms were recorded in acetonitrile solvent with $0.10 \mathrm{M} \mathrm{Bu}_{4} \mathrm{NPF}_{6}$ as supporting electrolyte using a glassy carbon working electrode, platinum counter electrode, and $\mathrm{Ag} / \mathrm{Ag}^{+}$reference electrode at a scan rate $500 \mathrm{mV} / \mathrm{s}$. Potentials referenced versus ferrocenium/ferrocene $\left(\mathrm{Fc}^{+} / \mathrm{Fc}^{0}\right)$ using an internal standard. 


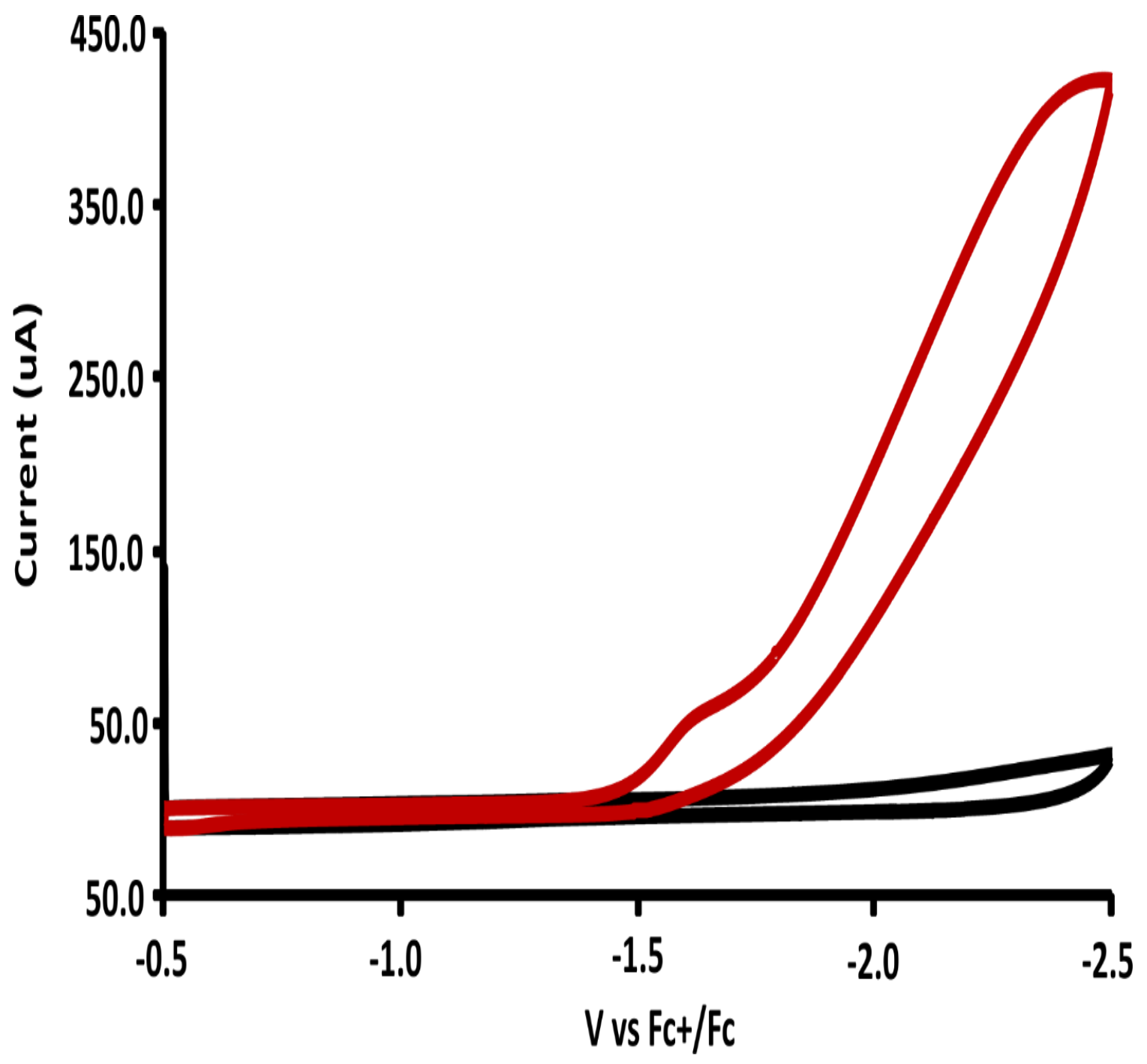

Figure A28. Control experiment for the catalysis of $\mathrm{NiL}^{3}$. Cyclic voltammogram of $0.30 \mathrm{mM} \mathrm{NiL}^{3}$ with $9.8 \mathrm{mM}$ acetic acid (red) and blank dimethylformamide with $9.8 \mathrm{mM}$ acetic acid in the absence of $\mathrm{NiL}^{3}$ (black). Votammograms were recorded in dimethylformamide solvent with $0.10 \mathrm{M}$ $\mathrm{Bu}_{4} \mathrm{NPF}_{6}$ as supporting electrolyte using a glassy carbon working electrode, platinum counter electrode, and $\mathrm{Ag} / \mathrm{Ag}^{+}$reference electrode at a scan rate $500 \mathrm{mV} / \mathrm{s}$. Potentials referenced versus ferrocenium/ferrocene $\left(\mathrm{Fc}^{+} / \mathrm{Fc}^{0}\right)$ using an internal standard. 


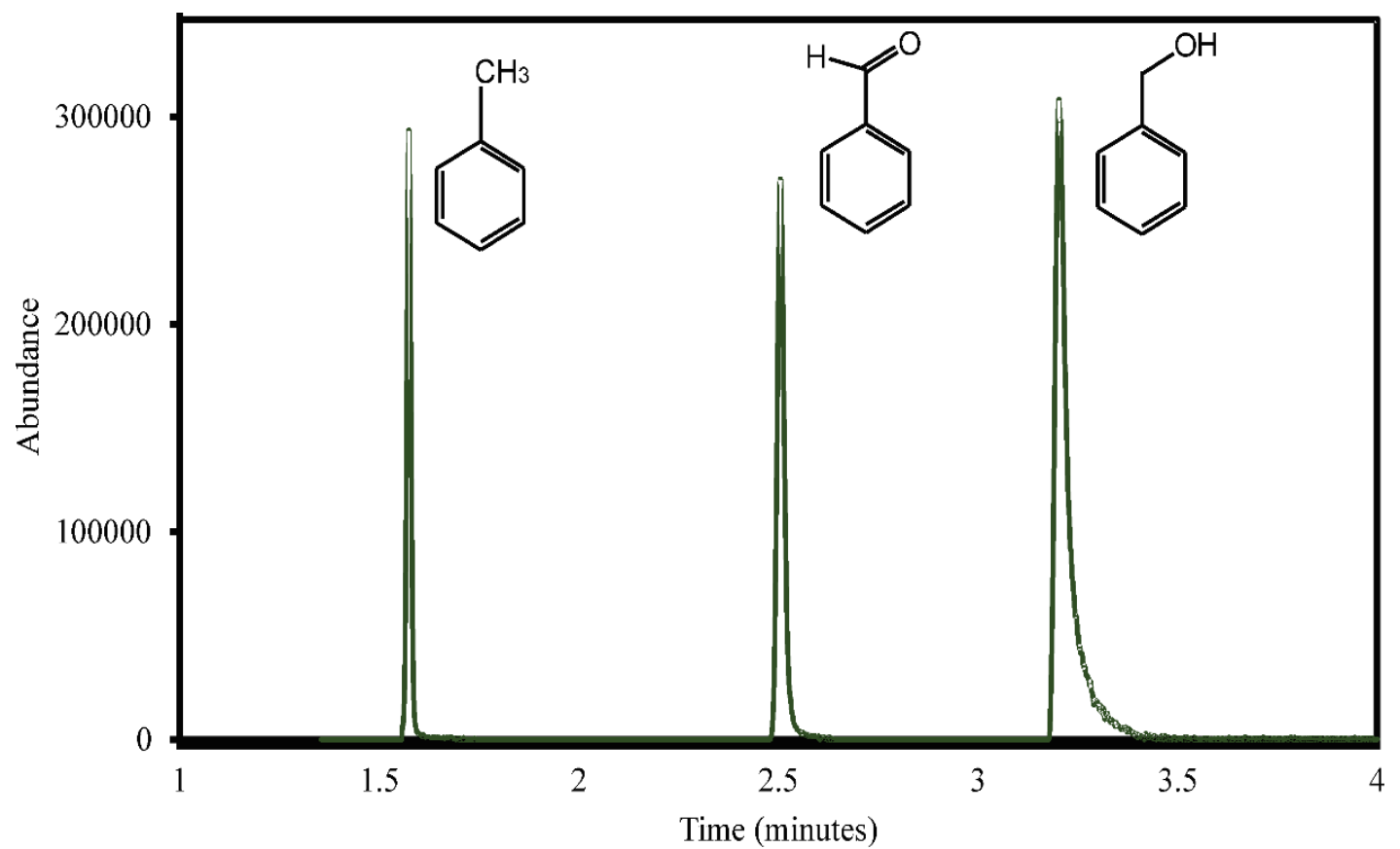

Figure A29. Representation of gas chromatogram for the copper catalyzed benzyl alcohol oxidation, peaks shown are toluene (internal standard), benzaldehyde (product) and benzyl alcohol (substrate).

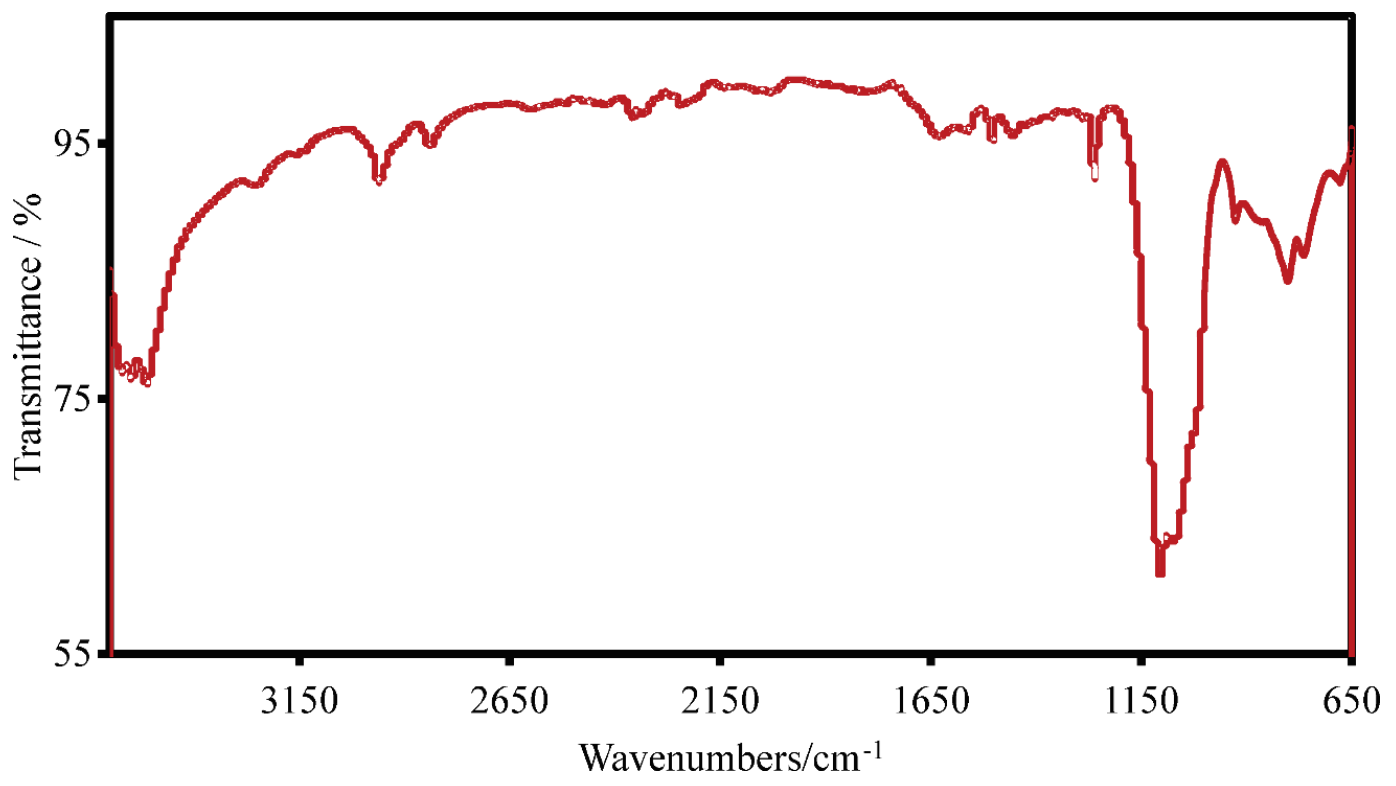

Figure A30. FT-IR spectrum of reduced Schiff base complex $\left[\mathrm{CuL}^{5}\right]\left(\mathrm{ClO}_{4}\right)_{2}$ collected on solid sample using ATR attachment. 


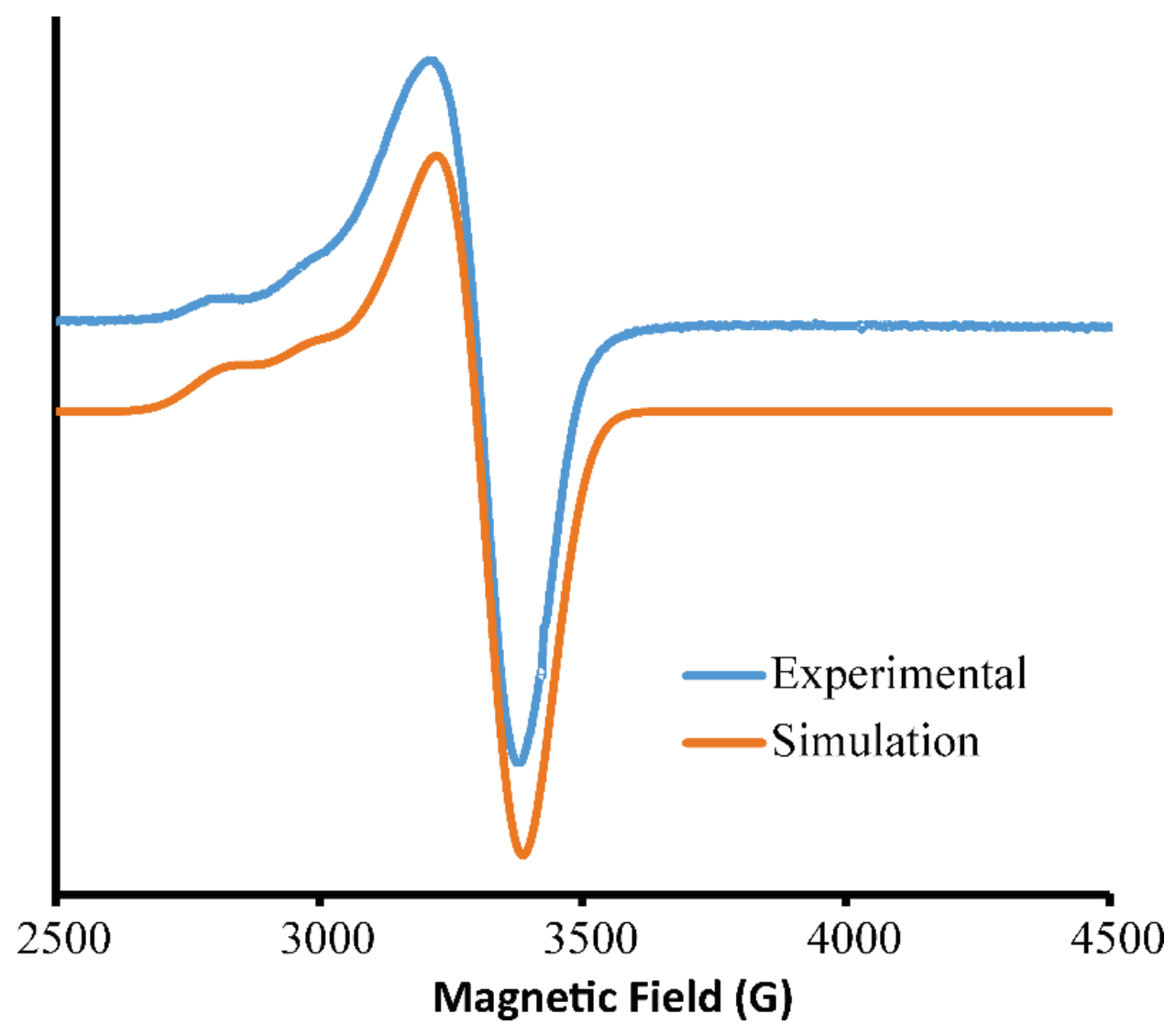

Figure A31. EPR spectrum of reduced Schiff base complex $\left[\mathrm{CuL}^{5}\right]\left(\mathrm{ClO}_{4}\right)_{2}$ collected on frozen acetonitrile solution at $77 \mathrm{~K}$.

Table T1. List of selected $\mathrm{H}$-bonding interactions in $\left[\mathrm{CuL}^{5}\right]\left(\mathrm{ClO}_{4}\right)_{2}$ and $\left[\mathrm{Cu}\left(\mathrm{HL}^{5}\right)\right]\left[\left(\mathrm{ClO}_{4}\right)_{3}\right]$.

\begin{tabular}{|l|l|l|l|l|}
\hline $\mathbf{D}-\mathbf{H} \cdots \mathbf{A}$ & $\mathbf{D}-\mathbf{H}(\mathbf{\AA})$ & $\mathbf{H} \cdots \mathbf{A}(\mathbf{A})$ & $\mathbf{D}-\mathbf{H} \cdots \mathbf{A}\left({ }^{\circ}\right)$ & $\mathbf{D} \cdots \mathbf{A}(\AA)$ \\
\hline$\left.\left[\mathbf{C u L}^{\mathbf{5}}\right](\mathbf{C l O})_{4}\right)_{2}$ & & & & \\
\hline $\mathrm{N} 3-\mathrm{H} 3 \mathrm{~N} \cdots \mathrm{O} 6$ & 1.00 & 2.30 & 159 & $3.248(4)$ \\
\hline $\mathrm{N} 4-\mathrm{H} 4 \mathrm{~N} \cdots \mathrm{O} 1$ & 0.99 & 2.20 & 118 & $2.811(3)$ \\
\hline$\left[\mathbf{C u}\left(\mathbf{H L}^{5}\right)\right]\left[(\mathbf{C l O})_{\mathbf{3}}\right]$ & & & & \\
\hline $\mathrm{N} 3-\mathrm{H} 3 \mathrm{~N} \cdots \mathrm{O} 1$ & $0.82(3)$ & $2.26(3)$ & $156(2)$ & $3.018(3)$ \\
\hline $\mathrm{N} 4-\mathrm{H} 4 \mathrm{~N} \cdots \mathrm{O} 22$ & $0.87(3)$ & $2.12(3)$ & $173(2)$ & $2.976(3)$ \\
\hline
\end{tabular}


A.1 Computational input coordinates for $\mathrm{NiL}^{3}$ and related compounds using B3LYP/ 6-311g(d,p) in acetonitrile

\begin{tabular}{|c|c|c|c|}
\hline \multicolumn{4}{|c|}{$\underline{\mathrm{NiL}^{3}}$} \\
\hline \multicolumn{4}{|c|}{ q $\mathrm{Ms}$} \\
\hline \multicolumn{4}{|c|}{$\begin{array}{ll}0 & 1\end{array}$} \\
\hline $\mathrm{Ni}$ & 1.298967264 & 1.716422563 & 0.713071468 \\
\hline $\mathrm{C}$ & 2.077098110 & -0.852510960 & 0.491389295 \\
\hline $\mathrm{N}$ & 1.773134330 & 0.186402198 & -0.234431064 \\
\hline $\mathrm{N}$ & 1.826356920 & 0.101489400 & -1.609083332 \\
\hline $\mathrm{C}$ & 1.456628243 & 1.248488769 & -2.136738890 \\
\hline S & 0.958096047 & 2.658176535 & -1.194682486 \\
\hline $\mathrm{C}$ & 2.480675590 & -2.168490180 & -0.075503141 \\
\hline $\mathrm{N}$ & 1.431975930 & 1.370106900 & -3.469802543 \\
\hline $\mathrm{C}$ & 1.739697353 & 0.264210738 & -4.353189292 \\
\hline $\mathrm{C}$ & 1.129474089 & 2.336962584 & 3.526368011 \\
\hline $\mathrm{N}$ & 1.640189805 & 0.652745991 & 2.194418338 \\
\hline $\mathrm{N}$ & 1.506619816 & 1.073419554 & 3.496785633 \\
\hline $\mathrm{C}$ & 1.986729953 & -0.577643835 & 1.932880409 \\
\hline S & 0.855462745 & 3.324454446 & 2.085124447 \\
\hline $\mathrm{C}$ & 2.253656241 & -1.605054861 & 2.980517434 \\
\hline $\mathrm{N}$ & 0.938903338 & 2.936088342 & 4.704959664 \\
\hline $\mathrm{C}$ & 1.056751568 & 2.255094468 & 5.980838971 \\
\hline $\mathrm{H}$ & 1.250598320 & 2.048394390 & -3.812289741 \\
\hline $\mathrm{H}$ & 0.626368925 & 3.653618400 & 4.691096792 \\
\hline $\mathrm{H}$ & 2.447779305 & -2.126202930 & -1.073134807 \\
\hline $\mathrm{H}$ & 3.411691239 & -2.386692390 & 0.219082884 \\
\hline $\mathrm{H}$ & 1.854987829 & -2.877224490 & 0.248789038 \\
\hline $\mathrm{H}$ & 1.663671094 & 0.566649150 & -5.303786215 \\
\hline $\mathrm{H}$ & 2.671825422 & -0.052436190 & -4.177427882 \\
\hline $\mathrm{H}$ & 1.096246434 & -0.483766140 & -4.188567690 \\
\hline $\mathrm{H}$ & 2.133652700 & -1.197574920 & 3.885317370 \\
\hline $\mathrm{H}$ & 3.191349969 & -1.940139030 & 2.886447947 \\
\hline & & & 154 \\
\hline
\end{tabular}




$\begin{array}{llll}\mathrm{H} & 1.615000739 & -2.366394510 & 2.870357114 \\ \mathrm{H} & 0.871759587 & 2.900905350 & 6.721017304 \\ \mathrm{H} & 1.982384841 & 1.891085820 & 6.079859484 \\ \mathrm{H} & 0.396574022 & 1.505426100 & 6.020447176\end{array}$

$\left[\mathrm{NiL}^{3}\right]^{-}$

q Ms

$-12$

Ni $\quad 1.279394000 \quad 1.728473000 \quad 0.701506000$

$\begin{array}{llll}\text { C } & 2.054425000 & -0.838838000 & 0.494547000\end{array}$

N $\quad \begin{array}{llll}1.754628000 & 0.192567000 & -0.250844000\end{array}$

$\mathrm{N} \quad \begin{array}{llll}1.795289000 & 0.115240000 & -1.608595000\end{array}$

$\begin{array}{llll}\text { C } & 1.453569000 & 1.257076000 & -2.172022000\end{array}$

S $\quad 0.998444000 \quad 2.716850000 \quad-1.252697000$

C $\quad 2.460583000 \quad-2.173227000 \quad-0.039963000$

$\mathrm{N} \quad \begin{array}{llll}1.443267000 & 1.344663000 & -3.510105000\end{array}$

$\begin{array}{llll}\text { C } & 1.792845000 & 0.245938000 & -4.400600000\end{array}$

$\begin{array}{llll}\text { C } & 1.064851000 & 2.346827000 & 3.544968000\end{array}$

$\begin{array}{llll}\mathrm{N} & 1.589132000 & 0.661021000 & 2.203871000\end{array}$

$\mathrm{N} \quad 1.446009000 \quad 1.085951000 \quad 3.488398000$

C $\quad \begin{array}{llll}1.962019000 & -0.562709000 & 1.934162000\end{array}$

$\begin{array}{llll}\text { S } & 0.767238000 & 3.355634000 & 2.104132000\end{array}$

$\begin{array}{llll}\text { C } & 2.259842000 & -1.598676000 & 2.968450000\end{array}$

$\mathrm{N} \quad 0.883634000 \quad 2.917817000 \quad 4.744696000$

$\begin{array}{llll}\text { C } & 1.087161000 & 2.228673000 & 6.012017000\end{array}$

$\mathrm{H} \quad 1.180220000 \quad 2.229010000 \quad-3.913481000$

$\mathrm{H} \quad 0.591456000 \quad 3.881368000 \quad 4.759247000$

$\mathrm{H} \quad 2.327023000 \quad-2.200741000 \quad-1.118171000$

$\mathrm{H} \quad 3.512293000 \quad-2.375264000 \quad 0.188488000$

H $\quad 1.870446000 \quad-2.969775000 \quad 0.420415000$

$\mathrm{H} \quad 1.697229000 \quad 0.595567000 \quad-5.427056000$ 


$\begin{array}{lrrr}\mathrm{H} & 2.820187000 & -0.084378000 & -4.229123000 \\ \mathrm{H} & 1.126826000 & -0.606854000 & -4.249030000 \\ \mathrm{H} & 2.302021000 & -1.142731000 & 3.954145000 \\ \mathrm{H} & 3.209269000 & -2.096291000 & 2.756135000 \\ \mathrm{H} & 1.482482000 & -2.370157000 & 2.973738000 \\ \mathrm{H} & 0.866880000 & 2.925648000 & 6.818578000 \\ \mathrm{H} & 2.119722000 & 1.884340000 & 6.108203000 \\ \mathrm{H} & 0.425926000 & 1.362987000 & 6.096122000\end{array}$

$\left[\mathrm{NiL}^{3} \mathrm{H}\right]$ (proton addition to the coordinated nitrogen)

\begin{tabular}{|c|c|c|c|}
\hline \multicolumn{4}{|c|}{ q $\mathrm{Ms}$} \\
\hline , & & & \\
\hline $\mathrm{Ni}$ & 1.274391000 & 1.754349000 & 0.696257000 \\
\hline $\mathrm{C}$ & 2.046816000 & -0.847910000 & 0.522642000 \\
\hline $\mathrm{N}$ & 1.660128000 & 0.200025000 & -0.239151000 \\
\hline N & 1.742460000 & 0.121429000 & -1.606773000 \\
\hline $\mathrm{C}$ & 1.414471000 & 1.232551000 & -2.196058000 \\
\hline S & 0.987525000 & 2.720107000 & -1.292284000 \\
\hline $\mathrm{C}$ & 2.487637000 & -2.135446000 & -0.106163000 \\
\hline $\mathrm{N}$ & 1.333640000 & 1.298412000 & -3.566953000 \\
\hline $\mathrm{C}$ & 1.858696000 & 0.225338000 & -4.398568000 \\
\hline $\mathrm{C}$ & 1.109058000 & 2.357109000 & 3.571768000 \\
\hline $\mathrm{N}$ & 1.670593000 & 0.713384000 & 2.179153000 \\
\hline $\mathrm{N}$ & 1.488965000 & 1.117574000 & 3.478088000 \\
\hline $\mathrm{C}$ & 1.983666000 & -0.574006000 & 1.909854000 \\
\hline S & 0.777794000 & 3.380374000 & 2.138286000 \\
\hline $\mathrm{C}$ & 2.218309000 & -1.556085000 & 3.017760000 \\
\hline $\mathrm{N}$ & 0.990182000 & 2.959964000 & 4.801604000 \\
\hline $\mathrm{C}$ & 1.031164000 & 2.174171000 & 6.026139000 \\
\hline $\mathrm{H}$ & 1.427615000 & 2.229886000 & -3.941893000 \\
\hline H & 0.373894000 & 3.758172000 & 4.813096000 \\
\hline
\end{tabular}




$\begin{array}{llll}\mathrm{H} & 1.697392000 & -2.560511000 & -0.733978000 \\ \mathrm{H} & 3.349217000 & -1.972853000 & -0.761944000 \\ \mathrm{H} & 2.765438000 & -2.876677000 & 0.641942000 \\ \mathrm{H} & 1.684502000 & 0.480589000 & -5.444290000 \\ \mathrm{H} & 2.932673000 & 0.056972000 & -4.245559000 \\ \mathrm{H} & 1.339257000 & -0.707873000 & -4.174414000 \\ \mathrm{H} & 3.024116000 & -1.220831000 & 3.678944000 \\ \mathrm{H} & 2.476436000 & -2.542827000 & 2.635890000 \\ \mathrm{H} & 1.325801000 & -1.655291000 & 3.644299000 \\ \mathrm{H} & 0.921340000 & 2.849888000 & 6.874826000 \\ \mathrm{H} & 1.991121000 & 1.661689000 & 6.108526000 \\ \mathrm{H} & 0.240015000 & 1.414338000 & 6.069086000 \\ \mathrm{H} & 2.296359806 & 0.157583132 & 2.726420119\end{array}$

$\left[\mathrm{NiL}^{3} \mathrm{H}\right]$ (proton addition to the hydrazino nitrogen)

\begin{tabular}{|c|c|c|c|}
\hline & 1.274391000 & 1.754349000 & 0.696257000 \\
\hline & 2.046816000 & -0.847910000 & 0.522642000 \\
\hline & 1.660128000 & 0.200025000 & -0.239151000 \\
\hline & 1.742460000 & 0.121429000 & -1.606773000 \\
\hline & 1.414471000 & 1.232551000 & -2.196058000 \\
\hline & 0.987525000 & 2.720107000 & -1.292284000 \\
\hline & 2.487637000 & -2.135446000 & -0.106163000 \\
\hline & 1.333640000 & 1.298412000 & -3.566953000 \\
\hline & 1.858696000 & 0.225338000 & -4.398568000 \\
\hline & 1.109058000 & 2.357109000 & 3.571768000 \\
\hline & 1.670593000 & 0.713384000 & 2.179153000 \\
\hline & 1.488965000 & 1.117574000 & 3.478088000 \\
\hline & 1.983666000 & -0.574006000 & 1.909854000 \\
\hline & 0.777794000 & 3.380374000 & 2.138286000 \\
\hline
\end{tabular}




$\begin{array}{lrrr}\mathrm{C} & 2.218309000 & -1.556085000 & 3.017760000 \\ \mathrm{~N} & 0.990182000 & 2.959964000 & 4.801604000 \\ \mathrm{C} & 1.031164000 & 2.174171000 & 6.026139000 \\ \mathrm{H} & 1.427615000 & 2.229886000 & -3.941893000 \\ \mathrm{H} & 0.373894000 & 3.758172000 & 4.813096000 \\ \mathrm{H} & 1.697392000 & -2.560511000 & -0.733978000 \\ \mathrm{H} & 3.349217000 & -1.972853000 & -0.761944000 \\ \mathrm{H} & 2.765438000 & -2.876677000 & 0.641942000 \\ \mathrm{H} & 1.684502000 & 0.480589000 & -5.444290000 \\ \mathrm{H} & 2.932673000 & 0.056972000 & -4.245559000 \\ \mathrm{H} & 1.339257000 & -0.707873000 & -4.174414000 \\ \mathrm{H} & 3.024116000 & -1.220831000 & 3.678944000 \\ \mathrm{H} & 2.476436000 & -2.542827000 & 2.635890000 \\ \mathrm{H} & 1.325801000 & -1.655291000 & 3.644299000 \\ \mathrm{H} & 0.921340000 & 2.849888000 & 6.874826000 \\ \mathrm{H} & 1.991121000 & 1.661689000 & 6.108526000 \\ \mathrm{H} & 0.240015000 & 1.414338000 & 6.069086000 \\ \mathrm{H} & 1.633495550 & 0.521948739 & 4.268240813\end{array}$

$\left[\mathrm{NiL}{ }^{3} \mathrm{H}\right]$ (proton addition to the amine nitrogen)
q Ms
$\begin{array}{ll}0 & 2\end{array}$
$\mathrm{Ni} \quad 1.274391000 \quad 1.754349000 \quad 0.696257000$
$\begin{array}{llll}\text { C } & 2.046816000 & -0.847910000 & 0.522642000\end{array}$
N $\quad \begin{array}{llll}1.660128000 & 0.200025000 & -0.239151000\end{array}$
$\begin{array}{llll}\mathrm{N} & 1.742460000 & 0.121429000 & -1.606773000\end{array}$
C $\quad \begin{array}{llll}1.414471000 & 1.232551000 & -2.196058000\end{array}$
$\begin{array}{llll}\text { S } & 0.987525000 & 2.720107000 & -1.292284000\end{array}$
$\begin{array}{llll}\text { C } & 2.487637000 & -2.135446000 & -0.106163000\end{array}$
$\mathrm{N} \quad 1.333640000 \quad 1.298412000 \quad-3.566953000$
C $\quad 1.858696000 \quad 0.225338000 \quad-4.398568000$ 


\begin{tabular}{llll}
$\mathrm{C}$ & 1.109058000 & 2.357109000 & 3.571768000 \\
$\mathrm{~N}$ & 1.670593000 & 0.713384000 & 2.179153000 \\
$\mathrm{~N}$ & 1.488965000 & 1.117574000 & 3.478088000 \\
$\mathrm{C}$ & 1.983666000 & -0.574006000 & 1.909854000 \\
$\mathrm{~S}$ & 0.777794000 & 3.380374000 & 2.138286000 \\
$\mathrm{C}$ & 2.218309000 & -1.556085000 & 3.017760000 \\
$\mathrm{~N}$ & 0.990182000 & 2.959964000 & 4.801604000 \\
$\mathrm{C}$ & 1.031164000 & 2.174171000 & 6.026139000 \\
$\mathrm{H}$ & 1.427615000 & 2.229886000 & -3.941893000 \\
$\mathrm{H}$ & 0.373894000 & 3.758172000 & 4.813096000 \\
$\mathrm{H}$ & 1.697392000 & -2.560511000 & -0.733978000 \\
$\mathrm{H}$ & 3.349217000 & -1.972853000 & -0.761944000 \\
$\mathrm{H}$ & 2.765438000 & -2.876677000 & 0.641942000 \\
$\mathrm{H}$ & 1.684502000 & 0.480589000 & -5.444290000 \\
$\mathrm{H}$ & 2.932673000 & 0.056972000 & -4.245559000 \\
$\mathrm{H}$ & 1.339257000 & -0.707873000 & -4.174414000 \\
$\mathrm{H}$ & 3.024116000 & -1.220831000 & 3.678944000 \\
$\mathrm{H}$ & 2.476436000 & -2.542827000 & 2.635890000 \\
$\mathrm{H}$ & 1.325801000 & -1.655291000 & 3.644299000 \\
$\mathrm{H}$ & 0.921340000 & 2.849888000 & 6.874826000 \\
$\mathrm{H}$ & 1.991121000 & 1.661689000 & 6.108526000 \\
$\mathrm{H}$ & 0.240015000 & 1.414338000 & 6.069086000 \\
\hline & 1.552625912 & 3.328221341 & 4.061304481
\end{tabular}

$\left[\mathrm{NiL}^{3} \mathrm{H}\right]$ (proton addition to the sulfur)
q Ms
$0 \quad 2$
$\mathrm{Ni} \quad 1.175499000 \quad 1.895996000 \quad 0.609192000$
C $\quad 2.070137000 \quad-0.739954000 \quad 0.456966000$
$\begin{array}{llll}\mathrm{N} & 1.703619000 & 0.249405000 & -0.314778000\end{array}$
$\mathrm{N} \quad 1.852986000 \quad 0.151497000 \quad-1.662789000$ 


\begin{tabular}{|c|c|c|c|}
\hline & 1.598331000 & 1.290518000 & -2.285052000 \\
\hline & 1.232462000 & 2.848594000 & -1.503433000 \\
\hline & 2.638771000 & -2.034943000 & -0.041687000 \\
\hline & 1.629756000 & 1.285129000 & -3.632820000 \\
\hline & 1.886112000 & 0.104392000 & -4.442909000 \\
\hline & 0.806415000 & 2.290711000 & 3.647524000 \\
\hline & 1.516099000 & 0.746144000 & 2.165179000 \\
\hline & 1.304132000 & 1.096167000 & 3.477724000 \\
\hline & 1.855526000 & -0.486512000 & 1.885032000 \\
\hline$S$ & 0.178679000 & 3.273573000 & 2.232031000 \\
\hline & 2.040125000 & -1.570202000 & 2.902941000 \\
\hline & 0.706563000 & 2.883474000 & 4.863130000 \\
\hline & 1.164980000 & 2.230792000 & 6.084685000 \\
\hline & 1.487788000 & 2.169057000 & -4.092589000 \\
\hline & 0.049167000 & 3.641922000 & 4.957107000 \\
\hline $\mathrm{H}$ & 1.871098000 & -2.817200000 & -0.067652000 \\
\hline & 3.015932000 & -1.904536000 & -1.054136000 \\
\hline & 3.445529000 & -2.392962000 & 0.601173000 \\
\hline & 1.756158000 & 0.374098000 & -5.490316000 \\
\hline & 2.903933000 & -0.269667000 & -4.296591000 \\
\hline & 1.190147000 & -0.699301000 & -4.192257000 \\
\hline F & 3.091424000 & -1.871465000 & 2.959953000 \\
\hline $\mathrm{H}$ & 1.466757000 & -2.460946000 & 2.631489000 \\
\hline & 1.726009000 & -1.226371000 & 3.885064000 \\
\hline & 1.111317000 & 2.952990000 & 6.897796000 \\
\hline & 2.197708000 & 1.903224000 & 5.963638000 \\
\hline & 0.551310000 & 1.359322000 & 6.333666000 \\
\hline & 0.782315000 & 4.424624000 & 2.612703000 \\
\hline
\end{tabular}

$\left[\mathrm{NiL}^{3} \mathrm{H}\right]$ (proton addition to the nickel)

q Ms 


\begin{tabular}{|c|c|c|c|}
\hline $\mathrm{Ni}$ & 1.274391000 & 1.754349000 & 0.696257000 \\
\hline $\mathrm{C}$ & 2.046816000 & -0.847910000 & 0.522642000 \\
\hline $\mathrm{N}$ & 1.660128000 & 0.200025000 & -0.239151000 \\
\hline $\mathrm{N}$ & 1.742460000 & 0.121429000 & -1.606773000 \\
\hline $\mathrm{C}$ & 1.414471000 & 1.232551000 & -2.196058000 \\
\hline S & 0.987525000 & 2.720107000 & -1.292284000 \\
\hline $\mathrm{C}$ & 2.487637000 & -2.135446000 & -0.106163000 \\
\hline $\mathrm{N}$ & 1.333640000 & 1.298412000 & -3.566953000 \\
\hline $\mathrm{C}$ & 1.858696000 & 0.225338000 & -4.398568000 \\
\hline $\mathrm{C}$ & 1.109058000 & 2.357109000 & 3.571768000 \\
\hline $\mathrm{N}$ & 1.670593000 & 0.713384000 & 2.179153000 \\
\hline $\mathrm{N}$ & 1.488965000 & 1.117574000 & 3.478088000 \\
\hline $\mathrm{C}$ & 1.983666000 & -0.574006000 & 1.909854000 \\
\hline S & 0.777794000 & 3.380374000 & 2.138286000 \\
\hline $\mathrm{C}$ & 2.218309000 & -1.556085000 & 3.017760000 \\
\hline $\mathrm{N}$ & 0.990182000 & 2.959964000 & 4.801604000 \\
\hline $\mathrm{C}$ & 1.031164000 & 2.174171000 & 6.026139000 \\
\hline $\mathrm{H}$ & 1.427615000 & 2.229886000 & -3.941893000 \\
\hline $\mathrm{H}$ & 0.373894000 & 3.758172000 & 4.813096000 \\
\hline $\mathrm{H}$ & 1.697392000 & -2.560511000 & -0.733978000 \\
\hline $\mathrm{H}$ & 3.349217000 & -1.972853000 & -0.761944000 \\
\hline $\mathrm{H}$ & 2.765438000 & -2.876677000 & 0.641942000 \\
\hline $\mathrm{H}$ & 1.684502000 & 0.480589000 & -5.444290000 \\
\hline $\mathrm{H}$ & 2.932673000 & 0.056972000 & -4.245559000 \\
\hline $\mathrm{H}$ & 1.339257000 & -0.707873000 & -4.174414000 \\
\hline $\mathrm{H}$ & 3.024116000 & -1.220831000 & 3.678944000 \\
\hline $\mathrm{H}$ & 2.476436000 & -2.542827000 & 2.635890000 \\
\hline $\mathrm{H}$ & 1.325801000 & -1.655291000 & 3.644299000 \\
\hline $\mathrm{H}$ & 0.921340000 & 2.849888000 & 6.874826000 \\
\hline 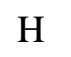 & 1.991121000 & 1.661689000 & 6.108526000 \\
\hline
\end{tabular}




$\begin{array}{llll}\mathrm{H} & 0.240015000 & 1.414338000 & 6.069086000 \\ \mathrm{H} & 0.764676207 & 3.473992151 & 0.333051461\end{array}$

$\left[\mathrm{NiL}^{3} \mathrm{H}\right]^{-}$(electron addition after the proton is added to coordinated nitrogen)

q $\mathrm{Ms}$

$\begin{array}{ll}-1 & 1\end{array}$

$\mathrm{Ni} \quad 1.774495000 \quad 1.844401000 \quad 0.743777000$

C $\quad 2.172904000 \quad-0.846145000 \quad 0.570352000$

$\mathrm{N} \quad 1.964194000 \quad 0.277064000 \quad-0.193545000$

$\mathrm{N} \quad 1.871080000 \quad 0.149821000 \quad-1.522944000$

C $\quad 1.587899000 \quad 1.304781000 \quad-2.115186000$

S $\quad 1.371049000 \quad 2.808423000 \quad-1.206049000$

C $\quad 2.267129000 \quad-2.185724000 \quad-0.094881000$

$\mathrm{N} \quad 1.451409000 \quad 1.328842000 \quad-3.450005000$

C $\quad \begin{array}{llll}1.577714000 & 0.155288000 & -4.304385000\end{array}$

$\begin{array}{llll}\text { C } & 1.223245000 & 2.339414000 & 3.553909000\end{array}$

$\begin{array}{llll}\mathrm{N} & 2.307757000 & 0.817350000 & 2.266661000\end{array}$

$\begin{array}{llll}\mathrm{N} & 1.643077000 & 1.109307000 & 3.523736000\end{array}$

C $\quad 2.269703000 \quad-0.608095000 \quad 1.918038000$

S $\quad \begin{array}{llll}1.301734000 & 3.467807000 & 2.165597000\end{array}$

C $\quad 2.451260000 \quad-1.593843000 \quad 3.020334000$

$\begin{array}{llll}\mathrm{N} & 0.724789000 & 2.849085000 & 4.707265000\end{array}$

$\begin{array}{llll}\text { C } & 0.543869000 & 2.041852000 & 5.905150000\end{array}$

$\mathrm{H} \quad 1.239492000 \quad 2.216035000 \quad-3.877059000$

$\mathrm{H} \quad 0.171247000 \quad 3.686168000 \quad 4.618260000$

$\mathrm{H} \quad 1.355160000 \quad-2.393117000 \quad-0.659694000$

$\mathrm{H} \quad 3.092856000 \quad-2.192382000 \quad-0.810470000$

$\mathrm{H} \quad 2.424784000 \quad-2.983753000 \quad 0.626917000$

$\mathrm{H} \quad 1.410216000 \quad 0.465259000 \quad-5.334352000$

$\mathrm{H} \quad 2.574463000 \quad-0.284003000 \quad-4.220327000$

$\mathrm{H} \quad 0.841455000 \quad-0.605385000 \quad-4.034232000$ 


$\begin{array}{lrrr}\mathrm{H} & 3.415088000 & -1.444784000 & 3.522607000 \\ \mathrm{H} & 2.412157000 & -2.617950000 & 2.654234000 \\ \mathrm{H} & 1.676979000 & -1.462782000 & 3.779319000 \\ \mathrm{H} & 0.235265000 & 2.697043000 & 6.719113000 \\ \mathrm{H} & 1.485074000 & 1.560050000 & 6.173854000 \\ \mathrm{H} & -0.212484000 & 1.260773000 & 5.768349000 \\ \mathrm{H} & 3.295616000 & 1.052795000 & 2.412209000\end{array}$

$\left[\mathrm{NiL}^{3} \mathrm{H}\right]^{-}$(electron addition after the proton is added to coordinated nitrogen)

\begin{tabular}{|c|c|c|c|}
\hline \multicolumn{4}{|c|}{ q $\mathrm{Ms}$} \\
\hline & & & \\
\hline $\mathrm{Ni}$ & 1.774495000 & 1.844401000 & 0.743777000 \\
\hline & 2.172904000 & -0.846145000 & 0.570352000 \\
\hline & 1.964194000 & 0.277064000 & -0.193545000 \\
\hline $\mathrm{N}$ & 1.871080000 & 0.149821000 & -1.522944000 \\
\hline & 1.587899000 & 1.304781000 & -2.115186000 \\
\hline & 1.371049000 & 2.808423000 & -1.206049000 \\
\hline & 2.267129000 & -2.185724000 & -0.094881000 \\
\hline & 1.451409000 & 1.328842000 & -3.450005000 \\
\hline $\mathrm{C}$ & 1.577714000 & 0.155288000 & -4.304385000 \\
\hline $\mathrm{C}$ & 1.223245000 & 2.339414000 & 3.553909000 \\
\hline $\mathrm{N}$ & 2.307757000 & 0.817350000 & 2.266661000 \\
\hline $\mathrm{N}$ & 1.643077000 & 1.109307000 & 3.523736000 \\
\hline$r$ & 2.269703000 & -0.608095000 & 1.918038000 \\
\hline & 1.301734000 & 3.467807000 & 2.165597000 \\
\hline & 2.451260000 & -1.593843000 & 3.020334000 \\
\hline & 0.724789000 & 2.849085000 & 4.707265000 \\
\hline $\mathrm{C}$ & 0.543869000 & 2.041852000 & 5.905150000 \\
\hline 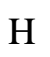 & 1.239492000 & 2.216035000 & -3.877059000 \\
\hline 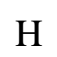 & 0.171247000 & 3.686168000 & 4.618260000 \\
\hline & 1.355160000 & -2.393117000 & -0.659694000 \\
\hline
\end{tabular}




$\begin{array}{llll}\mathrm{H} & 3.092856000 & -2.192382000 & -0.810470000 \\ \mathrm{H} & 2.424784000 & -2.983753000 & 0.626917000 \\ \mathrm{H} & 1.410216000 & 0.465259000 & -5.334352000 \\ \mathrm{H} & 2.574463000 & -0.284003000 & -4.220327000 \\ \mathrm{H} & 0.841455000 & -0.605385000 & -4.034232000 \\ \mathrm{H} & 3.415088000 & -1.444784000 & 3.522607000 \\ \mathrm{H} & 2.412157000 & -2.617950000 & 2.654234000 \\ \mathrm{H} & 1.676979000 & -1.462782000 & 3.779319000 \\ \mathrm{H} & 0.235265000 & 2.697043000 & 6.719113000 \\ \mathrm{H} & 1.485074000 & 1.560050000 & 6.173854000 \\ \mathrm{H} & -0.212484000 & 1.260773000 & 5.768349000 \\ \mathrm{H} & 3.295616000 & 1.052795000 & 2.412209000\end{array}$

$\left[\mathrm{NiL}^{3} \mathrm{H}\right]^{-}$(electron addition after the proton is added to hydrazino nitrogen)

\begin{tabular}{lrrr} 
q & \multicolumn{1}{l}{ s } & & \\
-1 & 1 & & \\
$\mathrm{Ni}$ & 1.324576000 & 1.758166000 & 0.697860000 \\
$\mathrm{C}$ & 2.085008000 & -0.853373000 & 0.514416000 \\
$\mathrm{~N}$ & 1.712306000 & 0.200236000 & -0.239308000 \\
$\mathrm{~N}$ & 1.800562000 & 0.124394000 & -1.600544000 \\
$\mathrm{C}$ & 1.460526000 & 1.242405000 & -2.186785000 \\
$\mathrm{~S}$ & 1.032778000 & 2.726294000 & -1.284395000 \\
$\mathrm{C}$ & 2.538772000 & -2.133948000 & -0.117427000 \\
$\mathrm{~N}$ & 1.393269000 & 1.304482000 & -3.542641000 \\
$\mathrm{C}$ & 1.830343000 & 0.213497000 & -4.399513000 \\
$\mathrm{C}$ & 1.010703000 & 2.397806000 & 3.581376000 \\
$\mathrm{~N}$ & 1.801163000 & 0.722048000 & 2.164883000 \\
$\mathrm{~N}$ & 1.451790000 & 1.144887000 & 3.437671000 \\
$\mathrm{C}$ & 2.005373000 & -0.594789000 & 1.903595000 \\
$\mathrm{~S}$ & 0.698652000 & 3.350869000 & 2.156813000 \\
$\mathrm{C}$ & 2.142201000 & -1.601827000 & 3.003499000
\end{tabular}




$\begin{array}{llll}\mathrm{N} & 0.827103000 & 2.908861000 & 4.805375000 \\ \mathrm{C} & 1.037907000 & 2.187713000 & 6.054344000 \\ \mathrm{H} & 1.356138000 & 2.227443000 & -3.943560000 \\ \mathrm{H} & 0.430865000 & 3.834498000 & 4.844494000 \\ \mathrm{H} & 1.761966000 & -2.547496000 & -0.767401000 \\ \mathrm{H} & 3.415316000 & -1.959799000 & -0.748803000 \\ \mathrm{H} & 2.800550000 & -2.882639000 & 0.628542000 \\ \mathrm{H} & 1.619939000 & 0.482225000 & -5.434360000 \\ \mathrm{H} & 2.902095000 & 0.008367000 & -4.294187000 \\ \mathrm{H} & 1.285961000 & -0.699995000 & -4.153685000 \\ \mathrm{H} & 2.976764000 & -1.363951000 & 3.674103000 \\ \mathrm{H} & 2.314807000 & -2.601112000 & 2.610148000 \\ \mathrm{H} & 1.231622000 & -1.646357000 & 3.612875000 \\ \mathrm{H} & 0.813562000 & 2.861239000 & 6.877811000 \\ \mathrm{H} & 2.078212000 & 1.863488000 & 6.151535000 \\ \mathrm{H} & 0.379455000 & 1.316576000 & 6.128162000 \\ \mathrm{H} & 1.737523000 & 0.587750000 & 4.233479000\end{array}$

$\left[\mathrm{NiL}{ }^{3} \mathrm{H}\right]^{-}$(electron addition after the proton is added to hydrazino nitrogen)

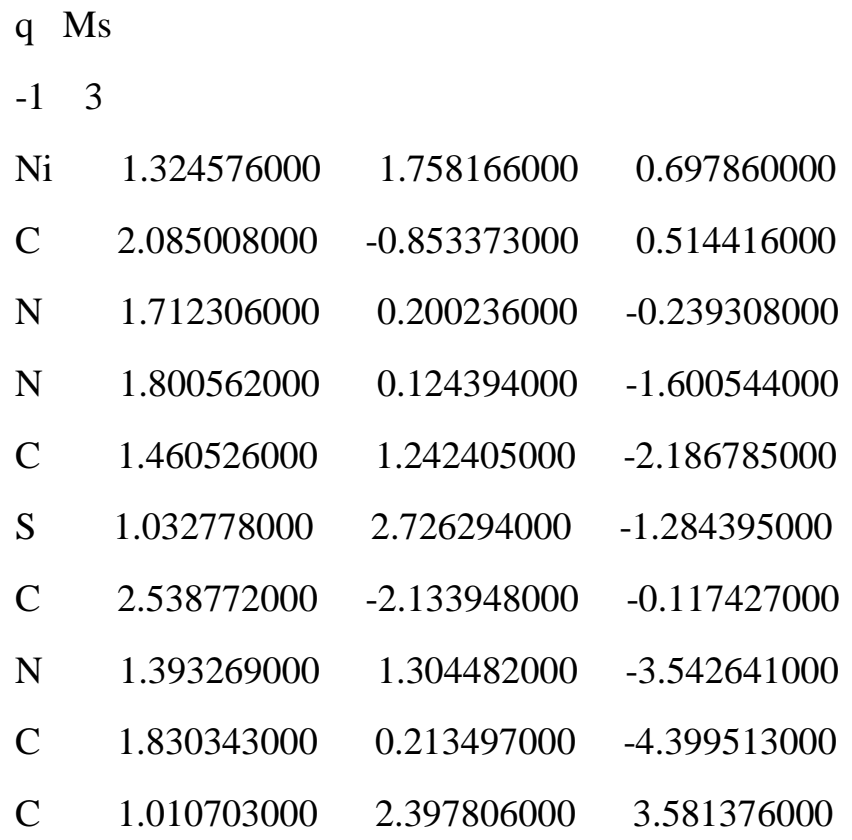




\begin{tabular}{|c|c|c|c|}
\hline & 1.801163000 & 0.722048000 & 2.164883000 \\
\hline & 1.451790000 & 1.144887000 & 3.437671000 \\
\hline & 2.005373000 & -0.594789000 & 1.903595000 \\
\hline$S$ & 0.698652000 & 3.350869000 & 2.156813000 \\
\hline C & 2.142201000 & -1.601827000 & 3.003499000 \\
\hline r & 0.827103000 & 2.908861000 & 4.805375000 \\
\hline C & 1.037907000 & 2.187713000 & 6.054344000 \\
\hline $\mathrm{H}$ & 1.356138000 & 2.227443000 & -3.943560000 \\
\hline $\mathrm{H}$ & 0.430865000 & 3.834498000 & 4.844494000 \\
\hline $\mathrm{H}$ & 1.761966000 & -2.547496000 & -0.767401000 \\
\hline $\mathrm{H}$ & 3.415316000 & -1.959799000 & -0.748803000 \\
\hline F & 2.800550000 & -2.882639000 & 0.628542000 \\
\hline $\mathrm{H}$ & 1.619939000 & 0.482225000 & -5.434360000 \\
\hline $\mathrm{H}$ & 2.902095000 & 0.008367000 & -4.294187000 \\
\hline $\mathrm{H}$ & 1.285961000 & -0.699995000 & -4.153685000 \\
\hline $\mathrm{H}$ & 2.976764000 & -1.363951000 & 3.674103000 \\
\hline $\mathrm{H}$ & 2.314807000 & -2.601112000 & 2.610148000 \\
\hline $\mathrm{H}$ & 1.231622000 & -1.646357000 & 3.612875000 \\
\hline $\mathrm{H}$ & 0.813562000 & 2.861239000 & 6.877811000 \\
\hline $\mathrm{H}$ & 2.078212000 & 1.863488000 & 6.151535000 \\
\hline $\mathrm{H}$ & 0.379455000 & 1.316576000 & 6.128162000 \\
\hline & 1.737523000 & 0.587750000 & 4.233479000 \\
\hline
\end{tabular}

$\left[\mathrm{NiL}^{3} \mathrm{H}\right]^{-}$(electron addition after the proton is added to amine nitrogen)

\begin{tabular}{|c|c|c|c|}
\hline \multicolumn{4}{|c|}{$\mathrm{q} \quad \mathrm{Ms}$} \\
\hline 1 & & & \\
\hline $\mathrm{Ni}$ & 1.302513000 & 1.775453000 & 0.654754000 \\
\hline $\mathrm{C}$ & 2.054121000 & -0.837723000 & 0.517614000 \\
\hline $\mathrm{N}$ & 1.740877000 & 0.223585000 & -0.254319000 \\
\hline $\mathrm{N}$ & 1.785025000 & 0.112548000 & -1.612271000 \\
\hline S & 1.455662000 & 1.225595000 & -2.217123000 \\
\hline
\end{tabular}




$\begin{array}{llll}\mathrm{S} & 1.023138000 & 2.718086000 & -1.335065000 \\ \mathrm{C} & 2.438072000 & -2.146979000 & -0.101743000 \\ \mathrm{~N} & 1.409340000 & 1.270026000 & -3.573196000 \\ \mathrm{C} & 1.867053000 & 0.175850000 & -4.414433000 \\ \mathrm{C} & 1.123341000 & 2.410674000 & 3.454781000 \\ \mathrm{~N} & 1.617207000 & 0.728439000 & 2.151668000 \\ \mathrm{~N} & 1.485629000 & 1.175819000 & 3.415935000 \\ \mathrm{C} & 1.974920000 & -0.561031000 & 1.900392000 \\ \mathrm{~S} & 0.817798000 & 3.449347000 & 2.074183000 \\ \mathrm{C} & 2.234429000 & -1.516679000 & 3.021059000 \\ \mathrm{~N} & 0.971679000 & 3.020721000 & 4.799427000 \\ \mathrm{C} & 1.075019000 & 2.095381000 & 5.979522000 \\ \mathrm{H} & 1.327507000 & 2.183255000 & -3.988865000 \\ \mathrm{H} & 0.066586000 & 3.500045000 & 4.827859000 \\ \mathrm{H} & 1.620766000 & -2.544401000 & -0.711489000 \\ \mathrm{H} & 3.293640000 & -2.019661000 & -0.771234000 \\ \mathrm{H} & 2.052331000 & 1.625230000 & 5.961667000 \\ \mathrm{H} & 2.697340000 & -2.889381000 & 0.651069000 \\ \mathrm{H} & 1.684528000 & 0.441582000 & -5.455191000 \\ \mathrm{H} & 2.935492000 & -0.027857000 & -4.279685000 \\ \mathrm{H} & 1.316700000 & -0.737822000 & -4.181352000 \\ \mathrm{H} & 3.053341000 & -1.161853000 & 3.655414000 \\ \mathrm{H} & 2.489896000 & -2.509304000 & 2.655313000 \\ \mathrm{H} & 1.354232000 & -1.604024000 & 3.665997000 \\ \mathrm{H} & 0.945373000 & 2.697343000 & 6.876148000 \\ \mathrm{H} & 1.669150000 & 3.765860000 & 4.898788000\end{array}$

$\left[\mathrm{NiL}^{3} \mathrm{H}\right]^{-}$(electron addition after the proton is added to amine nitrogen)

q Ms

$\begin{array}{ll}-1 & 3\end{array}$ 


\begin{tabular}{|c|c|c|c|}
\hline & 1.302513000 & 1.775453000 & 0.654754000 \\
\hline & 2.054121000 & -0.837723000 & 0.517614000 \\
\hline & 1.740877000 & 0.223585000 & -0.254319000 \\
\hline 1 & 1.785025000 & 0.112548000 & -1.612271000 \\
\hline $\mathrm{C}$ & 1.455662000 & 1.225595000 & -2.217123000 \\
\hline$S$ & 1.023138000 & 2.718086000 & -1.335065000 \\
\hline $\mathrm{C}$ & 2.438072000 & -2.146979000 & -0.101743000 \\
\hline & 1.409340000 & 1.270026000 & -3.573196000 \\
\hline $\mathrm{C}$ & 1.867053000 & 0.175850000 & -4.414433000 \\
\hline $\mathrm{C}$ & 1.123341000 & 2.410674000 & 3.454781000 \\
\hline $\mathrm{N}$ & 1.617207000 & 0.728439000 & 2.151668000 \\
\hline $\mathrm{N}$ & 1.485629000 & 1.175819000 & 3.415935000 \\
\hline $\mathrm{C}$ & 1.974920000 & -0.561031000 & 1.900392000 \\
\hline$S$ & 0.817798000 & 3.449347000 & 2.074183000 \\
\hline $\mathrm{C}$ & 2.234429000 & -1.516679000 & 3.021059000 \\
\hline $\mathrm{N}$ & 0.971679000 & 3.020721000 & 27000 \\
\hline $\mathrm{C}$ & 1.075019000 & 2.095381000 & 5.979522000 \\
\hline $\mathrm{H}$ & 1.327507000 & 2.183255000 & -3.988865000 \\
\hline $\mathrm{H}$ & 0.066586000 & 3.500045000 & 4.827859000 \\
\hline $\mathrm{H}$ & 1.620766000 & -2.544401000 & -0.711489000 \\
\hline $\mathrm{H}$ & 3.293640000 & -2.019661000 & -0.771234000 \\
\hline $\mathrm{H}$ & 2.697340000 & -2.889381000 & 0.651069000 \\
\hline $\mathrm{H}$ & 1.684528000 & 0.441582000 & -5.455191000 \\
\hline $\mathrm{H}$ & 2.935492000 & -0.027857000 & -4.279685000 \\
\hline $\mathrm{H}$ & 1.316700000 & -0.737822000 & -4.181352000 \\
\hline $\mathrm{H}$ & 3.053341000 & -1.161853000 & 3.655414000 \\
\hline $\mathrm{H}$ & 2.489896000 & -2.509304000 & 2.655313000 \\
\hline $\mathrm{H}$ & 1.354232000 & -1.604024000 & 3.665997000 \\
\hline $\mathrm{H}$ & 0.945373000 & 2.697343000 & 6.876148000 \\
\hline $\mathrm{H}$ & 2.052331000 & 1.625230000 & 5.961667000 \\
\hline & 0.294233000 & 1.346109000 & 5.895814000 \\
\hline
\end{tabular}


$\left[\mathrm{NiL}^{3} \mathrm{H}\right]^{-}$(electron addition after the proton is added to sulfur)

q Ms

$\begin{array}{ll}-1 & 1\end{array}$

Ni $\quad 1.161620000 \quad 1.900323000 \quad 0.606730000$

$\begin{array}{llll}\text { C } & 2.060863000 & -0.736436000 & 0.466771000\end{array}$

$\mathrm{N} \quad \begin{array}{llll}1.691085000 & 0.252092000 & -0.313248000\end{array}$

$\mathrm{N} \quad \begin{array}{llll}1.845989000 & 0.153901000 & -1.662101000\end{array}$

$\begin{array}{llll}\text { C } & 1.586439000 & 1.291198000 & -2.287022000\end{array}$

S $\quad 1.205583000 \quad 2.847043000 \quad-1.507819000$

C $\quad 2.635663000 \quad-2.032691000 \quad-0.022522000$

$\mathrm{N} \quad \begin{array}{llll}1.623078000 & 1.285840000 & -3.635395000\end{array}$

$\begin{array}{llll}\text { C } & 1.900305000 & 0.108931000 & -4.444150000\end{array}$

$\begin{array}{llll}\text { C } & 0.809580000 & 2.288168000 & 3.639179000\end{array}$

$\begin{array}{llll}\mathrm{N} & 1.506984000 & 0.761399000 & 2.168574000\end{array}$

$\mathrm{N} \quad 1.297697000 \quad 1.117014000 \quad 3.477920000$

C $\quad 1.844103000 \quad-0.475840000 \quad 1.894488000$

$\begin{array}{llll}\text { S } & 0.171162000 & 3.275454000 & 2.233219000\end{array}$

$\begin{array}{llll}\text { C } & 2.026989000 & -1.554768000 & 2.918085000\end{array}$

$\begin{array}{llll}\mathrm{N} & 0.722981000 & 2.867735000 & 4.843662000\end{array}$

$\begin{array}{llll}\text { C } & 1.186933000 & 2.202937000 & 6.056669000\end{array}$

$\mathrm{H} \quad 1.483903000 \quad 2.170063000 \quad-4.095525000$

$\mathrm{H} \quad 0.059797000 \quad 3.619376000 \quad 4.947024000$

$\mathrm{H} \quad 1.873350000 \quad-2.820415000 \quad-0.035934000$

$\mathrm{H} \quad 3.006253000 \quad-1.909673000 \quad-1.038065000$

$\mathrm{H} \quad 3.448510000 \quad-2.378753000 \quad 0.619385000$

$\mathrm{H} \quad \begin{array}{llll}1.780399000 & 0.379251000 & -5.492607000\end{array}$

$\mathrm{H} \quad 2.919683000 \quad-0.255959000 \quad-4.286038000$

H $\quad 1.208774000 \quad-0.701577000 \quad-4.203426000$

H $\quad 3.079815000 \quad-1.848834000 \quad 2.985010000$ 


$\begin{array}{lrrr}\mathrm{H} & 1.461807000 & -2.450182000 & 2.645149000 \\ \mathrm{H} & 1.702935000 & -1.209401000 & 3.896435000 \\ \mathrm{H} & 1.135570000 & 2.916832000 & 6.877177000 \\ \mathrm{H} & 2.219839000 & 1.878139000 & 5.928306000 \\ \mathrm{H} & 0.575581000 & 1.328013000 & 6.299323000 \\ \mathrm{H} & 0.773511000 & 4.428390000 & 2.610730000\end{array}$

$\left[\mathrm{NiL}^{3} \mathrm{H}\right]^{-}$(electron addition after the proton is added to sulfur)

$\begin{array}{lrrr}\mathrm{q} & \mathrm{Ms} & & \\ -1 & 3 & & \\ \mathrm{Ni} & 1.161620000 & 1.900323000 & 0.606730000 \\ \mathrm{C} & 2.060863000 & -0.736436000 & 0.466771000 \\ \mathrm{~N} & 1.691085000 & 0.252092000 & -0.313248000 \\ \mathrm{~N} & 1.845989000 & 0.153901000 & -1.662101000 \\ \mathrm{C} & 1.586439000 & 1.291198000 & -2.287022000 \\ \mathrm{~S} & 1.205583000 & 2.847043000 & -1.507819000 \\ \mathrm{C} & 2.635663000 & -2.032691000 & -0.022522000 \\ \mathrm{~N} & 1.623078000 & 1.285840000 & -3.635395000 \\ \mathrm{C} & 1.900305000 & 0.108931000 & -4.444150000 \\ \mathrm{C} & 0.809580000 & 2.288168000 & 3.639179000 \\ \mathrm{~N} & 1.506984000 & 0.761399000 & 2.168574000 \\ \mathrm{~N} & 1.297697000 & 1.117014000 & 3.477920000 \\ \mathrm{C} & 1.844103000 & -0.475840000 & 1.894488000 \\ \mathrm{~S} & 0.171162000 & 3.275454000 & 2.233219000 \\ \mathrm{C} & 2.026989000 & -1.554768000 & 2.918085000 \\ \mathrm{~N} & 0.722981000 & 2.867735000 & 4.843662000 \\ \mathrm{C} & 1.186933000 & 2.202937000 & 6.056669000 \\ \mathrm{H} & 1.483903000 & 2.170063000 & -4.095525000 \\ \mathrm{H} & 0.059797000 & 3.619376000 & 4.947024000 \\ \mathrm{H} & 1.873350000 & -2.820415000 & -0.035934000 \\ & 3.006253000 & -1.909673000 & -1.038065000\end{array}$




$\begin{array}{llll}\mathrm{H} & 3.448510000 & -2.378753000 & 0.619385000 \\ \mathrm{H} & 1.780399000 & 0.379251000 & -5.492607000 \\ \mathrm{H} & 2.919683000 & -0.255959000 & -4.286038000 \\ \mathrm{H} & 1.208774000 & -0.701577000 & -4.203426000 \\ \mathrm{H} & 3.079815000 & -1.848834000 & 2.985010000 \\ \mathrm{H} & 1.461807000 & -2.450182000 & 2.645149000 \\ \mathrm{H} & 1.702935000 & -1.209401000 & 3.896435000 \\ \mathrm{H} & 1.135570000 & 2.916832000 & 6.877177000 \\ \mathrm{H} & 2.219839000 & 1.878139000 & 5.928306000 \\ \mathrm{H} & 0.575581000 & 1.328013000 & 6.299323000 \\ \mathrm{H} & 0.773511000 & 4.428390000 & 2.610730000\end{array}$

$\left[\mathrm{NiL}^{3} \mathrm{H}\right]^{-}$(electron addition after the proton is added to nickel)

$\begin{array}{lrrr}\text { q } & \text { Ms } & & \\ -1 & 1 & & \\ \mathrm{Ni} & 1.117862000 & 1.880134000 & 0.645834000 \\ \mathrm{C} & 2.038253000 & -0.754321000 & 0.466918000 \\ \mathrm{~N} & 1.619196000 & 0.197616000 & -0.316321000 \\ \mathrm{~N} & 1.743459000 & 0.131661000 & -1.665345000 \\ \mathrm{C} & 1.473687000 & 1.281954000 & -2.249336000 \\ \mathrm{~S} & 1.085187000 & 2.807536000 & -1.393876000 \\ \mathrm{C} & 2.641403000 & -2.036165000 & -0.017205000 \\ \mathrm{~N} & 1.491236000 & 1.350964000 & -3.591149000 \\ \mathrm{C} & 1.766626000 & 0.213547000 & -4.458434000 \\ \mathrm{C} & 0.792509000 & 2.343552000 & 3.587498000 \\ \mathrm{~N} & 1.553394000 & 0.779113000 & 2.181245000 \\ \mathrm{~N} & 1.371074000 & 1.159691000 & 3.467069000 \\ \mathrm{C} & 1.879930000 & -0.456142000 & 1.902292000 \\ \mathrm{~S} & 0.184765000 & 3.329103000 & 2.239934000 \\ \mathrm{C} & 2.089736000 & -1.480829000 & 2.972550000 \\ \mathrm{~N} & 0.635887000 & 2.839834000 & 4.827854000\end{array}$




$\begin{array}{llll}\mathrm{C} & 1.075247000 & 2.161648000 & 6.038981000 \\ \mathrm{H} & 1.369084000 & 2.258755000 & -4.009205000 \\ \mathrm{H} & 0.143243000 & 3.713755000 & 4.911446000 \\ \mathrm{H} & 1.964234000 & -2.877148000 & 0.164676000 \\ \mathrm{H} & 2.830160000 & -1.972182000 & -1.086302000 \\ \mathrm{H} & 3.577137000 & -2.252150000 & 0.504165000 \\ \mathrm{H} & 1.646376000 & 0.537112000 & -5.491023000 \\ \mathrm{H} & 2.785387000 & -0.157257000 & -4.315220000 \\ \mathrm{H} & 1.071792000 & -0.603869000 & -4.255695000 \\ \mathrm{H} & 2.974973000 & -1.235123000 & 3.567988000 \\ \mathrm{H} & 2.213738000 & -2.479525000 & 2.558858000 \\ \mathrm{H} & 1.239922000 & -1.478906000 & 3.658648000 \\ \mathrm{H} & 0.843528000 & 2.800049000 & 6.890021000 \\ \mathrm{H} & 2.151417000 & 1.975837000 & 6.014051000 \\ \mathrm{H} & 0.565232000 & 1.202173000 & 6.162070000 \\ \mathrm{H} & 2.453316000 & 2.349586000 & 0.520196000\end{array}$

$\left[\mathrm{NiL}^{3} \mathrm{H}\right]^{-}$(electron addition after the proton is added to nickel)

$\begin{array}{lrrr}\text { q } & \text { Ms } & & \\ -1 & 3 & & \\ \mathrm{Ni} & 1.117862000 & 1.880134000 & 0.645834000 \\ \mathrm{C} & 2.038253000 & -0.754321000 & 0.466918000 \\ \mathrm{~N} & 1.619196000 & 0.197616000 & -0.316321000 \\ \mathrm{~N} & 1.743459000 & 0.131661000 & -1.665345000 \\ \mathrm{C} & 1.473687000 & 1.281954000 & -2.249336000 \\ \mathrm{~S} & 1.085187000 & 2.807536000 & -1.393876000 \\ \mathrm{C} & 2.641403000 & -2.036165000 & -0.017205000 \\ \mathrm{~N} & 1.491236000 & 1.350964000 & -3.591149000 \\ \mathrm{C} & 1.766626000 & 0.213547000 & -4.458434000 \\ \mathrm{C} & 0.792509000 & 2.343552000 & 3.587498000 \\ \mathrm{~N} & 1.553394000 & 0.779113000 & 2.181245000\end{array}$




$\begin{array}{llll}\mathrm{N} & 1.371074000 & 1.159691000 & 3.467069000 \\ \mathrm{C} & 1.879930000 & -0.456142000 & 1.902292000 \\ \mathrm{~S} & 0.184765000 & 3.329103000 & 2.239934000 \\ \mathrm{C} & 2.089736000 & -1.480829000 & 2.972550000 \\ \mathrm{~N} & 0.635887000 & 2.839834000 & 4.827854000 \\ \mathrm{C} & 1.075247000 & 2.161648000 & 6.038981000 \\ \mathrm{H} & 1.369084000 & 2.258755000 & -4.009205000 \\ \mathrm{H} & 0.143243000 & 3.713755000 & 4.911446000 \\ \mathrm{H} & 1.964234000 & -2.877148000 & 0.164676000 \\ \mathrm{H} & 2.830160000 & -1.972182000 & -1.086302000 \\ \mathrm{H} & 3.577137000 & -2.252150000 & 0.504165000 \\ \mathrm{H} & 1.646376000 & 0.537112000 & -5.491023000 \\ \mathrm{H} & 2.785387000 & -0.157257000 & -4.315220000 \\ \mathrm{H} & 1.071792000 & -0.603869000 & -4.255695000 \\ \mathrm{H} & 2.974973000 & -1.235123000 & 3.567988000 \\ \mathrm{H} & 2.213738000 & -2.479525000 & 2.558858000 \\ \mathrm{H} & 1.239922000 & -1.478906000 & 3.658648000 \\ \mathrm{H} & 0.843528000 & 2.800049000 & 6.890021000 \\ \mathrm{H} & 2.151417000 & 1.975837000 & 6.014051000 \\ \mathrm{H} & 0.565232000 & 1.202173000 & 6.162070000 \\ \mathrm{H} & 2.453316000 & 2.349586000 & 0.520196000\end{array}$

A.2 Computational input coordinates for $\mathrm{NiL}^{3}$ and related compounds using B3LYP/ 6-311g(d,p) in gas phase

\begin{tabular}{|c|c|c|c|}
\hline \multicolumn{4}{|c|}{$\underline{\mathrm{NiL}^{3}}$} \\
\hline \multicolumn{4}{|c|}{ q Ms } \\
\hline 0 & & & \\
\hline $\mathrm{Ni}$ & 1.298967264 & 1.716422563 & 0.713071468 \\
\hline $\mathrm{C}$ & 2.077098110 & -0.852510960 & 0.491389295 \\
\hline $\mathrm{N}$ & 1.773134330 & 0.186402198 & -0.234431064 \\
\hline $\mathrm{N}$ & 1.826356920 & 0.101489400 & -1.609083332 \\
\hline $\mathrm{C}$ & 1.456628243 & 1.248488769 & -2.136738890 \\
\hline
\end{tabular}




\begin{tabular}{|c|c|c|c|}
\hline & 0.958096047 & 2.658176535 & -1.194682486 \\
\hline & 2.480675590 & -2.168490180 & -0.075503141 \\
\hline & 1.431975930 & 1.370106900 & -3.469802543 \\
\hline & 1.739697353 & 0.264210738 & -4.353189292 \\
\hline & 1.129474089 & 2.336962584 & 3.526368011 \\
\hline & 1.640189805 & 0.652745991 & 2.194418338 \\
\hline & 1.506619816 & 1.073419554 & 3.496785633 \\
\hline C & 1.986729953 & -0.577643835 & 1.932880409 \\
\hline S & 0.855462745 & 3.324454446 & 2.085124447 \\
\hline & 2.253656241 & -1.605054861 & 2.980517434 \\
\hline & 0.938903338 & 2.936088342 & 4.704959664 \\
\hline C & 1.056751568 & 2.255094468 & 5.980838971 \\
\hline $\mathrm{H}$ & 1.250598320 & 2.048394390 & -3.812289741 \\
\hline $\mathrm{H}$ & 0.626368925 & 3.653618400 & 4.691096792 \\
\hline $\mathrm{H}$ & 2.447779305 & -2.126202930 & -1.073134807 \\
\hline $\mathrm{H}$ & 3.411691239 & -2.386692390 & 0.219082884 \\
\hline $\mathrm{H}$ & 1.854987829 & -2.877224490 & 0.248789038 \\
\hline F & 1.663671094 & 0.566649150 & -5.303786215 \\
\hline $\mathrm{H}$ & 2.671825422 & -0.052436190 & -4.177427882 \\
\hline H & 1.096246434 & -0.483766140 & -4.188567690 \\
\hline $\mathrm{H}$ & 2.133652700 & -1.197574920 & 3.885317370 \\
\hline $\mathrm{H}$ & 3.191349969 & -1.940139030 & 2.886447947 \\
\hline H & 1.615000739 & -2.366394510 & 2.870357114 \\
\hline $\mathrm{H}$ & 0.871759587 & 2.900905350 & 6.721017304 \\
\hline $\mathrm{H}$ & 1.982384841 & 1.891085820 & 6.079859484 \\
\hline & 0.396574022 & 1.505426100 & 6.020447176 \\
\hline
\end{tabular}

$\left[\mathrm{NiL}^{3}\right]^{-}$

q $\mathrm{Ms}$

$\begin{array}{ll}-1 & 2\end{array}$

Ni $\quad 1.288373000 \quad 1.729320000 \quad 0.702379000$ 


\begin{tabular}{|c|c|c|c|}
\hline & 2.058206000 & -0.839305000 & 0.496014000 \\
\hline & 1.757519000 & 0.190999000 & -0.250996000 \\
\hline & 1.792502000 & 0.113566000 & -1.605526000 \\
\hline & 1.451161000 & 1.264846000 & -2.155209000 \\
\hline & 1.008754000 & 2.718796000 & -1.247548000 \\
\hline & 2.461495000 & -2.172613000 & -0.048134000 \\
\hline & 1.435834000 & 1.347184000 & -3.498688000 \\
\hline & 1.774208000 & 0.243113000 & -4.381906000 \\
\hline & 1.075329000 & 2.350450000 & \\
\hline & 1.593877000 & 0.659829000 & 2.205504000 \\
\hline & 1.453601000 & 1.085744000 & 3.486476000 \\
\hline & 1.963092000 & -0.564778000 & 1.933515000 \\
\hline & 0.788673000 & 3.358742000 & 2.100452000 \\
\hline & 2.259873000 & -1.596297000 & 2.974975000 \\
\hline & 0.892338000 & 2.920195000 & 4.732633000 \\
\hline & 1.089275000 & 2.225906000 & 5.994684000 \\
\hline & 1.174322000 & & 3909000 \\
\hline & 0.604572000 & 3.884190000 & 4.737759000 \\
\hline & 2.441302000 & -2.144538000 & -1.134733000 \\
\hline & 3.470136000 & -2.440684000 & 0.282606000 \\
\hline & 1.785649000 & -2.958645000 & 0.303169000 \\
\hline & 1.668477000 & 0.580777000 & -5.412866000 \\
\hline & 2.802486000 & -0.089606000 & -4.217951000 \\
\hline & 1.110582000 & -0.608997000 & -4.214494000 \\
\hline & 2.149497000 & -1.159166000 & 3.964222000 \\
\hline & 3.278242000 & -1.981717000 & 2.864134000 \\
\hline & 1.579071000 & -2.448923000 & 2.884364000 \\
\hline & 0.866283000 & 2.917047000 & 6.807494000 \\
\hline & 2.120655000 & 1.877609000 & 6.093791000 \\
\hline & 0.428922000 & 1.358336000 & 0.071025000 \\
\hline
\end{tabular}


$\left[\mathrm{NiL}^{3} \mathrm{H}\right]$ (proton addition to the coordinated nitrogen)

\begin{tabular}{|c|c|c|c|}
\hline \\
\hline & & & \\
\hline & 1.129334000 & 1.714428000 & 0.693898000 \\
\hline & 1.956995000 & -0.862091000 & 0.521920000 \\
\hline & 1.635719000 & 0.196692000 & -0.250047000 \\
\hline & 1.677846000 & 0.113264000 & -1.614312000 \\
\hline & 1.309854000 & 1.215261000 & -2.181263000 \\
\hline & 0.825106000 & 2.676425000 & -1.294551000 \\
\hline & 2.379520000 & -2.183360000 & -0.051889000 \\
\hline J & 1.256392000 & 1.281522000 & -3.566399000 \\
\hline $\mathrm{C}$ & 1.958121000 & 0.284862000 & -4.354697000 \\
\hline $\mathrm{C}$ & 0.944135000 & 2.317933000 & 3.548759000 \\
\hline $\mathrm{N}$ & 1.439312000 & 0.652539000 & 2.186616000 \\
\hline & 1.337338000 & 1.088374000 & 3.479027000 \\
\hline $\mathrm{C}$ & 1.863486000 & -0.597227000 & 1.906315000 \\
\hline & 0.625050000 & 3.341664000 & 2.132291000 \\
\hline $\mathrm{C}$ & 2.200486000 & -1.596561000 & 2.974564000 \\
\hline $\mathrm{N}$ & 0.723552000 & 2.891140000 & 4.793277000 \\
\hline $\mathrm{C}$ & 1.271197000 & 2.254268000 & 5.977111000 \\
\hline $\mathrm{H}$ & 1.337483000 & 2.230155000 & -3.900159000 \\
\hline $\mathrm{H}$ & 0.812946000 & 3.895671000 & 4.765145000 \\
\hline $\mathrm{H}$ & 2.322145000 & -2.135029000 & -1.138285000 \\
\hline $\mathrm{H}$ & 3.409380000 & -2.440791000 & 0.228309000 \\
\hline $\mathrm{H}$ & 1.739463000 & -3.003140000 & 0.297464000 \\
\hline $\mathrm{H}$ & 1.805282000 & 0.502736000 & -5.415494000 \\
\hline $\mathrm{H}$ & 3.038219000 & 0.244486000 & -4.146185000 \\
\hline $\mathrm{H}$ & 1.550569000 & -0.704042000 & -4.137845000 \\
\hline $\mathrm{H}$ & 1.961166000 & -1.173021000 & 3.948879000 \\
\hline $\mathrm{H}$ & 3.266149000 & -1.861506000 & 2.968104000 \\
\hline & 1.638891000 & -2.530160000 & 2.847590000 \\
\hline
\end{tabular}




$\begin{array}{llll}\mathrm{H} & 0.996191000 & 2.845842000 & 6.854932000 \\ \mathrm{H} & 2.365765000 & 2.141591000 & 5.945643000 \\ \mathrm{H} & 0.847215000 & 1.254091000 & 6.081410000 \\ \mathrm{H} & 1.238764613 & -0.030347806 & 2.889073369\end{array}$

$\left[\mathrm{NiL}^{3} \mathrm{H}\right]$ (proton addition to the hydrazino nitrogen)

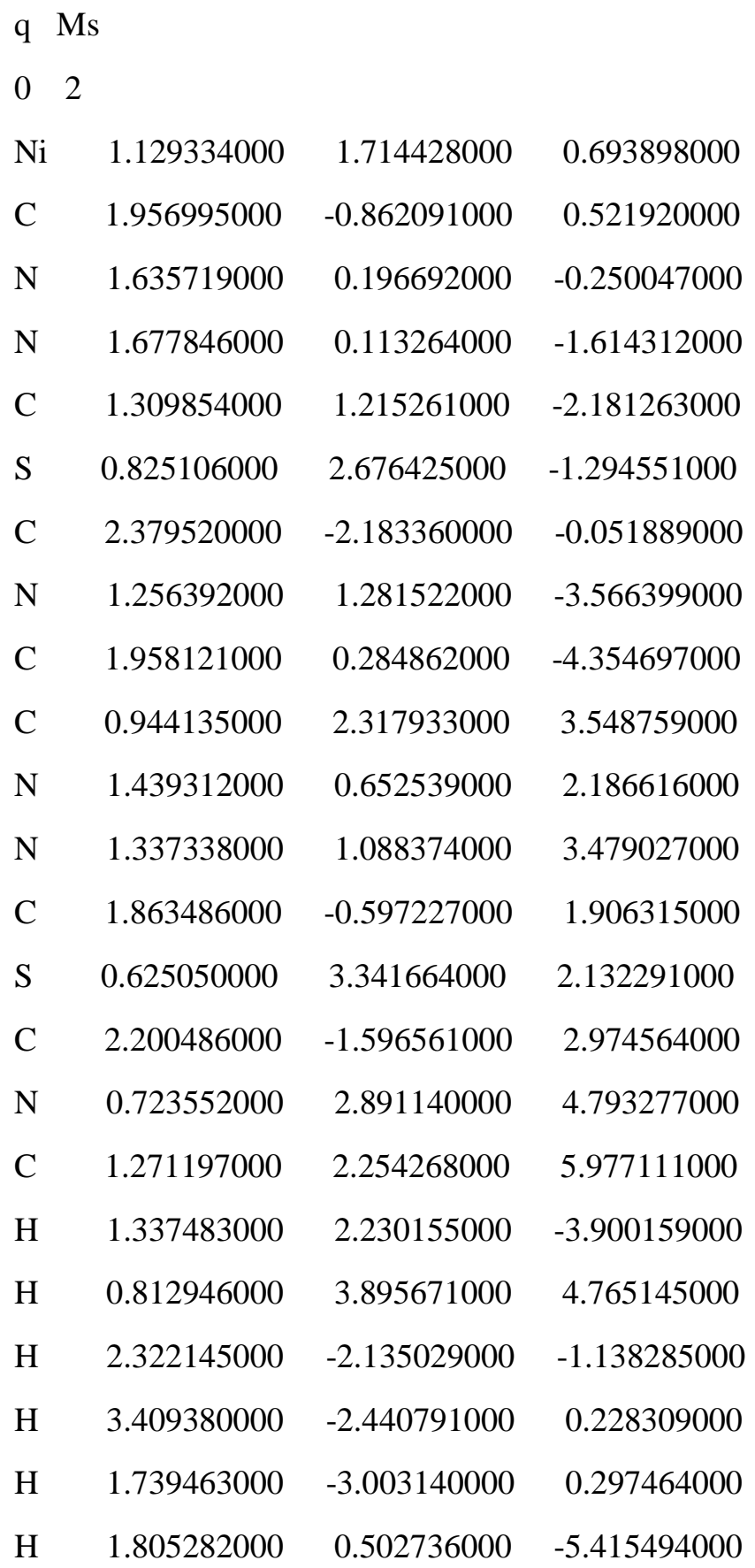




$\begin{array}{lrrr}\mathrm{H} & 3.038219000 & 0.244486000 & -4.146185000 \\ \mathrm{H} & 1.550569000 & -0.704042000 & -4.137845000 \\ \mathrm{H} & 1.961166000 & -1.173021000 & 3.948879000 \\ \mathrm{H} & 3.266149000 & -1.861506000 & 2.968104000 \\ \mathrm{H} & 1.638891000 & -2.530160000 & 2.847590000 \\ \mathrm{H} & 0.996191000 & 2.845842000 & 6.854932000 \\ \mathrm{H} & 2.365765000 & 2.141591000 & 5.945643000 \\ \mathrm{H} & 0.847215000 & 1.254091000 & 6.081410000 \\ \mathrm{H} & 1.542977113 & 0.521924391 & 4.277054190\end{array}$

$\left[\mathrm{NiL}^{3} \mathrm{H}\right]$ (proton addition to the amine nitrogen)

\begin{tabular}{|c|c|c|c|}
\hline & & בדיר & 3898000 \\
\hline & 1.956995000 & -0.862091000 & 0.521920000 \\
\hline & 1.635719000 & 0.196692000 & -0.250047000 \\
\hline & 1.677846000 & 0.113264000 & -1.614312000 \\
\hline & 1.309854000 & 1.215261000 & -2.181263000 \\
\hline & 0.825106000 & 2.676425000 & -1.294551000 \\
\hline & 2.379520000 & -2.183360000 & -0.051889000 \\
\hline & 1.256392000 & 1.281522000 & -3.566399000 \\
\hline C & 1.958121000 & 0.284862000 & -4.354697000 \\
\hline $\mathrm{C}$ & 0.944135000 & 2.317933000 & 3.548759000 \\
\hline $\mathrm{N}$ & 1.439312000 & 0.652539000 & 2.186616000 \\
\hline $\mathrm{N}$ & 1.337338000 & 1.088374000 & 3.479027000 \\
\hline$C$ & 1.863486000 & -0.597227000 & 1.906315000 \\
\hline & 0.625050000 & 3.341664000 & 2.132291000 \\
\hline C & 2.200486000 & -1.596561000 & 2.974564000 \\
\hline $\mathrm{N}$ & 0.723552000 & 2.891140000 & 4.793277000 \\
\hline $\mathrm{C}$ & 1.271197000 & 2.254268000 & 5.977111000 \\
\hline & 1.337483000 & 2.230155000 & -3.900159000 \\
\hline
\end{tabular}




$\begin{array}{lrrr}\mathrm{H} & 0.812946000 & 3.895671000 & 4.765145000 \\ \mathrm{H} & 2.322145000 & -2.135029000 & -1.138285000 \\ \mathrm{H} & 3.409380000 & -2.440791000 & 0.228309000 \\ \mathrm{H} & 1.739463000 & -3.003140000 & 0.297464000 \\ \mathrm{H} & 1.805282000 & 0.502736000 & -5.415494000 \\ \mathrm{H} & 3.038219000 & 0.244486000 & -4.146185000 \\ \mathrm{H} & 1.550569000 & -0.704042000 & -4.137845000 \\ \mathrm{H} & 1.961166000 & -1.173021000 & 3.948879000 \\ \mathrm{H} & 3.266149000 & -1.861506000 & 2.968104000 \\ \mathrm{H} & 1.638891000 & -2.530160000 & 2.847590000 \\ \mathrm{H} & 0.996191000 & 2.845842000 & 6.854932000 \\ \mathrm{H} & 2.365765000 & 2.141591000 & 5.945643000 \\ \mathrm{H} & 0.847215000 & 1.254091000 & 6.081410000 \\ \mathrm{H} & 0.240021952 & 2.095640736 & 5.158488738\end{array}$

$\left[\mathrm{NiL}^{3} \mathrm{H}\right]$ (proton addition to the sulfur)

\begin{tabular}{|c|c|c|c|}
\hline \multicolumn{4}{|c|}{$\mathrm{q} \mathrm{Ms}$} \\
\hline 0 & & & \\
\hline $\mathrm{Ni}$ & 1.129334000 & 1.714428000 & 0.693898000 \\
\hline $\mathrm{C}$ & 1.956995000 & -0.862091000 & 0.521920000 \\
\hline $\mathrm{N}$ & 1.635719000 & 0.196692000 & -0.250047000 \\
\hline $\mathrm{N}$ & 1.677846000 & 0.113264000 & -1.614312000 \\
\hline $\mathrm{C}$ & 1.309854000 & 1.215261000 & -2.181263000 \\
\hline S & 0.825106000 & 2.676425000 & -1.294551000 \\
\hline $\mathrm{C}$ & 2.379520000 & -2.183360000 & -0.051889000 \\
\hline $\mathrm{N}$ & 1.256392000 & 1.281522000 & -3.566399000 \\
\hline $\mathrm{C}$ & 1.958121000 & 0.284862000 & -4.354697000 \\
\hline $\mathrm{C}$ & 0.944135000 & 2.317933000 & 3.548759000 \\
\hline $\mathrm{N}$ & 1.439312000 & 0.652539000 & 2.186616000 \\
\hline $\mathrm{N}$ & 1.337338000 & 1.088374000 & 3.479027000 \\
\hline$C$ & 1.863486000 & -0.597227000 & 1.906315000 \\
\hline
\end{tabular}




$\begin{array}{lrrr}\mathrm{S} & 0.625050000 & 3.341664000 & 2.132291000 \\ \mathrm{C} & 2.200486000 & -1.596561000 & 2.974564000 \\ \mathrm{~N} & 0.723552000 & 2.891140000 & 4.793277000 \\ \mathrm{C} & 1.271197000 & 2.254268000 & 5.977111000 \\ \mathrm{H} & 1.337483000 & 2.230155000 & -3.900159000 \\ \mathrm{H} & 0.812946000 & 3.895671000 & 4.765145000 \\ \mathrm{H} & 2.322145000 & -2.135029000 & -1.138285000 \\ \mathrm{H} & 3.409380000 & -2.440791000 & 0.228309000 \\ \mathrm{H} & 1.739463000 & -3.003140000 & 0.297464000 \\ \mathrm{H} & 1.805282000 & 0.502736000 & -5.415494000 \\ \mathrm{H} & 3.038219000 & 0.244486000 & -4.146185000 \\ \mathrm{H} & 1.550569000 & -0.704042000 & -4.137845000 \\ \mathrm{H} & 1.961166000 & -1.173021000 & 3.948879000 \\ \mathrm{H} & 3.266149000 & -1.861506000 & 2.968104000 \\ \mathrm{H} & 1.638891000 & -2.530160000 & 2.847590000 \\ \mathrm{H} & 0.996191000 & 2.845842000 & 6.854932000 \\ \mathrm{H} & 2.365765000 & 2.141591000 & 5.945643000 \\ \mathrm{H} & 0.847215000 & 1.254091000 & 6.081410000 \\ \mathrm{H} & 0.232859051 & 4.603985455 & 1.985216852\end{array}$

$\left[\mathrm{NiL}^{3} \mathrm{H}\right]$ (proton addition to the nickel)

\begin{tabular}{|c|c|c|c|}
\hline \multicolumn{4}{|c|}{$\mathrm{q} \quad \mathrm{N}$} \\
\hline o & & & \\
\hline $\mathrm{Ni}$ & 1.129334000 & 1.714428000 & 0.693898000 \\
\hline $\mathrm{C}$ & 1.956995000 & -0.862091000 & 0.521920000 \\
\hline $\mathrm{N}$ & 1.635719000 & 0.196692000 & -0.250047000 \\
\hline $\mathrm{N}$ & 1.677846000 & 0.113264000 & -1.614312000 \\
\hline $\mathrm{C}$ & 1.309854000 & 1.215261000 & -2.181263000 \\
\hline S & 0.825106000 & 2.676425000 & -1.294551000 \\
\hline $\mathrm{C}$ & 2.379520000 & -2.183360000 & -0.051889000 \\
\hline 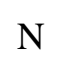 & 1.256392000 & 1.281522000 & -3.566399000 \\
\hline
\end{tabular}




\begin{tabular}{llll}
$\mathrm{C}$ & 1.958121000 & 0.284862000 & -4.354697000 \\
$\mathrm{C}$ & 0.944135000 & 2.317933000 & 3.548759000 \\
$\mathrm{~N}$ & 1.439312000 & 0.652539000 & 2.186616000 \\
$\mathrm{~N}$ & 1.337338000 & 1.088374000 & 3.479027000 \\
$\mathrm{C}$ & 1.863486000 & -0.597227000 & 1.906315000 \\
$\mathrm{~S}$ & 0.625050000 & 3.341664000 & 2.132291000 \\
$\mathrm{C}$ & 2.200486000 & -1.596561000 & 2.974564000 \\
$\mathrm{~N}$ & 0.723552000 & 2.891140000 & 4.793277000 \\
$\mathrm{C}$ & 1.271197000 & 2.254268000 & 5.977111000 \\
$\mathrm{H}$ & 1.337483000 & 2.230155000 & -3.900159000 \\
$\mathrm{H}$ & 0.812946000 & 3.895671000 & 4.765145000 \\
$\mathrm{H}$ & 2.322145000 & -2.135029000 & -1.138285000 \\
$\mathrm{H}$ & 3.409380000 & -2.440791000 & 0.228309000 \\
$\mathrm{H}$ & 1.739463000 & -3.003140000 & 0.297464000 \\
$\mathrm{H}$ & 1.805282000 & 0.502736000 & -5.415494000 \\
$\mathrm{H}$ & 3.038219000 & 0.244486000 & -4.146185000 \\
$\mathrm{H}$ & 1.550569000 & -0.704042000 & -4.137845000 \\
$\mathrm{H}$ & 1.961166000 & -1.173021000 & 3.948879000 \\
$\mathrm{H}$ & 3.266149000 & -1.861506000 & 2.968104000 \\
$\mathrm{H}$ & 1.638891000 & -2.530160000 & 2.847590000 \\
$\mathrm{H}$ & 0.996191000 & 2.845842000 & 6.854932000 \\
$\mathrm{H}$ & 2.365765000 & 2.141591000 & 5.945643000 \\
\hline & 0.847215000 & 1.254091000 & 6.081410000 \\
$\mathrm{H}$ & 0.55106194 & 3.413496452 & 0.330127711
\end{tabular}

$\left[\mathrm{NiL}^{3} \mathrm{H}\right]^{-}$(electron addition after the proton is added to coordinated nitrogen)
q $\mathrm{Ms}$
$\begin{array}{ll}-1 & 1\end{array}$
$\mathrm{Ni} \quad 0.834982000 \quad 1.574848000 \quad 0.738947000$
C $\quad 1.912962000 \quad-0.919928000 \quad 0.573027000$
$\mathrm{N} \quad 1.522196000 \quad 0.152198000 \quad-0.192910000$ 


\begin{tabular}{|c|c|c|c|}
\hline & 1.723517000 & 0.112375000 & -1.514241000 \\
\hline & 1.369195000 & 1.256613000 & -2.092694000 \\
\hline$S$ & 0.734813000 & 2.627858000 & -1.196026000 \\
\hline & 2.565484000 & -2.096327000 & -0.087961000 \\
\hline & 1.512378000 & 1.362567000 & -3.429177000 \\
\hline & 2.088220000 & 0.322847000 & -4.266826000 \\
\hline & 0.956940000 & 2.258143000 & 3.540436000 \\
\hline & 0.870145000 & 0.403817000 & 2.250981000 \\
\hline 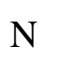 & 1.254644000 & 0.991533000 & 3.523212000 \\
\hline $\mathrm{C}$ & 1.657972000 & -0.787310000 & 1.913009000 \\
\hline S & 0.315587000 & 3.175078000 & 2.154006000 \\
\hline & 1.988805000 & -1.728630000 & 3.020423000 \\
\hline & 1.094531000 & 2.952296000 & 4.700540000 \\
\hline $\mathrm{C}$ & 1.664562000 & 2.359795000 & 5.898398000 \\
\hline $\mathrm{H}$ & 1.278048000 & 2.251348000 & -3.838741000 \\
\hline $\mathrm{H}$ & 1.115163000 & 3.954425000 & 4.605875000 \\
\hline $\mathrm{H}$ & 1.898280000 & -2.518994000 & -0.842967000 \\
\hline $\mathrm{H}$ & 3.470467000 & -1.780495000 & -0.612199000 \\
\hline $\mathrm{H}$ & 2.821054000 & -2.872487000 & 0.630821000 \\
\hline $\mathrm{H}$ & 2.011231000 & 0.636344000 & -5.307925000 \\
\hline $\mathrm{H}$ & 3.140367000 & 0.148895000 & -4.021853000 \\
\hline $\mathrm{H}$ & 1.549417000 & -0.617635000 & -4.135855000 \\
\hline $\mathrm{H}$ & 1.080807000 & -2.173869000 & 3.448688000 \\
\hline $\mathrm{H}$ & 2.483592000 & -1.188684000 & 3.829958000 \\
\hline $\mathrm{H}$ & 2.635785000 & -2.536776000 & 2.682406000 \\
\hline $\mathrm{H}$ & 1.545879000 & 3.061021000 & 6.725402000 \\
\hline $\mathrm{H}$ & 2.727996000 & 2.119623000 & 5.780336000 \\
\hline $\mathrm{H}$ & 1.136687000 & 1.435512000 & 6.137290000 \\
\hline & -0.098634000 & 0.089670000 & 2.374821000 \\
\hline
\end{tabular}

$\left[\mathrm{NiL}^{3} \mathrm{H}\right]^{-}$(electron addition after the proton is added to coordinated nitrogen) 


\begin{tabular}{|c|c|c|c|}
\hline & 1.912962000 & -0.919928000 & 0.573027000 \\
\hline & 1.522196000 & 0.152198000 & -0.192910000 \\
\hline & 1.723517000 & 0.112375000 & -1.514241000 \\
\hline & 1.369195000 & 1.256613000 & -2.092694000 \\
\hline & 0.734813000 & 2.627858000 & -1.196026000 \\
\hline & 2.565484000 & -2.096327000 & -0.087961000 \\
\hline & 1.512378000 & 1.362567000 & -3.429177000 \\
\hline & 2.088220000 & 0.322847000 & -4.266826000 \\
\hline & 0.956940000 & 2.258143000 & 3.540436000 \\
\hline & 0.870145000 & 0.403817000 & 2.250981000 \\
\hline & 1.254644000 & 0.991533000 & 3.523212000 \\
\hline & 1.657972000 & -0.787310000 & 1.913009000 \\
\hline & 0.315587000 & 3.175078000 & 2.154006000 \\
\hline & 1.988805000 & -1.728630000 & 3.020423000 \\
\hline & 1.094531000 & 2.952296000 & 4.700540000 \\
\hline & 1.664562000 & 2.359795000 & 5.898398000 \\
\hline & 1.278048000 & 2.251348000 & -3.838741000 \\
\hline & 1.115163000 & 3.954425000 & 4.605875000 \\
\hline & 1.898280000 & -2.518994000 & -0.842967000 \\
\hline & 3.470467000 & -1.780495000 & -0.612199000 \\
\hline & 2.821054000 & -2.872487000 & 0.630821000 \\
\hline & 2.011231000 & 0.636344000 & -5.307925000 \\
\hline & 3.140367000 & 0.148895000 & -4.021853000 \\
\hline & 1.549417000 & -0.617635000 & -4.135855000 \\
\hline & 1.080807000 & -2.173869000 & 3.448688000 \\
\hline & 2.483592000 & -1.188684000 & 3.829958000 \\
\hline & 2.635785000 & -2.536776000 & 2.682406000 \\
\hline & 1.545879000 & 3.061021000 & 6.725402000 \\
\hline
\end{tabular}




$\begin{array}{lrrr}\mathrm{H} & 2.727996000 & 2.119623000 & 5.780336000 \\ \mathrm{H} & 1.136687000 & 1.435512000 & 6.137290000 \\ \mathrm{H} & -0.098634000 & 0.089670000 & 2.374821000\end{array}$

$\left[\mathrm{NiL}^{3} \mathrm{H}\right]^{-}$(electron addition after the proton is added to hydrazino nitrogen)

$\begin{array}{lrrr}\text { q } & \text { Ms } & & \\ -1 & 1 & & \\ \mathrm{Ni} & 1.150798000 & 1.695109000 & 0.696974000 \\ \mathrm{C} & 1.988392000 & -0.889697000 & 0.514561000 \\ \mathrm{~N} & 1.680225000 & 0.184449000 & -0.238195000 \\ \mathrm{~N} & 1.694529000 & 0.085652000 & -1.591200000 \\ \mathrm{C} & 1.352214000 & 1.215514000 & -2.165223000 \\ \mathrm{~S} & 0.888329000 & 2.675352000 & -1.270944000 \\ \mathrm{C} & 2.361872000 & -2.188852000 & -0.131311000 \\ \mathrm{~N} & 1.333378000 & 1.284418000 & -3.520613000 \\ \mathrm{C} & 1.830511000 & 0.219904000 & -4.372691000 \\ \mathrm{C} & 1.079796000 & 2.417361000 & 3.559499000 \\ \mathrm{~N} & 1.302842000 & 0.563268000 & 2.165842000 \\ \mathrm{~N} & 1.391249000 & 1.122094000 & 3.434881000 \\ \mathrm{C} & 1.897366000 & -0.635472000 & 1.898880000 \\ \mathrm{~S} & 0.844127000 & 3.381802000 & 2.150036000 \\ \mathrm{C} & 2.340488000 & -1.546167000 & 3.001094000 \\ \mathrm{~N} & 0.927403000 & 2.947306000 & 4.797099000 \\ \mathrm{C} & 1.233509000 & 2.258096000 & 6.036729000 \\ \mathrm{H} & 1.183422000 & 2.197016000 & -3.916120000 \\ \mathrm{H} & 0.794885000 & 3.945055000 & 4.816320000 \\ \mathrm{H} & 3.214649000 & -2.054100000 & -0.802233000 \\ \mathrm{H} & 2.609919000 & -2.954354000 & 0.603923000 \\ & 1.537654000 & -2.557585000 & -0.749321000 \\ \mathrm{H} & 1.613730000 & 0.474118000 & -5.411094000 \\ \mathrm{H} & 2.910505000 & 0.070011000 & -4.257544000\end{array}$




$\begin{array}{lrrr}\mathrm{H} & 1.334392000 & -0.720456000 & -4.125819000 \\ \mathrm{H} & 1.508912000 & -1.833139000 & 3.660023000 \\ \mathrm{H} & 3.108124000 & -1.070332000 & 3.625426000 \\ \mathrm{H} & 2.771560000 & -2.465438000 & 2.609796000 \\ \mathrm{H} & 1.062786000 & 2.941774000 & 6.866693000 \\ \mathrm{H} & 2.277352000 & 1.922456000 & 6.075088000 \\ \mathrm{H} & 0.577110000 & 1.392498000 & 6.183868000 \\ \mathrm{H} & 1.365257000 & 0.500279000 & 4.232757000\end{array}$

$\left[\mathrm{NiL}^{3} \mathrm{H}\right]^{-}$(electron addition after the proton is added to hydrazino nitrogen)

$\begin{array}{lrrr}\text { q } & \text { Ms } & & \\ -1 & 3 & & \\ \mathrm{Ni} & 1.150798000 & 1.695109000 & 0.696974000 \\ \mathrm{C} & 1.988392000 & -0.889697000 & 0.514561000 \\ \mathrm{~N} & 1.680225000 & 0.184449000 & -0.238195000 \\ \mathrm{~N} & 1.694529000 & 0.085652000 & -1.591200000 \\ \mathrm{C} & 1.352214000 & 1.215514000 & -2.165223000 \\ \mathrm{~S} & 0.888329000 & 2.675352000 & -1.270944000 \\ \mathrm{C} & 2.361872000 & -2.188852000 & -0.131311000 \\ \mathrm{~N} & 1.333378000 & 1.284418000 & -3.520613000 \\ \mathrm{C} & 1.830511000 & 0.219904000 & -4.372691000 \\ \mathrm{C} & 1.079796000 & 2.417361000 & 3.559499000 \\ \mathrm{~N} & 1.302842000 & 0.563268000 & 2.165842000 \\ \mathrm{~N} & 1.391249000 & 1.122094000 & 3.434881000 \\ \mathrm{C} & 1.897366000 & -0.635472000 & 1.898880000 \\ \mathrm{~S} & 0.844127000 & 3.381802000 & 2.150036000 \\ \mathrm{C} & 2.340488000 & -1.546167000 & 3.001094000 \\ \mathrm{~N} & 0.927403000 & 2.947306000 & 4.797099000 \\ \mathrm{C} & 1.233509000 & 2.258096000 & 6.036729000 \\ \mathrm{H} & 1.183422000 & 2.197016000 & -3.916120000 \\ \mathrm{H} & 0.794885000 & 3.945055000 & 4.816320000\end{array}$




$\begin{array}{llll}\mathrm{H} & 3.214649000 & -2.054100000 & -0.802233000 \\ \mathrm{H} & 2.609919000 & -2.954354000 & 0.603923000 \\ \mathrm{H} & 1.537654000 & -2.557585000 & -0.749321000 \\ \mathrm{H} & 1.613730000 & 0.474118000 & -5.411094000 \\ \mathrm{H} & 2.910505000 & 0.070011000 & -4.257544000 \\ \mathrm{H} & 1.334392000 & -0.720456000 & -4.125819000 \\ \mathrm{H} & 1.508912000 & -1.833139000 & 3.660023000 \\ \mathrm{H} & 3.108124000 & -1.070332000 & 3.625426000 \\ \mathrm{H} & 2.771560000 & -2.465438000 & 2.609796000 \\ \mathrm{H} & 1.062786000 & 2.941774000 & 6.866693000 \\ \mathrm{H} & 2.277352000 & 1.922456000 & 6.075088000 \\ \mathrm{H} & 0.577110000 & 1.392498000 & 6.183868000 \\ \mathrm{H} & 1.365257000 & 0.500279000 & 4.232757000\end{array}$

$\left[\mathrm{NiL}^{3} \mathrm{H}\right]^{-}$(electron addition after the proton is added to amine nitrogen)

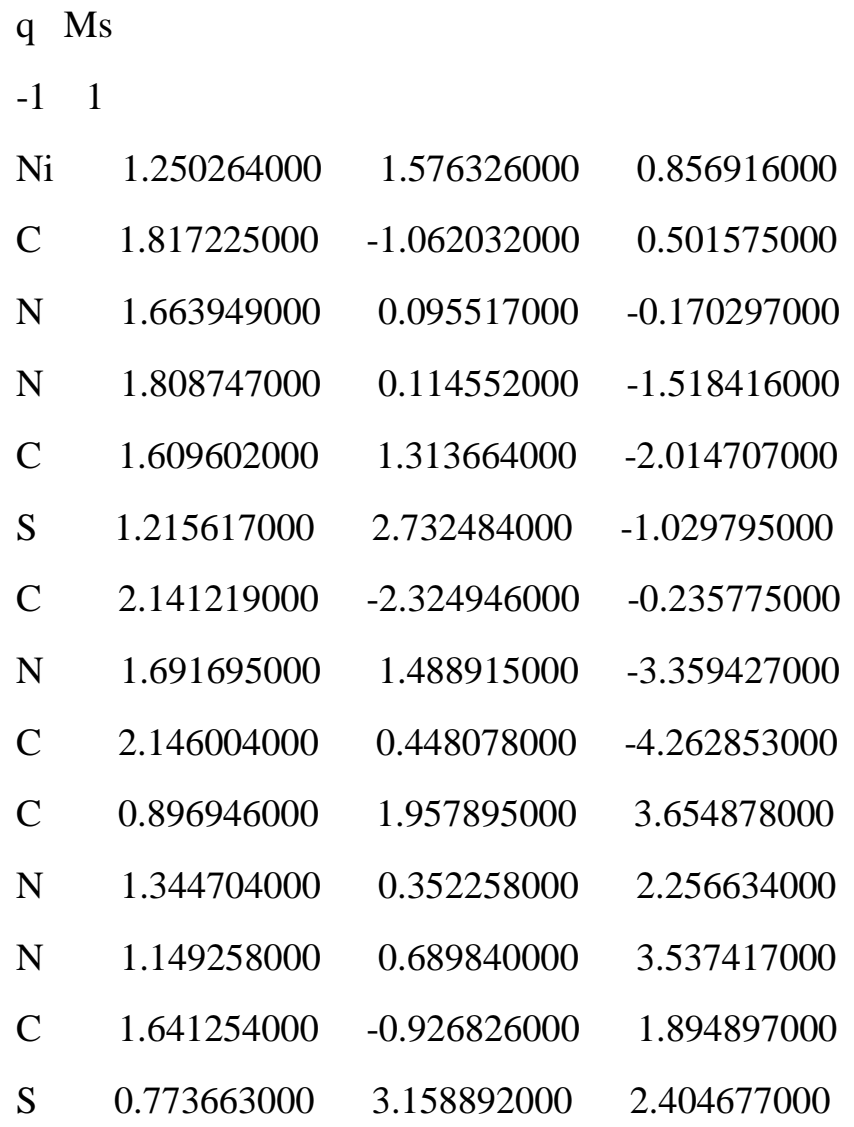




$\begin{array}{lrrr}\mathrm{C} & 1.747461000 & -2.004358000 & 2.925392000 \\ \mathrm{~N} & 0.654412000 & 2.359378000 & 5.059850000 \\ \mathrm{C} & 1.698732000 & 3.269650000 & 5.645252000 \\ \mathrm{H} & 1.683628000 & 2.441982000 & -3.681204000 \\ \mathrm{H} & -0.262130000 & 2.815655000 & 5.125288000 \\ \mathrm{H} & 1.363747000 & -2.548393000 & -0.972109000 \\ \mathrm{H} & 3.073566000 & -2.212383000 & -0.796500000 \\ \mathrm{H} & 2.237954000 & -3.174593000 & 0.439168000 \\ \mathrm{H} & 2.012003000 & 0.792962000 & -5.289192000 \\ \mathrm{H} & 3.200825000 & 0.193028000 & -4.104339000 \\ \mathrm{H} & 1.557413000 & -0.458407000 & -4.112382000 \\ \mathrm{H} & 0.805437000 & -2.111111000 & 3.474503000 \\ \mathrm{H} & 2.514177000 & -1.756928000 & 3.667560000 \\ \mathrm{H} & 1.997001000 & -2.966731000 & 2.481486000 \\ \mathrm{H} & 1.417120000 & 3.532250000 & 6.665449000 \\ \mathrm{H} & 1.755844000 & 4.151600000 & 5.011911000 \\ \mathrm{H} & 2.646211000 & 2.736240000 & 5.623403000 \\ \mathrm{H} & 0.610778000 & 1.477198000 & 5.579357000\end{array}$

$\left[\mathrm{NiL}^{3} \mathrm{H}\right]^{-}$(electron addition after the proton is added to amine nitrogen)

\begin{tabular}{|c|c|c|c|}
\hline \multicolumn{4}{|c|}{ q $\mathrm{Ms}$} \\
\hline-1 & & & \\
\hline $\mathrm{Ni}$ & 1.250264000 & 1.576326000 & 0.856916000 \\
\hline $\mathrm{C}$ & 1.817225000 & -1.062032000 & 0.501575000 \\
\hline $\mathrm{N}$ & 1.663949000 & 0.095517000 & -0.170297000 \\
\hline $\mathrm{N}$ & 1.808747000 & 0.114552000 & -1.518416000 \\
\hline $\mathrm{C}$ & 1.609602000 & 1.313664000 & -2.014707000 \\
\hline & 1.215617000 & 2.732484000 & -1.029795000 \\
\hline $\mathrm{C}$ & 2.141219000 & -2.324946000 & -0.235775000 \\
\hline I & 1.691695000 & 1.488915000 & -3.359427000 \\
\hline $\mathrm{C}$ & 2.146004000 & 0.448078000 & -4.262853000 \\
\hline
\end{tabular}




\begin{tabular}{|c|c|c|c|}
\hline & 0.896946000 & 1.957895000 & 554878000 \\
\hline & 1.344704000 & 0.352258000 & 2.256634000 \\
\hline & 1.149258000 & 0.689840000 & 3.537417000 \\
\hline & 1.641254000 & -0.926826000 & 1.894897000 \\
\hline & 0.773663000 & 3.158892000 & 2.404677000 \\
\hline & 1.747461000 & -2.004358000 & 2.925392000 \\
\hline & 0.654412000 & 2.359378000 & 5.059850000 \\
\hline & 1.698732000 & 3.269650000 & 5.645252000 \\
\hline & 1.683628000 & 2.441982000 & -3.681204000 \\
\hline & -0.262130000 & 2.815655000 & 5288000 \\
\hline & 1.363747000 & -2.548393000 & 09000 \\
\hline & 3.073566000 & -2.212383000 & -0.796500000 \\
\hline & 2.237954000 & -3.174593000 & 0.439168000 \\
\hline & 2.012003000 & 0.792962000 & -5.289192000 \\
\hline & 3.200825000 & 0.193028000 & -4.104339000 \\
\hline & 1.557413000 & -0.458407000 & -4.112382000 \\
\hline & 0.805437000 & -2.111111000 & 3.474503000 \\
\hline & 2.514177000 & -1.756928000 & 3.667560000 \\
\hline & 1.997001000 & -2.966731000 & 2.481486000 \\
\hline & 1.417120000 & 3.532250000 & 6.665449000 \\
\hline & 1.755844000 & 4.151600000 & 5.011911000 \\
\hline & 2.646211000 & 2.736240000 & 5.623403000 \\
\hline & 0.610778000 & 1.477198000 & 5.579357000 \\
\hline
\end{tabular}

$\left[\mathrm{NiL}^{3} \mathrm{H}\right]^{-}$(electron addition after the proton is added to sulfur)

\begin{tabular}{|c|c|c|c|}
\hline \multicolumn{4}{|c|}{$\mathrm{q} \mathrm{Ms}$} \\
\hline-1 & & & \\
\hline $\mathrm{Ni}$ & 1.234494000 & 1.900497000 & 0.602129000 \\
\hline $\mathrm{C}$ & 2.017142000 & -0.766649000 & 0.465988000 \\
\hline $\mathrm{N}$ & 1.794166000 & 0.270524000 & -0.311546000 \\
\hline 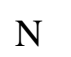 & 1.753191000 & 0.124459000 & -1.650274000 \\
\hline
\end{tabular}




\begin{tabular}{|c|c|c|c|}
\hline & 1.343664000 & 1.231045000 & -2.262844000 \\
\hline & 0.726891000 & 2.690736000 & -1.489177000 \\
\hline & 2.285579000 & -2.152157000 & -0.043130000 \\
\hline & 1.380275000 & 1.226103000 & -3.612327000 \\
\hline & 1.866458000 & 0.115068000 & -4.411447000 \\
\hline & 1.233515000 & 2.416761000 & 3.625578000 \\
\hline & 1.517264000 & 0.752095000 & 2.158505000 \\
\hline & 1.468829000 & & 3.467742000 \\
\hline & 1.983636000 & -0.446253000 & 1.886210000 \\
\hline$S$ & 1.257569000 & 3.582513000 & 2.213047000 \\
\hline & 2.434010000 & -1.428810000 & 2.924532000 \\
\hline & 0.932720000 & 2.969485000 & 4.836121000 \\
\hline & 0.909353000 & 2.141655000 & 6.037820000 \\
\hline & 1.002408000 & 2.039501000 & -4.067834000 \\
\hline & 1.235894000 & 3.923970000 & 4.957665000 \\
\hline $\mathrm{H}$ & 2.387518000 & -2.120458000 & -1.125868000 \\
\hline & 3.201436000 & -2.566144000 & 0.389726000 \\
\hline & 1.468079000 & -2.838122000 & 0.206448000 \\
\hline $\mathrm{H}$ & 1.827799000 & 0.403544000 & -5.462540000 \\
\hline & 2.896995000 & -0.134637000 & -4.147677000 \\
\hline $\mathrm{H}$ & 1.255359000 & -0.780287000 & -4.263295000 \\
\hline F & 2.197787000 & -1.063314000 & 3.921019000 \\
\hline $\mathrm{H}$ & 3.514945000 & -1.595146000 & 2.859797000 \\
\hline & 1.951705000 & -2.398272000 & 2.771659000 \\
\hline & 0.541559000 & 2.747628000 & 6.866378000 \\
\hline & 1.898365000 & 1.741566000 & 6.287524000 \\
\hline & 0.232771000 & 1.301364000 & 5.883823000 \\
\hline & 0.105790000 & 4.207074000 & 2.571591000 \\
\hline
\end{tabular}

$\left[\mathrm{NiL}^{3} \mathrm{H}\right]^{-}$(electron addition after the proton is added to sulfur) q Ms 


\begin{tabular}{|c|c|c|c|}
\hline $\mathrm{Ni}$ & 1.234494000 & 1.900497000 & 0.602129000 \\
\hline $\mathrm{C}$ & 2.017142000 & -0.766649000 & 0.465988000 \\
\hline $\mathrm{N}$ & 1.794166000 & 0.270524000 & -0.311546000 \\
\hline $\mathrm{N}$ & 1.753191000 & 0.124459000 & -1.650274000 \\
\hline $\mathrm{C}$ & 1.343664000 & 1.231045000 & -2.262844000 \\
\hline S & 0.726891000 & 2.690736000 & -1.489177000 \\
\hline $\mathrm{C}$ & 2.285579000 & -2.152157000 & -0.043130000 \\
\hline $\mathrm{N}$ & 1.380275000 & 1.226103000 & -3.612327000 \\
\hline $\mathrm{C}$ & 1.866458000 & 0.115068000 & -4.411447000 \\
\hline $\mathrm{C}$ & 1.233515000 & 2.416761000 & 3.625578000 \\
\hline $\mathrm{N}$ & 1.517264000 & 0.752095000 & 2.158505000 \\
\hline $\mathrm{N}$ & 1.468829000 & 1.164661000 & 3.467742000 \\
\hline $\mathrm{C}$ & 1.983636000 & -0.446253000 & 1.886210000 \\
\hline S & 1.257569000 & 3.582513000 & 2.213047000 \\
\hline $\mathrm{C}$ & 2.434010000 & -1.428810000 & 2.924532000 \\
\hline $\mathrm{N}$ & 0.932720000 & 2.969485000 & 4.836121000 \\
\hline $\mathrm{C}$ & 0.909353000 & 2.141655000 & 6.037820000 \\
\hline $\mathrm{H}$ & 1.002408000 & 2.039501000 & -4.067834000 \\
\hline $\mathrm{H}$ & 1.235894000 & 3.923970000 & 4.957665000 \\
\hline $\mathrm{H}$ & 2.387518000 & -2.120458000 & -1.125868000 \\
\hline $\mathrm{H}$ & 3.201436000 & -2.566144000 & 0.389726000 \\
\hline $\mathrm{H}$ & 1.468079000 & -2.838122000 & 0.206448000 \\
\hline $\mathrm{H}$ & 1.827799000 & 0.403544000 & -5.462540000 \\
\hline $\mathrm{H}$ & 2.896995000 & -0.134637000 & -4.147677000 \\
\hline $\mathrm{H}$ & 1.255359000 & -0.780287000 & -4.263295000 \\
\hline $\mathrm{H}$ & 2.197787000 & -1.063314000 & 3.921019000 \\
\hline $\mathrm{H}$ & 3.514945000 & -1.595146000 & 2.859797000 \\
\hline $\mathrm{H}$ & 1.951705000 & -2.398272000 & 2.771659000 \\
\hline $\mathrm{H}$ & 0.541559000 & 2.747628000 & 6.866378000 \\
\hline & 1.898365000 & 1.741566000 & 6.287524000 \\
\hline
\end{tabular}




$\begin{array}{llll}\mathrm{H} & 0.232771000 & 1.301364000 & 5.883823000 \\ \mathrm{H} & 0.105790000 & 4.207074000 & 2.571591000\end{array}$

$\left[\mathrm{NiL}^{3} \mathrm{H}\right]^{-}$(electron addition after the proton is added to nickel)

q $\mathrm{Ms}$

$\begin{array}{ll}-1 & 1\end{array}$

Ni $\quad \begin{array}{llll}1.007394000 & 1.810096000 & 0.617830000\end{array}$

$\begin{array}{llll}\text { C } & 2.003694000 & -0.780807000 & 0.466033000\end{array}$

$\mathrm{N} \quad \begin{array}{llll}1.838103000 & 0.263185000 & -0.301017000\end{array}$

$\mathrm{N} \quad \begin{array}{llll}1.886663000 & 0.157216000 & -1.654437000\end{array}$

$\begin{array}{llll}\text { C } & 1.332820000 & 1.194968000 & -2.244087000\end{array}$

S $\quad 0.455943000 \quad 2.507227000 \quad-1.412710000$

$\begin{array}{llll}\text { C } & 2.337701000 & -2.146598000 & -0.049592000\end{array}$

$\mathrm{N} \quad 1.382480000 \quad 1.272723000 \quad-3.590088000$

$\begin{array}{llll}\text { C } & 2.016089000 & 0.270035000 & -4.429603000\end{array}$

C $\quad \begin{array}{llll}1.297090000 & 2.425941000 & 3.545998000\end{array}$

$\begin{array}{llll}\mathrm{N} & 1.365534000 & 0.678283000 & 2.175187000\end{array}$

$\mathrm{N} \quad 1.289763000 \quad 1.110869000 \quad 3.454226000$

$\begin{array}{llll}\text { C } & 1.855093000 & -0.501800000 & 1.901486000\end{array}$

S $\quad \begin{array}{llll}1.520928000 & 3.528755000 & 2.185141000\end{array}$

$\begin{array}{llll}\text { C } & 2.287806000 & -1.479945000 & 2.950491000\end{array}$

N $\quad 1.170962000 \quad 2.977604000 \quad 4.773255000$

$\begin{array}{llll}\text { C } & 1.047824000 & 2.200742000 & 5.994909000\end{array}$

$\mathrm{H} \quad 0.873847000 \quad 2.027426000 \quad-4.018436000$

$\mathrm{H} \quad 1.209709000 \quad 3.981234000 \quad 4.822127000$

$\mathrm{H} \quad 2.464736000 \quad-2.107610000 \quad-1.128808000$

$\mathrm{H} \quad 3.257261000 \quad-2.522652000 \quad 0.408714000$

$\mathrm{H} \quad 1.541187000 \quad-2.859242000 \quad 0.188711000$

$\mathrm{H} \quad 1.981962000 \quad 0.612956000 \quad-5.463838000$

$\mathrm{H} \quad 3.057746000 \quad 0.125330000 \quad-4.135521000$

H $\quad 1.505339000 \quad-0.695123000 \quad-4.354264000$ 


$\begin{array}{lrrr}\mathrm{H} & 1.885248000 & -1.186022000 & 3.917272000 \\ \mathrm{H} & 3.380760000 & -1.506745000 & 3.028938000 \\ \mathrm{H} & 1.953406000 & -2.490789000 & 2.705434000 \\ \mathrm{H} & 0.947585000 & 2.890278000 & 6.833178000 \\ \mathrm{H} & 1.927662000 & 1.570068000 & 6.153182000 \\ \mathrm{H} & 0.169197000 & 1.551904000 & 5.959275000 \\ \mathrm{H} & -0.072118000 & 2.590004000 & 1.131268000\end{array}$

$\left[\mathrm{NiL}^{3} \mathrm{H}\right]^{-}$(electron addition after the proton is added to nickel)

\begin{tabular}{|c|c|c|c|}
\hline \multicolumn{4}{|c|}{$\mathrm{q} N$} \\
\hline & & & \\
\hline $\mathrm{Ni}$ & 1.007394000 & 1.810096000 & 0.617830000 \\
\hline $\mathrm{C}$ & 2.003694000 & -0.780807000 & 0.466033000 \\
\hline $\mathrm{N}$ & 1.838103000 & 0.263185000 & -0.301017000 \\
\hline $\mathrm{N}$ & 1.886663000 & 0.157216000 & -1.654437000 \\
\hline $\mathrm{C}$ & 1.332820000 & 1.194968000 & -2.244087000 \\
\hline & 0.455943000 & 2.507227000 & -1.412710000 \\
\hline & 2.337701000 & -2.146598000 & -0.049592000 \\
\hline & 1.382480000 & 1.272723000 & -3.590088000 \\
\hline $\mathrm{C}$ & 2.016089000 & 0.270035000 & -4.429603000 \\
\hline $\mathrm{C}$ & 1.297090000 & 2.425941000 & 3.545998000 \\
\hline & 1.365534000 & 0.678283000 & 2.175187000 \\
\hline $\mathrm{N}$ & 1.289763000 & 1.110869000 & 3.454226000 \\
\hline & 1.855093000 & -0.501800000 & 1.901486000 \\
\hline I & 1.520928000 & 3.528755000 & 2.185141000 \\
\hline 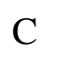 & 2.287806000 & -1.479945000 & 2.950491000 \\
\hline & 1.170962000 & 2.977604000 & 4.773255000 \\
\hline 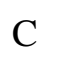 & 1.047824000 & 2.200742000 & 5.994909000 \\
\hline & 0.873847000 & 2.027426000 & -4.018436000 \\
\hline & 1.209709000 & 3.981234000 & 4.822127000 \\
\hline & 2.464736000 & -2.107610000 & -1.128808000 \\
\hline
\end{tabular}




$\begin{array}{llll}\mathrm{H} & 3.257261000 & -2.522652000 & 0.408714000 \\ \mathrm{H} & 1.541187000 & -2.859242000 & 0.188711000 \\ \mathrm{H} & 1.981962000 & 0.612956000 & -5.463838000 \\ \mathrm{H} & 3.057746000 & 0.125330000 & -4.135521000 \\ \mathrm{H} & 1.505339000 & -0.695123000 & -4.354264000 \\ \mathrm{H} & 1.885248000 & -1.186022000 & 3.917272000 \\ \mathrm{H} & 3.380760000 & -1.506745000 & 3.028938000 \\ \mathrm{H} & 1.953406000 & -2.490789000 & 2.705434000 \\ \mathrm{H} & 0.947585000 & 2.890278000 & 6.833178000 \\ \mathrm{H} & 1.927662000 & 1.570068000 & 6.153182000 \\ \mathrm{H} & 0.169197000 & 1.551904000 & 5.959275000 \\ \mathrm{H} & -0.199147253 & 2.549958837 & 0.433215775\end{array}$




\section{CURRICULUM VITAE}

NAME: $\quad$ Rahul Jain

ADDRESS: $\quad$ Department of Chemistry, University of Louisville, 2320 S. Brook St., Louisville, KY, 40292

E-mail: $\quad$ rahuljain10787@gmail.com

EDUCATION

\& TRAINING: Ph.D. Chemistry

University of Louisville, KY, USA

2012-2017

M.S. Chemistry

University of Louisville, KY, USA

2012-2016

M.S. Chemistry

Panjab University, Chandigarh, India

2009-2011

B.S. Chemistry

Panjab University, Chandigarh, India

2006-2009

AWARDS: $\quad$ Doctoral Dissertation Completion Award, Fall 2017.

Graduate Student Council Travel Award, Fall 2017.

Candidacy Fee Award, U of L, KY, Fall 2016.

\section{PUBLICATIONS:}

1) R. Jain, T. J. Gibson, M. S. Mashuta, R. M. Buchanan, C. A. Grapperhaus, "Copper catalysed aerobic oxidation of benzylic alcohols in an imidazole containing $\mathrm{N}_{4}$ ligand framework" Dalton Trans., 2016,45, 18356-18364

(From themed collection: Reactions Facilitated by Ligand Design.) 
2) R. Jain, M. S. Mashuta, R. M. Buchanan, C. A. Grapperhaus, "Electrocatalytic Hydrogen Evolution and Hydrogen Oxidation with a Ni(PS) $)_{2}$ Complex", Eur. J. Inorg. Chem., 2017, 31, 3714-3719

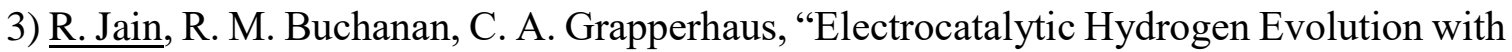
$\mathrm{Ni}\left(\mathrm{N}_{2} \mathrm{~S}_{2}\right)$ complex" (manuscript in prepn.)

\section{PRESENTATIONS:}

1) R. Jain, R. M. Buchanan, C. A. Grapperhaus, "Electrocatalytic hydrogen evolution reaction with bis(thiosemicarbazonato) Ni(II) complex" The Southeastern Regional Meeting of ACS (SERMACS), Charlotte, North Carolina - Nov. 2017 (poster)

2) R. Jain, A. Z. Haddad, M. S. Mashuta, C. A. Grapperhaus "Synthesis, characterization and electrochemical properties of new tetracoordinated Ni(II) and Zn(II) complexes with $P_{2} S_{2}$ type ligand framework" Pacifichem- The International Chemical Congress of Pacific Basin Societies, Honolulu, Hawaii, USA- Dec. 2015 (poster)

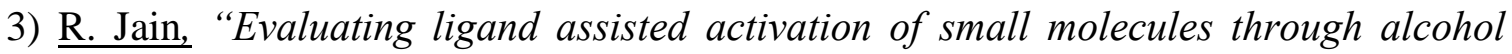
oxidation and proton reduction" Invited talk for Inorganic Chemistry Seminar Series, Department of Chemistry, Louisiana State University, Baton Rouge, LA- Sept. 2017. (invited talk)

4) R. Jain, A. Z. Haddad, M. S. Mashuta, R. M. Buchanan, C. A. Grapperhaus, "Electrocatalytic hydrogen production and hydrogen oxidation using tetradentate Nickel (II) and Zinc (II) complexes with $\mathrm{P}_{2} \mathrm{~S}_{2}$ ligand framework: Synthesis, Characterization and Mechanistic Insights" $254^{\text {th }}$ ACS National Meeting and Exposition, Washington, DC Aug. 2017. (talk)

5) R. Jain, T. J. Gibson, M. S. Mashuta, R. M. Buchanan, C. A. Grapperhaus, "Copper catalysed aerobic oxidation of benzylic alcohols in an imidazole containing $\mathrm{N}_{4}$ ligand framework" GSC Graduate Research Conference, University of Louisville, KY- Mar. 2017. (talk)

6) R. Jain, T. J. Gibson, M. S. Mashuta, R. M. Buchanan, C. A. Grapperhaus, "Copper catalysed aerobic oxidation of benzylic alcohols in an imidazole containing $\mathrm{N}_{4}$ ligand framework" $102^{\text {nd }}$ meeting of the Kentucky Academy of Sciences (KAS), University of Louisville, KY- Nov. 2016. (talk) 